\title{
Bridging the gap - implications of current COVID-19 fiscal rescue and recovery measures
}

\author{
Höhne, Niklas; Hans, Frederic; Olhoff, Anne
}

Published in:

Emissions Gap Report 2020

Publication date:

2020

Document Version

Publisher's PDF, also known as Version of record

Link back to DTU Orbit

Citation (APA):

Höhne, N., Hans, F., \& Olhoff, A. (2020). Bridging the gap - implications of current COVID-19 fiscal rescue and recovery measures. In Emissions Gap Report 2020

\section{General rights}

Copyright and moral rights for the publications made accessible in the public portal are retained by the authors and/or other copyright owners and it is a condition of accessing publications that users recognise and abide by the legal requirements associated with these rights.

- Users may download and print one copy of any publication from the public portal for the purpose of private study or research.

- You may not further distribute the material or use it for any profit-making activity or commercial gain

- You may freely distribute the URL identifying the publication in the public portal

If you believe that this document breaches copyright please contact us providing details, and we will remove access to the work immediately and investigate your claim 


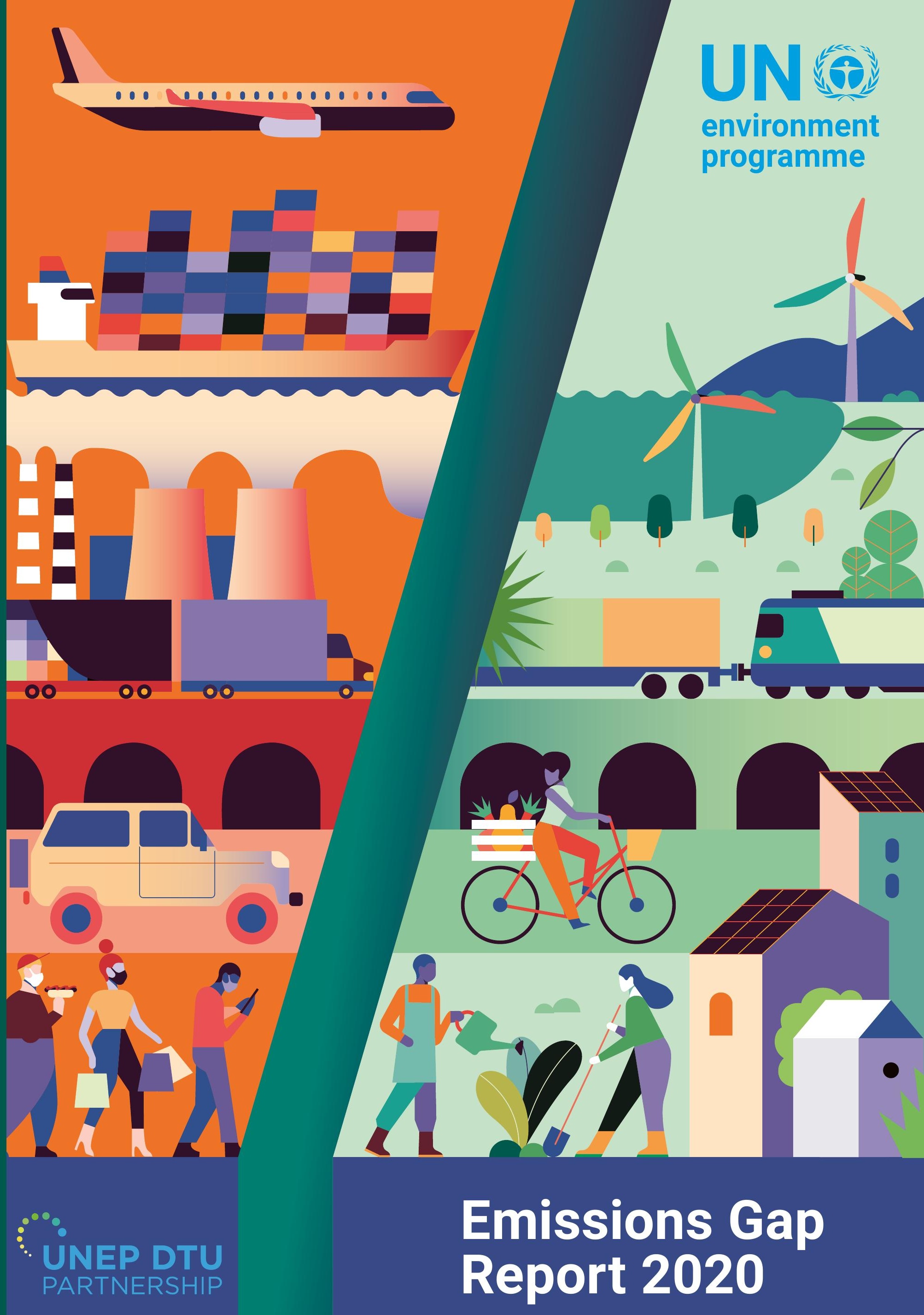




\section{ISBN: 978-92-807-3812-4}

Job number: DEW/2310/NA

This publication may be reproduced in whole or in part and in any form for educational or non-profit services without special permission from the copyright holder, provided acknowledgement of the source is made. The United Nations Environment Programme would appreciate receiving a copy of any publication that uses this publication as a source.

No use of this publication may be made for resale or any other commercial purpose whatsoever without prior permission in writing from the United Nations Environment Programme. Applications for such permission, with a statement of the purpose and extent of the reproduction, should be addressed to the Director, Communication Division, United Nations Environment Programme, P. O. Box 30552, Nairobi 00100, Kenya.

\section{Disclaimers}

The designations employed and the presentation of the material in this publication do not imply the expression of any opinion whatsoever on the part of the United Nations Environment Programme concerning the legal status of any country, territory or city or its authorities, or concerning the delimitation of its frontiers or boundaries. For general guidance on matters relating to the use of maps in publications please go to http://www.un.org/Depts/Cartographic/english/ htmain.htm

Mention of a commercial company or product in this document does not imply endorsement by the United Nations Environment Programme or the authors. The use of information from this document for publicity or advertising is not permitted. Trademark names and symbols are used in an editorial fashion with no intention on infringement of trademark or copyright laws.

The views expressed in this publication are those of the authors and do not necessarily reflect the views of the United Nations Environment Programme. We regret any errors or omissions that may have been unwittingly made.

() Maps, photos and illustrations as specified

\section{Suggested citation}

United Nations Environment Programme (2020). Emissions Gap Report 2020. Nairobi.

\section{Production}

United Nations Environment Programme (UNEP) and UNEP DTU Partnership (UDP).

\section{Supported by:}

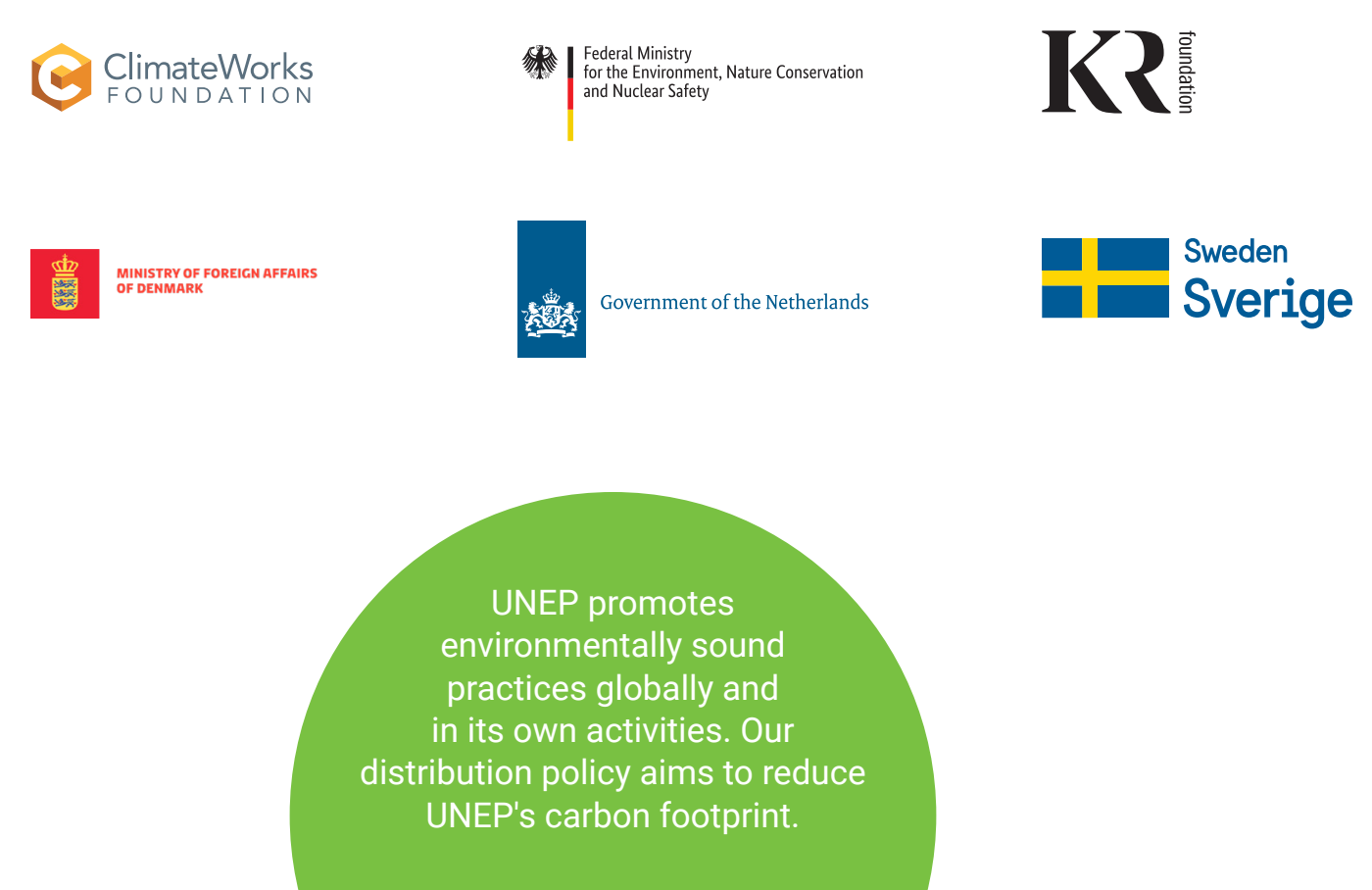




\section{Emissions Gap Report 2020}




\section{Acknowledgements}

The United Nations Environment Programme (UNEP) would like to thank the members of the steering committee, the lead and contributing authors, reviewers and the secretariat for their contribution to the preparation of this assessment report. Authors and reviewers have contributed to the report in their individual capacities. Their affiliations are only mentioned for identification purposes.

\section{Project steering committee}

Juliane Berger (German Environment Agency), John Christensen (UNEP DTU Partnership), Navroz K. Dubash (Centre for Policy Research, India), James Foster (UK Department for Business, Energy and Industrial Strategy), Samuel Karslake (UK Department for Business, Energy and Industrial Strategy), Mike Keoghan (UK Department for Business, Energy and Industrial Strategy), Jian Liu (UNEP), Simon Maxwell (independent), Surabi Menon (ClimateWorks Foundation), Bert Metz (European Climate Foundation), Katia Simeonova (United Nations Framework Convention on Climate Change - UNFCCC), Priyadarshi Shukla (Ahmedabad University) and Oksana Tarasova (World Meteorological Organization)

\section{Authors}

\section{Chapter 1}

Author: Anne Olhoff (UNEP DTU Partnership, Denmark)

\section{Chapter 2}

Lead authors: Takeshi Kuramochi (NewClimate Institute, Germany), Michel den Elzen (PBL Netherlands Environmental Assessment Agency, the Netherlands) and Glen P. Peters (Center for International Climate Research CICERO, Norway)

Contributing authors: Caitlin Bergh (University of Cape Town, South Africa), Monica Crippa (Joint Research Centre/ European Commission, European Union (EU)), Andreas Geiges (Climate Analytics, Germany), Catrina Godinho (HUMBOLDT-VIADRINA Governance Platform, Germany), Sofia Gonzales-Zuñiga (NewClimate Institute, Germany), Ursula Fuentes Hutfilter (Climate Analytics, Germany), Kimon Keramidas (Joint Research Centre/European Commission, EU), Yong Gun Kim (Korea Environment Institute, the Republic of Korea), Swithin Lui (NewClimate Institute, Germany), Zhu Liu (Tsinghua University, China), Jos Olivier (PBL Netherlands Environmental Assessment Agency, the Netherlands), Leonardo Nascimento (NewClimate Institute, Germany), Joana Portugal Pereira (Graduate School of Engineering (COPPE), Universidade Federal do Rio de Janeiro, Brazil), Değer Saygin (SHURA, Turkey), Claire Stockwell (Climate Analytics, Germany), Jorge Villareal (Iniciativa Climática de México, Mexico), William Wills (COPPE, Universidade Federal do Rio de Janeiro, Brazil)

\section{Chapter 3}

Lead authors: Joeri Rogelj (Grantham Institute, Imperial College London, UK; International Institute for Applied Systems Analysis - IIASA, Austria), Michel den Elzen (PBL Netherlands Environmental Assessment Agency, the Netherlands) and Joana Portugal Pereira (Graduate School of Engineering (COPPE), Universidade Federal do Rio de Janeiro, Brazil)

Contributing authors: Niklas Höhne (NewClimate Institute, Germany), Daniel Huppmann (International Institute for Applied Systems Analysis - IIASA, Austria), Gunnar Luderer (Potsdam Institute for Climate Impact Research, Germany)

\section{Chapter 4}

Lead authors: Niklas Höhne (NewClimate Institute, Germany), Frederic Hans (NewClimate Institute, Germany) and Anne Olhoff (UNEP DTU Partnership, Denmark)

Contributing authors: Parth Bhatia (Centre for Policy Research, India), Brian O'Callaghan (University of Oxford, UK), Sherillyn Raga (Overseas Development Institute, UK), Nigel Yau (University of Oxford, UK)

\section{Chapter 5}

Lead authors: Jasper Faber (CE Delft, the Netherlands) and David S. Lee (Manchester Metropolitan University, UK)

Contributing authors: Susanne Becken (Griffith University, Australia), James J. Corbett (Energy and Environmental Research Associates, USA), Nick Cumpsty (Imperial College London, UK), Gregg Fleming (Volpe Center, U.S. Department of Transportation, USA), Tore Longva (DNV GL, Norway), Marianne Tronstad Lund (Center for International Climate Research - CICERO, Norway), Tristan Smith (University College London, UK)

\section{Chapter 6}

Lead authors: Stuart Capstick (Cardiff University, Centre for Climate Change and Social Transformations, Tyndall Centre for Climate Change Research, UK), Radhika Khosla (University of Oxford, UK) and Susie Wang (Climate Outreach, UK)

Contributing authors: Nicole van den Berg (Utrecht University, the Netherlands), Diana Ivanova (University of Leeds, UK), Ilona M. Otto (Wegener Center for Climate and Global Change, University of Graz, and Potsdam Institute for Climate Impact Research, Germany), Timothy Gore (Oxfam International, UK), Adam Corner (Climate Outreach, Centre for Climate Change and Social Transformations, UK), Lewis Akenji (Hot or Cool Institute, Germany), Claire Hoolohan (University of Manchester, Centre for Climate Change and Social Transformations, Tyndall Centre for Climate Change Research, UK), Kate Power (KR Foundation, Denmark), Lorraine Whitmarsh (University of Bath, Centre for Climate Change and Social Transformations, Tyndall Centre for Climate Change Research, UK) 


\section{Reviewers}

Thibaut Abergel (International Energy Agency), Ritu Ahuja (The Energy and Resources Institute), Juan-Carlos Altamirano (World Resources Institute), Pieter Boot (PBL Netherlands Environmental Assessment Agency, the Netherlands), Kathryn Jennifer Bowen (Australian National University), Laura Brimont (Institute for Sustainable Development and International Relations), Jan Burck (Germanwatch), Marina Bylinsky (Airports Council International Europe), Sylvain Cail (Enerdata), Katherine Calvin (Pacific Northwest National Laboratory), Nicolas Campion (Danish Technical University), Jasmin Cantzler (GIZ), Cyril Cassisa (International Energy Agency), Rachel Chi Kiu Mok (World Bank), Laura Cozzi (International Energy Agency), Daniel Crow (International Energy Agency), Sophia David (UK Department for Business, Energy and Industrial Strategy), Chiara Delmastro (International Energy Agency), Steffen Dockweiler (Klimarådet), Sebastian Eastham (Massachusetts Institute of Technology), Lukas Fesenfeld (ETH Zurich), Olivia Flynn (UK Department for Transport), James Foster (UK Department for Business, Energy and Industrial Strategy), Andreas Frömelt (ETH Zurich), Katja Funke (International Monetary Fund), Harikumar Gadde (World Bank), Mengpin Ge (World Resources Institute), Franck Gouéry (EU Directorate-General for Climate Action), Jukka-Pekka Jalkanen (Finnish Meteorological Institute), Yasuko Kameyama (National Institute for Environmental Studies, Japan), Samuel Karslake (UK Department for Business, Energy and Industrial Strategy), Noah Kaufman (Columbia University), Terry Keating (United States Environmental Protection Agency), Enrique Maurtua Konstantinidis (Fundación Ambiente y Recursos Naturales), Gabriel Labbate (United Nations Environment Programme), Alan David Lee (World Bank), Gerd Leipold (HUMBOLDT-VIADRINA Governance Platform), Mason Scott Lester (Danish Technical University), Sharon Lo (UK Department for Business, Energy and Industrial Strategy), Karan Mangotra (The Energy and Resources Institute), Toshihiko Masui (National Institute for Environmental Studies, Japan), Patrick Matthewson (UK Department for Business, Energy and Industrial Strategy), Axel Michaelowa (Perspectives Climate Group), Daniel Beat Müller (Norwegian University of Science and Technology), Andrei Mungiu (EU delegation to the Carbon Offsetting and Reduction Scheme for International Aviation - CORSIA), Marie Münster (Danish Technical University), Tirthankar Nag (International Management Institute, Kolkata), Miles Perry (EU Directorate-General for Climate Action), Apostolos Petropoulos (International Energy Agency), Annie Petsonk (Environmental Defense Fund), Pedro Piris-Cabezas (Environmental Defense Fund), Rhian ReesOwen (UK Department for Business, Energy and Industrial Strategy), Yann Robiou du Pont (Institute for Sustainable Development and International Relations), Michael Russo (University of Aveiro), Mateo Salazar (Vivid Economics), Himanshu Sharma (United Nations Environmental Programme), Chandra Shekhar Sinha (World Bank), Sandhya Srinivasan (World Bank), Julia Steinberger (University of Leeds), Kentaro Tamura (Institute for Global Environmental Strategies, Japan), Jacopo Tattini
(International Energy Agency), Jacob Teter (International Energy Agency), Tom Van lerland (EU Directorate-General for Climate Action), Tiffany Vass (International Energy Agency), Benjamin Walker (UK Department for Business, Energy and Industrial Strategy), George Williams (UK Department for Business, Energy and Industrial Strategy), Zhao Xiusheng (Tsinghua University)

\section{Chief scientific editors}

Anne Olhoff (UNEP DTU Partnership) and John Christensen (UNEP DTU Partnership)

\section{Editorial support}

Olivier Bois von Kursk (UNEP DTU Partnership) and James Haselip (UNEP DTU Partnership)

\section{Secretariat and project coordination}

Anne Olhoff (UNEP DTU Partnership), Olivier Bois von Kursk (UNEP DTU Partnership), John Christensen (UNEP DTU Partnership), Kaisa Uusimaa (UNEP), Maarten Kappelle (UNEP), Ying Wang (UNEP) and Edoardo Zandri (UNEP)

\section{Media and launch support}

Daniel Cooney (UNEP), David Cole (UNEP), Carlota Estalella Alba (UNEP), Florian Fussstetter (UNEP), Keishamaza Rukikaire (UNEP), Maria Vittoria Galassi (UNEP), Michael Logan (UNEP), Nancy Groves (UNEP), Neha Sud (UNEP), Pooja Munshi (UNEP), Viola Kup (UNEP), Mette Annelie Rasmussen (UNEP DTU Partnership), Lasse Hemmingsen (UNEP DTU Partnership) and several other members of the UNEP communication division

\section{Design and layout}

Joseph \& Sebastian (Cover), Caren Weeks (Figures), Strategic Agenda (Layout)

\section{Translation of the executive summary and language editing}

Strategic Agenda

\section{Thanks also to:}

Niklas Hagelberg (UNEP), Pinya Sarasas (UNEP), Angeline Djampou (UNEP), Sofía Méndez Mora (UNEP), Garrette Clark (UNEP), Susan Mutebi-Richards (UNEP), Harsha Dave (UNEP), Abdelmenam Mohamed (UNEP), Mohamed Atani (UNEP), Ekaterina Tegina (UNEP), Roel Hoenders (International Maritime Organization - IMO), Camille Bourgeon (IMO), John Calleya (IMO), Gerd Leipold (Climate Transparency), Catrina Godinho (Climate Transparency) and Beatriz Martinez Romera (University of Copenhagen)

Finally, UNEP would like to thank the ClimateWorks Foundation, the Danish Ministry of Foreign Affairs, the Dutch Ministry of Economic Affairs and Climate Policy, the German Federal Ministry for the Environment, Nature Conservation and Nuclear Safety (BMU), the KR Foundation and the Swedish International Development Cooperation Agency (SIDA) for supporting the work of the Emissions Gap Report. 


\section{Contents}

Acknowledgements $\quad$ V

Glossary $\quad$ IX

Foreword XIII

$\begin{array}{ll}\text { Executive summary } & \text { XIV }\end{array}$

$\begin{array}{lll}\text { Chapter } 1 & \text { Introduction } & 1\end{array}$

$1.1 \quad$ Context of the Emissions Gap Report $2020 \quad 1$

$\begin{array}{lll}1.2 & \text { Focus and approach of the report } & 1\end{array}$

1.3 Structure of the report 2

Chapter 2 Global emissions trends and G20 status and outlook 3

2.1 Introduction 3

$2.2 \quad$ Current global emissions: status and trends 4

2.3 Achievement of Cancun Pledges by G20 members, considering the potential impact

$2.4 \quad$ of COVID-19 10

Assessment of $\mathrm{G} 20$ members progress towards NDC targets

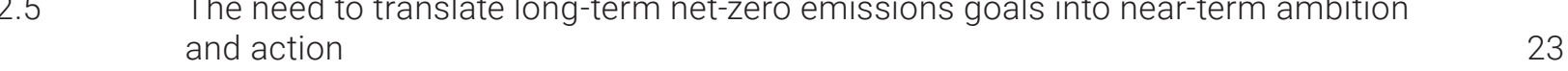

$\begin{array}{lll}\text { Chapter } 3 & \text { The emissions gap } & 25\end{array}$

$\begin{array}{lll}3.1 & \text { Introduction } & 25\end{array}$

$\begin{array}{lll}3.2 & \text { The } 2030 \text { emissions gap } & 25\end{array}$

3.3 Scenarios considered for the 2030 gap assessment 28

Implications of the COVID-19 pandemic and associated rescue and recovery
measures on GHG emissions by 2030

Implications of the emissions gap for the feasibility of achieving the long-term
temperature goal of the Paris Agreement

$\begin{array}{ll}\text { Chapter } 4 & \begin{array}{l}\text { Bridging the gap - implications of current COVID-19 fiscal rescue and recovery } \\ \text { measures }\end{array}\end{array}$

$4.1 \quad$ Introduction 36

4.2 Unprecedented global fiscal spending on economic rescue and recovery measures 37

4.3 Fiscal COVID-19 spending has so far primarily supported the global status quo of
high-carbon economic production

4.4 Emerging lessons and examples for governments in the pursuit of low-carbon
economic recovery

Chapter 5 Bridging the gap - the role of international shipping and aviation 52

$5.1 \quad$ Introduction and framing 52

$5.2 \quad$ Current emissions, projections and drivers 52

$5.3 \quad$ Mitigation options $\quad 55$

$5.4 \quad$ Pathways to lower emissions 58

$\begin{array}{lll}5.5 & \text { Conclusions } & 60\end{array}$

Chapter 6 Bridging the gap - the role of equitable low-carbon lifestyles 62

$6.1 \quad$ The consumption problem and why lifestyles are critical to tackling climate change 62

6.2 Achieving lifestyle emissions reduction by sector 64

6.3 Realizing lifestyle change: which mechanisms encourage low-carbon lifestyles? 70

$\begin{array}{lll}6.4 & \text { Integrated policies in each sector } & 73\end{array}$

$\begin{array}{ll}6.5 & \text { Looking forward } \\ \end{array}$

$\begin{array}{ll}\text { References } & 76\end{array}$ 



\section{Glossary}

This glossary is compiled according to the Lead Authors of the Report drawing on glossaries and other resources available on the websites of the following organizations, networks and projects: Intergovernmental Panel on Climate Change, United Nations Environment Programme, United Nations Framework Convention on Climate Change and World Resources Institute.

Baseline/reference: The state against which change is measured. In the context of transformation pathways, the term 'baseline scenarios' refers to scenarios that are based on the assumption that no mitigation policies or measures will be implemented beyond those that are already in force and/or are legislated or planned to be adopted. Baseline scenarios are not intended to be predictions of the future, but rather counterfactual constructions that can serve to highlight the level of emissions that would occur without further policy effort. Typically, baseline scenarios are then compared to mitigation scenarios that are constructed to meet different goals for greenhouse gas emissions, atmospheric concentrations or temperature change. The term 'baseline scenario' is used interchangeably with 'reference scenario' and 'no policy scenario'. In much of the literature the term is also synonymous with the term 'business as usual (BAU) scenario', although the term 'BAU' has fallen out of favour because the idea of 'business as usual' in century-long socioeconomic projections is hard to fathom.

Bioenergy: Energy derived from any form of biomass such as recently living organisms or their metabolic by-products.

Cancun Pledge: During 2010, many countries submitted their existing plans for controlling greenhouse gas emissions to the Climate Change Secretariat and these proposals were formally acknowledged under the United Nations Framework Convention on Climate Change (UNFCCC). Developed countries presented their plans in the shape of economywide targets to reduce emissions, mainly up to 2020, while developing countries proposed ways to limit their growth of emissions in the shape of plans of action.

Carbon dioxide emission budget (or carbon budget): For a given temperature rise limit, for example a $1.5^{\circ} \mathrm{C}$ or $2^{\circ} \mathrm{C}$ long-term limit, the corresponding carbon budget reflects the total amount of carbon emissions that can be emitted for temperatures to stay below that limit. Stated differently, a carbon budget is the area under a carbon dioxide $\left(\mathrm{CO}_{2}\right)$ emission trajectory that satisfies assumptions about limits on cumulative emissions estimated to avoid a certain level of global mean surface temperature rise.

Carbon dioxide equivalent $\left(\mathrm{CO}_{2} \mathrm{e}\right)$ : A way to place emissions of various radiative forcing agents on a common footing by accounting for their effect on climate. It describes, for a given mixture and amount of greenhouse gases, the amount of $\mathrm{CO}_{2}$ that would have the same global warming ability, when measured over a specified time period. For the purpose of this report, greenhouse gas emissions (unless otherwise specified) are the sum of the basket of greenhouse gases listed in Annex $\mathrm{A}$ to the Kyoto Protocol, expressed as $\mathrm{CO}_{2} \mathrm{e}$ assuming a 100-year global warming potential.

Carbon intensity: The amount of emissions of $\mathrm{CO}_{2}$ released per unit of another variable such as gross domestic product, output energy use, transport or agricultural/forestry products.

\section{Carbon offset: See Offset.}

Carbon price: The price for avoided or released $\mathrm{CO}_{2}$ or $\mathrm{CO}_{2} \mathrm{e}$ emissions. This may refer to the rate of a carbon tax or the price of emission permits. In many models that are used to assess the economic costs of mitigation, carbon prices are used as a proxy to represent the level of effort in mitigation policies.

Carbon tax: A levy on the carbon content of fossil fuels. Because virtually all of the carbon in fossil fuels is ultimately emitted as $\mathrm{CO}_{2}$, a carbon tax is equivalent to an emission tax on $\mathrm{CO}_{2}$ emissions.

Co-benefits: The positive effects that a policy or measure aimed at one objective might have on other objectives, without yet evaluating the net effect on overall social welfare. Co-benefits are often subject to uncertainty and depend on, among others, local circumstances and implementation practices. Co-benefits are often referred to as ancillary benefits.

Conditional NDC: NDC proposed by some countries that are contingent on a range of possible conditions, such as the ability of national legislatures to enact the necessary laws, ambitious action from other countries, realization of finance and technical support, or other factors. 
Conference of the Parties (COP): The supreme body of the United Nations Framework Convention on Climate Change. It currently meets once a year to review the Convention's progress.

Current policy trajectory: This trajectory is based on estimates of 2020 emissions considering projected economic trends and current policy approaches including policies at least through 2015. Estimates may be based on either official data or independent analysis.

\section{Deforestation: Conversion of forest to non-forest.}

Economic mitigation potential: The mitigation potential, which takes into account social costs and benefits and social discount rates, assuming that market efficiency is improved by policies and measures and barriers are removed.

Emissions gap: The difference between the greenhouse gas emission levels consistent with a specific probability of limiting the mean global temperature rise to below $2{ }^{\circ} \mathrm{C}$ or $1.5^{\circ} \mathrm{C}$ in 2100 above pre-industrial levels and the $\mathrm{GHG}$ emission levels consistent with the global effect of the NDCs, assuming full implementation from 2020.

Emission pathway: The trajectory of annual greenhouse gas emissions over time.

Fiscal measure: Fiscal, monetary or regulatory intervention by a government to reinvigorate economic activity in response to a crisis.

Global warming potential: An index representing the combined effect of the differing times greenhouse gases remain in the atmosphere and their relative effectiveness in absorbing outgoing infrared radiation.

Greenhouse gases: The atmospheric gases responsible for causing global warming and climatic change. The major greenhouse gases are carbon dioxide $\left(\mathrm{CO}_{2}\right)$, methane $\left(\mathrm{CH}_{4}\right)$ and nitrous oxide $\left(\mathrm{N}_{2} \mathrm{O}\right)$. Less prevalent, but very powerful, GHGs are hydrofluorocarbons (HFCs), perfluorocarbons (PFCs) and sulphur hexafluoride $\left(\mathrm{SF}_{6}\right)$.

Integrated assessment models: Models that seek to combine knowledge from multiple disciplines in the form of equations and/or algorithms in order to explore complex environmental problems. As such, they describe the full chain of climate change, from production of greenhouse gases to atmospheric responses. This necessarily includes relevant links and feedbacks between socioeconomic and biophysical processes.

Intended nationally determined contributions: INDCs are submissions from countries describing the national actions that they intend to take to reach the Paris Agreement's longterm temperature goal of limiting warming to well below $2^{\circ} \mathrm{C}$. Once a country has ratified the Paris Agreement, its INDC is automatically converted to its NDC (see below), unless it chooses to further update it. INDCs are thus only used in this publication in reference to countries that have not yet ratified the Paris Agreement.

Kigali Amendment: The Kigali Amendment to the Montreal Protocol on Substances that Deplete the Ozone Layer aims for the phase-down of hydrofluorocarbons (HFCs) by cutting their production and consumption.

Kyoto Protocol: An international agreement, standing on its own, and requiring separate ratification by governments, but linked to the UNFCCC. The Kyoto Protocol, among other things, sets binding targets for the reduction of greenhouse gas emissions by industrialized countries.

Land use, land-use change and forestry (LULUCF): A greenhouse gas inventory sector that covers emissions and removals of greenhouse gases resulting from direct humaninduced land use, land-use change and forestry activities.

Likely chance: A likelihood greater than 66 per cent chance. Used in this assessment to convey the probabilities of meeting temperature limits.

Lock-in: Lock-in occurs when a market is stuck with a standard even though participants would be better off with an alternative.

Mitigation: In the context of climate change, a human intervention to reduce the sources, or enhance the sinks of greenhouse gases. Examples include using fossil fuels more efficiently for industrial processes or electricity generation, switching to solar energy or wind power, improving the insulation of buildings and expanding forests and other 'sinks' to remove greater amounts of $\mathrm{CO}_{2}$ from the atmosphere.

Monetary measure: Central bank and/or government action to adjust the supply of money and credit, often facilitated by altering rates of interest.

Monitoring, reporting and verification: A process/concept that potentially supports greater transparency in the climate change regime.

Nationally determined contributions: Submissions by countries that have ratified the Paris Agreement which presents their national efforts to reach the Paris Agreement's long-term temperature goal of limiting warming to well below $2^{\circ} \mathrm{C}$. New or updated NDCs are to be submitted in 2020 and every five years thereafter. NDCs thus represent a country's current ambition/target for reducing emissions nationally.

Non-State and subnational actors: 'Non-State and subnational actors' includes companies, cities, subnational regions and investors that take or commit to climate action.

Offset (in climate policy): A unit of $\mathrm{CO}_{2} \mathrm{e}$ emissions that is reduced, avoided, or sequestered to compensate for emissions occurring elsewhere. 
Recovery-type measure: Fiscal, monetary or regulatory intervention by a government to reinvigorate economic activity in response to a crisis.

Rescue-type measure: Immediate fiscal, monetary or regulatory intervention by a government to protect citizens' lives and socioeconomic well-being and/or to provide emergency support to businesses and the economy in response to a crisis.

Scenario: A description of how the future may unfold based on 'if-then' propositions. Scenarios typically include an initial socioeconomic situation and a description of the key driving forces and future changes in emissions, temperature or other climate change-related variables.

Shared Socioeconomic Pathways (SSP): Scenarios of projected socioeconomic global changes up to 2100 . They are used to derive greenhouse gas emissions scenarios associated with different climate policies scenarios.

Short-lived climate forcer: Compounds in the atmosphere that cause warming and have lifetimes roughly below 20 years, including black carbon, ozone, methane and many hydrofluorocarbons.

Source: Any process, activity or mechanism that releases a greenhouse gas, an aerosol or a precursor of a greenhouse gas or aerosol into the atmosphere. 

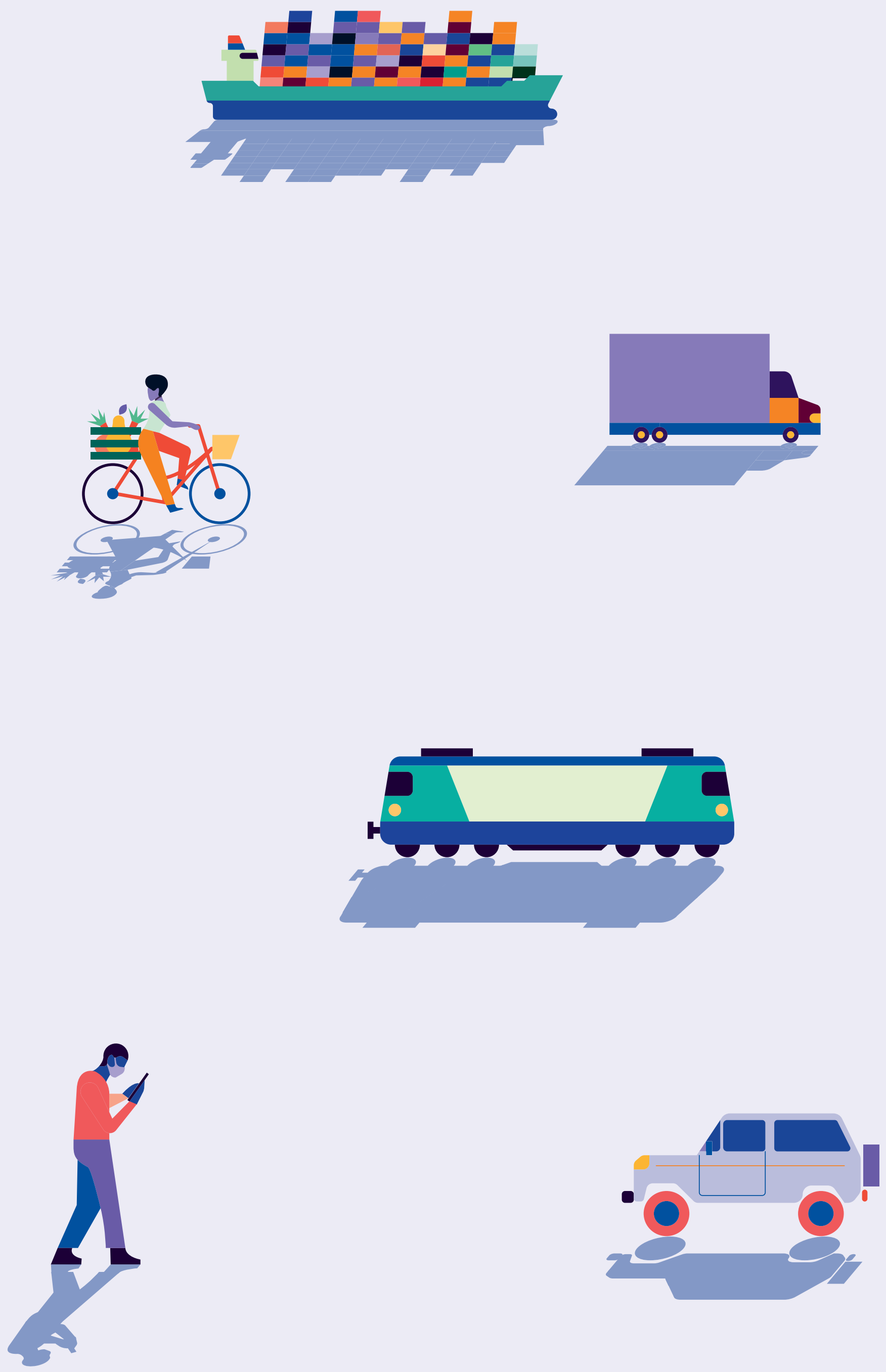


\section{Foreword}

As the world deals with the ongoing impacts of the COVID-19 pandemic, the climate crisis has not gone away. Greenhouse gas (GHG) emissions hit a new high in 2019. The year 2020 is on course to be the warmest on record. Wildfires, storms and droughts continue to wreak havoc while glaciers melt at unprecedented rates.

The pandemic-linked economic slowdown is expected to cause a drop of up to 7 per cent in carbon dioxide emissions this year. However, as the UNEP Emissions Gap Report 2020 shows, this dip will have an insignificant impact on the Paris Agreement goal of limiting global warming to well below $2^{\circ} \mathrm{C}$, and pursuing $1.5^{\circ} \mathrm{C}$, unless the international community prioritizes a green recovery. The report says that the expected 2020 fall in emissions translates to a $0.01^{\circ} \mathrm{C}$ reduction of global warming by 2050. Overall, we are heading for a world that is $3.2^{\circ} \mathrm{C}$ warmer by the end of this century, even with full implementation of unconditional nationally determined contributions (NDCs) under the Paris Agreement.

There is good news in the finding that a green pandemic recovery could shave up to 25 per cent off the emissions we would expect to see in 2030 with implementation of unconditional NDCs - bringing the world close to the $2^{\circ} \mathrm{C}$ pathway. The report identifies recovery measures to deliver these cuts while supporting other environmental, social and economic goals. These include direct support for zero-emissions technologies and infrastructure, reducing fossil fuel subsidies, and backing nature-based solutions including large-scale landscape restoration and reforestation.

Some G20 members have already announced green recovery measures. Yet COVID-19 fiscal spending, as at October 2020, had overwhelmingly supported the status quo or fostered new high-carbon investments. While there have also been stronger pledges on climate - including China targeting

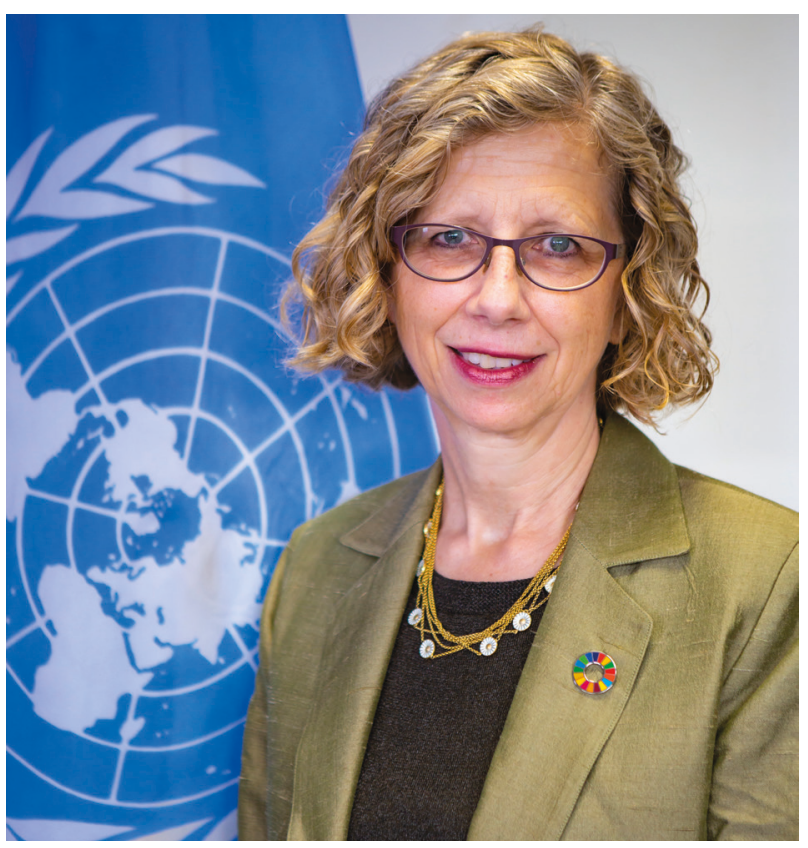

carbon neutrality by 2060 , South Africa by 2050, and the Japanese and European Union net-zero GHG target of midcentury - they are yet to be reflected in updated NDCs. Governments must go greener in the next stage of COVID-19 fiscal interventions and increase their NDC ambitions in 2021.

The report finds that stronger action must include facilitating, encouraging and mandating changes in consumption behaviour by individuals and the private sector - enabling consumers to avoid high-carbon consumption by, for example, redesigning cities, making housing more efficient and promoting better, less wasteful diets. The wealthy bear the greatest responsibility in this area. The combined emissions of the richest 1 per cent of the global population account for more than twice the combined emissions of the poorest 50 per cent. This elite will need to reduce their footprint by a factor of 30 to stay in line with the Paris Agreement targets.

The pandemic is a warning that we must urgently shift from our destructive development path, which is driving the three planetary crises of climate change, nature loss and pollution. But it is clearly also a major opportunity. I urge governments, businesses and individuals - particularly those with the greatest climate footprint - to take this opportunity to protect our climate and nature for decades to come.

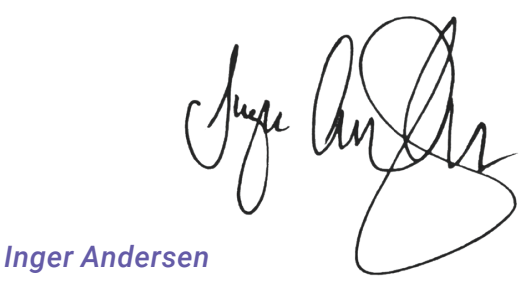

Executive Director

United Nations Environment Programme 


\section{Executive summary - Emissions Gap Report 2020}

\section{Introduction}

This eleventh edition of the United Nations Environment Programme (UNEP) Emissions Gap Report has been produced in a year where the COVID-19 crisis has dominated the news and policymaking and has caused immense suffering and economic and social disruption worldwide. This economic disruption has briefly slowed - but far from eliminated - the historic and ever-increasing burden of human activity on the Earth's climate. This burden is observable in the continuing rise in extreme weather events, including wildfires and hurricanes, and in the melting of glaciers and ice at both poles. The year 2020 has set new records - they will not be the last.

As in previous years, this report assesses the gap between estimated future global greenhouse gas (GHG) emissions if countries implement their climate mitigation pledges and the global emission levels from least-cost pathways that are aligned with achieving the temperature goals of the Paris Agreement. This difference between "where we are likely to be and where we need to be" is known as the 'emissions gap'

The report also examines two areas that are highly relevant for bridging the gap and which have become even more relevant in the wake of the COVID-19 pandemic: the shipping and aviation sectors, where international emissions are not covered by nationally determined contributions (NDCs), and lifestyle change.

Reflecting the unusual circumstances, the 2020 report deviates from its usual approach of exclusively considering consolidated data from previous years as the basis for assessment. To maximize its policy relevance, preliminary assessments of the implications of the pandemic and associated rescue and recovery measures are included throughout the report.

Are we on track to bridging the gap? Absolutely not.

Although 2020 emissions will be lower than in 2019 due to the COVID-19 crisis and associated responses, GHG concentrations in the atmosphere continue to rise, with the immediate reduction in emissions expected to have a negligible long-term impact on climate change. However, the unprecedented scale of COVID-19 economic recovery measures presents the opening for a low-carbon transition that creates the structural changes required for sustained emissions reductions. Seizing this opening will be critical to bridging the emissions gap.
The United Nations Secretary-General is calling on governments to use COVID-19 recovery as an opportunity to create more sustainable, resilient and inclusive societies. Aligned with this, the United Nations Framework Convention on Climate Change (UNFCCC) has stressed that governments could integrate and specify some of their post-COVID-19 recovery plans and policies in their new or updated NDCs and long-term mitigation strategies, both of which countries are requested to submit in 2020.

The most significant and encouraging development in terms of climate policy in 2020 is the growing number of countries that have committed to achieving net-zero emissions goals by around mid-century. These commitments are broadly consistent with the Paris Agreement temperature goal, provided they are achieved globally. The litmus test of these announcements will be the extent to which they are reflected in near-term policy action and in significantly more ambitious NDCs for the period to 2030

As in previous years, the 2020 Emissions Gap Report has been guided by a distinguished steering committee and prepared by an international team of leading scientists, assessing all available information, including that published in the context of the Intergovernmental Panel on Climate Change (IPCC) reports, as well as in other recent scientific studies. The assessment process has been transparent and participatory. The assessment methodology and preliminary findings were made available to the governments of the countries specifically mentioned in the report to provide them with the opportunity to comment on the findings.

\section{GHG emissions continued to increase - in 2019.}

Global GHG emissions continued to grow for the third consecutive year in 2019, reaching a record high of $52.4 \mathrm{GtCO}_{2} \mathrm{e}$ (range: \pm 5.2 ) without land-use change (LUC) emissions and $59.1 \mathrm{GtCO}_{2} \mathrm{e}$ (range: $\pm 5.9)$ when including LUC.

Fossil carbon dioxide $\left(\mathrm{CO}_{2}\right)$ emissions (from fossil fuels and carbonates) dominate total GHG emissions including LUC (65 per cent) and consequently the growth in $\mathrm{GHG}$ emissions. Preliminary data suggest that fossil $\mathrm{CO}_{2}$ emissions reached a record $38.0 \mathrm{GtCO}_{2}$ (range: \pm 1.9 ) in 2019 .

Since 2010, GHG emissions without LUC have grown at 1.3 per cent per year on average, with 
preliminary data suggesting a 1.1 per cent increase in 2019. When including the more uncertain and variable LUC emissions, global GHG emissions have grown 1.4 per cent per year since 2010 on average, with a more rapid increase of 2.6 per cent in 2019 due to a large increase in vegetation forest fires. LUC emissions account for around 11 per cent of the global total, with the bulk of the emissions occurring in relatively few countries.

- Over the last decade, the top four emitters (China, the United States of America, EU27+UK and India) have contributed to 55 per cent of the total GHG emissions without LUC. The top seven emitters (including the Russian Federation, Japan and international transport) have contributed to 65 per cent, with G20 members accounting for 78 per cent. The ranking of countries changes dramatically when considering per capita emissions (figure ES.2).

There is some indication that the growth in global $\mathrm{GHG}$ emissions is slowing. However, GHG emissions are declining in Organisation of Economic Cooperation and Development (OECD) economies and increasing in non-OECD economies. Many OECD economies have had a peak in $\mathrm{GHG}$ emissions, with efficiency improvements and growth in low-carbon energy sources more than offsetting the growth in economic activity. Despite improving energy efficiency and increasing low-carbon sources, emissions continue to rise in countries with strong growth in energy use to meet development needs.

There is a general tendency that rich countries have higher consumption-based emissions (emissions allocated to the country where goods are purchased and consumed, rather than where they are produced) than territorial-based emissions, as they typically have cleaner production, relatively more services and more imports of primary and secondary products. In the 2000s, the gap between consumption and production was growing in rich countries but stabilized following the 2007-2008 global financial crisis. Even though rich countries have had higher consumption-based emissions than territorial-based emissions over the last decade, both emission types have declined at similar rates.

Figure ES.1. Global GHG emissions from all sources

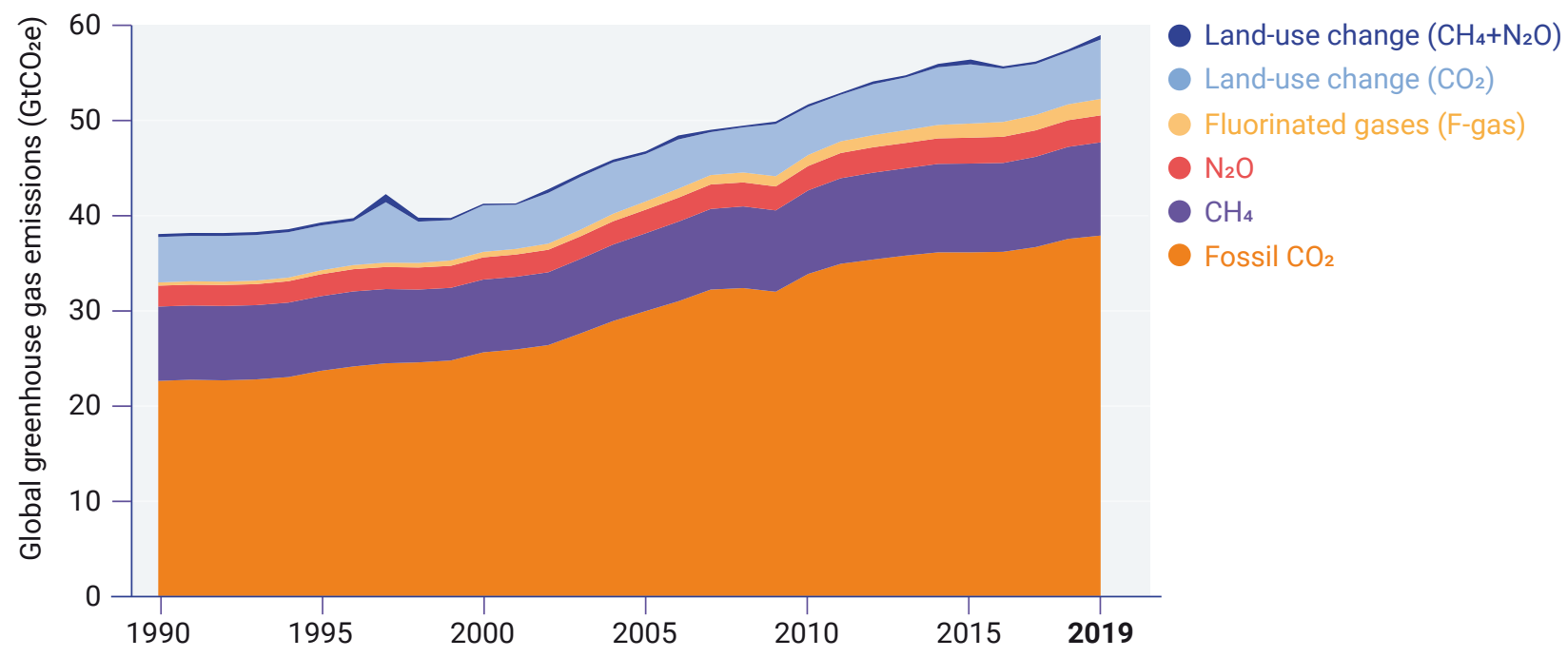

$2 \mathrm{CO}_{2}$ emissions could decrease by about 7 per cent in 2020 (range: 2-12 per cent) compared with 2019 emission levels due to COVID-19, with a smaller drop expected in $\mathrm{GHG}$ emissions as non- $\mathrm{CO}_{2}$ is likely to be less affected. However, atmospheric concentrations of GHGs continue to rise.

- The reduction in GHG emissions in 2020 due to COVID-19 is likely to be significantly larger than the 1.2 per cent reduction during the global financial crisis in the late 2000s. Studies indicate that the biggest changes have occurred in transport as COVID-19 restrictions were targeted to limit mobility, though reductions have also occurred in other sectors (figure ES.3).

- Although $\mathrm{CO}_{2}$ emissions will decrease in 2020, the resulting atmospheric concentrations of major GHGs $\left(\mathrm{CO}_{2}\right.$, methane $\left(\mathrm{CH}_{4}\right)$ and nitrous oxide $\left.\left(\mathrm{N}_{2} \mathrm{O}\right)\right)$ continued to increase in both 2019 and 2020 . Sustained reductions in emissions to reach netzero $\mathrm{CO}_{2}$ are required to stabilize global warming, while achieving net-zero GHG emissions will result in a peak then decline in global warming. 
Figure ES.2. Absolute GHG emissions of the top six emitters (excluding LUC emissions) and international transport (left) and per capita emissions of the top six emitters and the global average (right)

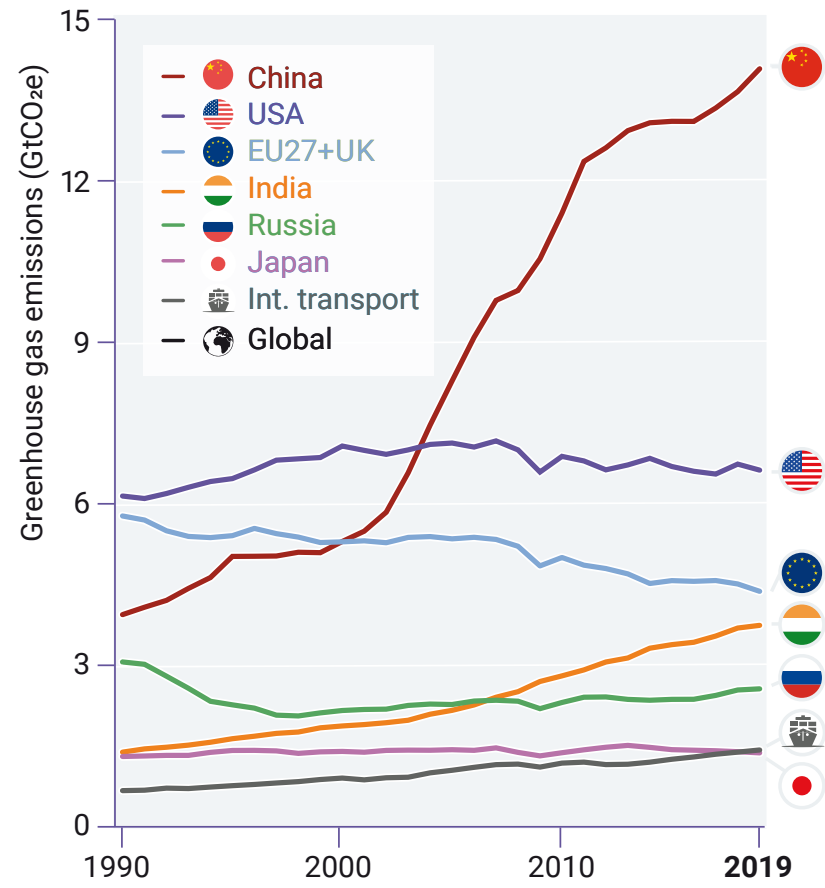

The COVID-19 crisis offers only a short-

3. term reduction in global emissions and will not contribute significantly to emissions reductions by 2030 unless countries pursue an economic recovery that incorporates strong decarbonization.

- Assessments of the implications of the COVID-19 pandemic and associated recovery measures on emissions by 2030 are still few and highly uncertain. However, this report provides explorative projections based on available studies (figure ES.4).

- The impact of the general slowdown of the economy due to the COVID-19 pandemic and associated rescue and recovery responses is expected to reduce global $\mathrm{GHG}$ emissions by about $2-4 \mathrm{GtCO}_{2} \mathrm{e}$ by 2030 compared with the pre-COVID-19 current policies scenario (figure ES.4 - current trends scenario). This assumes a pronounced short-term dip in $\mathrm{CO}_{2}$ emissions, after which emissions follow pre-2020 growth trends.

- If the initial short-term dip in $\mathrm{CO}_{2}$ emissions is followed by growth trends with lower decarbonization rates due to countries' potential rollback of climate policies as part of COVID-19 responses, the decrease in global emissions by 2030 is projected to be significantly smaller at around $1.5 \mathrm{GtCO}_{2} \mathrm{e}$ and may actually increase

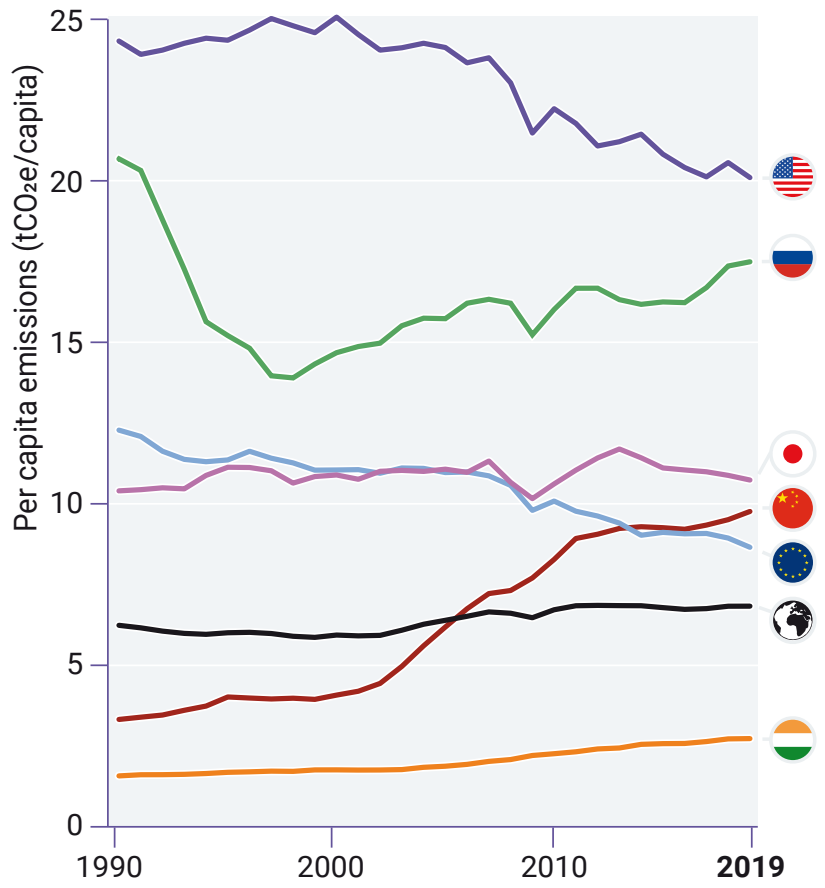

by around $1 \mathrm{GtCO}_{2} \mathrm{e}$ (figure ES. 4 - rebound to fossil fuels second-hit and single-hit scenarios, respectively) compared with the pre-COVID-19 current policies scenario.

Global GHG emissions are only projected to be significantly reduced by 2030 if COVID-19 economic recovery is used as an opening to pursue strong decarbonization (figure ES.4 - IEA sustainable recovery scenario). This could result in global GHG emissions of $44 \mathrm{GtCO}_{2}$ e by 2030 , a reduction of 15 $\mathrm{GtCO}_{2} \mathrm{e}$ (just over 25 per cent) by 2030 compared with the pre-COVID-19 current policies scenario.

There is a significant opportunity for countries to integrate low-carbon development in their COVID-19 rescue and recovery measures, and to incorporate these into new or updated NDCs and long-term mitigation strategies that are scheduled to be available in time for the reconvened twentysixth session of the Conference of the Parties (COP 26) in 2021. 
Figure ES.3. Reduction in emissions in 2020 relative to 2019 levels due to COVID-19 lockdowns

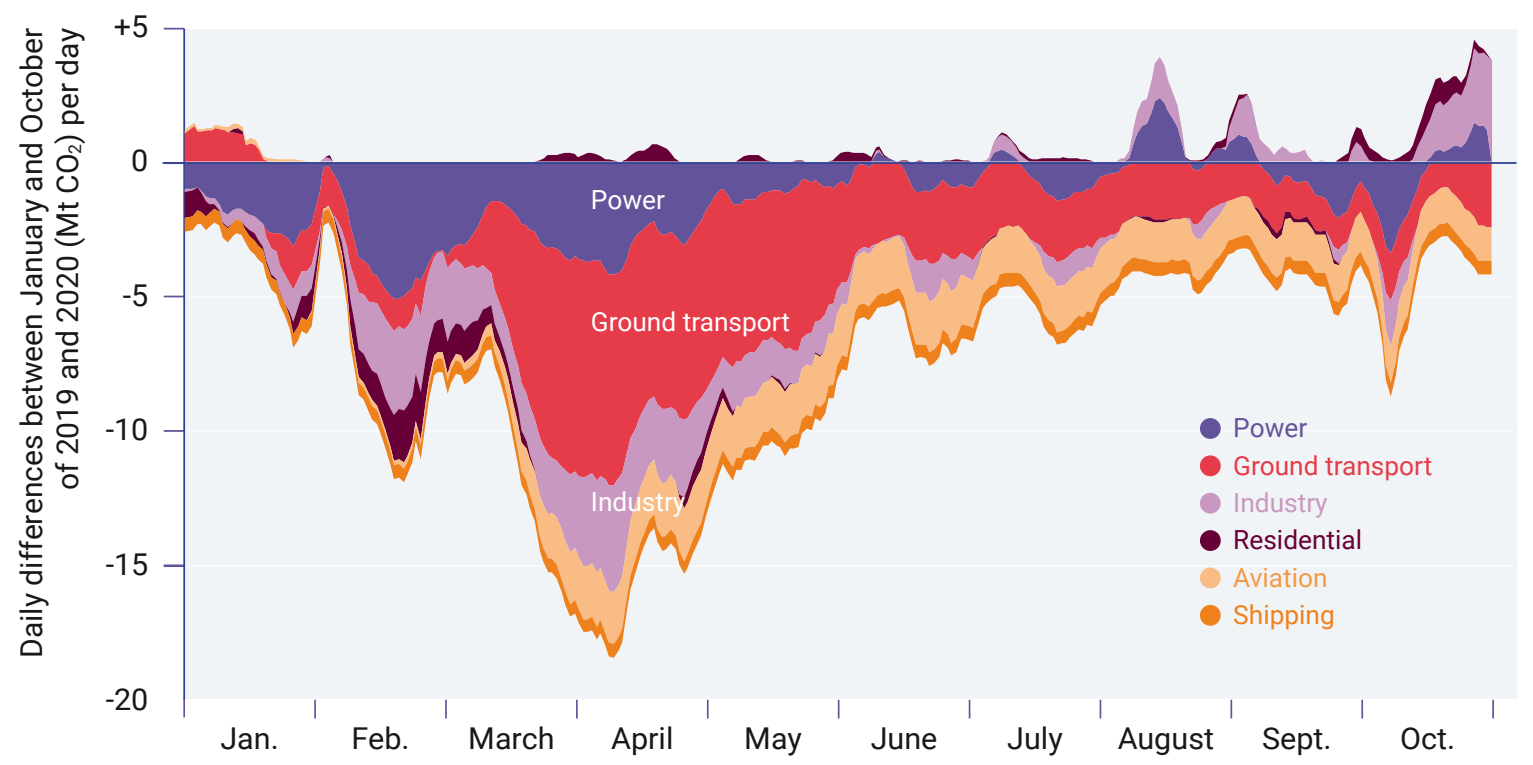

\section{The growing number of countries that are committing to net-zero emissions goals by around mid-century is the most significant and encouraging climate policy development of 2020 . To remain feasible and credible, it is imperative that these commitments are urgently translated into strong near-term policies and action, and are reflected in the NDCs.}

At the time of completing this report, 126 countries covering 51 per cent of global GHG emissions have net-zero goals that are formally adopted, announced or under consideration. If the United States of America adopts a net-zero GHG target by 2050 , as suggested in the Biden-Harris climate plan, the share would increase to 63 per cent.

The following G20 members have net-zero emissions goals: France and the United Kingdom, which have legally enshrined their 2050 net-zero GHG emissions goals; the European Union, which aims to achieve net-zero GHG emissions by 2050; China, which announced plans to achieve carbon neutrality before 2060; Japan, which announced a goal of net-zero GHG emissions by 2050; the Republic of Korea, the president of which committed the country to becoming carbon neutral by 2050 in a speech to parliament; Canada, which has indicated its intention to legislate a goal of netzero emissions (though it is unclear if this refers to just $\mathrm{CO}_{2}$ or all GHGs) by 2050; South Africa, which aims to achieve net-zero carbon emissions by 2050; and Argentina and Mexico, which are both part of the UNFCCC Climate Ambition Alliance working towards net-zero emissions by 2050 .
- There has been limited progress of G20 members in terms of providing formal submissions to the UNFCCC by 2020 of mid-century, long-term low GHG emission development strategies and new or updated NDCs. As at mid-November 2020, nine G20 members (Canada, the European Union, France, Germany, Japan, Mexico, South Africa, the United Kingdom and the United States of America) have submitted long-term low GHG development strategies to the UNFCCC, all of which were submitted before net-zero emissions goals were adopted. No G20 member has officially submitted a new or updated NDC target.

Although the recent announcements of netzero emissions goals are very encouraging, they highlight the vast discrepancy between the ambitiousness of these goals and the inadequate level of ambition in the NDCs for 2030. Furthermore, there is inconsistency between the emission levels implied by current policies and those projected under current NDCs by 2030, and, more importantly, those necessary for achieving net-zero emissions by 2050 .

- To make significant progress towards achieving the long-term temperature goal of the Paris Agreement by 2030 , two steps are urgently required. First, more countries need to develop long-term strategies that are consistent with the Paris Agreement, and second, new and updated NDCs need to become consistent with the net-zero emissions goals. 
Figure ES.4. Global total GHG emissions by 2030 under the original current policies scenario based on pre-COVID-19 studies and various 'what if' scenarios using explorative calculations (post-COVID-19) (median and $10^{\text {th }}$ to $90^{\text {th }}$ percentile range)

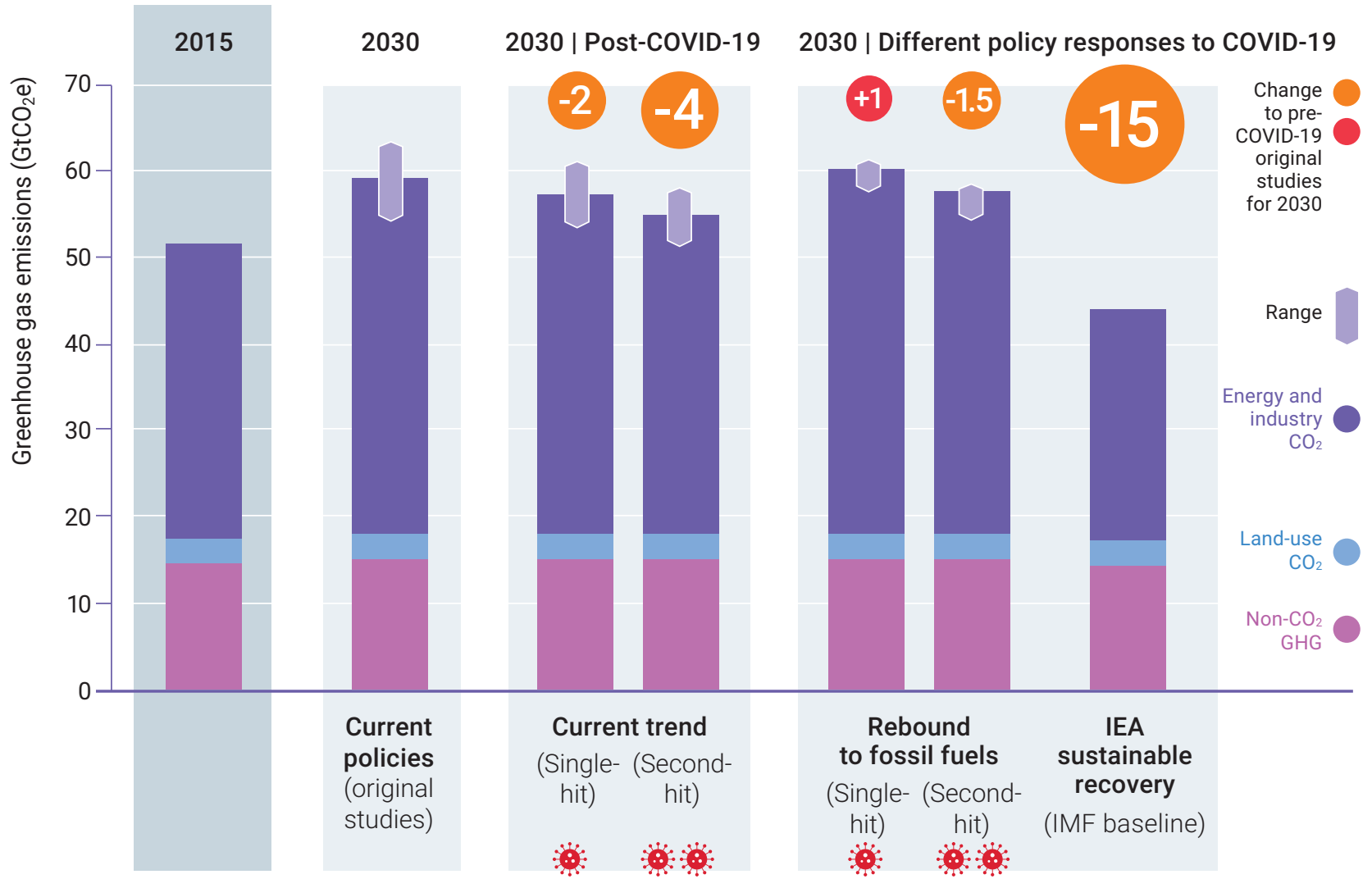

5 Collectively, G20 members are projected

5. to overachieve their modest 2020 Cancun Pledges, but they are not on track to achieve their NDC commitments. Nine G20 members are on track to achieve their 2030 NDC commitments, five members are not on track, and for two members there is a lack of sufficient information to determine this.

- In line with previous Emissions Gap Reports, this report pays close attention to $\mathrm{G} 20$ members, as they account for around 78 per cent of global GHG emissions and thereby largely determine global emission trends and the extent to which the 2030 emissions gap will be closed.

- Collectively, the G20 members are projected to overachieve their 2020 Cancun Pledges, even without considering the expected impact of COVID-19. According to the latest pre-COVID-19 scenario studies, South Africa is now projected to likely achieve its Cancun Pledge. The United States of America is also projected to achieve its Cancun Pledge, though only when the expected impact of COVID-19 is considered. It is still unlikely or uncertain whether Canada, Indonesia, Mexico and the Republic of Korea will achieve their Cancun Pledges, even when COVID-19 implications are considered.

Collectively, the $\mathrm{G} 20$ members are not on track to achieve their unconditional NDC commitments based on pre-COVID-19 projections. Nine of the 16 G20 members (counting the EU27+UK as one), are on track (Argentina, China, EU27+UK, India, Japan, Mexico, the Russian Federation, South Africa and Turkey). Five G20 members are projected to fall short and therefore require further action (Australia, Brazil, Canada, the Republic of Korea and the United States of America). Projections for Indonesia and Saudi Arabia are inconclusive.

The impacts of COVID-19 and economic recovery measures on 2030 emissions of individual G20 members may be significant, although estimates are still highly uncertain and vary across the few studies available. 
6 The emissions gap has not been narrowed compared with 2019 and is, as yet, unaffected by COVID-19. By 2030, annual emissions need to be $15 \mathrm{GtCO}_{2} \mathrm{e}$ (range: $12-19 \mathrm{GtCO}_{2} \mathrm{e}$ ) lower than current unconditional NDCs imply for a $2^{\circ} \mathrm{C}$ goal, and $32 \mathrm{GtCO}_{2} \mathrm{e}$ (range: $29-36$ $\mathrm{GtCO}_{2} \mathrm{e}$ ) lower for the $1.5^{\circ} \mathrm{C}$ goal. Collectively, current policies fall short $3 \mathrm{GtCO}_{2}$ e of meeting the level associated with full implementation of the unconditional NDCs.

The emissions gap for 2030 is defined as the difference between global total GHG emissions from least-cost scenarios that keep global warming to $2^{\circ} \mathrm{C}, 1.8^{\circ} \mathrm{C}$ or $1.5^{\circ} \mathrm{C}$ with varying levels of likelihood and the estimated global total GHG emissions resulting from a full implementation of the NDCs.

- The three temperature scenarios allow for various

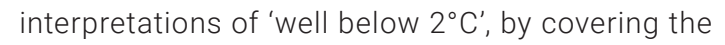
entire range of below $2^{\circ} \mathrm{C}$ to below $1.5^{\circ} \mathrm{C}$ (table
ES.1). Each scenario considers a least-cost climate change mitigation pathway that starts long-term reductions from 2020. These are calculated from the scenarios that were compiled as part of the mitigation pathway assessment of the IPCC Special Report on Global Warming of $1.5^{\circ} \mathrm{C}$.

The NDC and current policies scenarios are based on updated data provided by 10 modelling groups. As at mid-November 2020, none of the major emitters have submitted new or updated NDCs with stronger targets for 2030. Overall, NDC target updates from 2019 are expected to reduce total emissions by less than 1 per cent by 2030 .

Collectively, 2030 emission levels fall short of what the NDCs imply: the deficit is about $3 \mathrm{GtCO}_{2} \mathrm{e}$ under the unconditional NDC scenario, and about 5 $\mathrm{GtCO}_{2} \mathrm{e}$ under the conditional NDC scenario.

- The emissions gap between estimated global total emissions by 2030 under the NDC scenarios and

Table ES.1. Global total GHG emissions in 2030 under different scenarios (median and $10^{\text {th }}$ to $90^{\text {th }}$ percentile range), temperature implications, and the resulting emissions gap (based on the pre-COVID-19 current policies scenario)

\begin{tabular}{|c|c|c|c|c|c|c|c|c|c|}
\hline \multirow{2}{*}{$\begin{array}{l}\text { Scenario } \\
\text { (rounded to the } \\
\text { nearest gigaton) }\end{array}$} & \multirow{2}{*}{$\begin{array}{l}\text { Number } \\
\text { of scenarios } \\
\text { in set }\end{array}$} & \multirow{2}{*}{$\begin{array}{l}\text { Global total } \\
\text { emissions } \\
\text { in } 2030 \\
{\left[\mathrm{GtCO}_{2} \mathrm{e}\right]}\end{array}$} & \multicolumn{3}{|c|}{$\begin{array}{c}\text { Estimated } \\
\text { temperature outcomes }\end{array}$} & \multirow{2}{*}{$\begin{array}{l}\text { Closest } \\
\text { corresponding } \\
\text { IPCC SR1.5 } \\
\text { scenario class } \\
\end{array}$} & \multicolumn{3}{|c|}{$\begin{array}{l}\text { Emissions Gap in } 2030 \\
{\left[\mathrm{GtCO}_{2} \mathrm{e}\right]}\end{array}$} \\
\hline & & & $\begin{array}{c}50 \% \\
\text { probability }\end{array}$ & $\begin{array}{c}66 \% \\
\text { probability }\end{array}$ & $\begin{array}{c}90 \% \\
\text { probability }\end{array}$ & & $\begin{array}{l}\text { Below } \\
2.0^{\circ} \mathrm{C}\end{array}$ & $\begin{array}{l}\text { Below } \\
1.8^{\circ} \mathrm{C}\end{array}$ & $\begin{array}{c}\text { Below } \\
1.5^{\circ} \mathrm{C} \\
\text { in } 2100\end{array}$ \\
\hline 2010 policies & 6 & $64(60-68)$ & & & & & & & \\
\hline Current policies & 8 & $59(56-65)$ & & & & & $\begin{array}{c}17 \\
(15-22)\end{array}$ & $\begin{array}{c}24 \\
(21-28)\end{array}$ & $\begin{array}{c}34 \\
(31-39)\end{array}$ \\
\hline $\begin{array}{l}\text { Unconditional } \\
\text { NDCs }\end{array}$ & 11 & $56(54-60)$ & & & & & $\begin{array}{c}15 \\
(12-19)\end{array}$ & $\begin{array}{c}21 \\
(18-25)\end{array}$ & $\begin{array}{c}32 \\
(29-36)\end{array}$ \\
\hline $\begin{array}{l}\text { Conditional } \\
\text { NDCs }\end{array}$ & 12 & $53(51-56)$ & & & & & $\begin{array}{c}12 \\
(9-15)\end{array}$ & $\begin{array}{c}18 \\
(15-21)\end{array}$ & $\begin{array}{c}29 \\
(26-31)\end{array}$ \\
\hline $\begin{array}{l}\text { Below } 2.0^{\circ} \mathrm{C} \\
(66 \% \text { probability })\end{array}$ & 29 & $41(39-46)$ & $\begin{array}{c}\text { Peak: } \\
1.7-1.8^{\circ} \mathrm{C} \\
\text { In } 2100: \\
1.6-1.7^{\circ} \mathrm{C}\end{array}$ & $\begin{array}{c}\text { Peak: } \\
1.9-2.1^{\circ} \mathrm{C} \\
\text { In } 2100: \\
1.8-1.9^{\circ} \mathrm{C}\end{array}$ & $\begin{array}{c}\text { Peak: } \\
2.4-2.6^{\circ} \mathrm{C} \\
\text { In } 2100: \\
2.3-2.5^{\circ} \mathrm{C}\end{array}$ & $\begin{array}{c}\text { Higher } \\
2{ }^{\circ} \mathrm{C} \text { pathways }\end{array}$ & & & \\
\hline $\begin{array}{l}\text { Below } 1.8^{\circ} \mathrm{C} \\
(66 \% \text { probability })\end{array}$ & 43 & $35(31-41)$ & $\begin{array}{c}\text { Peak: } \\
1.6-1.7^{\circ} \mathrm{C} \\
\text { In } 2100: \\
1.3-1.6^{\circ} \mathrm{C}\end{array}$ & $\begin{array}{c}\text { Peak: } \\
1.7-1.8^{\circ} \mathrm{C} \\
\text { In } 2100: \\
1.5-1.7^{\circ} \mathrm{C}\end{array}$ & $\begin{array}{c}\text { Peak: } \\
2.1-2.3^{\circ} \mathrm{C} \\
\text { In } 2100: \\
1.9-2.2^{\circ} \mathrm{C}\end{array}$ & $\begin{array}{c}\text { Lower } \\
2{ }^{\circ} \mathrm{C} \text { pathways }\end{array}$ & & & \\
\hline $\begin{array}{l}\text { Below } 1.5^{\circ} \mathrm{C} \\
\text { in } 2100 \text { and } \\
\text { peak below } \\
1.7^{\circ} \mathrm{C} \text { (both with } \\
66 \% \text { probability) }\end{array}$ & 13 & $25(22-31)$ & $\begin{array}{c}\text { Peak: } \\
1.5-1.6^{\circ} \mathrm{C} \\
\text { In } 2100: \\
1.2-1.3^{\circ} \mathrm{C}\end{array}$ & $\begin{array}{c}\text { Peak: } \\
1.6-1.7^{\circ} \mathrm{C} \\
\text { In } 2100: \\
1.4-1.5^{\circ} \mathrm{C}\end{array}$ & $\begin{array}{c}\text { Peak: } \\
2.0-2.1^{\circ} \mathrm{C} \\
\text { In } 2100: \\
1.8-1.9^{\circ} \mathrm{C}\end{array}$ & $\begin{array}{c}1.5^{\circ} \mathrm{C} \text { with } \\
\text { no or limited } \\
\text { overshoot }\end{array}$ & & & \\
\hline
\end{tabular}


under pathways limiting warming to below $2^{\circ} \mathrm{C}$ and $1.5^{\circ} \mathrm{C}$ is large (see figure ES.5). Full implementation of unconditional NDCs is estimated to still result in a gap of $15 \mathrm{GtCO}_{2} \mathrm{e}$ (range: $12-19 \mathrm{GtCO}_{2} \mathrm{e}$ ) by 2030 compared with the below $2^{\circ} \mathrm{C}$ scenario. The emissions gap between implementing the unconditional NDCs and the below $1.5^{\circ} \mathrm{C}$ pathway is about $32 \mathrm{GtCO}_{2} \mathrm{e}$ (range: $29-36 \mathrm{GtCO}_{2} \mathrm{e}$ ). Full implementation of both unconditional and conditional NDCs would reduce each of these gaps by around $3 \mathrm{GtCO}_{2} \mathrm{e}$

Since there have been no updates to the temperature scenarios and only minor updates to the NDC scenarios, the estimated emissions gap remains unchanged from 2019. Similarly, the gap is as yet unaffected by COVID-19.

However, the current policies scenario is likely to be affected by COVID-19. As shown in figure ES.4, current projections imply effects on 2030 emissions ranging from $+1 \mathrm{GtCO}_{2} \mathrm{e}$ to $-15 \mathrm{GtCO}_{2} \mathrm{e}$ compared with the pre-COVID-19 current policies scenario shown in figure ES.5. This could bring emissions by 2030 to below the levels associated with the NDC scenarios. A reduction in global GHG emissions of $15 \mathrm{GtCO}_{2} \mathrm{e}$ would bring 2030 emissions within the range consistent with leastcost scenarios that keep global warming to below $2^{\circ} \mathrm{C}$, but not in line with $1.5^{\circ} \mathrm{C}$

Figure ES.5. Global GHG emissions under different scenarios and the emissions gap in 2030 (median and $10^{\text {th }}$ to $90^{\text {th }}$ percentile range; based on the pre-COVID-19 current policies scenario)

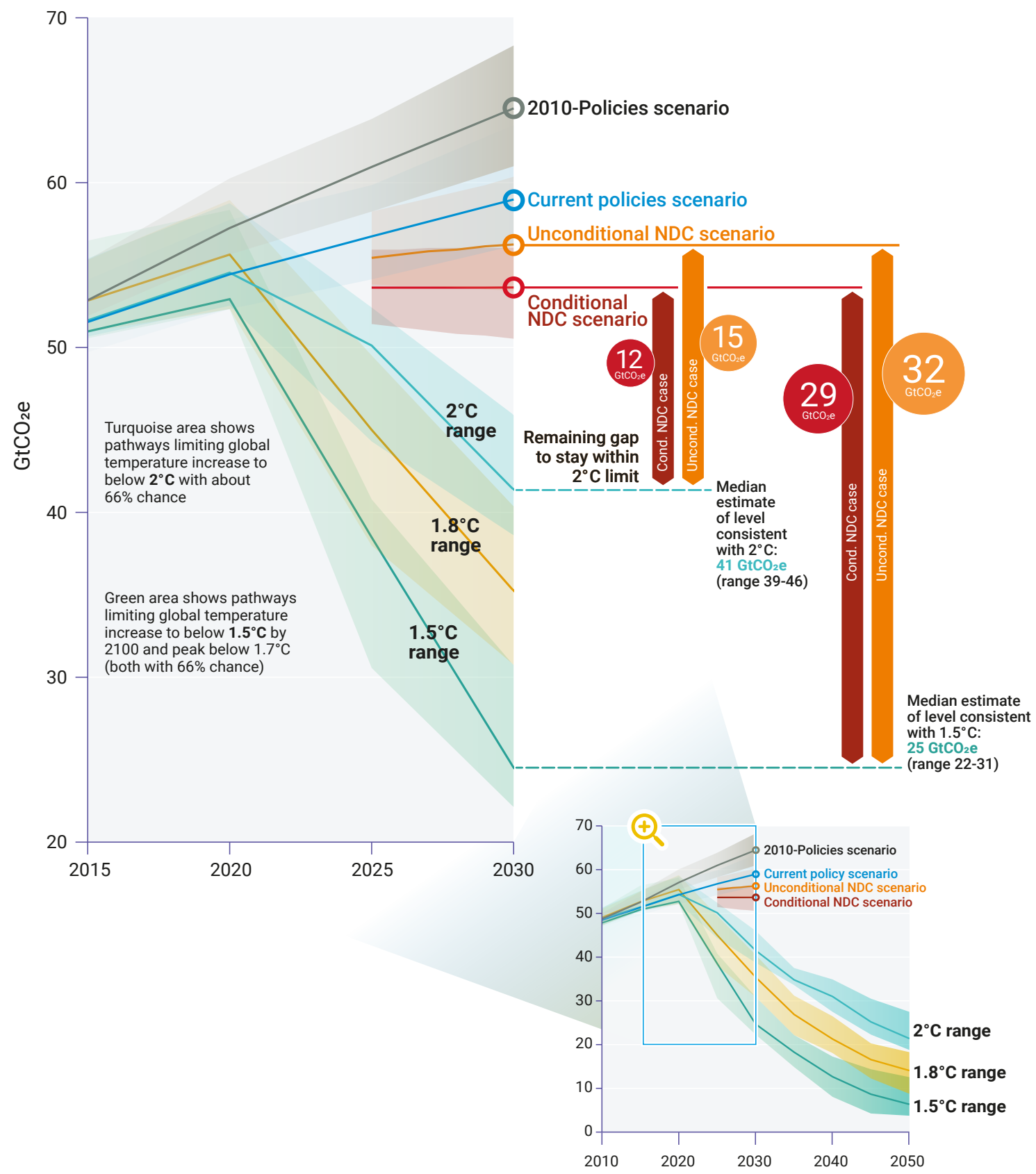


7 Current NDCs remain seriously inadequate to achieve the climate goals of the Paris Agreement and would lead to a temperature increase of at least $3^{\circ} \mathrm{C}$ by the end of the century. Recently announced net-zero emissions goals could reduce this by about $0.5^{\circ} \mathrm{C}$, provided that short-term NDCs and corresponding policies are made consistent with the net-zero goals.

A dramatic strengthening of ambition is needed if the Paris Agreement goals are to be achieved. In line with the findings of previous editions of the Emissions Gap Report, countries must collectively increase their NDC ambitions threefold to get on track to a $2^{\circ} \mathrm{C}$ goal and more than fivefold to get on track to the $1.5^{\circ} \mathrm{C}$ goal.

The lack of sufficient mitigation action to date has added significantly to the challenge of meeting the Paris Agreement goals. Global average emissions reductions required per year to meet emission levels by 2030 that are consistent with the $2^{\circ} \mathrm{C}$ and $1.5^{\circ} \mathrm{C}$ scenarios have increased remarkably. By now, they are approximately more than double and four times what they would have been respectively had serious collective climate action started in 2010. Failure to significantly reduce global emissions by 2030 will make it impossible to keep global warming below $1.5^{\circ} \mathrm{C}$.

- Unconditional NDCs are consistent with limiting warming to $3.2^{\circ} \mathrm{C}$ by the end of the century ( 66 per cent probability). If both conditional and unconditional NDCs are fully implemented, this estimate is $0.2^{\circ} \mathrm{C}$ lower. The pre-COVID-19 current policies scenario, on the other hand, results in higher emissions by 2030, which unless strengthened would result in an average global temperature rise of $3.5^{\circ} \mathrm{C}$ by 2100 .

COVID-19 containment measures have significantly reduced global GHG emissions in 2020. However, unless these are followed by economic rescue and recovery measures that support a low-carbon transition, this dip in global GHG emissions is estimated to result in no more than a $0.01^{\circ} \mathrm{C}$ reduction of global warming by 2050 , which by then is expected to have exceeded $1.5^{\circ} \mathrm{C}$.

The temperature projections change when considering the potential effects of the recently announced net-zero emissions goals. Preliminary estimates suggest that, collectively, these goals could further lower the temperature projections consistent with unconditional NDCs by about half a degree Celsius to around $2.7^{\circ} \mathrm{C}$. If the United States of America also adopts a net-zero GHG target by 2050, as suggested in the Biden-Harris climate plan, projections until the end of the century are estimated to be $0.6^{\circ} \mathrm{C}-0.7^{\circ} \mathrm{C}$ lower in aggregate compared with the global warming estimate for current unconditional NDCs, i.e. around $2.5-2.6^{\circ} \mathrm{C}$.

\section{- COVID-19-related fiscal spending by \\ 6. governments is of unprecedented scale, currently amounting to roughly US\$12 trillion globally, or 12 per cent of global gross domestic product (GDP) in 2020. For G20 members, fiscal spending amounts to around 15 per cent of GDP on average for 2020 .}

- To date, most governments have focused on funding rescue measures to protect lives and businesses in their immediate economic response to COVID-19, with some including conditions that encourage businesses to decarbonize. Given the varied COVID-19 impacts and response timelines, some governments are also starting to fund recovery measures to reinvigorate their economies.

There are large disparities in fiscal spending around the world. Average fiscal spending of G20 members currently hovers around 15 per cent, reaching as high as 40 per cent for some members. For middle-income and developing countries, however, this figure is much lower at less than 6 per cent of GDP.

So far, the opening for using fiscal rescue and recovery measures to stimulate the economy while simultaneously accelerating a lowcarbon transition has largely been missed. It is not too late to seize future opportunities, without which achieving the Paris Agreement goals is likely to slip further out of reach.

As at October 2020, COVID-19 fiscal spending has primarily supported the global status quo of highcarbon economic production or had neutral effects on $\mathrm{GHG}$ emissions. While it is understandable that immediate rescue measures were directed to incumbent industry, later rescue and recovery measures could have supported low-carbon development, without forsaking opportunities for economic gain.

Based on four main trackers of COVID-19 fiscal investments, few G20 members have put words into action in terms of low-carbon rescue and recovery measures (i.e. those resulting in reduced $G H G$ emissions). Around one-quarter of G20 members have dedicated shares of their spending (up to 3 per cent of GDP) explicitly to low-carbon measures. For most, spending has been predominantly highcarbon (implying net negative effects on GHG 
Figure ES.6. Non-exhaustive overview of total fiscal rescue and recovery measures of G20 members with high-carbon, neutral and low-carbon effects as a share of 2019 GDP

High-carbon effects Neutral/Unclear

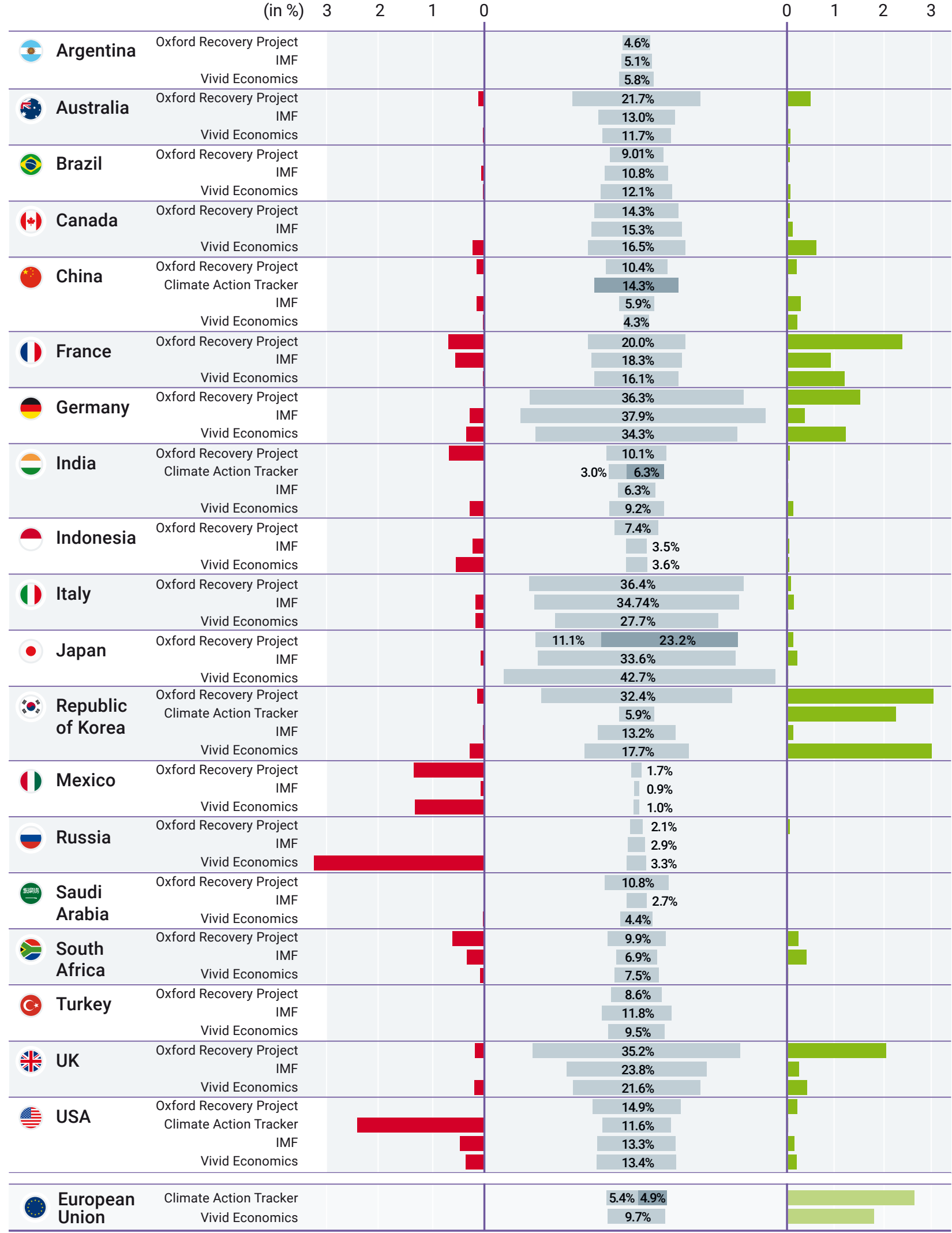


emissions) or neutral (having no discernible effects on GHG emissions). In a number of cases, it is still unclear what effect countries' measures will have on GHG emissions (figure ES.6).

Policies with positive impacts on reducing $\mathrm{GHG}$ emissions have been slightly more prevalent in fiscal recovery measures than rescue measures. This is noteworthy, as the next stages of COVID-19 fiscal interventions are likely to shift a greater proportion of capital towards recovery measures, indicating that there is potential for increased implementation of low-carbon measures.

- It is still in the hands of policymakers whether global economic rescue and recovery responses to the COVID-19 pandemic will lead to decreased or increased global GHG emissions in the longer term. The future can still be shaped through decisions yet to be made on the composition and implementation of announced recovery packages and future recovery actions.

\section{Early COVID-19 fiscal rescue and recovery - measures provide valuable insight for policymakers designing measures for the immediate future.}

- Many fiscal rescue and recovery measures can simultaneously support rapid, employmentintensive and cost-effective economic recovery and a low-carbon transition. Broad categories include:

- support for zero-emissions technologies and infrastructure, for example, low-carbon and renewable energy, low-carbon transport, zeroenergy buildings and low-carbon industry

- support for research and development of zeroemissions technologies

- fossil fuel subsidies through fiscal reform

- nature-based solutions, including large-scale landscape restoration and reforestation.

Conversely, some fiscal rescue and recovery measures are likely to perpetuate high-carbon and environmentally damaging development. These include:

- fossil fuel-based infrastructure investments or fiscal incentives for high-carbon technologies and projects

- waivers or rollbacks of environmental regulations

- bailouts of fossil fuel-intensive companies without conditions for low-carbon transition or environmental sustainability (such as airlines, internal combustion automotive companies, industrial industries and fossil energy companies).

11.

Domestic and international shipping and - aviation currently account for around 5 per cent of global $\mathrm{CO}_{2}$ emissions and are projected to increase significantly. International emissions from shipping and aviation are not covered under the NDCs and, based on current trends, are projected to consume between 60 and 220 per cent of allowable $\mathrm{CO}_{2}$ emissions by 2050 under IPCC illustrative $1.5^{\circ} \mathrm{C}$ scenarios (figure ES.7).

Combined, the shipping and aviation sectors currently account for approximately $2 \mathrm{GtCO}_{2}$ per year (distributed evenly across the two sectors) and emissions have increased in the past decades. About 71 per cent of the $\mathrm{CO}_{2}$ emissions from shipping and 65 per cent of emissions from aviation are international and are not included in national totals reported to the UNFCCC but are instead added as memo items. International emissions are not covered under the NDCs of most signatories to the Paris Agreement. However, because ships and aircraft are often active on both domestic and international routes, there are synergies in addressing domestic and international shipping and aviation emissions.

\section{2.}

Current policy frameworks to address

- emissions are weak and additional policies are required to bridge the gap between the current trajectories of shipping and aviation and GHG emissions pathways consistent with the Paris Agreement temperature goals. Changes in technology, operations, fuel use and demand all need to be driven by new policies.

International aviation currently intends to meet its International Civil Aviation Organization (ICAO) goals through heavily relying on carbon offsets, which do not represent absolute reductions, but at best provide time to transition to low-carbon fuels and implement energy efficiency improvements. At worst, offsets create a disincentive for investment in sector decarbonization and delay the necessary transition. Current carbon offsetting is therefore not a long-term solution and its role should only be temporary.

Improvements in technology and operations can improve the fuel efficiency of transport if policies incentivize them, but projected increases in demand (even considering potential impacts of 
Figure ES.7. Global $\mathrm{CO}_{2}$ emissions pathways limiting global warming to $1.5^{\circ} \mathrm{C}$ and $\mathrm{CO}_{2}$ emissions from international shipping and aviation

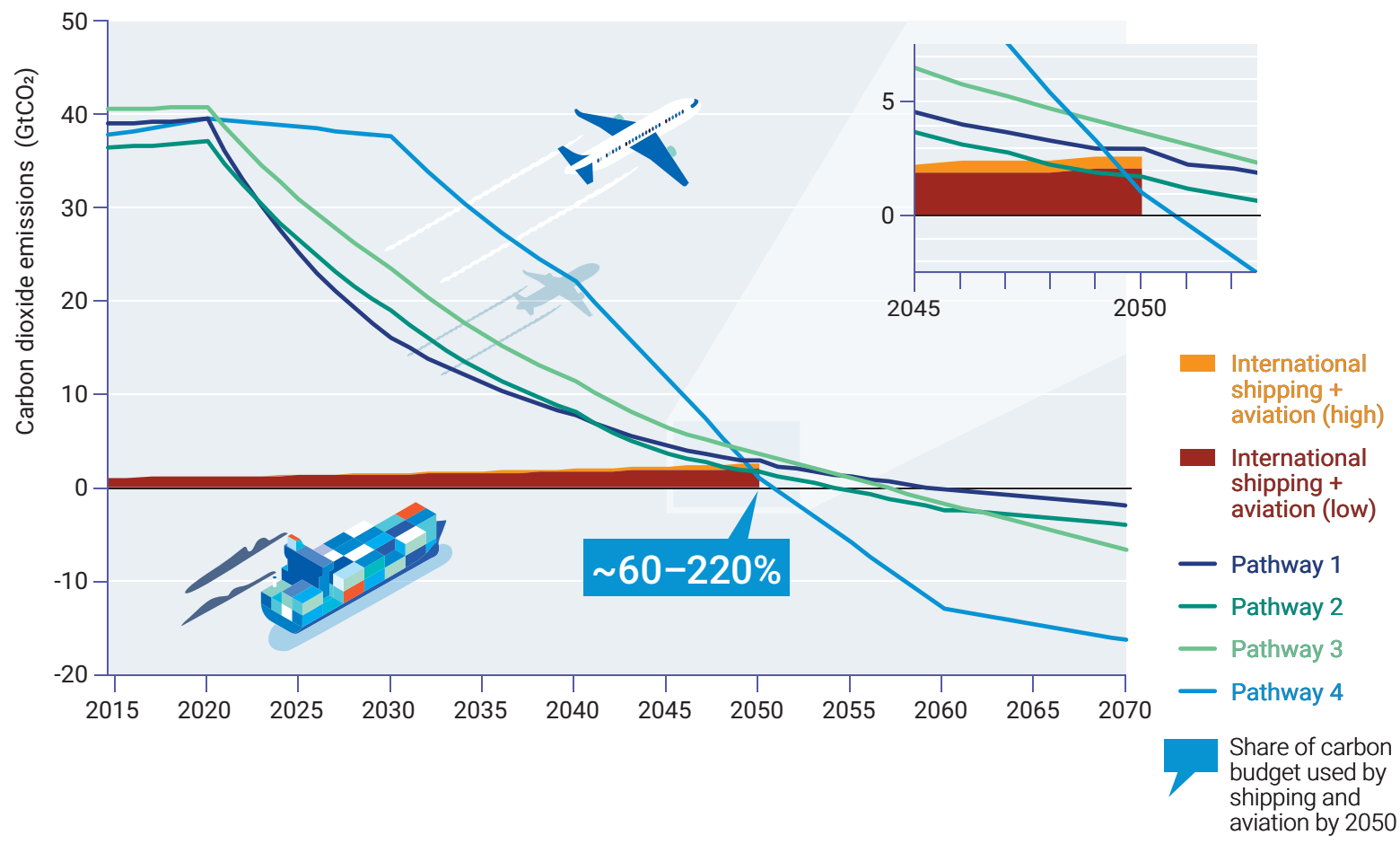

the current global COVID-19 pandemic) mean that the improvements will not result in decarbonization and absolute reductions of $\mathrm{CO}_{2}$ for either the aviation or shipping sectors.

Both sectors, will therefore need to maximize their energy efficiency while rapidly transitioning away from fossil fuels. Although there are technologically mature production processes for non-fossil fuels, rapid scale-up of new production and supply chains is required and hinges on policies to mandate the use of these fuels, as their costs are much higher.

- Biofuels and synthetic kerosene from biomass or $\mathrm{CO}_{2}$ and hydrogen have lower carbon footprints than fossil hydrocarbon fuels, provided the biomass is sourced sustainably. These are probably the most realistic fuel alternatives for aviation and shipping in the short to medium term, but will compete with other uses, such as road transport.

For ships, $\mathrm{CO}_{2}$-free ammonia is an option, given that a ship's design is less constrained than that of a plane in terms of volume, fuel mass and safety.

- The hydrogen feedstock used in ammonia and synthetic hydrocarbon fuel will only present net benefits if the production is powered by renewable electricity, $\mathrm{CO}_{2}$ is produced from non-fossil sources, or $\mathrm{CO}_{2}$ is removed from the atmosphere.
Long-term fuel alternatives, such as electricity or $\left(\mathrm{CO}_{2}\right.$-free) hydrogen will require different aircraft and ship designs and will likely only be applicable for certain purposes.

Regardless of the feedstock and process, the cost of fuel will increase severalfold, raising the overall cost of both aviation and shipping. This will likely supress demand, especially for aviation, which may ultimately be the most effective means to manage the sector's emissions.

\section{Lifestyle changes are a prerequisite for and for bridging the emissions gap. Around two thirds of global emissions are linked to the private household activities according to consumption-based accounting. Reducing emissions through lifestyle changes requires changing both broader systemic conditions and individual actions.}

Lifestyle emissions are influenced by social and cultural conventions, the built environment and financial and policy frameworks. Governments have a major role in setting the conditions under which lifestyle changes can occur, through shaping policy, regulations and infrastructure investments. At the same time, it is necessary for citizens to be active participants in changing their lifestyles through taking steps to reduce personal emissions 
and fostering societal change as consumers, citizens, owners of assets and members of communities. The participation of civil society is necessary to bring about wider changes in the social, cultural, political and economic systems in which people live.

Lifestyle emissions are linked to many sources and sectors. Foremost among these are mobility, residential and food, each of which contributes close to 20 per cent of lifestyle emissions, thus implying strong mitigation potential in these areas. For example, foregoing one long-haul return flight has the potential to reduce annual personal emissions by $1.9 \mathrm{tCO}_{2} \mathrm{e}$ per capita on average. Home energy emissions can be tackled through improving existing and new housing stock. The use of renewable electricity by households could also reduce emissions by approximately $1.5 \mathrm{tCO}_{2} \mathrm{e}$ per capita per year for those on higher incomes. In terms of food, shifting consumption towards low-carbon diets has strong emissions reduction potential. Moving to a vegetarian diet, for example, could reduce emissions by an average of $0.5 \mathrm{tCO}_{2} \mathrm{e}$ per capita per year.

There are numerous examples of good practices in both the developing and developed world that show it is possible to lead more sustainable lifestyles. Such examples include: replacing domestic short-haul flights with rail journeys and providing incentives and the infrastructure necessary for cycling and car-sharing, while restricting petrol cars; improving the energy efficiency of housing and renewable energy defaults from grid providers; ensuring the provision of low-carbon food in the public sector and developing policies to reduce food waste.

\section{Equity is central to addressing lifestyles. of the global population account for more than twice the combined share of the poorest 50 per cent.}

Compliance with the $1.5^{\circ} \mathrm{C}$ goal of the Paris Agreement will require reducing consumption emissions to a per capita lifestyle footprint of around $2-2.5 \mathrm{tCO}_{2} \mathrm{e}$ by 2030 . This means that the richest 1 per cent would need to reduce their current emissions by at least a factor of 30 , while per capita emissions of the poorest 50 per cent could increase by around three times their current levels on average (figure ES.8).

COVID-19 has provided insight into how rapid lifestyle changes can be brought about by governments (who must create conditions that make lifestyle changes possible), civil society actors (who must encourage positive social norms and a sense of collective agency for lifestyle changes) and infrastructure (which must support behaviour changes). The lockdown period in many countries may be long enough to establish new, lasting routines if supported by longerterm measures. In planning the recovery from COVID-19, governments have an opportunity to catalyse low-carbon lifestyle changes by disrupting entrenched practices.

Figure ES.8. Per capita and absolute $\mathrm{CO}_{2}$ consumption emissions by four global income groups for 2015

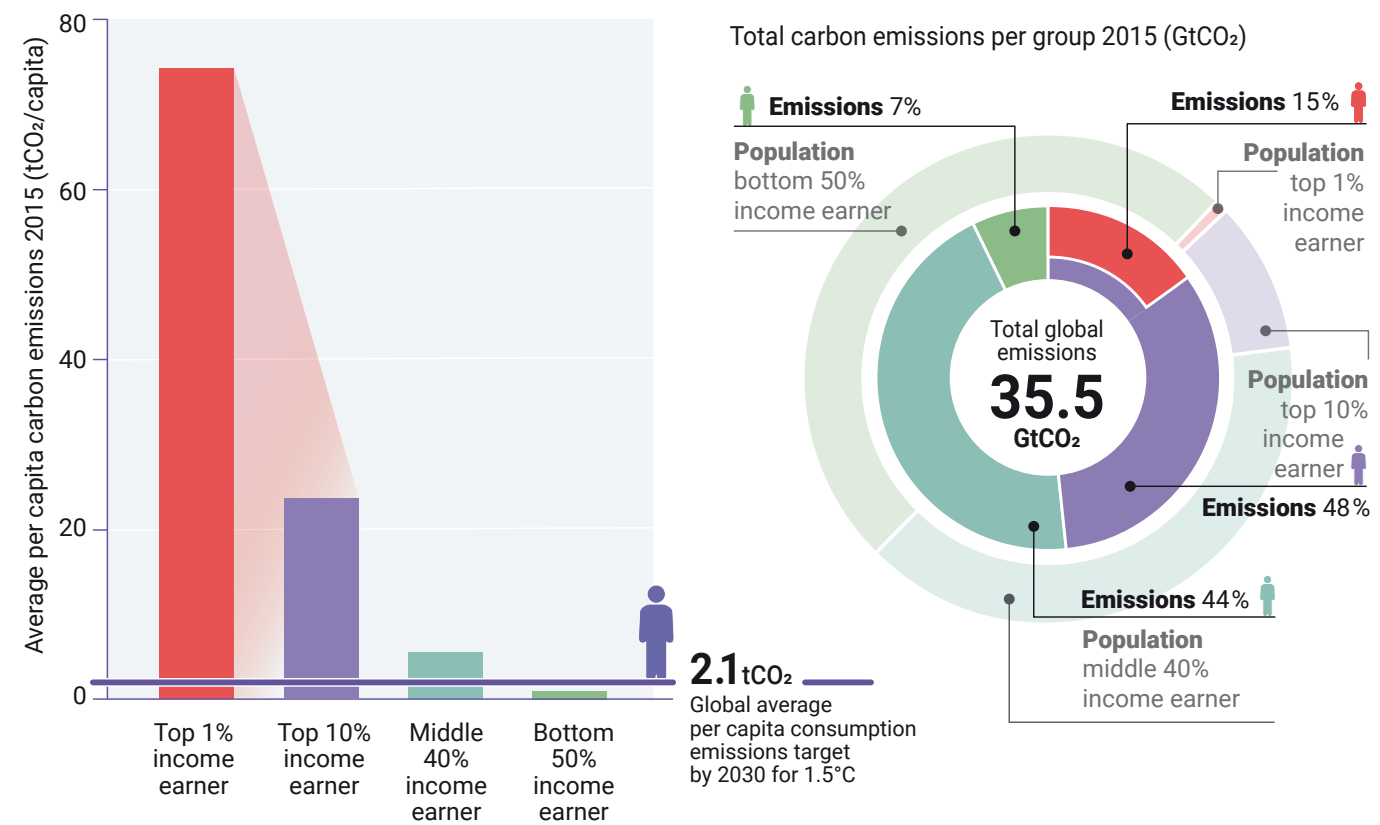




$$
\hat{k}
$$




\section{Introduction}

Author:

Anne Olhoff (UNEP DTU Partnership)

\subsection{Context of the Emissions Gap Report 2020}

This eleventh edition of the United Nations Environment Programme (UNEP) Emissions Gap Report has been produced in a year in which the COVID-19 crisis has dominated both the news and policymaking, causing immense suffering and economic and social disruption. The economic disruption has briefly slowed - but far from eliminated - the historic and ever-increasing burden of our activity on the Earth's climate. This burden is manifested in the continuing rise in extreme weather events, including wildfires and hurricanes, and in the melting of glaciers and of ice at both the poles. This year, Arctic sea ice cover shrank to its second lowest extent since the beginning of modern record-keeping (National Aeronautics and Space Administration [NASA] 2020), the USA is about to break the record on climate-related weather events costing more than US\$1billion each (National Oceanic and Atmospheric Administration [NOAA] 2020) and 2020 is on course to become the warmest year on record globally (CarbonBrief 2020). The year 2020 has set new records: they will not be the last.

It is clear that global carbon dioxide $\left(\mathrm{CO}_{2}\right)$ and greenhouse gas (GHG) emissions in 2020 will experience a sizeable drop compared with 2019 levels as a result of the COVID-19 crisis. Yet, enhanced climate ambition and action remain as urgent as ever. Although 2020 GHG emissions will decline, GHG concentrations in the atmosphere continue to rise (World Meteorological Organization (WMO) 2020) and the immediate reduction in emissions caused by COVID-19 lockdown measures is assessed to have a negligible longterm impact on climate change (Forster et al. 2020).

How governments around the world respond to COVID-19 and post-COVID-19 recovery will be critical to achieving the goals of the Paris Agreement. The unprecedented scale of COVID-19 economic recovery measures offers an opening for a low-carbon transition that creates the structural changes required for sustained emission reductions. Seizing this opening will be essential to bridging the emissions gap.

The United Nations Secretary-General is calling on governments to use COVID-19 recovery as an opportunity to create more sustainable, resilient and inclusive societies (United Nations 2020). Aligned with this, the United Nations Framework Convention on Climate Change (UNFCCC) has stressed that governments can integrate and specify some of their post-COVID-19 recovery plans and policies in their new or updated nationally determined contributions (NDCs) as well as in their long-term mitigation strategies - both of which countries are requested to submit this year (United Nations Framework Convention on Climate Change [UNFCCC] 2020).

The most significant and encouraging climate policy development of 2020 is the growing number of countries that have announced net-zero emissions goals around the middle of this century. These commitments are broadly consistent with the Paris Agreement temperature goal, provided they are achieved globally. The litmus test of these announcements will be the extent to which they are reflected in near-term policy action and in significantly more ambitious NDCs for the period to 2030.

\subsection{Focus and approach of the report}

Each year, the Emissions Gap Report provides an updated assessment of the gap between estimated future global GHG emissions if countries implement their climate mitigation pledges, and the global emission levels from least-cost pathways that are aligned with achieving the Paris Agreement goal of limiting global warming to well below $2^{\circ} \mathrm{C}$ and pursuing $1.5^{\circ} \mathrm{C}$. This difference between where we will likely be and where we need to be is known as the 'emissions gap'

The reports also look at opportunities for bridging the emissions gap. This year, the report focuses on three areas that are highly relevant for our ability to bridge the gap and that have become even more pertinent in the wake of COVID-19: i) the role of COVID-19 fiscal rescue and recovery measures in the global transition to decarbonization; ii) the role and opportunities for reducing emissions from the shipping and aviation sectors, where international emissions are not covered by the NDCs; and iii) the role of lifestyle change in decarbonization. 
Reflecting the unusual circumstances of 2020, this year's report deviates from its usual approach of exclusively considering consolidated data from previous years as the basis for assessment. To maximize its policy relevance, preliminary assessments of the implications of the COVID-19 pandemic and associated rescue and recovery measures are included throughout the report.

As in previous years, this Emissions Gap Report has been prepared by an international team consisting of 51 leading scientists from 35 expert institutions across 18 countries, assessing all available information, including that published in the context of the Intergovernmental Panel on Climate Change (IPCC) reports, as well as in other recent scientific studies. The assessment process has been overseen by a distinguished steering committee and has been transparent and participatory. All chapters have undergone an extensive external review process. In addition, the assessment methodology and preliminary findings were made available to the governments of the countries specifically mentioned in the report in order to provide them with the opportunity to comment on the findings.

\subsection{Structure of the report}

The report is organized into six chapters, including this introduction. Chapter 2 assesses the trends in global GHG emissions and G20 member progress towards their Cancun
Pledges in 2020 and their NDCs in 2030. In addition, it considers the potential implications of COVID-19 on G20 emissions projections. Chapter 3 updates the assessment of the likely emissions gap in 2030. Furthermore, the chapter provides a preliminary assessment of how COVID-19 and associated rescue and recovery measures may impact global GHG emissions in 2030 under various scenarios. The chapter then looks at the implications of the emissions gap on the feasibility of achieving the long-term temperature goal of the Paris Agreement.

Chapter 4 assesses the size and extent to which COVID-19 fiscal rescue and recovery measures to date can be said to support low-carbon or high-carbon development. It also outlines emerging lessons for governments in the pursuit of a low-carbon economic recovery.

The two final chapters of this year's report cover areas that have received limited attention in previous Emissions Gap Reports, but that receive much international attention and have been particularly affected by COVID-19. Chapter 5 looks at the trends and opportunities for decarbonizing the shipping and aviation sectors, with a particular focus on international transport. Finally, chapter 6 assesses the role and opportunities for reducing GHG emissions through lifestyle and behavioural change, paying particular attention to inequalities in per capita emissions within and across countries and the systemic changes necessary to support and induce lifestyle change. 


\title{
2 Global emissions trends and G20 status and outlook
}

\author{
Lead authors: \\ Takeshi Kuramochi (NewClimate Institute, Germany), Michel den Elzen (PBL Netherlands Environmental Assessment \\ Agency, the Netherlands) and Glen P. Peters (Center for International Climate Research - CICERO, Norway)

\section{Contributing authors:} \\ Caitlin Bergh (University of Cape Town, South Africa), Monica Crippa (Joint Research Centre/European Commission, \\ European Union (EU)), Andreas Geiges (Climate Analytics, Germany), Catrina Godinho (HUMBOLDT-VIADRINA Governance \\ Platform, Germany), Sofia Gonzales-Zuñiga (NewClimate Institute, Germany), Ursula Fuentes Hutfilter (Climate Analytics, \\ Germany), Kimon Keramidas (Joint Research Centre/European Commission, EU), Yong Gun Kim (Korea Environment \\ Institute, the Republic of Korea), Swithin Lui (NewClimate Institute, Germany), Zhu Liu (Tsinghua University, China), Jos \\ Olivier (PBL Netherlands Environmental Assessment Agency, the Netherlands), Leonardo Nascimento (NewClimate Institute, \\ Germany), Joana Portugal Pereira (Graduate School of Engineering (COPPE), Universidade Federal do Rio de Janeiro, Brazil), \\ Değer Saygin (SHURA, Turkey), Claire Stockwell (Climate Analytics, Germany), Jorge Villareal (Iniciativa Climática de México, \\ Mexico), William Wills (COPPE, Universidade Federal do Rio de Janeiro, Brazil)
}

\subsection{Introduction}

This chapter assesses the latest trends in greenhouse gas (GHG) emissions and the progress of $\mathrm{G} 20$ members towards both the Cancun Pledges for 2020 and nationally determined contributions (NDCs) for 2025 and 2030. Throughout the chapter, the implications of the COVID-19 pandemic on emissions in 2020 and by 2030 are considered.

The chapter is organized as follows: section 2.2 takes stock of the current trends in total global GHG and carbon dioxide $\left(\mathrm{CO}_{2}\right)$ emissions from fossil fuel use and industry-related sources. These trends are discussed in the context of global peaking of emissions and general economic trends. Sections 2.3 and 2.4 assess $\mathrm{G} 20$ members' progress, both collectively and individually, towards their Cancun Pledges and NDCs. ${ }^{1}$ The assessment covers all individual G20 members and regions, including the European Union and its three individual Member States (France, Germany and Italy), as well as the United Kingdom (hereafter EU27+UK) as one member. ${ }^{2}$ Section 2.5 provides an update of announced net-zero emissions goals and the implications for short- to medium-term action in the context of new and updated NDCs.
All GHG emission figures in this report are expressed using the 100-year global warming potentials (GWPs) from the Intergovernmental Panel on Climate Change (IPCC) Fourth Assessment Report (AR4), ${ }^{3}$ unless otherwise noted. With regard to historical emissions data, section 2.2 uses globally consistent and independent data sets rather than officially reported United Nations Framework Convention on Climate Change (UNFCCC) inventory reports, whereas sections 2.3 and 2.4 use UNFCCC inventory reports when comparing historical emissions to individual G20 members' NDC targets. Please see Annex I for more information about the definitions of scenarios, GWPs and land use, land-use change and forestry (LULUCF) accounting used in the chapter.

The methodology and preliminary findings of this chapter were made available to the governments of the countries specifically mentioned to provide them with the opportunity to comment on the findings.

1 Turkey has not ratified the Paris Agreement, so its 2030 target remains an intended nationally determined contribution (INDC). Hereinafter, both INDCs and NDCs are referred to as NDCs, except when specifically referring to Turkey's INDC

2 The United Kingdom has left the European Union but is in a transition period until the end of 2020, during which the NDC submitted by the European Union still applies to it.

3 This change was made to be more in line with the decisions made at the twenty-fourth session of the Conference of the Parties (COP 24) in Katowice, where Parties agreed to use GWPs from the IPCC Fifth Assessment Report (AR5) for reporting reasons. However, a full switch to using AR5 GWPs in this report is not yet possible as the literature is still not up to date on this decision. 


\subsection{Current global emissions: status and trends}

\subsubsection{GHG emissions up to 2019}

\section{Global trends}

GHG emissions grew in 2019 for the third consecutive year, indicating that the slowdown in emissions growth during 2015 and 2016 was short-lived (figure 2.1). Since 2010, GHG emissions (excluding land-use change (LUC)) have grown 1.4 per cent per year on average, with preliminary data suggesting a 1.1 per cent increase in 2019. When including the more uncertain and variable emissions from LUC, global GHG emissions also grew 1.4 per cent per year since 2010 on average, but increased a more rapid 2.6 per cent in 2019 due to a significant increase in forest fires, particularly in Asia and the Amazon. GHG emissions ${ }^{4}$ reached a record high of $52.4 \mathrm{GtCO}_{2} \mathrm{e}$ (range: \pm 5.2 ) in 2019 without LUC emissions and increased by $5.5 \mathrm{GtCO}_{2}$ (range: \pm 2.6 ) when including the more uncertain LUC, which pushes the total to $59.1 \mathrm{GtCO}_{2} \mathrm{e}$ (range: \pm 5.9 ) (figure 2.1). Land-use emission estimates used in this report are based on the average of two separate models (leading to higher overall emissions) (Friedlingstein et al. 2019) and included $\mathrm{CO}_{2}$ and nitrous oxide $\left(\mathrm{N}_{2} \mathrm{O}\right)$ emissions from LUC (Olivier and Peters 2020, in preparation). If the same data set was used as in previous years (Houghton and Nassikas 2017; blue dotted line in figure 2.1), global 2019 emissions would have been lower at $57.1 \mathrm{GtCO}_{2} \mathrm{e}$ or $56.7 \mathrm{GtCO}_{2} \mathrm{e}$ if excluding methane $\left(\mathrm{CH}_{4}\right)$ and $\mathrm{N}_{2} \mathrm{O}$ emissions from LUC.

Figure 2.1. Global GHG emissions from all sources

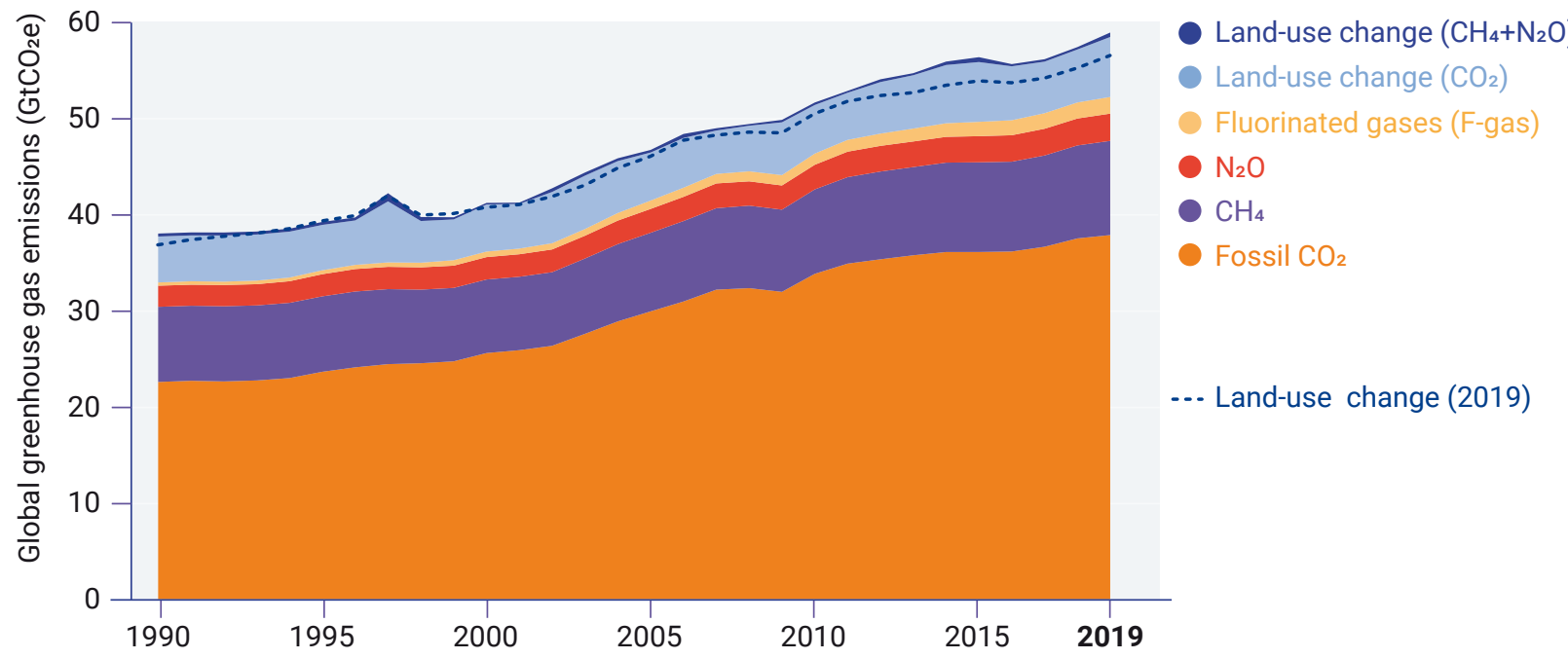

Note: The dotted line shows the global emissions using a different data set for LUC (Houghton and Nassikas 2017), as in earlier Emissions Gap Reports.

Sources: Crippa et al. (2020); Olivier and Peters (2020, in preparation); Friedlingstein et al. (2019)

Each GHG contributes differently to total GHG emissions (figure 2.1 and table 2.1). Fossil $\mathrm{CO}_{2}$ emissions ${ }^{5}$ account for most GHG emissions, including LUC, as well as the growth in GHG emissions. Preliminary data suggest that fossil $\mathrm{CO}_{2}$ emissions reached a record $38.0 \mathrm{GtCO}_{2}$ (range: \pm 1.9 ) in 2019, with some differences among data sets due to uncertainty in Chinese coal use in $2019 .{ }^{6}$ Fossil $\mathrm{CO}_{2}$ has grown 1.3 per cent per year on average since 2010 and grew

4 Emissions data used in this report are based on analysis from EDGAR (Crippa et al. 2020), PBL (Olivier and Peters 2020, in preparation) and the Global Carbon Project (GCP) for LUC. These data sets are used in order to provide globally consistent and updated emissions estimates, which means that there may be minor differences to officially reported UNFCCC inventory reports. Fossil $\mathrm{CO}_{2}, \mathrm{CH}_{4}$ and $\mathrm{N}_{2} \mathrm{O}$ emissions are based on the methods used in previous Emissions Gap Reports (Olivier and Peters 2019), with updates based on the most recently available data. In this 2020 report, LUC emissions from the GCP are used, which takes the average of two bookkeeping data sets (Hansis, Davis and Pongratz 2015; Houghton and Nassikas 2017). Previous Emissions Gap Reports only used one bookkeeping model (Houghton and Nassikas 2017), which means that total GHG emissions are higher than in previous reports, with LUC emissions exhibiting no significant trend over time. For the first time, this year's report includes $\mathrm{CH}_{4}$ and $\mathrm{N}_{2} \mathrm{O}$ emissions from LUC (Olivier, Schure and Peters 2017), though these are small in comparison to LUC CO 2 emissions. The report also includes uncertainties with one standard deviation of \pm 5 per cent for $\mathrm{CO}_{2}, \pm 30$ per cent for $\mathrm{CH}_{4}, \pm 50$ per cent for $\mathrm{N}_{2} \mathrm{O}$ and \pm 100 per cent for fluorinated gases (Olivier et al. 2017), and $2.6 \mathrm{GtCO}_{2}$ for LUC (Friedlingstein et al. 2019). The presented uncertainty ranges are consistent with IPCC AR5 (Blanco et al. 2014). GWPs are from the IPCC AR4. All estimates for 2019 emissions should be considered preliminary. Uncertainties are added in quadrature and assumed independent.

5 Fossil $\mathrm{CO}_{2}$ emissions include $\mathrm{CO}_{2}$ emissions from fossil fuels and from carbonates.

6 In this report, $\mathrm{CO}_{2}$ emissions from fossil fuels and industry grew 0.9 per cent in 2019 (Crippa et al. 2020). The updated Global Carbon Budget estimates that fossil fuel emissions grew 0.1 per cent in 2019 (Friedlingstein et al. in review). Most other estimates do not include process emissions from cement manufacturing. EDGAR estimates that process emissions from cement manufacturing grew 5.1 per cent in 2019 , while the GCP estimates 3.3 per cent in 2019. For combustion-related emissions only, BP estimated a 0.5 per cent growth in emissions (BP 2020), with the IEA and GCP both estimating no change (IEA 2020b), which differs to the EDGAR estimate of 0.6 per cent. The differences in these estimates for 2019 (EDGAR and BP versus GCP and IEA) are primarily due to uncertainty in the growth of Chinese coal use in 2019. 
0.9 per cent in 2019. The growth in fossil $\mathrm{CO}_{2}$ emissions in 2019 was due to a modest increase in energy use ( 1.3 per cent in 2019), offset by favourable weather patterns reducing heating and cooling needs (International Energy Agency [IEA] 2020a). $\mathrm{CO}_{2}$ emissions from LUC significantly change from year-to-year due to climatic conditions. Over the last decade, $\mathrm{CO}_{2}$ emissions from LUC have had a downward trend according to Houghton and Nassikas (2017) and upward trend according to Hansis, Davis and Pongratz (2015). The average of these two data sets for the last decade is $5.5 \mathrm{GtCO}_{2}$ (range: \pm 2.6 , one standard deviation) and shows little change in trend given the large uncertainties $^{7}$ (Friedlingstein et al. 2019; Shukla et al.
2019). In this report, the average of these two data sets are used as there is currently no scientific justification to use one data set over the other. $\mathrm{CH}_{4}$ emissions, the next most significant $\mathrm{GHG}$, have grown 1.2 per cent per year on average since 2010 and grew 1.3 per cent in 2019. $\mathrm{N}_{2} \mathrm{O}$ emissions have grown 1.1 per cent per year on average from 2010 to 2019, while fluorinated gases (sulphur hexafluoride (SF6), hydrofluorocarbons (HFCs) and perfluorochemicals (PFCs)) have grown 4.7 per cent per year on average since 2010 and grew 3.8 per cent in 2019. All GHGs continue to increase in line with trends over the last decade, with only fossil $\mathrm{CO}_{2}$ emissions showing a significant change in trend since the 2000s (2000-2009).

Table 2.1. Key statistics for GHG emissions shares and trends and highest emitting countries and regions

\begin{tabular}{|c|c|c|c|c|c|}
\hline & $\begin{array}{l}\text { GHG emissions } \\
2019\left(\mathrm{GtCO}_{2} \mathrm{e}\right)\end{array}$ & $\begin{array}{c}\text { GHG emissions } \\
2019\left(\mathrm{tCO}_{2} \mathrm{e} /\right. \\
\text { person })\end{array}$ & $\begin{array}{l}\text { Emissions share } \\
2010-2019(\%)\end{array}$ & $\begin{array}{l}\text { Emissions growth } \\
2010-2019(\% / y r)\end{array}$ & $\begin{array}{l}\text { Growth in } \\
2019(\%)\end{array}$ \\
\hline Fossil $\mathrm{CO}_{2}$ & 38 & & 65 & 1.3 & 0.9 \\
\hline Methane $\left(\mathrm{CH}_{4}\right)$ & 9.8 & & 17 & 1.2 & 1.3 \\
\hline Nitrous oxide $\left(\mathrm{N}_{2} \mathrm{O}\right)$ & 2.8 & & 4.9 & 1.1 & 0.8 \\
\hline Fluorinated gases & 1.7 & & 2.6 & 4.7 & 3.8 \\
\hline GHGs without LUC & 52.4 (range: \pm 5.2 ) & & 89 & 1.4 & 1.1 \\
\hline $\mathrm{LUC} \mathrm{CO} 2$ & 6.3 & & 10 & 1.3 & 13.3 \\
\hline $\mathrm{LUC} \mathrm{CH}_{4} \& \mathrm{~N}_{2} \mathrm{O}$ & 0.5 & & 0.5 & 3.7 & 84.6 \\
\hline GHGs with LUC & 59.1 (range: \pm 5.9 ) & & 100 & 1.4 & 2.6 \\
\hline \multicolumn{6}{|l|}{$\begin{array}{l}\text { Countries (GHGs } \\
\text { without LUC) }\end{array}$} \\
\hline China & 14 & 9.7 & 26 & 2.3 & 3.1 \\
\hline $\begin{array}{l}\text { United States of } \\
\text { America }\end{array}$ & 6.6 & 20.0 & 13 & -0.1 & -1.7 \\
\hline EU27+UK & 4.3 & 8.6 & 9.3 & -1.1 & -3.1 \\
\hline India & 3.7 & 2.7 & 6.6 & 3.3 & 1.3 \\
\hline Russian Federation & 2.5 & 17.4 & 4.8 & 1 & 0.8 \\
\hline Japan & 1.4 & 10.7 & 2.8 & 0.1 & -1.6 \\
\hline International transport & 1.4 & & 2.5 & 2.3 & 2.9 \\
\hline GHGs without LUC & $\mathbf{5 2 . 4}$ (range: \pm 5.2 ) & 6.8 & 65 & 1.4 & 1.1 \\
\hline
\end{tabular}

7 The Houghton and Nassikas (2017) and Hansis, Davis and Pongratz (2015) data sets are both updated for 2019 in Friedlingstein et al. (2019). 


\section{Regional trends excluding LUC}

While global emissions data provide important information on collective progress, they mask the dynamics at the country level (figure 2.2 - left: absolute; right: per capita). This section focuses on trends excluding LUC emissions, which are discussed later. The top four emitters (China,
United States of America, EU27+UK and India) contributed to 55 per cent of total GHG emissions without LUC over the last decade. The top seven emitters (including the Russian Federation, Japan and international transport) account for 65 per cent, while $\mathrm{G} 20$ members account for 78 per cent.

Figure 2.2. Absolute GHG emissions of the top six emitters (excluding LUC emissions) and international transport (left) and per capita emissions of the top six emitters and the global average (right)

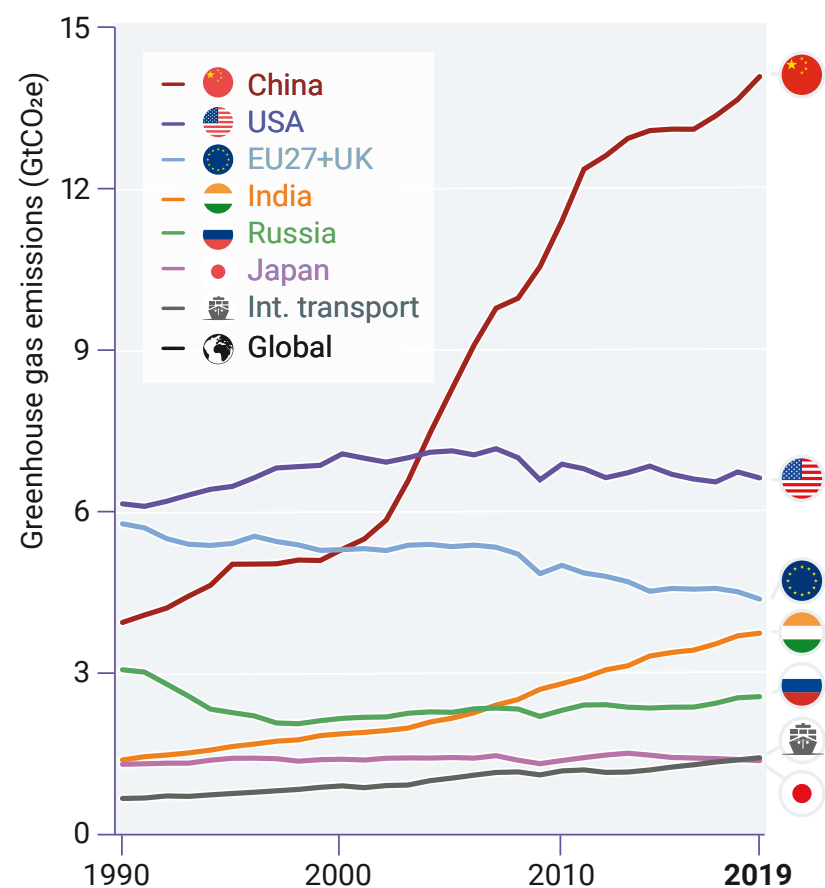

Source: Crippa et al. (2020)

China emits more than one-quarter of global GHG emissions and has per capita emissions that are around 40 per cent above the global average. Despite rapid growth during the 2000s, the increase in GHG emissions has slowed in China over the last decade. From 2014 to 2016 GHG emissions showed little to no growth due to a reduction in coal use, but started to grow again from 2016. In the last decade, GHG emissions have grown 2.4 per cent on average, growing 3.1 per cent in 2019 to reach a record high $14.0 \mathrm{GtCO}_{2} \mathrm{e}$. Chinese coal use may have peaked in 2013, but that peak may be crossed given its growth from 2016 onwards. The United States of America emits 13 per cent of global GHG emissions and has per capita emissions that are three times the global average. However, over the last decade, the country's GHG emissions have been in decline ( 0.4 per cent per year), decreasing by 1.7 per cent in 2019, which partially offsets the increase of 3.0 per cent in 2018 that was due to greater energy demand in response to an unusually warm summer and cold winter. Changes in the United States of America's emissions continue to be driven by the shift away from coal towards gas and renewables. The EU27+UK emits 8.6 per cent of global GHG emissions and has per capita emissions that are 25 per cent above the global average. Emissions have steadily declined by 1.5 per cent per year in the last decade, with a steeper decline of 3.0 per cent observed in 2019. Europe had a stronger decline in coal use

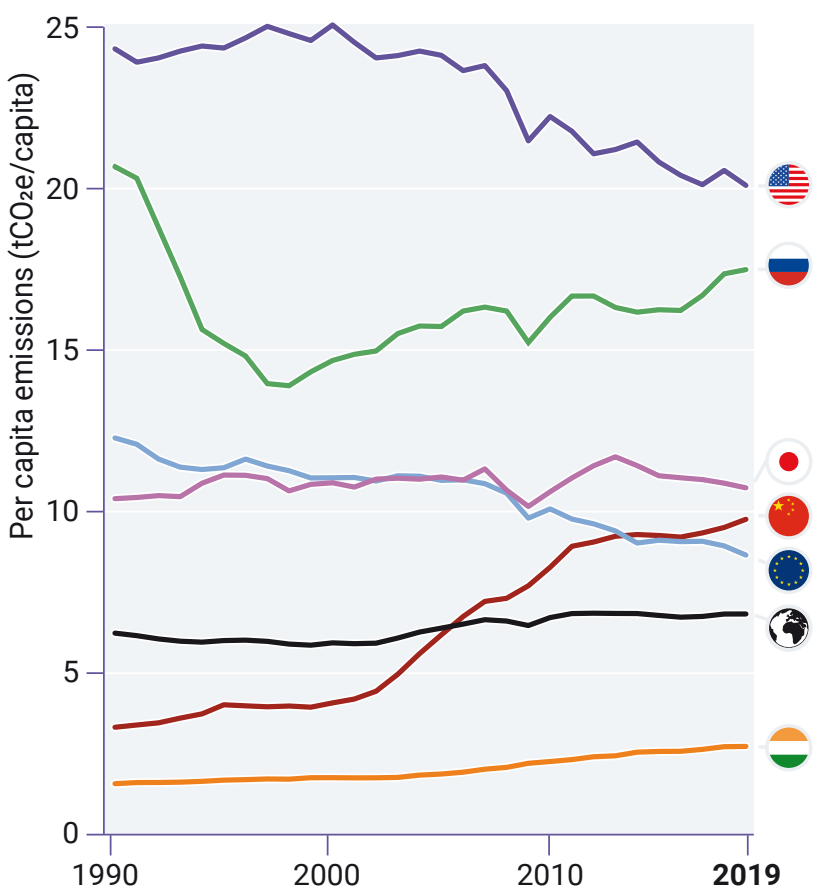

in 2019, following the European Union Emissions Trading System's (EU ETS) higher allowance prices. India emits 7.1 per cent of global emissions and has per capita emissions that are 60 per cent lower than the global average. Emissions grew just 1.4 per cent in 2019, which is much lower than the average of 3.3 per cent per year over the last decade. This slower-than-expected growth was primarily due to increased hydropower from a record monsoon and weaker economic growth, along with the country's continued growth in renewables. The Russian Federation (4.9 per cent) and Japan (2.7 per cent) are the next largest emitters, followed by international transport (aviation and shipping), which represents around 2.6 per cent of GHG emissions that are growing strongly at a rate of 2.3 per cent per year (figure 2.2).

In today's globalized world there is a weakened connection between where goods and services are purchased (consumed) and where emissions occur. Consumptionbased emissions are allocated to countries where goods and services are consumed, which differs to territorial-based emissions, as they exclude national emissions required to produce exported products, instead including emissions from other countries to import products (consumption territorial - exports + imports). Rich countries generally tend to have higher consumption-based emissions (figure 2.3), 
as they have cleaner production, relatively more services and more imports of primary and secondary products. In the 2000s, the gap between consumption and production was growing in rich countries but stabilized following the 2007-2008 global financial crisis (Pan et al. 2017). Despite rich countries having greater consumption-based emissions than territorial-based emissions, both have declined at similar rates in the last decade (Le Quéré et al. 2019). Consumption-based emissions can also be used to allocate emissions to the products purchased (food, clothing, electronic products), and not the sectors emitting (agriculture, electricity, industry). Although consumptionbased emissions are more uncertain, they provide additional information to help refine climate policies (see chapter 6).

Figure 2.3. Consumption-based $\mathrm{CO}_{2}$ emissions (dotted line) compared with territorial-based $\mathrm{CO}_{2}$ emissions (solid line) for the top six emitters
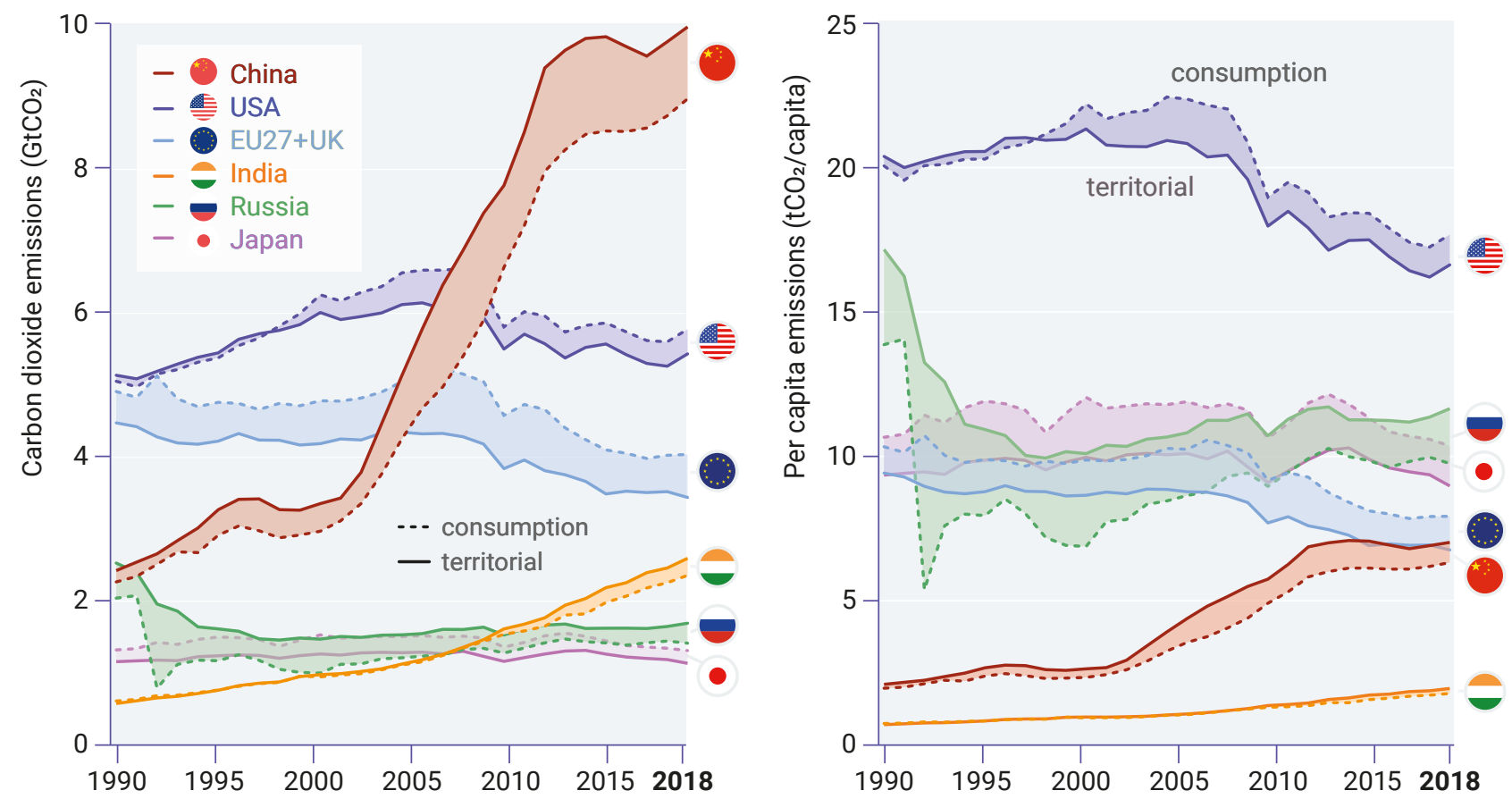

Note: Shading shows the net trade difference for absolute emissions (left) and per capita emissions (right).

Source: Friedlingstein et al. (2019)

\section{Sector trends in GHG emissions}

The distribution of GHG emissions across sectors is an important consideration for policymaking (figure 2.4). Many studies primarily focus on fossil $\mathrm{CO}_{2}$ emissions (65 per cent of total global GHG emissions), which are primarily associated with energy use. The inclusion of $\mathrm{CH}_{4}$ and $\mathrm{N}_{2} \mathrm{O}$ emissions highlights the importance of the agriculture sector in emission trends. This section considers the sector distribution of all GHG emissions, including non$\mathrm{CO}_{2}$ emissions.

Energy transformation dominates GHG emissions, with electricity and heat generation accounting for 24 per cent of total GHG emissions in the last decade and other energy transformation and fugitive emissions adding another 10 per cent. Emissions from energy use in buildings and other sectors, such as agriculture and fishing, are around 7 per cent. The industry sector has significant emissions from energy use (11 per cent of total GHG emissions), in additional to industrial processes ( 9 per cent) from mineral products (such as cement) and other chemical reactions. The transport sector has contributed to around 14 per cent of global GHG emissions on average over the last decade, with road transport - a sector that continues to have strong growth - primarily responsible. Shipping and aviation are relatively smaller than road transport, with emissions in international territory comprising 2.2 per cent of total $\mathrm{GHG}$ emissions. Agriculture and waste are 15 per cent of total GHG emissions, with most emissions from enteric fermentation (ruminant animals, such as cattle), nitrogen fertilizers on agricultural soils, and municipal waste. LUC, primarily associated with agricultural activities, is around 11 per cent of the total and has larger inter-annual variations.

Emissions are growing in all sectors, though there are signs that growth is slowing for electricity and heat generation, due to a stronger growth in renewables and decline in coal. 
Figure 2.4. GHG emissions at the sectoral level

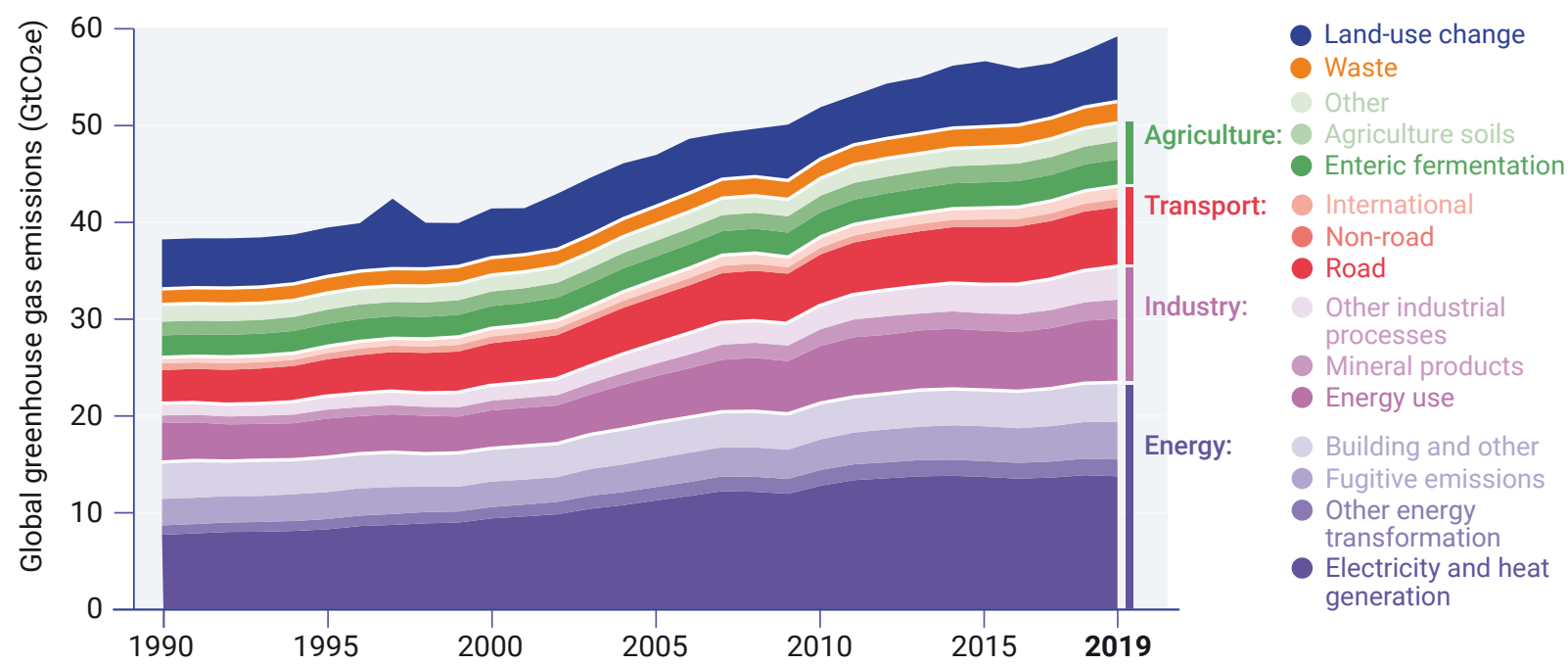

Source: Crippa et al. (2020)

\section{Regional LUC trends}

Emissions from LUC are around 11 per cent of the global total, but the bulk of these emissions are from relatively few countries. Unfortunately, there is no globally consistent and widely accepted country-level data set of LUC emissions. This is due to two main reasons: data availability and definitions. First, the two land-use models used in this report (Hansis, Davis and Pongratz 2015; Houghton and Nassikas 2017) have country-level estimates, but they are not sufficiently robust at the country level to conduct a reliable assessment (Friedlingstein et al. 2019). Similarly, data from the Food and Agriculture Organization of the United Nations (FAO) cover all countries, but do not fully capture carbon dynamics and only report five- or ten-year averages due to the relatively simple method used (Tubiello et al. in review). Furthermore, country-reported UNFCCC emission inventories only cover Annex I countries. Second, LUC is defined in several different manners. For example, the scientific community often only considers direct influences on land use, while FAO and UNFCCC emission inventories include a more expansive definition of 'managed lands', which captures a much larger component of the carbon sink (Grassi et al. 2018). Estimates using these different definitions should not be compared as they report quite different emissions.

Emissions from LUC predominantly originate from several key countries (Tubiello et al. in review). The largest emitters from land conversions (for example, forests converted to cropland or pastures) are Brazil, Indonesia and the Democratic Republic of the Congo. The largest managed sinks (for example, forests remaining forests) are in China, the Russian Federation, the United States of America and Brazil. When combining the conversions (sources) and managed sinks (Grassi et al. 2018), the countries with the biggest net LUC emissions are the Democratic Republic of the Congo, Brazil and Indonesia, while China, the Russian Federation and the United States of America have the largest net sinks. Reducing deforestation and enhancing carbon sinks can lead to significant emissions reductions and benefits for biodiversity conservation and ecosystem services in key countries, while also greatly contributing to global mitigation efforts.

\section{How close are peak GHG emissions?}

Growth in global GHG emissions has averaged 1.4 per cent per year since 2010, which is lower than the growth rate of 2.4 per cent per year from 2000 to 2009 . In the past decade, two years (2015 and 2016) have had almost zero growth (after removing inter-annual variations from LUC), indicating to some extent that the growth in global GHG emissions is slowing. From 2010 to 2015, GHG emissions without the variable LUC data grew at a rate of 2.2 per cent per year, which slowed to 1.2 per cent per year from 2015 to 2019 . Despite the indication that global GHG emissions growth is slowing, dynamics at the country level are significantly different, with GHG emissions declining in Organisation of Economic Co-operation and Development (OECD) economies and increasing in non-OECD economies.

Many OECD economies have had a peak in GHG emissions, as efficiency improvements, structural change and growth in low-carbon energy sources have been enough to overcome the growth in economic activity. Despite improving energy efficiency and increasing low-carbon sources, emissions continue to rise in countries with strong growth in energy use to meet development needs (Le Quéré et al. 2019). Globally, emissions from coal may have peaked, with rapid declines observed in Europe and the United States of America, and slower growth in China, despite an increase in other regions. Oil and particularly gas are increasingly driving the growth in global emissions, with gas now the largest contributor to fossil $\mathrm{CO}_{2}$ emissions (Peters et al. 2020). Non-fossil energy sources continue to grow rapidly and now exceed that of fossil sources in electricity generation. However, whether these factors have been sufficient to cause global GHG 
emissions to peak is unknown, due to the rapidly unfolding and tragic consequences of COVID-19.

\subsubsection{How might COVID-19 affect GHG emissions in $2020 ?$}

In response to the health crises created by COVID-19, most countries have implemented various measures to help avoid its spread. These measures have had unprecedented effects on many aspects of the global economy, and consequently emissions. This section provides a synthesis of the estimated effects of the COVID-19 crisis on emissions in 2020 based on available studies. Most studies have focused on changes in energy use and $\mathrm{CO}_{2}$ emissions, with less attention given to how non- $\mathrm{CO}_{2}$ emissions may have changed.

$\mathrm{CO}_{2}$ emissions are generally estimated based on reported energy use, but these data are not available in real time. To estimate emissions during 2020, studies have used various proxy data, such as information on mobility from Google, Apple and TomTom, real-time data on electricity generation and other similar statistics that indicate activity levels. Some studies have estimated emissions for the year to date (Liu et al. 2020), while others have additionally estimated emissions for the full year (Le Quéré et al. 2020). For the year to date, Liu et al. found that emissions have declined 7.1 per cent cumulatively to 1 November 2020, including both the effects of COVID-19 restrictions and underlying changes in the global energy system (figure 2.5). Le Quéré et al. (2020) focused only on changes due to the COVID-19 restrictions, finding that global daily emissions decreased a maximum of 17 per cent in April 2020, with emissions reductions for the full year estimated at 7 per cent (range: 2-12 per cent, updated to mid-June) if some restrictions remain to the end of 2020, which is now the case. A key driver for the uncertainty is the extent of COVID-19 restrictions for the remainder of 2020. Recent full-year estimates for 2020 emissions compared with 2019 include a decrease of 7 per cent (IEA 2020b) and 8.5 per cent (Enerdata 2020) in $\mathrm{CO}_{2}$ emissions. Based on this, emissions reductions in 2020 are likely to fall within the range of 2-12 per cent per cent as suggested by Le Quéré et al. (2020). All studies indicate that the biggest changes have occurred in transport, as COVID-19 restrictions were targeted to limit mobility, though small reductions have also occurred in other sectors (figure 2.5).

Figure 2.5. Reduction in emissions in 2020 relative to 2019 levels due to COVID-19 lockdowns

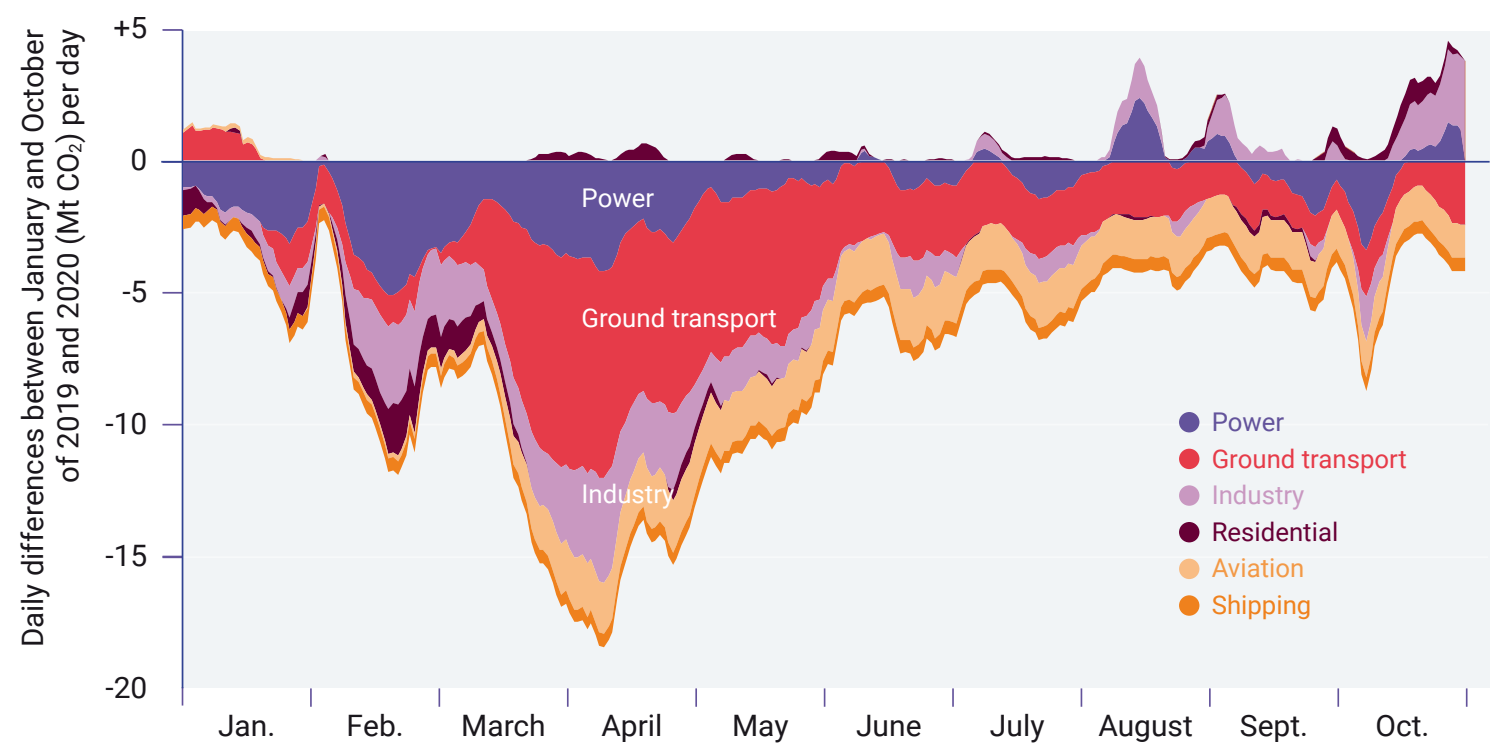

Source: Liu et al. (2020)

Based on these studies, the expected reduction in $\mathrm{CO}_{2}$ emissions is 7 per cent in 2020 (range: 2-12 per cent), with a smaller drop in $\mathrm{GHG}$ emissions as non- $\mathrm{CO}_{2}$ is likely to be less affected (Forster et al. 2020). The reduction is unprecedented and significantly larger than the reduction of 0.9 per cent in $\mathrm{CO}_{2}$ emissions during the 2007-2008 global financial crisis ( 0.6 per cent for all GHGs).

Most relevant for climate, is how countries respond in the years beyond 2020. Previous analysis has shown that emissions often rebound after crises (Peters et al. 2012), though the nature of the rebound depends on the crisis
(Hanna, Xu and Victor 2019). As the COVID-19 crisis eases emissions will rebound, but how far and how fast is highly uncertain (IEA 2020d) and depends primarily on the choices made by governments. If COVID-19 recovery packages focus on accelerating the ongoing renewable energy transition, then emissions may continue to decline depending on how large and long-term the recovery packages are (see chapter 4) 


\subsection{Achievement of Cancun Pledges by $\mathrm{G} 20$ members, considering the potential impact of COVID-19}

Collectively, G20 members are projected to overachieve their Cancun Pledges. ${ }^{8}$ Even without consideration of the potential impacts of COVID-19, Australia, Brazil, China, EU27+UK, India, Japan, the Russian Federation, and this year, also South Africa, are projected to meet their 2020 pledges with currently implemented policies. For South Africa, the change compared with the 2019 assessment reflects revised (lower) historical emissions data as well as lower projections from the new Integrated Resource Plan (Climate Action Tracker 2019; Keramidas et al. 2020). For Australia, the Government projected in December 2019 that they would miss its "point in time" 2020 target, but will overachieve its carbon budget target for the 2013-2020 period (Commonwealth of Australia 2019). Several individual members (Canada, Indonesia, Mexico, the Republic of Korea and the United States of America) are still projected to miss their pledges or are not expected to achieve them with great certainty.

Consideration of the potential impacts of COVID-19 is only likely to change this conclusion for the United States of America, where available assessments suggest that the country will achieve its Cancun Pledge (reducing GHG emissions to 17 per cent below 2005 levels) when accounting for the expected impact of COVID-19. The latest analysis by the U.S. Energy Information Administration projects a 10 per cent decrease in energy-related $\mathrm{CO}_{2}$ emissions in 2020 compared with 2019 (U.S. Energy Information Administration [EIA] 2020), partly due to the effects of fuel switching. The Rhodium Group (Larsen et al. 2020) and Climate Action Tracker (2020b) estimate reductions of 10-16 per cent and 10-11 per cent (excluding LULUCF), respectively, for all GHGs.

Few country-specific estimates are available for other countries. If it is assumed that the $2-12$ per cent reduction in $\mathrm{CO}_{2}$ emissions in 2020 (referred to earlier in this chapter; Le Quéré et al. 2020) applies to all GHG emissions of individual G20 members, Canada, Mexico and the Republic of Korea are still unlikely to achieve their pledges based on latest GHG inventory data (2017 for Mexico and the Republic of Korea, 2018 for Canada) and emission trends in recent years. For Indonesia, it remains uncertain whether 2020 emissions would meet their Cancun Pledge, due to the uncertainty on LULUCF emissions.

\subsection{Assessment of G20 members' progress towards NDC targets}

This section assesses the progress of G20 members towards their NDC targets based on emissions projections published before the COVID-19 pandemic (section 4.2.1), and also provides some preliminary findings regarding the potential impact of COVID-19 and related policy responses on $\mathrm{G} 20$ emissions by 2030 (section 4.2.2).

Projections of GHG emissions were compiled and reviewed to assess the emission levels expected for G20 members under existing policies (the 'current policies scenario') ${ }^{9}$ and whether the members are likely to meet their respective emissions reduction targets for 2030. Projections of the current policies scenario assume that no additional mitigation policies and measures are taken beyond those adopted and/or implemented as of a certain cut-off date (den Elzen et al. 2019).

The progress assessment is based on the first NDCs (INDC for Turkey). ${ }^{10}$ As at mid-November 2020, no G20 member has officially submitted a new or updated NDC to reflect a revised NDC target (Japan resubmitted its original NDC target in March 2020) (United Framework Convention on Climate Change [UNFCCC] undated a). This report follows the methodology of den Elzen et al. (2019) to enable a robust comparison of projections from different data sources, including both official sources published by G20 governments and sources published by independent research institutions. European Union Member States are not assessed individually, and all projections for the European Union include the United Kingdom.

The most important caveat for the 2020 assessment is the impact of the COVID-19 pandemic on the current policies scenario projections. As most projections to date were published or prepared before the pandemic was declared, they do not account for its potentially significant impact not only for emission trends in 2020 and 2021, but also until 2030. As previously mentioned, the impact of the pandemic on 2030 emissions projections for some individual G20 members is discussed in section 2.4.2. Other important caveats are similar to those of previous Emissions Gap Reports (adapted from den Elzen et al. 2019). First, whether a country is projected to achieve or miss its Cancun Pledge or NDC targets with existing policies depends on both the strength and stringency of the existing climate policy packages and the ambition level of the targets given structural factors (such as demographic and

8 European Union Member States are not assessed individually. Argentina, Saudi Arabia and Turkey have not made 2020 pledges.

9 Current policy scenario projections assume that no additional mitigation action is taken beyond current policies, even if it results in NDC targets not being achieved or being overachieved (United Nations Environment Programme [UNEP] 2015; den Elzen et al. 2019). Current policy projections reflect all adopted and implemented policies, which for the purpose of this report are defined as legislative decisions, executive orders or their equivalent. This implies that officially announced plans or strategies alone would not qualify, while individual executive orders to implement such plans or strategies would qualify.

10 As Turkey has not ratified the Paris Agreement, its submission to the UNFCCC remains an INDC. Acknowledging this, the report refers to NDCs for simplicity in the rest of the chapter. 
macroeconomic trends) that shape how easy or difficult a target is to achieve. Although targets have been assessed as diverging in ambition, this report does not assess the degree of each country's efforts to achieve a certain mitigation projection, and does not assess the ambition of the targets in the context of equity principles. Countries that are projected to achieve their NDCs with existing policies are therefore not necessarily undertaking more mitigation actions than countries that are projected to miss them, and vice versa. Second, current policies scenario projections are subject to the uncertainty associated with macroeconomic trends, such as gross domestic product (GDP), population growth and technology developments, as well as the impact of policies. Some Cancun Pledges and NDCs are also subject to the uncertainty of future GDP growth and other underlying assumptions. These all add to the fundamental uncertainty resulting from COVID-19.

Up-to-date emissions projections published since November 2019 were collected from official documents, namely countries' recently published National Communications and fourth biennial reports of five G20 members ('with measures' scenarios). ${ }^{11}$ Estimates were also collected for the current policies scenario and NDC scenario projections from independent studies and several new national models and integrated assessment model studies for China, India, Japan, the Russian Federation and the United States of America through the Linking Climate and Development Policies - Leveraging International Networks and Knowledge Sharing (CD-LINKS) project (Roelfsema et al. 2020), as well as independent global studies, such as the Climate Action Tracker (2019), Joint Research Centre of the European Commission (Keramidas et al. 2020) and PBL Netherlands Environmental Assessment Agency (Kuramochi et al. 2019; PBL 2020; Roelfsema et al. 2020). All data sources, including the updated studies, are presented in table 2.2. Policy cutoff dates ranged from 2017 to 2019 across studies. The emissions figures include LULUCF, unless otherwise stated.

Table 2.2. Official and independent sources used to estimate emissions in the target year under the NDC and current policies scenarios for $\mathrm{G} 20$ members

\begin{tabular}{|c|c|c|c|}
\hline Country & $\begin{array}{l}\text { NDC scenario: } \\
\text { Official data } \\
\text { sources }^{1}\end{array}$ & $\begin{array}{l}\text { Current policies scenario: } \\
\text { Official data sources }\end{array}$ & $\begin{array}{l}\text { Current policies scenario and NDC scenario: }{ }^{2} \\
\text { Independent sources (1. global models and } \\
\text { 2. national models) }\end{array}$ \\
\hline Argentina & $\begin{array}{l}\text { Revised NDC } \\
\text { (Government of } \\
\text { Argentina 2016) }\end{array}$ & N/A & $\begin{array}{l}\text { 1. Climate Action Tracker (2019), Joint } \\
\text { Research Centre (Keramidas et al. 2020), } \\
\text { University of Melbourne (Meinshausen } \\
\text { and Alexander 2017) (NDC only) } \\
\text { 2. Keesler, Orifici and Blanco (2019) }\end{array}$ \\
\hline Australia & $N / A$ & $\begin{array}{l}\text { Commonwealth of Australia } \\
\text { (2019), UNFCCC Biennial } \\
\text { Reports data portal (BR4) } \\
\text { (UNFCCC undated b) }\end{array}$ & $\begin{array}{l}\text { 1. Climate Action Tracker, Joint Research } \\
\text { Centre, PBL (Kuramochi et al. 2019; PBL } \\
\text { 2020; Roelfsema et al. 2020), University of } \\
\text { Melbourne (NDC only) } \\
\text { 2. Climate Works Australia (ClimateWorks } \\
\text { Australia 2018) }\end{array}$ \\
\hline Brazil & $\begin{array}{l}\text { NDC (UNFCCC } \\
\text { undated a) }\end{array}$ & N/A & $\begin{array}{l}\text { 1. Climate Action Tracker, Joint Research } \\
\text { Centre, PBL, University of Melbourne (NDC } \\
\text { only) } \\
\text { 2. Graduate School of Engineering (COPPE) } \\
\text { (Rochedo et al. 2018) }\end{array}$ \\
\hline Canada & $\begin{array}{l}\text { NDC, Environment } \\
\text { and Climate Change } \\
\text { Canada (2020a) }\end{array}$ & $\begin{array}{l}\text { UNFCCC Biennial Reports } \\
\text { data portal (BR4) }\end{array}$ & $\begin{array}{l}\text { 1. Climate Action Tracker, Joint Research } \\
\text { Centre, PBL, University of Melbourne (NDC } \\
\text { only) }\end{array}$ \\
\hline
\end{tabular}

11 Japan's 'with measures' scenario is excluded as it also considers the expected impact of planned policy measures (Government of Japan $2019 a)$ and is therefore not considered a current policy scenario under the definition used in the UNEP Emissions Gap Report series. 


\begin{tabular}{|c|c|c|c|}
\hline China & N/A & N/A & $\begin{array}{l}\text { 1. Climate Action Tracker, Joint Research } \\
\text { Centre, PBL, CD-LINKS (Roelfsema et al. } \\
\text { 2020), University of Melbourne (NDC only), } \\
\text { Pacific Northwest National Laboratory } \\
\text { (PNNL) (NDC only) (Fawcett et al. 2015) } \\
\text { 2. National Center for Climate Change } \\
\text { Strategy and International Cooperation } \\
\text { (NCSC) (Fu, Zou and Liu 2017), }{ }^{3} \text { Energy } \\
\text { Research Institute (ERI) - Integrated } \\
\text { Policy Assessment Model for China } \\
\text { (IPAC) (Roelfsema et al. 2020), Tsinghua } \\
\text { University - The Integrated MARKAL- } \\
\text { EFOM System (TIMES) (Roelfsema et al. } \\
\text { 2020) }\end{array}$ \\
\hline EU27+UK & $\begin{array}{l}\text { European } \\
\text { Environment } \\
\text { Agency (EEA) (2019) }\end{array}$ & $\begin{array}{l}\text { EEA (2019), European } \\
\text { Commission (2018; 2020b) } \\
\text { UNFCCC Biennial Reports } \\
\text { data portal (BR4, 'with } \\
\text { measures' scenario only) }\end{array}$ & $\begin{array}{l}\text { 1. Climate Action Tracker, Joint Research } \\
\text { Centre, PBL, University of Melbourne (NDC } \\
\text { only) }\end{array}$ \\
\hline India & N/A & $\mathrm{N} / \mathrm{A}$ & $\begin{array}{l}\text { 1. Climate Action Tracker, Joint Research } \\
\text { Centre, PBL, CD-LINKS (Roelfsema et al. } \\
\text { 2020), University of Melbourne (NDC only), } \\
\text { PNNL (NDC only) } \\
\text { 2. Mitra et al. (2017), Dubash et al. (2018), } \\
\text { The Energy and Resources Institute } \\
\text { (TERI) - MARKAL (Roelfsema et al. 2020), } \\
\text { Indian Institute of Management (IIM) - } \\
\text { Asian-Pacific Integrated Model (AIM) India } \\
\text { (Roelfsema et al. 2020) }\end{array}$ \\
\hline Indonesia & NDC & N/A & $\begin{array}{l}\text { 1. Climate Action Tracker, Joint Research } \\
\text { Centre, PBL, University of Melbourne (NDC } \\
\text { only) }\end{array}$ \\
\hline Japan & NDC & $\mathrm{N} / \mathrm{A}^{4}$ & $\begin{array}{l}\text { 1. Climate Action Tracker, Joint Research } \\
\text { Centre, PBL, CD-LINKS (Roelfsema et al. } \\
\text { 2020), University of Melbourne (NDC only) } \\
\text { 2. National Institute for Environmental } \\
\text { Studies (NIES) - AIM/Enduse model } \\
\text { (Roelfsema et al. 2020), Research Institute } \\
\text { of Innovative Technology for the Earth } \\
\text { (RITE) - DNE model (Roelfsema et al. } \\
\text { 2020) }\end{array}$ \\
\hline Mexico & $\begin{array}{l}\text { NDC, Government of } \\
\text { Mexico (2015) }\end{array}$ & N/A & $\begin{array}{l}\text { 1. Climate Action Tracker, Joint Research } \\
\text { Centre, PBL }\end{array}$ \\
\hline $\begin{array}{l}\text { Russian } \\
\text { Federation }\end{array}$ & $\begin{array}{l}\text { NDC (UNFCCC } \\
2017)\end{array}$ & $\begin{array}{l}\text { UNFCCC Biennial Reports } \\
\text { data portal (BR4) }\end{array}$ & $\begin{array}{l}\text { 1. Climate Action Tracker, Joint Research } \\
\text { Centre, PBL, CD-LINKS (Roelfsema et al. } \\
\text { 2020), PNNL (NDC only) } \\
\text { 2. HSE - TIMES model (Roelfsema et al. } \\
\text { 2020) }\end{array}$ \\
\hline
\end{tabular}




\begin{tabular}{|c|c|c|c|}
\hline $\begin{array}{l}\text { Saudi } \\
\text { Arabia }\end{array}$ & $\begin{array}{l}\text { N/A: Saudi Arabia } \\
\text { did not formulate } \\
\text { a post-2020 GHG } \\
\text { target (UNFCCC } \\
\text { undated a) }\end{array}$ & N/A & $\begin{array}{l}\text { 1. Climate Action Tracker (based on } \\
\text { King Abdullah University of Science } \\
\text { and Technology [KAUST] 2014), Joint } \\
\text { Research Centre }\end{array}$ \\
\hline $\begin{array}{l}\text { South } \\
\text { Africa }\end{array}$ & NDC & $\mathrm{N} / \mathrm{A}$ & $\begin{array}{l}\text { 1. Climate Action Tracker, Joint Research } \\
\text { Centre, PBL }\end{array}$ \\
\hline $\begin{array}{l}\text { Republic of } \\
\text { Korea }\end{array}$ & NDC & N/A & $\begin{array}{l}\text { 1. Climate Action Tracker, Joint Research } \\
\text { Centre, PBL }\end{array}$ \\
\hline Turkey & $\begin{array}{l}\text { INDC (UNFCCC } \\
\text { 2017) }\end{array}$ & $\begin{array}{l}\text { UNFCCC Biennial Reports } \\
\text { data portal (BR4) }\end{array}$ & $\begin{array}{l}\text { 1. Climate Action Tracker, Joint Research } \\
\text { Centre, PBL }\end{array}$ \\
\hline $\begin{array}{l}\text { United } \\
\text { States of } \\
\text { America }\end{array}$ & $\begin{array}{l}\text { NDC, United States } \\
\text { Department of State } \\
(2016)\end{array}$ & N/A & $\begin{array}{l}\text { 1. Climate Action Tracker, Joint Research } \\
\text { Centre, PBL, CD-LINKS (Roelfsema et al. } \\
\text { 2020) } \\
\text { 2. PNNL - GCAM model (Roelfsema et al. } \\
\text { 2020), Chai et al. (2017), Rhodium Group } \\
\text { (Larsen et al. 2020) }\end{array}$ \\
\hline
\end{tabular}

Notes:

1. References provided only when the NDC emission levels are available in absolute terms.

2. Data collected when NDC target emission levels in absolute terms were not available in official documents.

3. Augmented with historical non- $\mathrm{CO}_{2} \mathrm{GHG}$ emissions data from China's First Biennial Update Report on Climate Change (People's Republic of China 2016), combined with the median estimate of the 2010-2030 non- $\mathrm{CO}_{2}$ emissions growth rates for China from five integrated assessment models (Tavoni et al. 2014), to produce economy-wide figures.

4. The 'with measures' scenario from the latest biennial report is not included because it is an NDC achievement scenario, which includes planned policies.

Source: Updated from den Elzen et al. (2019)

\subsubsection{Progress assessment based on pre-COVID-19 studies}

This section assesses progress of G20 members towards their NDC targets based on emissions projections published before the COVID-19 pandemic, as few updates considering the potential impact of COVID-19 and related policy responses were available as at October 2020. An assessment of the potential impact of the pandemic on emissions by 2030 based on a limited set of studies is provided in section 2.4.2. Although, the emissions projections reviewed here do not consider the implications of COVID-19 on future GHG emissions, they provide important information about the impact of recent policy developments in respective G20 member countries and regions.

Collectively, G20 members are not on track to achieve their unconditional NDCs based on current policies. Nine of the 16 G20 members, counting the EU27+UK as one member, are likely to achieve their unconditional NDC targets (INDC for Turkey) under current policies (figure 2.6). These members are Argentina (new compared with the 2019 assessment),
China, EU27+UK,12 India, Japan (back in this group since the 2018 assessment), Mexico, the Russian Federation, South Africa (new) and Turkey (see table 2.3). Among them, four countries (Argentina, India, the Russian Federation and Turkey) are projected to reach emission levels that are 14-34 per cent lower than their respective NDC emissions target levels (figure 2.6).

The assessment has changed compared with the 2019 assessment for the following three countries:

Argentina is now expected to achieve its unconditional NDC target with current policies. The median projection from independent analyses has been revised downward, partially due to downwardrevised economic growth and LULUCF projections (see table 2.4 for recent developments).

For Japan, current policies scenario projections for 2030 have been close to the NDC target for the past several years. The country's GHG emissions

12 All emissions projections for the European Union reviewed in this report include the United Kingdom. 
have been decreasing continually since 2013 due to increased renewable electricity generation, reduced electricity consumption and reduced total end-use energy consumption.

For South Africa, the central estimate from independent analyses (see table 2.2) has been revised significantly downward. This is mainly due to the consideration of the recently updated Integrated Resource Plan (see table 2.4 for details) (Republic of South Africa, Department of Energy 2019) and the likelihood of its implementation, as well as the most recent national GHG inventory report that noted flattened emission trends between 2010 and 2015

Substantial changes in the current policies projections compared with the 2019 assessment are also observed for other $\mathrm{G} 20$ members projected to achieve their unconditional NDC targets:

- The central estimate for the EU27+UK was revised downward, meaning it is now projected to overachieve its 40 per cent $\mathrm{GHG}$ reduction target for 2030. The change in assessment mainly reflects that the underlying studies now account for the full implementation of directives, regulations and legislation adopted in 2018 and 2019 that comprise the Clean Planet for All policy package. According to a baseline scenario that assumes full implementation of adopted policies in climate, energy and transport, emissions for the EU27 could reduce around 45 per cent below 1990 levels by 2030 (European Commission 2020b). If the status of policy implementation is considered at the level of European Union Member States, studies indicate that additional collective effort is required both by Member States and the European Union to meet its energy efficiency target as part of the NDC (EEA 2019). Additional Member State measures are in preparation, as indicated by the national energy and climate plans submitted in 2020, which have been assessed by the European Commission as being consistent with a 41 per cent reduction (European Commission 2020a).

The central estimate for the Russian Federation's 2030 emissions projections decreased by about $300 \mathrm{MtCO}_{2} \mathrm{e}$ due to the independent analyses' consideration of the 2019 national GHG inventory report, which made significant downward revisions on the historical emissions data compared with previous inventory reports.

For other G20 members that are projected to meet their NDC targets, India's 2030 emissions projections show a small decrease, partly due to a strong growth in renewable energy deployment, while the projections for China, Mexico and Turkey have not changed substantially compared with the 2019 assessment.

Figure 2.6. GHG emission projections (all gases and sectors, including LULUCF) for individual G20 members by 2030 under different scenarios published before the COVID-19 outbreak and compared with historical emissions from national GHG inventories

\section{Figure 2.6a.}

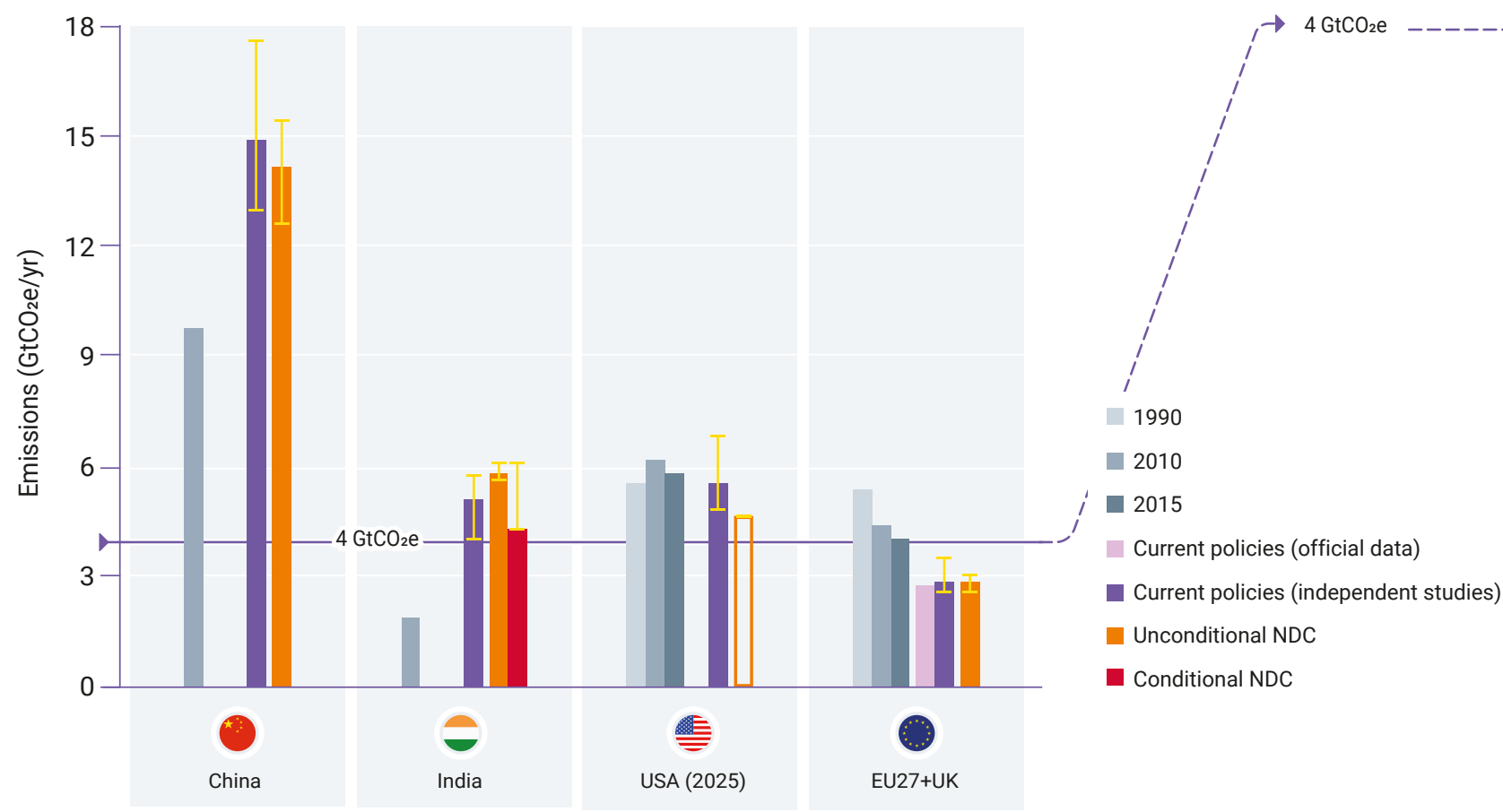


For five G20 members, GHG emissions by 2030 are projected to fall short of their unconditional NDC target and require further action of varying degree: Australia, Brazil, Canada, the Republic of Korea and the United States of America.

- For Australia and the Republic of Korea, the central estimates of independent analyses remain consistent with those of the 2019 assessment.

- For Brazil, the central estimates of independent analyses have increased from the 2019 assessment due to an upward revision of emissions projections in the land-use sector.

- For Canada, the emissions projections are revised downward compared with their previous assessments in both official (Environment and Climate Change Canada 2020b) and independent analyses (in part due to a large downward revision by the Joint Research Centre (Keramidas et al. 2020)). However, overall, the nation is still projected to miss its NDC target, unless policies are strengthened. Canada has acknowledged this and in September 2020 it committed to bring forward enhanced measures that will allow the country to meet and exceed its target.

For the United States of America, the government has revised, rescinded and/or replaced regulations, but the GHG emissions projections remain similar to previous projections. The central estimate for 2025 under current policies scenario projections is still far from the NDC target level (central estimate: $5.8 \mathrm{GtCO}_{2} \mathrm{e}$ compared with $4.7 \mathrm{GtCO}_{2} \mathrm{e}$ ). As the withdrawal of the United States of America from the Paris Agreement took effect on 4 November 2020, the country no longer has an official NDC. However, its former NDC for 2025 is still included as a reference. In November 2020, Joe Biden won the presidential election (NBC News 2020). President-elect Biden intends an immediate return to the Paris Agreement (Biden 2020). This can be achieved in 2021, without the intervention of Congress.

For the Republic of Korea, it should be noted that the current policies scenario projections could be revised downward significantly, when the total amount of emissions allowances (caps) under Korean Emissions Trading Scheme (K-ETS) are set for years towards 2030 and reflected in the emissions projections. According to the third Master Plan for the K-ETS established in December 2019, the emissions caps for Phase III (2021-2025) will be strictly set to be consistent with the annual target emissions from the 2030 Greenhouse Gas Reduction Roadmap, while the emission caps for Phase IV will be set to achieve the NDC target for 2030. The emissions cap for Phase III has recently been set (see table 2.4).

Figure 2.6b.

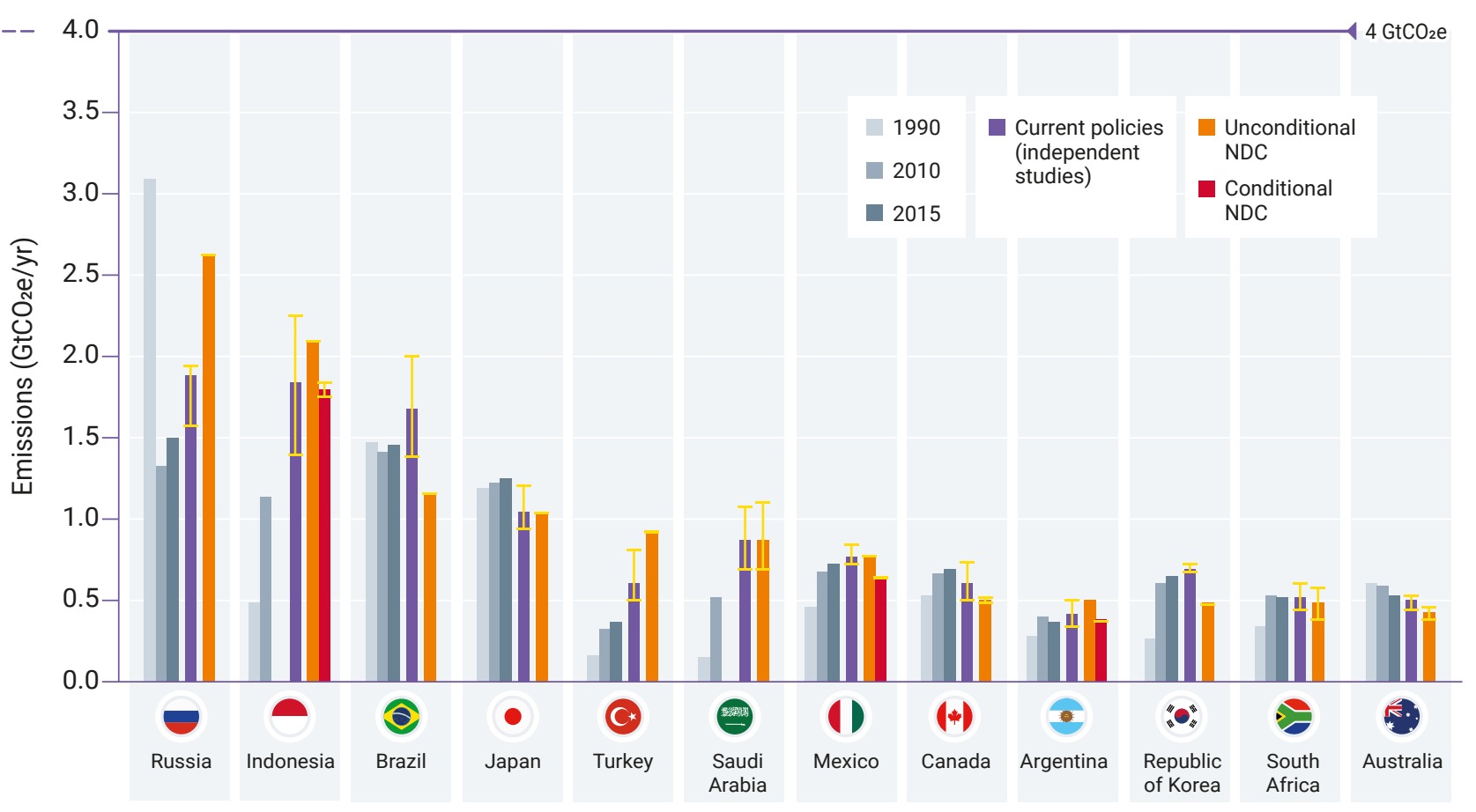

Notes: i) The data sources of the scenarios are described in table 2.2. ii) For reporting reasons, the emission projections for China, the EU27+UK, India and the United States of America are shown in figure 2.6a, and the other countries shown in figure 2.6b, using two different vertical axes. iii) For the United States of America, which withdrew from the Paris Agreement on 4 November 2020 , the former NDC for 2025 is presented for reference (hatched). 
Table 2.3. Assessment of $G 20$ member's progress towards achieving unconditional NDC targets under current policies based on independent studies published before the COVID-19 outbreak

\begin{tabular}{|c|c|c|c|c|}
\hline \multicolumn{2}{|c|}{$\begin{array}{l}\text { Projected to meet the unconditional } \\
\text { NDC target with currently } \\
\text { implemented policies }\end{array}$} & \multicolumn{2}{|c|}{$\begin{array}{l}\text { Expected to meet the unconditional NDC target } \\
\text { with additional policy measures and/or stricter } \\
\text { enforcement of existing policies }\end{array}$} & \multirow[t]{2}{*}{$\begin{array}{l}\text { Uncertain or } \\
\text { insufficient } \\
\text { information }\end{array}$} \\
\hline $\begin{array}{l}\text { Overachievement } \\
\text { of the target by } \\
\text { more than } 15 \text { per } \\
\text { cent }\end{array}$ & $\begin{array}{l}\text { Overachievement } \\
\text { of the target by } \\
\text { less than } 15 \text { per } \\
\text { cent* }^{*}\end{array}$ & $\begin{array}{l}\text { Projected emissions } \\
0-15 \text { per cent above } \\
\text { the NDC target }\end{array}$ & $\begin{array}{l}\text { Projected emissions } 15 \\
\text { per cent or more above } \\
\text { the NDC target }\end{array}$ & \\
\hline 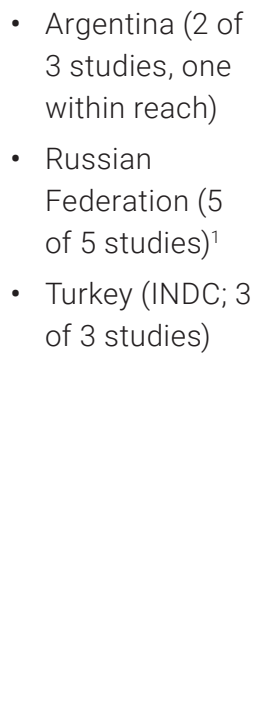 & $\begin{array}{l}\text { - } \text { China (2 of } 6 \\
\text { studies, one } \\
\text { within reach) } \\
\text { - } \text { EU27+UK (1 } \\
\text { of } 3 \text { studies, } \\
\text { one within } \\
\text { reach) })^{1,2,3} \\
\text { - } \text { India (6 of } \\
7 \text { studies) } \\
\text { - Japan (2 of } 4 \\
\text { studies, one } \\
\text { within reach) } \\
\text { - } \text { Mexico (2 of } \\
3 \text { studies) } \\
\text { - } \text { South Africa (2 } \\
\text { of } 3 \text { studies) }\end{array}$ & $\begin{array}{l}\text { - } \text { Australia (4 of } \\
4 \text { studies) }\end{array}$ & $\begin{array}{l}\text { - } \text { Brazil (4 of } 4 \text { studies) } \\
\text { - } \text { Canada (3 of } 3 \text { studies) }{ }^{1} \\
\text { - } \text { Republic of Korea (3 of } \\
3 \text { studies) }{ }^{5} \\
\text { - } \text { United States of } \\
\text { America (2025; } 7 \text { of } \\
7 \text { studies. Withdrawn } \\
\text { from the Paris } \\
\text { Agreement) }\end{array}$ & $\begin{array}{l}\text { - Indonesia (1 of } 3 \\
\text { studies projects } \\
\text { meeting the target, } \\
1 \text { study projects } \\
\text { target within reach) } \\
\text { - Saudi Arabia (1 of } \\
2 \text { studies projects } \\
\text { meeting the target, } \\
\text { one within reach) }\end{array}$ \\
\hline
\end{tabular}

Notes: The assessment is based on the number of independent studies (table 2.2) that support the findings. These are compared to the available studies, as indicated in brackets, and the average estimate (median for countries with five studies or more) of the current policies scenario projections across all studies with the average 2030 NDC target.

1. Current policies scenario projections from official publications were also examined. The number of scenarios that support the above findings out of the total number of official scenarios are: Australia: 1 of 1; Canada: 1 of 1; Russian Federation: 1 of 1; European Union: 2 of 4 (see chapter footnote 4)

2. Climate Action Tracker indicates that upper-end projections would miss the NDC target range. Joint Research Centre analysis projected that the European Union would almost reach the target, with less than $10 \mathrm{MtCO}_{2} \mathrm{e}$ difference by 2030 .

3. Three official studies for EU27+UK (European Commission 2018; EEA 2019; UNFCCC undated b (BR4, 'with measures scenario')) and one official study for EU27 (European Commission 2020b) were assessed in addition to three independent studies. The evaluation was made based on an independent analysis by PBL that took into account the best recently adopted policy packages (Kuramochi et al. 2019) and official projections that considered full implementation of current European Union-wide policies (European Commission 2018; European Commission 2020b)

4. South Africa's current policies scenario projections were compared with the upper-bound estimate of the NDC range.

5. The Korean Emissions Trading Scheme (K-ETS) is an instrument to fully achieve the country's NDC target and covers about 70 per cent of its GHG emissions. At the time when three studies containing emissions projections for the Republic of Korea were conducted, a Master Plan for K-ETS Phase III (2021-2025) and IV (2026-2030) and a National Emission Allowance Allocation Plan for Phase III were not established. Thus, the three independent studies do not explicitly assume an implementation of the emissions caps consistent with the NDC target for the phases after 2020, which partially explains why they project the Republic of Korea to miss its NDC target under current policies.

Studies do not agree on whether Indonesia and Saudi Arabia are on track to meet their unconditional NDCs. For Indonesia, this mainly results from the uncertainty surrounding LULUCF emissions due to peat fires. The projection this year is considerably lower than the previous assessment due to updated GHG inventory data and the upward revision of renewable electricity generation projections (Kuramochi et al. 2019). For Saudi Arabia, the limited information about its NDC target and policies to achieve this target prevented a detailed assessment of the country's progress

Collectively, G20 members are not on track to achieve their unconditional NDCs based on current policies. The aggregate 
emissions of $\mathrm{G} 20$ members by 2030 are projected to be 40.1 $\mathrm{GtCO}_{2} \mathrm{e}^{13}$ (range: $35.8-42.6 \mathrm{GtCO}_{2} \mathrm{e}$ ), which is $0.9 \mathrm{GtCO}_{2} \mathrm{e}$ lower than projected in the 2019 report and about 26 per cent above 2010 levels (range: 7-48 per cent). These estimates do not consider the potential implications of the COVID-19 pandemic and related economic responses, but instead reflect various factors, including the impact of policies adopted in recent years, as well as revisions in GHG inventory data, changes in emissions scenario methodologies and underlying assumptions on macroeconomic drivers. Current policies imply increased 2030 emissions compared with 2010 levels for several G20 members (Argentina, Brazil, China, India, Indonesia, Mexico, the Republic of Korea, Russia, Saudi Arabia and South Africa).

Collectively, G20 members need to reduce their GHG emissions further by about $0.3 \mathrm{GtCO}_{2}$ e per year by 2030 to achieve unconditional NDC target emission levels and by about $2.4 \mathrm{GtCO}_{2}$ e per year to achieve conditional NDC target emission levels. If the $1.7 \mathrm{GtCO}_{2}$ e per year overachievement of unconditional NDCs by India, the Russian Federation and Turkey are excluded, and it is assumed that these countries will follow their current policies trajectory rather than that implied by their unconditional NDCs (as done in many NDC scenario projections from global models presented in chapter 3), then the G20 members will be collectively short of achieving both unconditional and conditional NDCs by about $2.1 \mathrm{GtCO}_{2}$ e per year and $3.4 \mathrm{GtCO}_{2}$ e per year, respectively, by 2030. The estimated difference between the current policies scenario and NDC scenario projections for G20 members remains similar to 2019 Emissions Gap Report projections. ${ }^{14}$

A sizeable number of policies adopted by G20 members over the past year have the potential to positively and negatively affect progress towards NDC targets (table 2.4). Many of these policies were adopted after the publication of the scenario studies reviewed in this section and were therefore not taken into account. Although several policies are expected to have positive mitigation outcomes, there are many that have negative implications for emissions, such as fossil fuel extraction projects, coal-fired power plant construction plans, and rollbacks of environmental regulations during the COVID-19 pandemic, as table 2.4 illustrates (for COVID-19 implications, see section 2.4.2 and chapter 4).

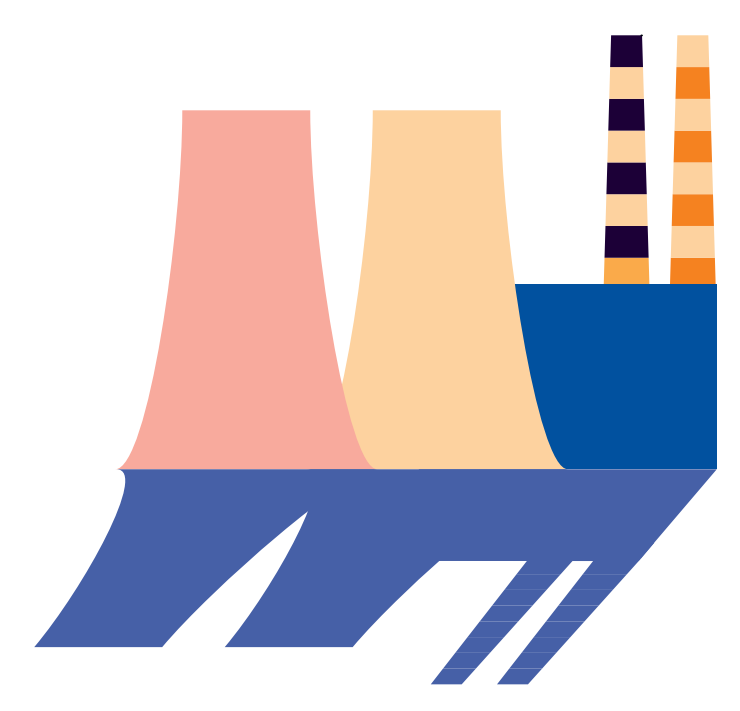

13 Central estimate of three studies that cover all G20 members (Climate Action Tracker 2019a; Kuramochi et al. 2019; Keramidas et al. 2020).

14 The values presented here are smaller than those reported in the 2019 report, though this is largely due to the 2019 report using an extrapolated 2030 estimate for the NDC of the United States of America, which was for 2024, whereas this year's report uses the former NDC emission levels for 2025 as they are. 
Table 2.4. Overview of key policy measures adopted by G20 members in 2019 and 2020 that would significantly affect the achievement of NDC targets, including selected COVID-19 measures

\begin{tabular}{|c|c|}
\hline $\begin{array}{l}\text { Country/ } \\
\text { region }\end{array}$ & Key policy measures adopted in 2019 and 2020 \\
\hline Argentina & $\begin{array}{l}\text { - In November 2019, the National Climate Change Law on Adaptation and Mitigation was approved in } \\
\text { Congress by consensus. } \\
\text { - The future of 'Vaca Muerta' (large reserve of shale oil and gas) remains highly uncertain. Its economic } \\
\text { viability and attractiveness are at stake due to a plunge in oil prices and reduced demand. The } \\
\text { Government is renegotiating its foreign debt with the International Monetary Fund (IMF), with the } \\
\text { future of Vaca Muerta dependent on the results of these negotiations. }\end{array}$ \\
\hline Australia & $\begin{array}{l}\text { - No new renewable energy targets for post-2020 have been put forward (the } 2020 \text { target was achieved } \\
\text { a year early). } \\
\text { - The Government has announced plans to support investment in natural gas, in a gas-led recovery to } \\
\text { the pandemic, including through government investment in gas infrastructure. } \\
\text { - The Technology Investment Roadmap Discussion Paper, published in May 2020, proposes changing } \\
\text { the remit of two renewable energy government agencies and advocates for natural gas and carbon } \\
\text { capture and storage (CCS). } \\
\text { - The First Low Emissions Technology Statement, published in September 2020, outlines the five } \\
\text { technologies requiring investment for emissions reduction: clean hydrogen, energy storage, low- } \\
\text { carbon materials, CCS and soil carbon sequestration. A new AUD } 1.9 \text { billion investment package was } \\
\text { also announced in September } 2020 \text { to support the above activities and energy productivity, excluding } \\
\text { support for renewable energy technologies. }\end{array}$ \\
\hline Brazil & $\begin{array}{l}\text { - The Government has recently approved the Forest+ project, which will fund environmental services } \\
\text { linked with conservation efforts. However, rollbacks continue to hinder efforts to stop deforestation. } \\
\text { - Three-quarters of the latest energy auction (October 2019) went to renewable energy, with the } \\
\text { remainder going to natural gas. Solar (18 per cent) had the lowest cost of all technologies. Despite } \\
\text { this, investments in fossil fuel energy infrastructure still dominate the current 10-year energy plan. The } \\
\text { spring } 2020 \text { auction was postponed due the pandemic. }\end{array}$ \\
\hline Canada & $\begin{array}{l}\text { - The Minister of Environment and Climate Change reversed his } 2019 \text { decision not to subject a coal } \\
\text { mine expansion project to a federal environmental impact assessment after claims that such action } \\
\text { was inconsistent with Canada's founding member status of the Powering Past Coal Alliance. } \\
\text { - Canada has announced that it will establish a Clean Power Fund to help finance the development and } \\
\text { linking of clean energy to transmission systems, including support for an Atlantic Loop that will help } \\
\text { the country's most eastern provinces transition away from coal-fired electricity generation. } \\
\text { - Regulations regarding fugitive and venting } \mathrm{CH}_{4} \text { emissions from upstream oil and gas production came } \\
\text { into effect at the beginning of } 2020 \text {. These regulations are part of Canada's commitment to reduce } \\
\mathrm{CH}_{4} \text { emissions in the sector by } 40-45 \text { per cent below } 2012 \text { levels by } 2025 \text {. } \\
\text { - Canada continues to invest in electric vehicle (EV) charging infrastructure and has provided funding } \\
\text { to support EV purchase incentives as part of its sales targets for EVs of } 10 \text { per cent by } 2025,30 \text { per } \\
\text { cent by } 2030 \text { and } 100 \text { per cent by } 2040 \text {. Further support measures are anticipated as part of COVID-19 } \\
\text { economic recovery measures. }\end{array}$ \\
\hline
\end{tabular}


- Mandatory carbon pricing has been in effect across Canada since 2019. Provinces and territories may implement their own pricing systems, provided that they meet certain criteria, or apply the federal system. The federal carbon pricing system consists of a charge on fossil fuels and a regulated emissions trading system for heavy industry. For direct pricing systems in Canada, the carbon price is CAD 30/ $/ \mathrm{CO}_{2} \mathrm{e}$ in 2020, which will rise to CAD 10/year to CAD 50/ $\mathrm{CCO}_{2} \mathrm{e}$ in 2022. Some provinces have challenged the constitutionality of the carbon pricing legislation, with lower courts split on the issue. Canada's top court heard the case in September 2020 and reserved judgment.

- The new coal-fired power monitor up to 2023 allows or restricts provinces to permit construction of new coal-fired power plants. Restrictions were rolled back compared with the 2019 monitor, with more provinces permitted to construct new plants.

- The target for the new energy vehicles (NEVs) market share in total car sales was raised from 20 per cent to 25 per cent by 2025, with the Government extending the NEV purchase tax exemption programme and subsidies programme until 2022.

- Partly in response to COVID-19, the Government will prioritize acceleration of its New Infrastructure Plan. In 2020, China added 200,000 EV charging facilities nationwide, which is an increase of about 16.5 per cent compared with 2019. As at October 2020, 21 ultra-high voltage (UHV) power transmission projects have been commissioned, six of which are under construction. Infrastructure to connect large-scale rural renewable projects to densely populated areas, along with new inter-city high-speed rail networks will also be promoted.

- China will scale up its NDC by adopting more vigorous policies and measures. China aims to peak $\mathrm{CO}_{2}$ emissions before 2030 and achieve carbon neutrality before 2060 (Ministry of Foreign Affairs of the People's Republic of China 2020).

European - The European Union adopted the European Green Deal to become climate neutral by 2050 in December 2019. The European Green Deal includes the development of a climate law, which was proposed by the European Commission in March 2020 and is in discussion between the European Council and European Parliament.

- In July 2020, the European Council (European Union Heads of State and government) agreed on the main elements of a proposed recovery package known as NextGenerationEU. This package is additional to the European Union's 2021-2027 budget and would total EUR 750 billion in grants and loans. Thirty per cent of NextGenerationEU funds and the European Union's long-term budget for 2021-2027 have been earmarked for climate action. All funds will support the 2030 climate target and 2050 climate neutrality objective.

- In September 2020, the European Commission proposed that the European Union increase its domestic emissions target to at least 55 per cent below 1990 levels by 2030 (including LULUCF). In October 2020, the European Parliament voted for a reduction of 60 per cent. Considerations are ongoing in the European Council on how to revise the target.

- No new coal-fired power plants were built in the first half of 2020 and the country's coal fleet shrank by $0.3 \mathrm{GW}$. However, there are still plans to expand coal-fired power generation in the future. Domestic coal production could reach record levels in 2020.

- India plans to expand solar investments in its agriculture sector to develop 25 GW of capacity by 2022 through the Pradhan Mantri-Kisan Urja Suraksha evam Utthan (PM-KUSUM) scheme. (At the national level, India has a renewable energy capacity target of $175 \mathrm{GW}$ by 2022).

- The second phase of the Faster Adoption and Manufacturing of Electric Vehicles (FAME II) project, which came into effect in April 2019, provides support to EV purchases and charging infrastructure.

- Indian railways aims to completely electrify the network by 2023 and in July 2020 announced its plans to achieve net-zero emissions by 2030. 
Indonesia - In January 2020, the Government put a cap on domestic coal below market value to boost consumption. It also plans to subsidize fuel for industries and businesses using roughly 14 per cent of the budget reserved for its National Economic Recovery programme.

- Indonesia has postponed the 2020 geothermal auctions, with the demand for solar photovoltaic (PV) panels dropping 70 per cent during the pandemic, due to reduced household and government spending for rooftop installations.

\begin{tabular}{|c|c|}
\hline Japan & $\begin{array}{l}\text { - The Government aims to establish a concrete plan to phase out the country's inefficient coal-fired } \\
\text { - According to Japan's new strategy on coal-fired power plant finance overseas, the Government } \\
\text { will not, in principle, support the installation of projects in countries whose energy issues and } \\
\text { decarbonization policies have not been deeply accounted for in a bilateral context (the strategy does } \\
\text { not apply to ongoing projects). } \\
\text { - The new midterm deployment plan for offshore wind power will be proposed by the end of } 2020 \\
\text { through the Public-Private Council on Enhancement of Industrial Competitiveness for Offshore Wind } \\
\text { Power Generation. }\end{array}$ \\
\hline Mexico & $\begin{array}{l}\text { - Mexico passed a bill on fiscal support to its state-owned petroleum company (Pemex), which would } \\
\text { allow Pemex to continue its investments in oil exploration and extraction. } \\
\text { The Government established a policy to strengthen energy security in the country, which effectively } \\
\text { halts private renewable energy investment in Mexico and prioritizes state-owned fossil fuel-fired } \\
\text { power plants supplied with coal, heavy oil and natural gas. However, as the judiciary processes } \\
\text { against this policy are still ongoing, the renewable electricity dispatch continues and its use has not } \\
\text { been affected. No significant renewable power capacity has been added in 2020, with the dispatch of } \\
\text { renewables in the country's electricity matrix (excluding large hydropower) reaching just } 13 \text { per cent in } \\
\text { September } 2020 \text {. }\end{array}$ \\
\hline $\begin{array}{l}\text { Republic of } \\
\text { Korea }\end{array}$ & $\begin{array}{l}\text { - The Ninth Electricity Plan is currently in development, but its draft already includes electricity } \\
\text { generation targets that are lower for coal and nuclear and higher for renewables and natural gas, } \\
\text { compared with the Eighth Electricity Plan. The new plan's targets for } 2034 \text { are } 17 \text { per cent for nuclear, } \\
15 \text { per cent for coal, } 32.3 \text { per cent for natural gas and } 40 \text { per cent for renewables. } \\
\text { - The Government's Green New Deal includes a plan to boost renewable energy deployment (with the } \\
\text { focus on offshore wind farms and building installations) and low-carbon infrastructure, as well as } \\
\text { support to build a smart grid for efficient energy management and put } 1.13 \text { million EVs and 200,000 } \\
\text { hydrogen vehicles on the roads by } 2025 \text {. } \\
\text { - In October 2020, the National Emission Allowance Allocation Plan for Phase III (2021-2025) was } \\
\text { established. The plan sets the total emission allowances (caps) for Phase III. According to the plan, the } \\
\text { portion of allowances allocated through an auction is being increased to } 10 \text { per cent, with the number } \\
\text { of industries that have a benchmark methodology applied for free allocation also set to increase } \\
\text { compared with Phase II. }\end{array}$ \\
\hline $\begin{array}{l}\text { Russian } \\
\text { Federation }\end{array}$ & $\begin{array}{l}\text { - The long-delayed } 2035 \text { Energy Strategy was adopted in June 2020, which focuses on expanding fossil } \\
\text { fuel production, exports and domestic consumption. Plans for expanding renewable energy generation } \\
\text { are absent. } \\
\text { - A draft energy efficiency plan, published in August 2020, sets a } 2030 \text { target of reducing total energy } \\
\text { intensity of GDP by } 20 \text { per cent below } 2017 \text { levels. }\end{array}$ \\
\hline
\end{tabular}




\begin{tabular}{|c|c|}
\hline $\begin{array}{l}\text { Saudi } \\
\text { Arabia }\end{array}$ & $\begin{array}{l}\text { - The Government launched the third round of its National Renewable Energy Program, tendering } 1.2 \\
\text { GW of solar PV. Rounds } 1 \text { and } 2 \text { tendered around } 2.2 \mathrm{GW} \text { of solar PV in total. } \\
\text { - As part of the economic recovery response to the pandemic, the Government has temporarily } \\
\text { increased consumers' electricity subsidies in commercial, industrial and agriculture sectors. These } \\
\text { subsidies provide additional support to the electricity system, powered almost exclusively by } \\
\text { fossil fuels. }\end{array}$ \\
\hline $\begin{array}{l}\text { South } \\
\text { Africa }\end{array}$ & $\begin{array}{l}\text { - South Africa has revised its } 2011 \text { Integrated Resource Plan. The } 2019 \text { Integrated Resource Plan aims } \\
\text { to decommission over } 35 \mathrm{GW} \text { (of } 42 \mathrm{GW} \text { currently operating) of Eskom's coal generation capacity by } \\
2050 \text { ( } 5.4 \mathrm{GW} \text { by } 2022 \text { and } 10.5 \mathrm{GW} \text { by 2030). The plan also includes the construction of } 7.2 \mathrm{GW} \text { of new } \\
\text { coal capacity, } 15.8 \mathrm{GW} \text { of wind capacity and } 7.4 \mathrm{GW} \text { of solar capacity by } 2030 \text {. } \\
\text { - In 2020, the chemicals and energy group Sasol announced the launch of a } 2030 \text { emissions road map } \\
\text { for its South African operations. The road map details its path to at least a } 10 \text { per cent reduction in } \\
\text { GHG emissions by } 2030 \text { compared with a } 2017 \text { baseline, and was developed with a long-term view. }\end{array}$ \\
\hline Turkey & $\begin{array}{l}\text { - Turkey continues to expand its coal-fired power generation with almost } 32 \mathrm{GW} \text { of planned capacity in } \\
\text { various stages of planning; } 1.3 \mathrm{GW} \text { of this is currently under construction. } \\
\text { - Turkey announced that it would seek tenders for small-scale renewable projects of } 1 \mathrm{GW} \text { in total in } \\
\text { early } 2021 \text {. Some renewable energy auctions have already taken place, such as the } 1 \mathrm{GW} \text { solar PV } \\
\text { auction in } 2017 \text { and two } 1 \mathrm{GW} \text { onshore wind auctions in } 2017 \text { and 2019, respectively. } \\
\text { - Since } 2019 \text {, Turkey has had the energy saving target of } 15 \text { per cent for public buildings, which it aims to } \\
\text { achieve by } 2023 \text { as part of its National Energy Efficiency Action Plan 2017-2023. }\end{array}$ \\
\hline $\begin{array}{l}\text { United } \\
\text { Kingdom }\end{array}$ & $\begin{array}{l}\text { - The United Kingdom will phase out coal-fired power generation earlier than originally planned after } \\
\text { bringing forward the phase-out date by one year to } 2024 \text {. In the first half of } 2020 \text {, the country went } 67 \\
\text { days without coal-fired power, the longest period since the Industrial Revolution began. } \\
\text { - GBP } 70 \text { million has been allocated to support hydrogen developments, including two production } \\
\text { plants. However, a comprehensive strategy for the sector has not yet been developed. } \\
\text { - The United Kingdom was considering moving its ban on new petrol and diesel cars forward by five } \\
\text { years from } 2040 \text { to } 2035 \text { and held public consultations at the beginning of } 2020 \text {. In November } 2020 \text {, } \\
\text { the Government announced it was considering more ambitious plans to bring the ban forward by } 10 \\
\text { years to 2030. A decarbonization plan for the entire transport sector is expected by the end of the year. }\end{array}$ \\
\hline $\begin{array}{l}\text { United } \\
\text { States of } \\
\text { America }\end{array}$ & $\begin{array}{l}\text { - The United States of America withdrew from the Paris Agreement on } 4 \text { November } 2020 . \\
\text { - The Clean Power Plan, which aimed to reduce emissions from the power sector by } 32 \text { per cent below } \\
2005 \text { levels by 2030, is being replaced with the Affordable Clean Energy (ACE) plan. ACE limits the } \\
\text { scope of the plan to efficiency measures or CCS technologies. It is currently under at least two legal } \\
\text { challenges. } \\
\text { - The Safer Affordable Fuel-Efficient (SAFE) Vehicles Rule revised fuel efficiency standards set by the } \\
\text { previous Administration to less stricter ones. The SAFE rule now requires automakers to improve the } \\
\text { fuel efficiency of their light duty vehicles by } 1.5 \text { per cent annually (previously } 5 \text { per cent) and to reach } \\
40 \text { miles per gallon by } 2025 \text { (previously set at } 54 \text { miles per gallon). The rule also revokes California's } \\
\text { waiver to set its own emission standards for cars and trucks that are stricter than the federal } \\
\text { standards. }\end{array}$ \\
\hline
\end{tabular}

Note: See chapter 4 for an overview of COVID-19 fiscal rescue and recovery measures.

Sources: Based on Climate Action Tracker (2020c); Climate Transparency (2020); Moisio et al. (2020)

To supplement these findings presented, figure 2.7 shows projected per capita GHG emissions for the 16 G20 members, counting the European Union, its three Member
States and the United Kingdom as one (EU27+UK), under the current policies and unconditional NDC scenarios based on independent studies and 2010 historical data 
from national GHG inventories. ${ }^{15}$ G20 members are shown in decreasing order of NDC emissions projections. Overall, average G20 annual emissions per capita by 2030 are projected to decline compared with 2010 levels under the unconditional NDC scenario. The figure illustrates that there are large differences in per capita emission levels across G20 members. For example, the projected per capita emissions of India are about half of the G20 average, whereas Saudi Arabia's per capita emissions are projected to reach three times the $\mathrm{G} 20$ average by 2030. All but five G20 members (the European Union, India, Indonesia, Mexico and Turkey) are projected to still emit more than the 2010
G20 average ( $7 \mathrm{tCO}_{2} \mathrm{e}$ per capita) by 2030 under current policies. For comparison, the $\mathrm{G} 20$ average per capita emissions consistent with $2^{\circ} \mathrm{C}$ warming would roughly be around $5 \mathrm{tCO}_{2} \mathrm{e}$ per capita by 2030 (authors' estimate based on den Elzen et al. 2019). Among OECD members, ${ }^{16}$ the EU27+UK performs well in terms of both absolute and per capita emission levels by 2030 and their change rates compared with 2010 levels, although it should be noted that their consumption-based emissions are considerably higher as shown in figure 2.3. Mexico also performs well in terms of the projected development of per capita emissions under both current policies and NDC scenarios.

Figure 2.7. Per capita GHG emissions (including LULUCF) of the G20 and its individual members by 2030 (2025 for the United States of America) under NDC and current policies scenarios (central estimates) published before the COVID-19 outbreak and compared with 2010 historical emissions

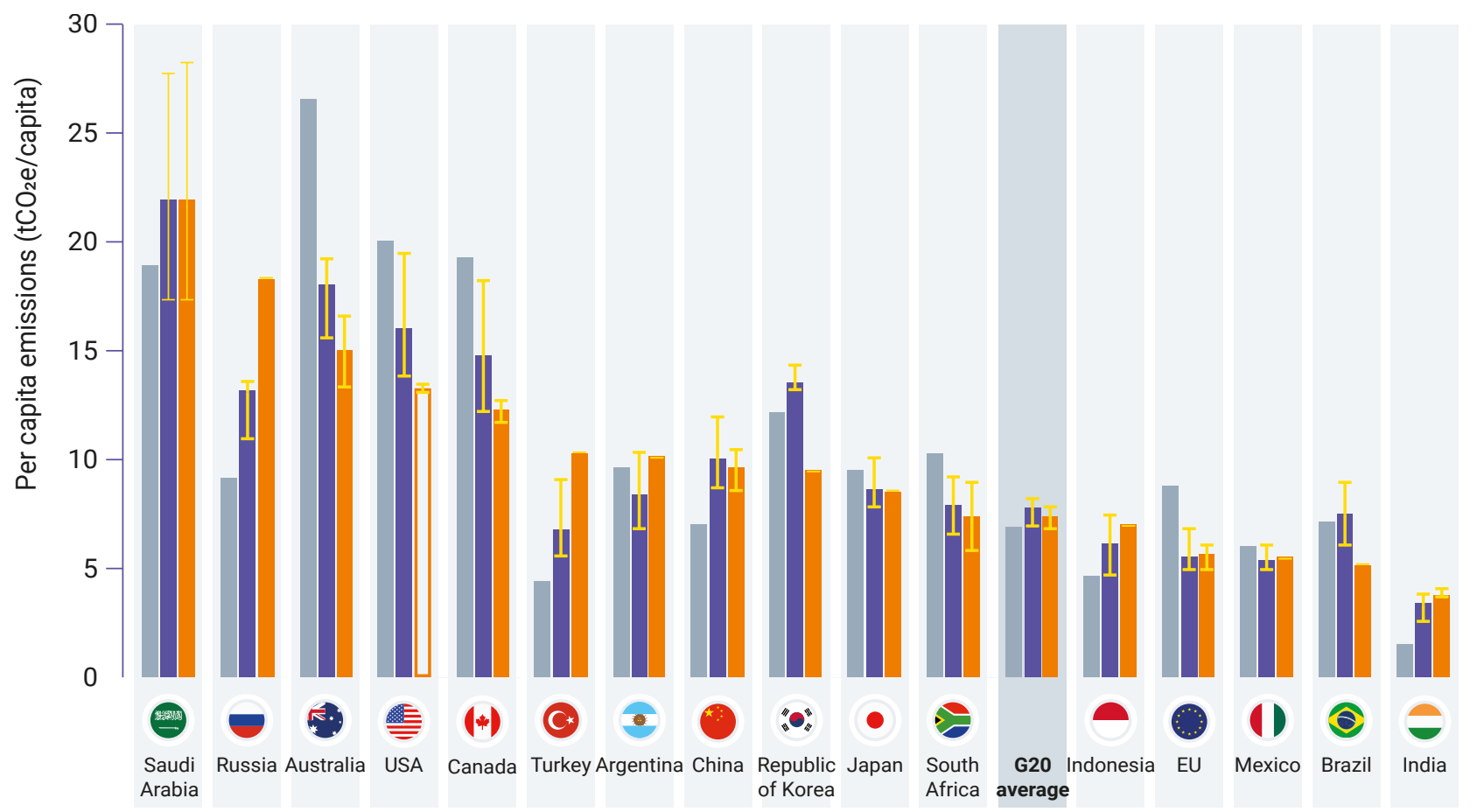

Notes: i) For the United States of America, which withdrew from the Paris Agreement on 4 November 2020, the former NDC for 2025 is presented for reference (hatched). ii) Data on historical and projected (medium fertility variant) population per country is taken from the 2019 Revision of the World Population Prospects (United Nations Department of Economic and Social Affairs [UN DESA] 2019). iii) The figures presented here may not exactly match official data due to the differences in data sources. iv) G20 members are sorted in decreasing order of NDC emissions projections. v) To estimate G20 total emissions for NDC scenarios, current policies scenario projections (central estimates) were used for India, Russia and Turkey. vi) The G20 average for NDCs used the United States of America's 2025 NDC target estimates, while the G20 average for the current policies scenario used the United States of America's 2030 emission estimates.

\subsubsection{Estimated impact of COVID-19 and associated policy responses on 2030 emissions for individual G20 members}

This section summarizes preliminary findings on the potential impacts of COVID-19 and associated policy responses by $\mathrm{G} 20$ members on GHG emissions by 2030 . By nature, these findings are highly uncertain. First, the literature assessing these potential impacts is sparse and based on very limited information about how COVID-19 has affected the economy and subsequently GHG emissions across G20 members in 2020. Second, the literature adopts simplistic and speculative assumptions about the longerterm impacts of COVID-19 and associated responses. Third, a comparison of pre- and post-COVID-19 projections

15 Note that the 2010 estimates are not the same as those in the bottom panel of figure 2.2 due to the differences in data sources and the consideration of land-use sector emissions.

16 Australia, Canada, the European Union, Japan, Mexico, the Republic of Korea, Turkey and the United States of America. 
requires distinguishing the impact of COVID-19 and associated responses from the impact of other factors, such as recently adopted policies unrelated to COVID-19, the use of updated national GHG inventory data for years 2019 and earlier, and methodological changes. A synthesis of the literature on COVID-19 stimulus measures implemented in key emitting economies is presented in chapter 4.

Looking at individual G20 members, multiple $\mathrm{CO}_{2}$ and/or GHG emissions scenario studies are available for seven
G20 members (table 2.5). Note that the studies included in table 2.5 are not fully comparable due to differences in the coverage of GHGs and sectors, the scenarios examined and scenario definitions across studies. That said, studies on the United States of America seem to agree on the magnitude of the COVID-19 impact on 2030 emissions projections, noting a reduction of around 5-10 per cent compared with preCOVID-19 projections. Two studies (Climate Action Tracker 2020c; IEA 2020e) also indicate that India may see larger reductions by 2030 compared with other major emitters.

Table 2.5. Comparison of 2030 emissions projections post-COVID-19 compared with pre-COVID-19

\begin{tabular}{l|l|l|l} 
Country and region & $\begin{array}{l}\text { IEA World Energy Outlook } \\
2020 \text { (stated policies } \\
\text { scenario, energy-related } \\
\mathrm{CO}_{2} \text { emissions only) }\end{array}$ & Climate Action Tracker ${ }^{3}$ & Other studies \\
\hline Brazil & $-2.4 \%$ & $-5.2 \%$ to $-4.4 \%$ & N/A \\
\hline China & $-1.2 \%$ & $-6.0 \%$ to $-0.5 \%$ & N/A \\
\hline EU27 & N/A & $-6.6 \%$ to $-0.1 \%$ & $-0.2 \%$ (NDC implementation \\
\hline India & $-18.6 \%$ & $-11.8 \%$ to $-8.5 \%$ & Scenario) \\
\hline Japan & $-3.3 \%$ & $-13.2 \%$ to $-5.5 \%$ & N/A \\
\hline Russian Federation & $-2.4 \%$ & $-6.2 \%$ to $-1.9 \%$ & N/A \\
\hline
\end{tabular}

Notes: The comparison is based on current policy scenario projections for all GHG emissions excluding LULUCF, unless otherwise noted. N/A: not available.

1. IEA (2020e). The stated policies scenario "incorporates our assessment of all the policy ambitions and targets that have been legislated for or announced by governments around the world" (IEA 2020e) and "assumes that significant risks to public health are brought under control over the course of 2021, allowing for a steady recovery in economic activity".

2. Comparison was not possible because World Energy Outlook 2019 included the United Kingdom as part of the European Union, whereas World Energy Outlook 2020 excluded the United Kingdom.

3. Climate Action Tracker (2020c)

4. European Commission (2020b)

5. Larsen et al. (2020)

\subsection{The need to translate long-term net- zero emissions goals into near-term ambition and action}

The message of this chapter is clear: all countries urgently need to strengthen their mitigation ambition and accelerate action to change current emission trends and get on track to achieving the long-term temperature goals of the Paris
Agreement. This is especially the case for G20 members, who account for about 78 per cent of global emissions. Most G20 major emitters have only made marginal progress in shifting their future emissions trajectories downward (Höhne et al. 2020), with several others not even on track to meet their NDCs. The most significant and encouraging development in 2020 is the growing number of countries that are committing to various net-zero emissions goals by 2050 . 
As at November 2020, 126 countries covering 51 per cent of global GHG emissions are covered by net-zero goals that are formally adopted, announced or under consideration (Climate Action Tracker 2020a, based on Energy and Climate Intelligence Unit 2020).17 If the United States of America were to also adopt a net-zero GHG target by 2050, as suggested in the Biden-Harris climate plan (Biden 2020), the share could increase up to 63 per cent. Of the G20 members, the following have net-zero emissions goals:

- France legally enshrined its goal to achieve netzero GHG emissions by 2050 (Journal officiel de la République Française 2019).

The United Kingdom legally enshrined its 2050 netzero GHG emissions goal (United Kingdom 2019).

The European Union aims to be climate neutral through achieving net-zero GHG emissions by 2050 (Croatian Presidency of the Council of the European Union and the European Commission 2020).

At the United Nations General Assembly, China announced its aim for a $\mathrm{CO}_{2}$ emissions peak before 2030 and to achieve carbon neutrality before 2060 (Ministry of Foreign Affairs of the People's Republic of China 2020).

In October 2020, Japan announced a goal of net-zero GHG emissions by 2050 (Ministry of Foreign Affairs of Japan 2020), strengthening their previous goal of achieving a decarbonized society as early as possible in the second half of this century (Government of Japan 2019b).

The President of the Republic of Korea committed to carbon neutrality by 2050 in his speech to parliament (Cheong Wa Dae 2020).

Canada has indicated its intention to legislate a goal of net-zero emissions ${ }^{18}$ by 2050 (Governor General of Canada 2020).

- South Africa aspires to net-zero carbon emissions by 2050 (Republic of South Africa 2020).

Argentina and Mexico are part of the UNFCCC Climate Ambition Alliance working towards net-zero carbon emissions by 2050 (UNFCCC 2019).

Progress is significantly slower when considering the formal submissions of mid-century, long-term low GHG emission development strategies and new or updated NDCs that countries are invited or requested, respectively, to submit to the UNFCCC by 2020. As at mid-November 2020, nine G20 members (Canada, the European Union, France, Germany, Japan, Mexico, South Africa, United Kingdom and the United States of America) ${ }^{19}$ have submitted long-term low GHG development strategies to the UNFCCC, though no G20 member has officially submitted a new or updated NDC target (Japan resubmitted its original NDC target in March 2020) (UNFCCC undated a).

Although the recent announcements of net-zero emissions goals are very encouraging, they highlight the vast discrepancy between the ambitiousness of these goals and the inadequate level of ambition in the NDCs for 2030. Furthermore, there is inconsistency between the emission levels implied by current policies and those projected under current NDCs by 2030 (of 2.1-3.5 $\mathrm{GtCO}_{2} \mathrm{e}$ per year), and, more importantly, those necessary for achieving net-zero emissions by 2050 .

To make significant progress towards achieving the longterm temperature goals of the Paris Agreement by 2030, two next steps are urgently required. First, more countries need to develop long-term strategies that are consistent with the Paris Agreement, in particular, by setting time frames for net-zero emissions. Second, new and updated NDCs need to become consistent with the net-zero emission goals (Levin et al. 2020). It will therefore be particularly important to ensure coordination between the development of the next NDCs and the long-term strategies in order to enable a seamless transition to a decarbonization pathway that is consistent with the Paris Agreement (Levin and Fransen 2019), and to transform the announced net-zero emissions goals into detailed shorter-term implementation plans and mitigation targets that are reflected in the NDCs for 2030.

Previous Emissions Gap Reports have highlighted the large menu of options and opportunities to strengthen mitigation ambition and action (Fransen and Höhne 2018; Höhne et al. 2019). Model-based, multidisciplinary assessments could also be a key aspect when informing policymakers and engaging stakeholders in the process of developing updated NDCs and long-term strategies (Weitzel et al. 2019).

As the world deals with the COVID-19 pandemic, the implementation of sustainable recovery packages that boost economic growth and create jobs while building more resilient and cleaner energy systems is essential to ensuring that significant mitigation progress is made by 2030 (IEA 2020c).

17 Countries with proposed legislation or targets under discussion include those that have signed up to the UNFCCC's Climate Ambition Alliance (UNFCCC 2019).

18 It is not clear if 'net zero' refers to $\mathrm{CO}_{2}$ emissions only or all $\mathrm{GHG}$ emissions.

19 The government of the United States of America has removed the mid-century strategy from all its websites following the country's withdrawal from the Paris Agreement (Climate Action Tracker 2020b). 


\title{
3 The emissions gap
}

\author{
Lead authors: \\ Joeri Rogelj (Grantham Institute, Imperial College London, UK; International Institute for Applied Systems Analysis - IIASA, \\ Austria), Michel den Elzen (PBL Netherlands Environmental Assessment Agency, the Netherlands) and Joana Portugal \\ Pereira (Graduate School of Engineering (COPPE), Universidade Federal do Rio de Janeiro, Brazil)
}

\section{Contributing authors:}

Niklas Höhne (NewClimate Institute, Germany), Daniel Huppmann (IIASA, Austria), Gunnar Luderer (Potsdam Institute for Climate Research, Germany)

\subsection{Introduction}

This chapter updates the assessment of the emissions gap for 2030. Consistent with previous Emissions Gap Reports, the emissions gap is defined as the difference between projected global greenhouse gas (GHG) emissions under full implementation of nationally determined contributions (NDCs) and emissions under least-cost pathways consistent with the Paris Agreement long-term goal of limiting global average temperature increase to well below $2^{\circ} \mathrm{C}$ and pursing efforts to limiting it to $1.5^{\circ} \mathrm{C}$ compared with pre-industrial levels (section 3.2). This chapter assesses up-to-date emissions scenarios that underlie the quantification of the emissions gap (section 3.3).

The emissions projections for the current policies and NDC scenarios published in the literature mainly predate the COVID-19 outbreak. Potential implications of COVID-19 on 2030 emissions are therefore explored based on expert knowledge and indicative calculations (section 3.4), which is consistent with the approach used in chapter 2 . The implications of failing to bridge the emissions gap by 2030 and the feasibility of achieving the long-term temperature goals of the Paris Agreement are also discussed (section 3.5).

The key questions assessed in this chapter are: What is the likely emissions gap for 2030? What is the impact of the COVID-19 pandemic and associated recovery measures on emissions by 2030? What are the temperature implications? What does the 2030 emissions gap imply in a longer-term, mid-century context?

\subsection{The 2030 emissions gap}

In line with previous reports, the emissions gap for 2030 is defined as the difference between global total GHG emissions from least-cost scenarios that keep global warming to below $2^{\circ} \mathrm{C}, 1.8^{\circ} \mathrm{C}$ or $1.5^{\circ} \mathrm{C}$ with varying levels of likelihood, and the estimated global GHG emissions resulting from a full implementation of the NDCs. This section updates the gap based on estimated levels of GHG emissions in 2030 for the seven scenarios considered in this assessment and further described in section 3.3. Table 3.1 provides a full overview of 2030 emission levels for these scenarios, as well as the resulting emissions gap, while Figure 3.1 illustrates the emissions gap for 2030.

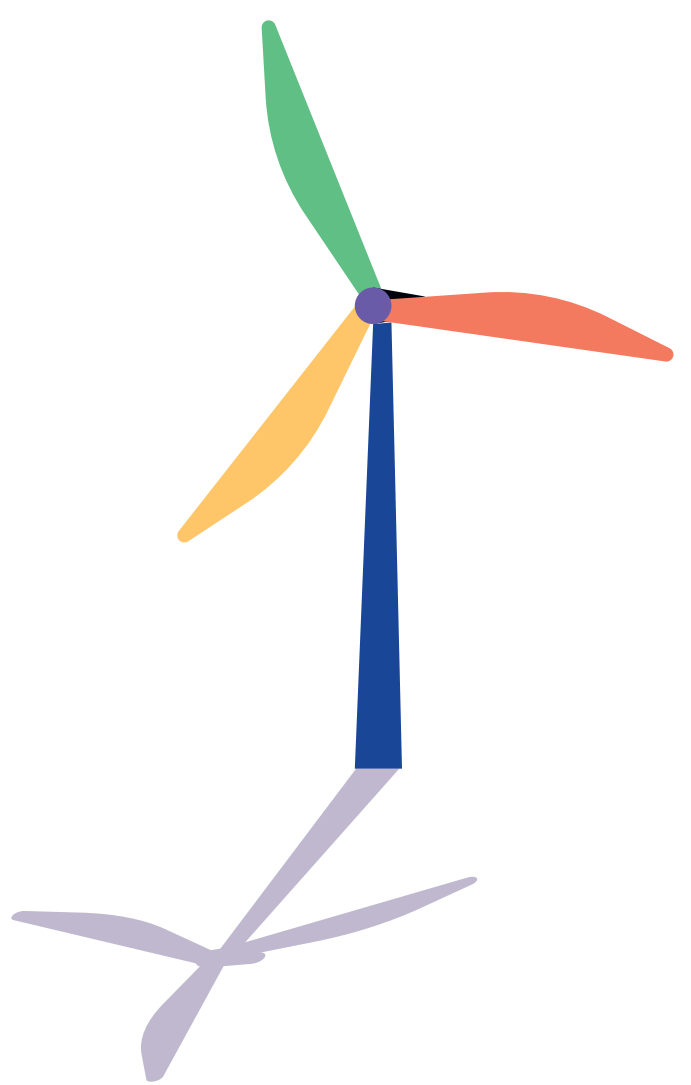


Table 3.1. Global total GHG emissions in 2030 under different scenarios (median and $10^{\text {th }}$ to $90^{\text {th }}$ percentile range), temperature implications, and the resulting emissions gap (based on the pre-COVID-19 current policies scenario)

\begin{tabular}{|c|c|c|c|c|c|c|c|c|c|}
\hline \multirow{2}{*}{$\begin{array}{l}\text { Scenario } \\
\text { (rounded to the } \\
\text { nearest gigaton) }\end{array}$} & \multirow{2}{*}{$\begin{array}{l}\text { Number } \\
\text { of scenarios } \\
\text { in set }\end{array}$} & \multirow{2}{*}{$\begin{array}{l}\text { Global total } \\
\text { emissions } \\
\text { in } 2030 \\
{\left[\mathrm{GtCO}_{2} \mathrm{e}\right]}\end{array}$} & \multicolumn{3}{|c|}{$\begin{array}{c}\text { Estimated } \\
\text { temperature outcomes }\end{array}$} & \multirow{2}{*}{$\begin{array}{l}\text { Closest } \\
\text { corresponding } \\
\text { IPCC SR1.5 } \\
\text { scenario class } \\
\end{array}$} & \multicolumn{3}{|c|}{$\begin{array}{l}\text { Emissions Gap in } 2030 \\
{\left[\mathrm{GtCO}_{2} \mathrm{e}\right]}\end{array}$} \\
\hline & & & $\begin{array}{c}50 \% \\
\text { probability }\end{array}$ & $\begin{array}{c}66 \% \\
\text { probability }\end{array}$ & $\begin{array}{c}90 \% \\
\text { probability }\end{array}$ & & $\begin{array}{l}\text { Below } \\
2.0^{\circ} \mathrm{C}\end{array}$ & $\begin{array}{l}\text { Below } \\
1.8^{\circ} \mathrm{C}\end{array}$ & $\begin{array}{c}\text { Below } \\
1.5^{\circ} \mathrm{C} \\
\text { in } 2100 \\
\end{array}$ \\
\hline 2010 policies & 6 & $64(60-68)$ & & & & & & & \\
\hline Current policies & 8 & $59(56-65)$ & & & & & $\begin{array}{c}17 \\
(15-22)\end{array}$ & $\begin{array}{c}24 \\
(21-28)\end{array}$ & $\begin{array}{c}34 \\
(31-39)\end{array}$ \\
\hline $\begin{array}{l}\text { Unconditional } \\
\text { NDCs }\end{array}$ & 11 & $56(54-60)$ & & & & & $\begin{array}{c}15 \\
(12-19)\end{array}$ & $\begin{array}{c}21 \\
(18-25)\end{array}$ & $\begin{array}{c}32 \\
(29-36)\end{array}$ \\
\hline $\begin{array}{l}\text { Conditional } \\
\text { NDCs }\end{array}$ & 12 & $53(51-56)$ & & & & & $\begin{array}{c}12 \\
(9-15)\end{array}$ & $\begin{array}{c}18 \\
(15-21)\end{array}$ & $\begin{array}{c}29 \\
(26-31)\end{array}$ \\
\hline $\begin{array}{l}\text { Below } 2.0^{\circ} \mathrm{C} \\
(66 \% \text { probability })\end{array}$ & 29 & $41(39-46)$ & $\begin{array}{l}\text { Peak: } \\
1.7-1.8^{\circ} \mathrm{C} \\
\text { In } 2100: \\
1.6-1.7^{\circ} \mathrm{C}\end{array}$ & $\begin{array}{c}\text { Peak: } \\
1.9-2.1^{\circ} \mathrm{C} \\
\text { In } 2100: \\
1.8-1.9^{\circ} \mathrm{C}\end{array}$ & $\begin{array}{c}\text { Peak: } \\
2.4-2.6^{\circ} \mathrm{C} \\
\text { In } 2100: \\
2.3-2.5^{\circ} \mathrm{C}\end{array}$ & $\begin{array}{c}\text { Higher } \\
2^{\circ} \mathrm{C} \text { pathways }\end{array}$ & & & \\
\hline $\begin{array}{l}\text { Below } 1.8^{\circ} \mathrm{C} \\
(66 \% \text { probability })\end{array}$ & 43 & $35(31-41)$ & $\begin{array}{l}\text { Peak: } \\
1.6-1.7^{\circ} \mathrm{C} \\
\text { In } 2100: \\
1.3-1.6^{\circ} \mathrm{C}\end{array}$ & $\begin{array}{c}\text { Peak: } \\
1.7-1.8^{\circ} \mathrm{C} \\
\text { In } 2100: \\
1.5-1.7^{\circ} \mathrm{C}\end{array}$ & $\begin{array}{c}\text { Peak: } \\
2.1-2.3^{\circ} \mathrm{C} \\
\text { In } 2100: \\
1.9-2.2^{\circ} \mathrm{C}\end{array}$ & $\begin{array}{c}\text { Lower } \\
2^{\circ} \mathrm{C} \text { pathways }\end{array}$ & & & \\
\hline $\begin{array}{l}\text { Below } 1.5^{\circ} \mathrm{C} \\
\text { in } 2100 \text { and } \\
\text { peak below } \\
1.7^{\circ} \mathrm{C} \text { (both with } \\
66 \% \text { probability) }\end{array}$ & 13 & $25(22-31)$ & $\begin{array}{l}\text { Peak: } \\
1.5-1.6^{\circ} \mathrm{C} \\
\text { In } 2100: \\
1.2-1.3^{\circ} \mathrm{C}\end{array}$ & $\begin{array}{c}\text { Peak: } \\
1.6-1.7^{\circ} \mathrm{C} \\
\text { In } 2100: \\
1.4-1.5^{\circ} \mathrm{C}\end{array}$ & $\begin{array}{c}\text { Peak: } \\
2.0-2.1^{\circ} \mathrm{C} \\
\text { In } 2100: \\
1.8-1.9^{\circ} \mathrm{C}\end{array}$ & $\begin{array}{c}1.5^{\circ} \mathrm{C} \text { with } \\
\text { no or limited } \\
\text { overshoot }\end{array}$ & & & \\
\hline
\end{tabular}

Note: The gap numbers and ranges are calculated based on the original numbers (without rounding), which may differ from the rounded numbers (third column) in the table. Numbers are rounded to full $\mathrm{GtCO}_{2} \mathrm{e}$. GHG emissions have been aggregated with 100 -year global warming potentials (GWP) values of the Intergovernmental Panel on Climate Change (IPCC) Fourth Assessment Report (AR4) (to be consistent with table 2.4 of the IPCC Special Report on Global Warming of $1.5^{\circ} \mathrm{C}$ (SR1.5), whereas the United Nations Environment Programme (UNEP) Emissions Gap Report 2018 used GWP values of the IPCC Second Assessment Report (SAR)). The NDC and current policies emissions projections are updated from the presented numbers in cross-chapter box 11 of the IPCC SR1.5 (Bertoldi et al. 2018), with new studies that were published after the IPCC literature cut-off date. Pathways were grouped in three categories depending on whether their maximum cumulative $\mathrm{CO}_{2}$ emissions were less than $600 \mathrm{GtCO}_{2}$, between 600 and $900 \mathrm{GtCO}$, or between 900 and 1,300 $\mathrm{GtCO}_{2}$, respectively, from 2018 onwards until net-zero $\mathrm{CO}_{2}$ emissions are reached, or until the end of the century if the net-zero point is not reached before. The estimated temperature outcomes represent estimates of global average surface air temperature (GSAT), most consistent with the impact assessment of the IPCC Fifth Assessment Report (AR5). Pathways assume limited action until 2020 and cost-optimal mitigation thereafter. Estimated temperature outcomes are based on the IPCC AR5 method (Meinshausen et al. 2011; Clarke et al. 2014). 
Figure 3.1. Global GHG emissions under different scenarios and the emissions gap in 2030 (median and $10^{\text {th }}$ to $90^{\text {th }}$ percentile range; based on the pre-COVID-19 current policies scenario)

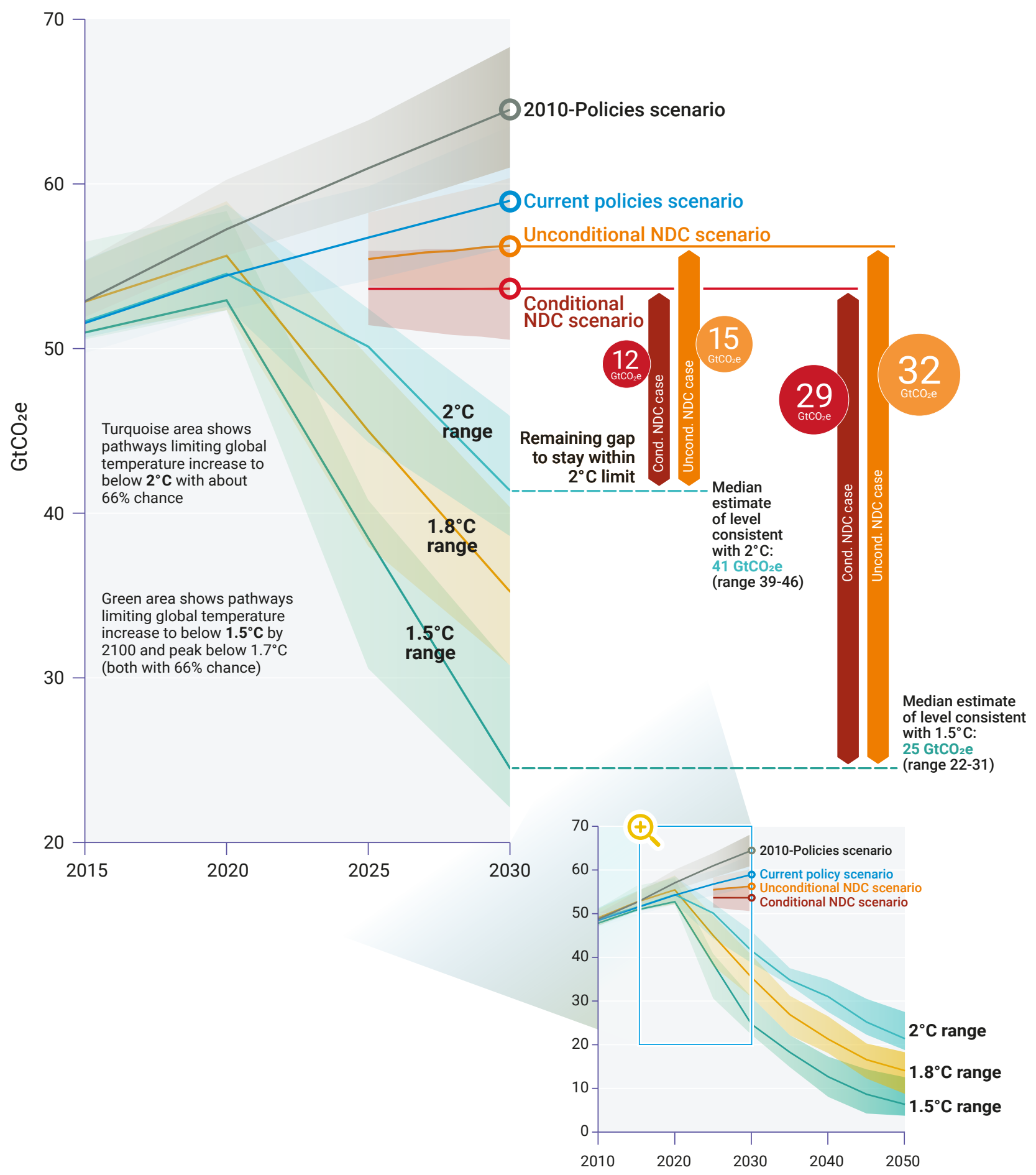

Note: This figure shows total $\mathrm{GHG}$ emissions. The inset shows how $1.5^{\circ} \mathrm{C}, 1.8^{\circ} \mathrm{C}$ and $2.0^{\circ} \mathrm{C}$ scenarios continue to 2050 . In contrast to $\mathrm{CO}_{2}$ emissions, total $\mathrm{GHG}$ emissions do not reach net zero by 2050 in the $1.5^{\circ} \mathrm{C}$ scenario, but about $10-20$ years later (table 2.4 in Rogelj et al. 2018 and section 3.5).

As figure 3.1 shows, the gap between the unconditional NDC scenario (56 $\mathrm{GtCO}_{2} \mathrm{e}$ in 2030) and least-cost pathways limiting warming to below $2^{\circ} \mathrm{C}$ in 2100 with limited overshoot (41 $\mathrm{GtCO}_{2} \mathrm{e}$ in 2030) is $15 \mathrm{GtCO}_{2} \mathrm{e}$ (range: $12-19 \mathrm{GtCO}_{2} \mathrm{e}$ ), whereas the gap between the unconditional NDCs scenario and least-cost pathways limiting warming to below $1.5^{\circ} \mathrm{C}$ in 2100 with limited overshoot $\left(25 \mathrm{GtCO}_{2} \mathrm{e}\right.$ in 2030) is $32 \mathrm{GtCO}_{2} \mathrm{e}$ (range: $29-36 \mathrm{GtCO}_{2} \mathrm{e}$ ). The full implementation of both unconditional and conditional NDCs would reduce each of these gaps by around $3 \mathrm{GtCO}_{2} \mathrm{e}$. 
The emissions gap is unchanged compared with 2019, meaning that countries need to strengthen their NDC ambitions dramatically, specifically threefold to achieve a $2^{\circ} \mathrm{C}$ goal and more than fivefold to achieve the $1.5^{\circ} \mathrm{C}$ goal.

There are two reasons why the gap has not changed. First, adjustments to the NDC scenarios have been very minor: as at November 2020, none of the major emitters had submitted new or updated NDCs with stronger NDC targets for 2030 Overall, any NDC target updates from 2019 are expected to reduce total 2030 emissions by less than 1 per cent (section 3.2.2). Second, no new $1.5^{\circ} \mathrm{C}, 1.8^{\circ} \mathrm{C}$ and $2.0^{\circ} \mathrm{C}$ scenarios have been added to the assessment since 2019 .

Furthermore, the 2020 gap assessment is unaffected by the COVID-19 pandemic. As noted in figure 3.1, this gap assessment is still based on scenarios that do not specifically consider the implications of COVID-19 and related rescue and recovery measures. COVID-19 will only affect the gap assessment if the NDC scenarios and/or the $1.5^{\circ} \mathrm{C}, 1.8^{\circ} \mathrm{C}$ and $2.0^{\circ} \mathrm{C}$ long-term scenarios are affected. In turn, NDC estimates will only be affected by COVID-19 and related measures if NDCs are updated in response to the pandemic or if projections of NDC emissions from countries with intensity targets are revised. At present, there are no studies available that quantify this, but at the global scale it is expected to be only a second-order effect. Similarly, COVID-19 and associated rescue and recovery measures will only affect long-term pathways to keep global warming to $1.5^{\circ} \mathrm{C}$ or well below $2^{\circ} \mathrm{C}$ if they result in a structural shift of the economy. Although COVID-19 lockdown measures have resulted in a sharp temporary decline in global fossil fuel carbon dioxide $\left(\mathrm{CO}_{2}\right)$ emissions in 2020 (see chapter 2), there is currently no firm scientific evidence to confirm a structural shift of the economy towards higher or lower emissions in the long term. The gap assessment between NDCs and least-cost pathways thus remains unaffected by the COVID-19 pandemic, although current policy projections could be impacted (section 3.3).

\subsection{Scenarios considered for the 2030 gap assessment}

This section updates the scenarios considered for the 2030 emissions gap assessment. These scenarios comprise reference scenarios, NDC scenarios and least-cost mitigation scenarios starting in 2020 and consistent with specific temperature targets.

\subsubsection{Reference scenarios and updates}

Reference scenarios are used as benchmarks to track progress in emission reductions. Two reference scenarios are considered: the 2010 policies scenario and the current policies scenario.

The 2010 policies scenario projects global GHG emissions assuming no new climate policies have been put in place from 2010 onwards. Similar to the Emissions Gap Report
2019, the data for this scenario are based on the baseline projections of Shared Socioeconomic Pathway (SSP2: middle of the road) scenarios from six modelling studies that also underpin the current policies scenario projections as of 2019 (the CD-LINKS Scenario Database, version 1.0) (McCollum et al. 2018; Roelfsema et al. 2020). This scenario database has not changed for SSP2 compared with 2019.

The current policies scenario projects global GHG emissions assuming all currently adopted and implemented policies (defined as legislative decisions, executive orders, or equivalent) are realized and that no additional measures are undertaken. The data for this scenario are updated and based on the current policies projections (cut-off year for policies: 2019) of the Climate Action Tracker (2019), International Energy Agency (IEA 2019) World Energy Outlook 2019, Joint Research Centre (Prospective Outlook on Long-term Energy Systems (POLES) model) (Keramidas et al. 2020), and PBL Netherlands Environmental Assessment Agency (Integrated Model to Assess the Global Environment (IMAGE)) (den Elzen et al. 2019; Kuramochi et al. 2019; PBL 2020). Four international modelling groups that were also included in the 2019 report provided updated projections in Roelfsema et al. (2020): the International Institute for Applied Systems Analysis (IIASA, using the MESSAGE-GLOBIOM model) (Fricko et al. 2017); the National Institute for Environmental Studies (NIES, using the AIM model) (Fujimori et al. 2017); the Potsdam Institute for Climate Impact Research (PIK, using the REMIND-MAgPIE model) (Luderer et al. 2015); Resources for the Future Euro-Mediterranean Center on Climate Change (RFF-CMCC) European Institute on Economics and the Environment (using the World Induced Technical Change Hybrid (WITCH) model) (Emmerling et al. 2016). One additional modelling group was also included from Roelfsema et al., the Computable Framework for Energy and the Environment (COFFEE) model of the Graduate School of Engineering (COPPE) of Universidade Federal do Rio de Janeiro (Rochedo et al. 2018). It should be noted that the latter five current policy projections from Roelfsema et al. (2020) originally use 31 December 2016 as their cut-off date for current policies. Post-2016 policies, rollback of policies since 2017 , or planned policies to be implemented are not included. Policies are also assumed to be realized (Roelfsema et al. 2020). To ensure comparability, these latter five current policy projections have been adjusted to reflect changes to 2019. The influence of moving the policy cut-off date from 2016 to 2019 was analysed by comparing the results of the four modelling studies that provide estimates for both cut-off dates (United Nations Environment Programme [UNEP] 2017), which gave an estimated reduction of $1.5 \mathrm{GtCO}_{2} \mathrm{e}$ (range: -0.4 to -3.0). The emissions projections of the last five modelling studies are adjusted accordingly to reflect the best estimate of the most recent current policies. Overall, this only has a small impact on the globally aggregated emissions projections for which the uncertainty ranges are large. The median estimate of global GHG emissions by 2030 for the current policies scenario is $59 \mathrm{GtCO}_{2} \mathrm{e}$ (range: $56-65 \mathrm{GtCO}_{2} \mathrm{e}$ ) (for comparison, 2019 emissions were $\left.54 \mathrm{GtCO}_{2} \mathrm{e}\right)$, which is 
$1 \mathrm{GtCO}_{2} \mathrm{e}$ lower than the median estimate of the Emissions Gap Report 2019 of $60 \mathrm{GtCO}_{2} \mathrm{e}$ (range: $58-64 \mathrm{GtCO}_{2} \mathrm{e}$ ). The change in projections varies across model studies, ranging from -0.5 to $-3 \mathrm{GtCO}_{2} \mathrm{e}$.
The current policies scenario does not take implications of COVID-19 and related rescue and recovery measures into account. These are explored in section 3.4 .

\section{Box 3.1. Comparing emission estimates across chapters}

The historical estimates in chapter 2 are independent and should not be directly compared to the estimates in chapter 3. Under the current policies scenario used to assess the emissions gap, global 2019 GHG emissions are estimated to be about $53.6 \mathrm{GtCO}_{2} \mathrm{e}$, which is lower than the 2019 estimate of $59.1 \mathrm{GtCO}_{2} \mathrm{e}$ reported in chapter 2. The estimate provided in chapter 2 is derived from land-use change (LUC) emissions of $6.8 \mathrm{GtCO}_{2} \mathrm{e}$, which differs to LUC emissions of $3.8 \mathrm{GtCO}_{2} \mathrm{e}$ as calculated by most models used in chapter 3 (similar to Houghton and Nassikas 2017). The difference to be considered is therefore $56.7 \mathrm{GtCO}_{2} \mathrm{e}$ against $53.6 \mathrm{GtCO}_{2} \mathrm{e}$, which is relatively small and well within the certainty range of the emissions estimates. Both estimates show a similar increase of around 12 per cent compared with 2010 levels. There could be multiple reasons why the median emissions projections of the models (used in chapter 3 ) are lower than the independent historical emission estimates (used in chapter 2). For example, models may be calibrated to an earlier database (in contrast to the yearly updates of historical data), calibrations may be based on other emissions databases (such as IEA, PRIMAP or earlier versions of EDGAR), or models may not include all emission sources. The nine global models used for the current policies scenario cover a wide range of global GHG emissions for 2010 (47-50 $\mathrm{GtCO}_{2} \mathrm{e}$ ), whereas the historical emissions database has an estimate of $50 \mathrm{GtCO}_{2} \mathrm{e}$.

\subsubsection{NDC scenarios and updates}

The NDC scenarios estimate the levels of GHG emissions projected as a result of the implementation of the mitigation actions pledged by countries in their NDCs. In line with previous Emissions Gap Reports, two NDC scenarios are considered: the unconditional and conditional NDC scenarios. The NDC scenarios of the 2020 report are based on the same data sources as the current policies scenario and are provided by the same 10 modelling groups as cited above, with updates for the Joint Research Centre, PBL and the Climate Action Tracker. PBL and the Climate Action Tracker have also analysed the impact of NDC target updates on global emissions by 2030 (last update 20 September 2020), which is estimated to be limited, resulting in reductions in total emissions by 2030 of less than 1 per cent compared with NDC scenarios without target updates reported since the Emissions Gap Report 2019.

The effect of the COVID-19 pandemic on projected emissions under the NDC scenarios is limited so far, as NDC targets of major emitting countries, such as the G20 economies, have not changed at this point. For countries, whose reduction targets are defined per unit of gross domestic product (GDP), in particular China and India with intensity targets, the pandemic may likely affect the NDC emissions projections due to its impact on GDP growth, though information at this level is not yet available.

\subsubsection{Mitigation scenarios consistent with the Paris Agreement}

GHG emissions by 2030 that are consistent with a leastcost pathway towards limiting global warming below $2^{\circ} \mathrm{C}$, $1.8^{\circ} \mathrm{C}$ and $1.5^{\circ} \mathrm{C}$ are estimated in the same way as for the 2019 report and calculated from the scenarios underlying the IPCC Special Report on Global Warming of $1.5^{\circ} \mathrm{C}$ (SR1.5) (Huppmann et al. 2018a; Huppmann et al. 2018b; Rogelj et al. 2018). Maximum cumulative $\mathrm{CO}_{2}$ emissions from 2018 onwards are used to classify scenario groups, which is consistent with the approach of the IPCC SR1.5, which groups scenarios based on their maximum temperature outcome (Intergovernmental Panel on Climate Change [IPCC] 2018; Rogelj et al. 2018). This approach enables a close mapping of scenarios to the maximum temperature increase they would cause and thus informs various possible interpretations of the Paris Agreement long-term temperature goal (United Nations Framework Convention on Climate Change [UNFCCC] 2015; Schleussner et al. 2016). A comparison with the IPCC SR1.5 approach is provided in box 3.2

The three temperature scenario groups represent various degrees of ambition that range from limiting warming to around $2^{\circ} \mathrm{C}$, to interpretations of limiting warming to well below $2^{\circ} \mathrm{C}$, to pursuing to limit warming to $1.5^{\circ} \mathrm{C}$ (see table 3.1). Each scenario considers a least-cost climate change mitigation pathway that starts long-term reductions from 2020. 


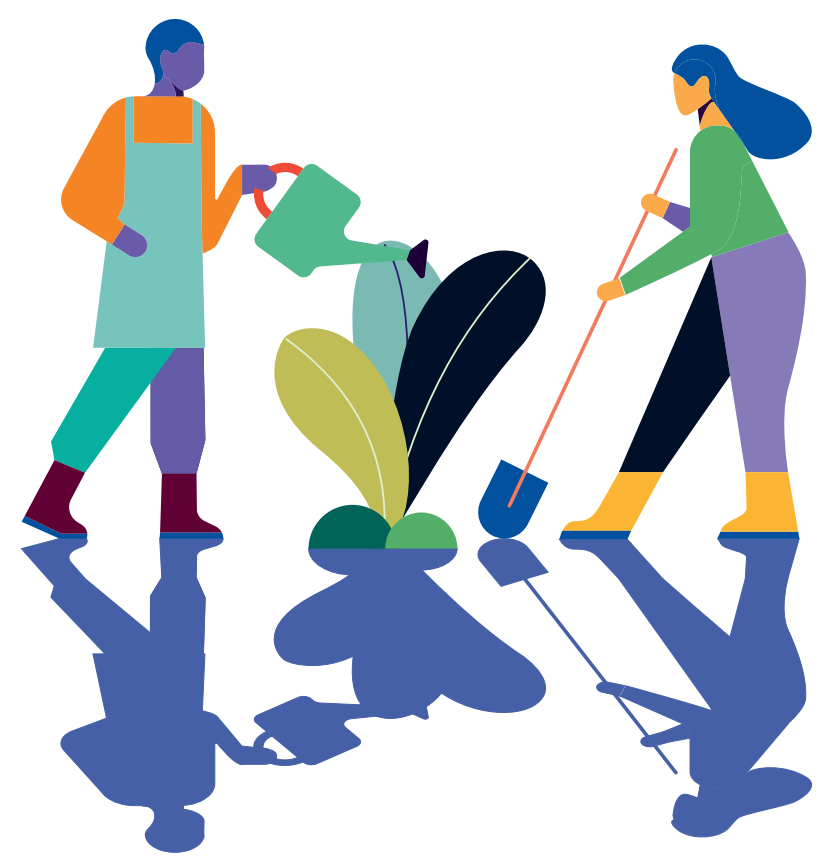

Below $20^{\circ} \mathrm{C}$ scenario: This scenario limits maximum cumulative $\mathrm{CO}_{2}$ emissions from 2018 until the time net-zero $\mathrm{CO}_{2}$ emissions are reached (or until 2100 if net-zero emissions are not reached before) ${ }^{1}$ to between 900 and 1,300 $\mathrm{GtCO}_{2}$, and cumulative 2018-2100 emissions to at most $1,200 \mathrm{GtCO}_{2}$, when net negative $\mathrm{CO}_{2}$ emissions in the second half of the century are included. It is consistent with limiting warming below $2.0^{\circ} \mathrm{C}$ with about 66 per cent probability, both at the time of peak global warming and at the end of the century. The median estimate of $2030 \mathrm{GHG}$ emissions for this scenario is $41 \mathrm{GtCO}_{2} \mathrm{e}$, which falls in the middle of the $36-45 \mathrm{GtCO}_{2} \mathrm{e}$ range estimated for the lower $2^{\circ} \mathrm{C}$ scenario category of the IPCC SR1.5 (see table 2.4 in Rogelj et al. 2018).

- Below $1.8^{\circ} \mathrm{C}$ scenario: This scenario limits maximum cumulative $\mathrm{CO}_{2}$ emissions from 2018 until the time net-zero $\mathrm{CO}_{2}$ emissions are reached (or until 2100 if net-zero emissions are not reached before) to between 600 and $900 \mathrm{GtCO}_{2}$, and cumulative 20182100 emissions to at most $900 \mathrm{GtCO}_{2}$. It is consistent with limiting warming over the course and at the end of the century to below $1.8^{\circ} \mathrm{C}$ with about 66 per cent or greater probability. The median estimate of 2030 emissions for this scenario is $35 \mathrm{GtCO}_{2} \mathrm{e}$. This scenario is included to provide more granular information on how emissions reduction requirements for 2030 change with gradually increasing stringency of global mitigation action.

Below $1.5^{\circ} \mathrm{C}$ in 2100 scenario: This scenario limits maximum cumulative $\mathrm{CO}_{2}$ emissions from 2018 until the time net-zero $\mathrm{CO}_{2}$ emissions are reached (or until 2100 if net-zero emissions are not reached before) to $600 \mathrm{GtCO}_{2}$, and cumulative 2018-2100 to at most 380 $\mathrm{GtCO}_{2}$, when net negative $\mathrm{CO}_{2}$ emissions in the second half of the century are included. ${ }^{2}$ It is consistent with limiting global warming to below $1.5^{\circ} \mathrm{C}$ in 2100 with about 66 per cent probability, while limiting peak global warming during the twenty-first century to about $1.6-1.7^{\circ} \mathrm{C}$ with about 66 per cent or greater probability. This class of scenarios is consistent with the scenarios in IPCC SR $1.5^{\circ} \mathrm{C}$ that limit warming to $1.5^{\circ} \mathrm{C}$ with no or limited overshoot (explained in box 3.2; see also characteristics in table 3.1). The median estimate of 2030 emissions of $25 \mathrm{GtCO}_{2} \mathrm{e}$ falls well within the range of $22-28 \mathrm{GtCO}_{2} \mathrm{e}$ of the IPCC SR1.5 $1.5^{\circ} \mathrm{C}$ scenarios with no or limited overshoot (see table 2.4 in Rogelj et al. 2018).

1 Potential net negative emissions that some scenarios achieve in the second half of the century are not counted towards the maximum cumulative $\mathrm{CO}_{2}$ emissions used here. If a scenario does not achieve net-zero $\mathrm{CO}_{2}$ emissions before 2100 but still limits warming to below a specific temperature threshold, it is assumed that global $\mathrm{CO}_{2}$ emissions reach net zero immediately or shortly after 2100.

2 The $380 \mathrm{GtCO}_{2}$ value represents the highest value of cumulative $\mathrm{CO}_{2}$ emissions over the $2018-2100$ period found in the scenarios available for this report's analysis. In theory, a $420 \mathrm{GtCO}_{2}$ cut-off would suffice for a scenario to be included in this category based on the IPCC SR1.5 (Rogelj et al. 2018). 
Box 3.2. Technical comparison with the IPCC Special Report on Global Warming of $1.5^{\circ} \mathrm{C}$

The analysis included in this chapter is consistent with the latest assessment of the IPCC SR1.5 (2018). The range of Kyoto- $\mathrm{GHG}$ emissions in 2030 consistent with limiting warming to $1.5^{\circ} \mathrm{C}$ used in this report $\left(24 \mathrm{GtCO}_{2} \mathrm{e} /\right.$ year with a range of $22-30 \mathrm{GtCO}_{2} \mathrm{e} /$ year) closely matches the 25-30 $\mathrm{GtCO}_{2} \mathrm{e} /$ year range reported in IPCC SR1.5 (2018) for scenarios limiting global warming to $1.5^{\circ} \mathrm{C}$ with no or limited overshoot. Differences are attributed to the exclusive use of scenarios that start emissions reductions from 2020 onwards in this report, compared with the wider set used in IPCC SR1.5. Overall, these minor changes do not affect the assessment of the adequacy of current NDCs for limiting warming to $1.5^{\circ} \mathrm{C}$ or well below $2^{\circ} \mathrm{C}$.

Cumulative $\mathrm{CO}_{2}$ emissions from 2018 onward never exceed $600 \mathrm{GtCO}_{2}$ in the below $1.5^{\circ} \mathrm{C}$ by 2100 scenario. This broadly corresponds to the remaining carbon budget for limiting warming to $1.5^{\circ} \mathrm{C}$ with 50 per cent probability $\left(580 \mathrm{GtCO}_{2}\right.$ from 2018 until net-zero emissions are reached) of IPCC SR1.5, suggesting that temperature overshoot is limited to less than $0.1^{\circ} \mathrm{C}$ with 50 per cent probability, and to $1.6-1.7^{\circ} \mathrm{C}$ with 66 per cent probability. Cumulative $\mathrm{CO}_{2}$ emissions from 2018 until the end of the century are at most 380 $\mathrm{GtCO}_{2}$ in the available scenarios, which is less than the IPCC SR1. 5 remaining carbon budget of $420 \mathrm{GtCO}_{2}$ for limiting warming to $1.5^{\circ} \mathrm{C}$ with 66 per cent probability. Cumulative $\mathrm{CO}_{2}$ emissions from 2018 onward never exceed $900 \mathrm{GtCO}_{2}$ in the below $1.8^{\circ} \mathrm{C}$ scenario. Using the IPCC SR1.5 assessment, this $900 \mathrm{GtCO}_{2}$ equates to a 66 per cent probability of limiting warming to about $1.8^{\circ} \mathrm{C}$, and also corresponds to about a 50 per cent probability of limiting warming to $1.7^{\circ} \mathrm{C}$. For the below $2^{\circ} \mathrm{C}$ scenario, maximum cumulative $\mathrm{CO}_{2}$ emissions from 2018 never exceed 1,300 $\mathrm{GtCO}_{2}$ and from 2018 to 2100 are $1,200 \mathrm{GtCO}_{2}$ when accounting for net negative emissions in the second half of the century. Using the IPCC SR1.5 assessment, this $1,200 \mathrm{GtCO}_{2}$ equates to limiting warming to below $2^{\circ} \mathrm{C}$ with at least 66 per cent probability by 2100 , though there is a slightly lower probability at peak warming during the century. This suggest that the probability of limiting warming to $1.9^{\circ} \mathrm{C}$ is about 50 per cent.

Source: Adapted based on box 3.2 of the Emissions Gap Report 2018 (Luderer et al. 2018)

\subsection{Implications of the COVID-19 pandemic and associated rescue and recovery measures on GHG emissions by 2030}

The COVID-19 pandemic and associated rescue and recovery measures impact global GHG emissions. This section analyses how they impact current policy projections under different assumptions. Due to the high uncertainty surrounding how the pandemic will develop and impact $\mathrm{CO}_{2}$ emissions in particular, only explorative calculations are presented. As indicated in chapter 2, 2020 global $\mathrm{CO}_{2}$ emissions may drop 7 per cent (range: 2-12 per cent) below 2019 levels depending on how national epidemics and lockdowns develop over time. Almost all the emissions reductions are due to a temporary drop in activity resulting from lockdown measures, which include, for example, the transport sector, with people requested to stay home and halt travelling, as well as economic activity. Since these emissions reductions are not the result of structural changes, they may quickly reverse once lockdown measures are lifted (Forster et al. 2020; Le Quéré et al. 2020). This means that a pronounced short-term dip in energy- and industry-related $\mathrm{CO}_{2}$ emissions is anticipated, after which emissions may follow the pre-2020 growth trend.

Implications of the COVID-19 pandemic and associated rescue and recovery measures on 2030 emissions and global emissions pathways towards meeting the temperature goals of the Paris Agreement were assessed in a recent study (Dafnomilis et al. 2020), which presents 'what if' scenarios based on explorative calculations and using sources available before June 2020. This methodology is used here, with some adjustments made to the GDP data. Using the short-term GDP projections of the Organisation for Economic Co-operation and Development (OECD) single-hit and second-hit scenarios for 2020 and $2021^{3}$ (Organisation for Economic Co-operation and Development [OECD] 2020a; OECD 2020b), two post-COVID-19 economic growth scenarios are calculated. These economic projections are combined with two scenarios for future decarbonization rates (i.e. change in fossil $\mathrm{CO}_{2}$ emissions per unit of GDP): one based on the pre-COVID-19 current policies scenario from the original model studies (labelled current trends), and one based on a post-COVID-19 scenario with lower decarbonization rates due to the rollback of current policies in countries (see chapter 2) and possible delays in climate

3 The projected GDP growth rates for 2020 and 2021 are -6 per cent and 5.2 per cent in the OECD single-hit scenario and -7.6 per cent and 2.8 per cent in the OECD second-hit scenario. 
policy implementation (labelled rebound to fossil fuels) The rationale behind the second scenario is that several countries have announced emissions-intensive policies to stimulate economic recovery, therefore putting climate policies at risk of being rolled back (Climate Action Tracker 2020a; Miosio et al. 2020; Vivid Economics 2020). This impact is quantified by applying a decarbonization rate that is 50 per cent lower than the rate of the original model study for 2021-2024 (Dafnomilis et al. 2020).

The total energy and industry $\mathrm{CO}_{2}$ emissions for 2021-2024 are calculated using a Kaya decomposition (Kaya 1990). For 2025-2030, fossil $\mathrm{CO}_{2}$ emissions follow the same growth trend as suggested by the original model projections. The non- $\mathrm{CO}_{2} \mathrm{GHG}$ emissions and $\mathrm{CO}_{2}$ land-use-related emissions for 2020-2030 are identical to the original pre-COVID-19 projections. However, preliminary data suggest that there may be an expansion of farming and livestock activities due to COVID-19-related consumption changes and market disruptions (Food and Agriculture Organization of the United Nations [FAO] 2020), which could lead to increased methane $\left(\mathrm{CH}_{4}\right)$ and nitrous oxide $\left(\mathrm{N}_{2} \mathrm{O}\right)$ emissions. Deforestation rates in South American and Asian regions are also expected to increase due to a lack of regulatory measures, limited budgets and weak enforcement of adopted legislation to protect native ecosystems (Amador-Jimenez et al. 2020; Azevedo 2020; López-Feldman et al. 2020; Rondeau et al. 2020).

Figure 3.2. Global total GHG emissions by 2030 under the original current policies scenario based on pre-COVID-19 studies and various 'what if' scenarios using explorative calculations (post-COVID-19) (median and 10 to to $90^{\text {th }}$ percentile range)

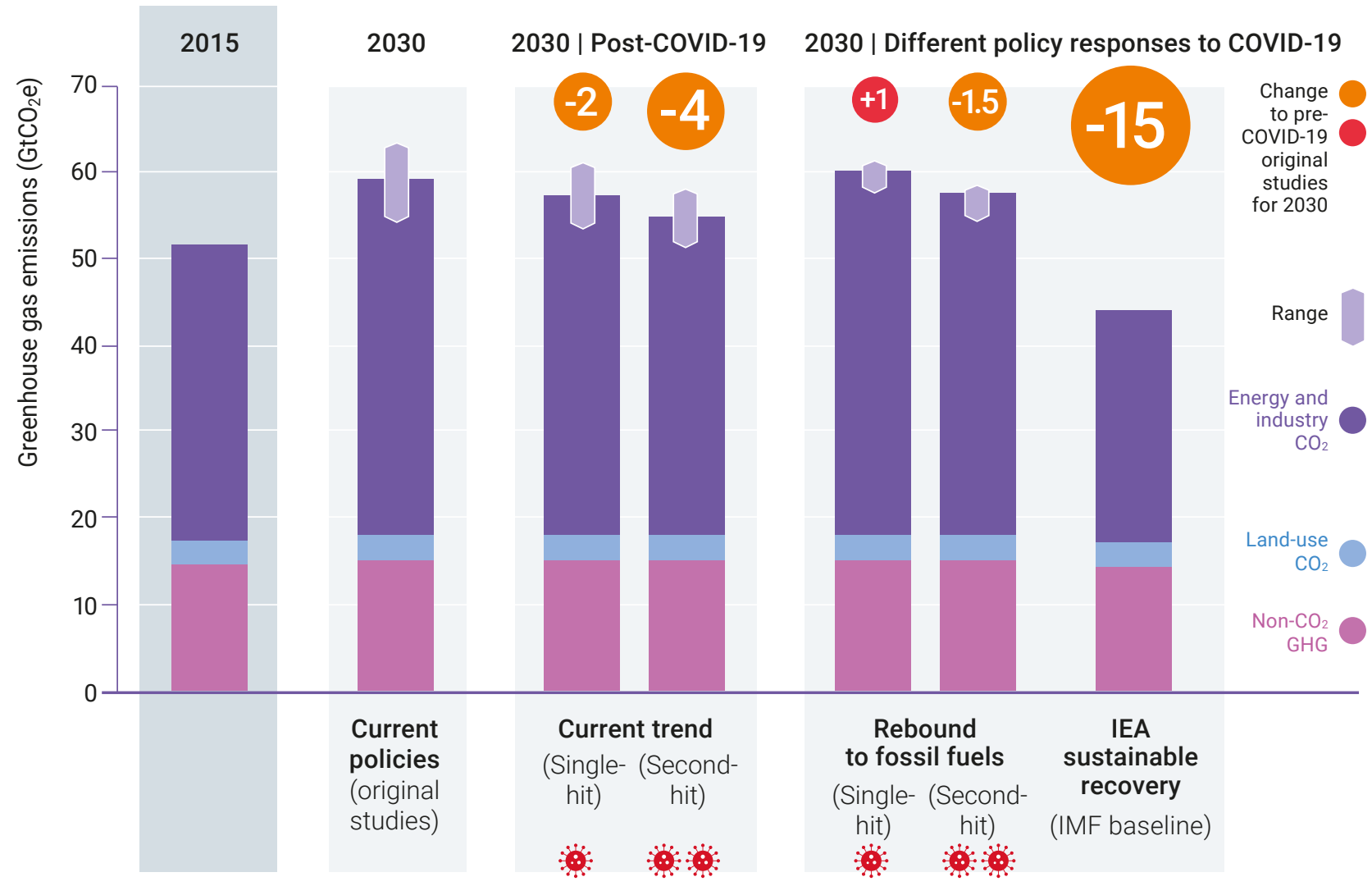

Figure 3.2 shows projected GHG emissions by 2030 under each of these scenarios. The impact of the general slowdown of the economy due to the COVID-19 pandemic and its associated policy responses (figure 3.2 - current trend) would lead to a reduction in global GHG emissions by 2030 of about 2-4 $\mathbf{G t C O}_{2} \mathbf{e}$ (equivalent to 3-7 per cent) compared with the pre-COVID-19 estimates for OECD's single-hit and second-hit scenarios. This assumes a pronounced short- term dip in $\mathrm{CO}_{2}$ emissions, after which emissions follow pre-2020 growth trends. The Climate Action Tracker (2020a) finds a similar difference of about $2-4 \mathrm{GtCO}_{2} \mathrm{e}$ between the post- and pre-COVID-19 current policies projections by 2030. Comparing the IEA's World Energy Outlook 2020 (IEA 2020b) post-COVID-19 global energy and industry $\mathrm{CO}_{2}$ emissions projections for their stated policies scenario ${ }^{4}$ (estimates published in 2019) suggests a similar difference

4 No directly comparable figures could be obtained for the IEA World Energy Outlook 2020 (2020c) because the 2020 edition does not provide current policies scenario projections. The following are used instead: i) the stated policies scenario, in which COVID-19 is gradually brought under control and the global economy return to pre-crisis levels the same year (this scenario reflects all current announced policy intentions and targets); ii) the delayed recovery scenario, which is designed with the same policy assumptions as the stated policies scenario, but shows lasting damage to economic prospects following a prolonged pandemic (IEA 2020c). 
of about 1.5-4 $\mathrm{GtCO}_{2} \mathrm{e}$ between the post- and pre-COVID-19 stated policies projections by 2030 .

If the initial short-term dip in $\mathrm{CO}_{2}$ emissions is followed by growth trends with lower decarbonization rates due to countries' potential rollback of climate policies as part of COVID-19 responses, the decrease in global emissions by 2030 is projected to be significantly smaller at around $\mathbf{1 . 5} \mathbf{G t C O}_{2} \mathbf{e}$ (instead of $4 \mathrm{GtCO}_{2} \mathrm{e}$ ) and may actually increase by around $\mathbf{1} \mathbf{G t C O}_{2} \mathbf{e}$ (instead of $-2 \mathrm{GtCO}_{2} \mathrm{e}$ ) (figure 3.2 rebound to fossil fuels second-hit and single-hit scenarios, respectively) compared with the pre-COVID-19 current policies scenario.

Around the world, countries are launching economic rescue and recovery measures to cushion the impacts of the COVID-19 pandemic. Future global GHG emissions depend critically on the extent to which recovery measures are green (low carbon), which at present is difficult to evaluate comprehensively (see chapter 4). At the global level, the impact of 'green recovery' responses can be estimated based on the IEA's (2020a) Sustainable Recovery Plan and its associated global energy and industry $\mathrm{CO}_{2}$ emissions projections under the IEA (2020b) sustainable recovery scenario. For the $\mathrm{GHG}$ emissions projections in figure 3.2, the IEA's energy and industry $\mathrm{CO}_{2}$ emissions were supplemented with land-use $\mathrm{CO}_{2}$ and non- $\mathrm{CO}_{2}$ emissions projections under current policies of the model studies underlying the original current policies scenario. The emissions projections in figure 3.2 also adopted the IEA's (2020b) assumption of a $0.8 \mathrm{GtCO}_{2} \mathrm{e}$ emissions reduction following investments to tackle $\mathrm{CH}_{4}$ leakages from oil and gas operations by 2024, and kept this reduction constant to 2030. Figure 3.2 shows that 2030 emissions are only projected to be significantly reduced if COVID-19 economic recovery is used as an opportunity to pursue strong decarbonization. The sustainable recovery scenario results in global GHG emissions of $44 \mathrm{GtCO}_{2} \mathrm{e}$ by 2030, which is a reduction of $\mathbf{1 5} \mathbf{G t C O}_{2} \mathbf{e}$ (just over 25 per cent) compared with the original current policies scenario used for the emissions gap assessment, and would bring 2030 emissions within the range consistent with least-cost pathways that limit global warming to below $2^{\circ} \mathrm{C}$ (table 3.1). More dedicated attention would be required to reach levels consistent with limiting global warming to below $1.8^{\circ} \mathrm{C}$ or $1.5^{\circ} \mathrm{C}$.

As noted in the beginning of this section, the emissions projections for the post-COVID-19 policy scenarios are highly indicative. They are based on simple calculations compared to the model-based pre-COVID projections and are driven by a wide range of GDP estimates for 2020 and 2021 from the OECD single-hit and second-hit scenarios published in June 2020 (OECD 2020a; OECD 2020b). The more recent GDP estimates of the IMF (2020) (June) and the OECD (2020c) Economic Outlook (September) are both within the projected GDP range of the OECD June estimates. Applying the more recent GDP estimates would result in GHG emissions projections for 2030 that are closer to those of the current trends scenario (figure 3.2 - single- hit). It should be noted that the post-COVID-19 projections do not yet include information based on announcements of specific economic recovery measures (Miosio et al. 2020; Vivid Economics 2020). GHG emissions projections greatly depend on the starting point of calculations, in this case, the impact of COVID-19 on $2020 \mathrm{CO}_{2}$ emissions, and are therefore likely to change in the coming months as the pandemic evolves and a vaccine becomes available worldwide. At present, it is unclear how temporary changes in international trade, consumption and mobility in urban areas will evolve in the medium term. Once countries lift lockdown measures, patterns are expected to return to preCOVID-19 levels. Similarly, it is uncertain how oil market prices will evolve and how oil exporters and producers will adapt to price changes of fossil resources. The projections reported in this chapter are therefore highly preliminary and primarily provide an indication of the magnitude of the direct effect of COVID-19 and related measures.

\subsection{Implications of the emissions gap for the feasibility of achieving the long- term temperature goal of the Paris Agreement}

The previous sections clearly show that current NDCs remain insufficient to bridge the emissions gap by 2030 and that the size of the gap is as large as the 2019 assessment's estimate. They also indicate that emissions continue to rise under the (pre-COVID-19) current policies scenario and that COVID-19 is only likely to significantly reduce total GHG emissions by 2030 if used as an opening for economic recovery that fosters strong decarbonization. This section examines the implications of inadequate and delayed shortterm action in achieving the long-term temperature goals of the Paris Agreement.

\subsubsection{Implications of postponing action in the context of long-term zero emissions goals}

Achieving the long-term temperature goals of the Paris Agreement to limit global warming to well below $2^{\circ} \mathrm{C}$ and pursue $1.5^{\circ} \mathrm{C}$ depends strongly on implementing mitigation action by 2030 . Taking a longer-term perspective illustrates how the low-carbon transition challenge until 2050 depends critically on this near-term action.

The Paris Agreement aims to reach net-zero GHG emissions in the second half of this century, which means that any remaining $\mathrm{CO}_{2}$ and non- $\mathrm{CO}_{2}$ emissions are balanced with net $\mathrm{CO}_{2}$ removal or negative emissions. When calculated using the 100-year global warming potentials (GWPs) typically applied by the United Nations Framework Convention on Climate Change (UNFCCC) to compare different GHGs, global warming will peak and then gradually decline thereafter. The timing of global net-zero $\mathrm{CO}_{2}$ and $\mathrm{GHG}$ emissions provides milestones for pathways that are consistent with the Paris Agreement and can be estimated from long-term emissions scenarios. According to the IPCC SR1.5, limiting warming to $1.5^{\circ} \mathrm{C}$ with no or limited overshoot requires global $\mathrm{CO}_{2}$ 
and GHG emissions to reach net zero around 2050 (range: 2046-2055) and 2067 (range: 2061-2084), respectively. For temperature limits higher than $1.5^{\circ} \mathrm{C}$, the timing would be later (see table 2.4 in Rogelj et al. 2018). It should be noted that these net-zero target years are for the global pathways and therefore need to be achieved collectively. Setting netzero targets for individual countries involves considerations of equity and fairness, which means that national net-zero targets do not necessarily have to coincide with the net-zero years and global pathways.

Previous Emissions Gap Reports have highlighted the key implications of postponing mitigation action and failing to bridge the 2030 emissions gap (Luderer et al. 2018), which are summarized in figure 3.3. Furthermore, the implications of postponed action are apparent when looking across the Emissions Gap Reports produced to date (UNEP
2019; Höhne et al. 2020). The global average emissions reductions required per year to meet 2030 emission levels that are consistent with the $2^{\circ} \mathrm{C}$ and $1.5^{\circ} \mathrm{C}$ scenarios are by now approximately quadruple and more than double, respectively, what they would have been had serious collective climate action started in 2010 . This remarkable increase in annual emission reduction rates due to the lack of sufficient action add significantly to the challenge of meeting the Paris Agreement.

The conclusion is clear: postponing ambitious climate action, thereby delaying the path towards reaching netzero emissions, will make it impossible to achieve the Paris Agreement temperature goal of limiting global warming to $1.5^{\circ} \mathrm{C}$. Greater climate action is therefore needed by 2030 to make reducing global $\mathrm{GHG}$ emissions to levels consistent with $1.5^{\circ} \mathrm{C}$ pathways feasible.

Figure 3.3. Long-term implications of not closing the emissions gap by 2030

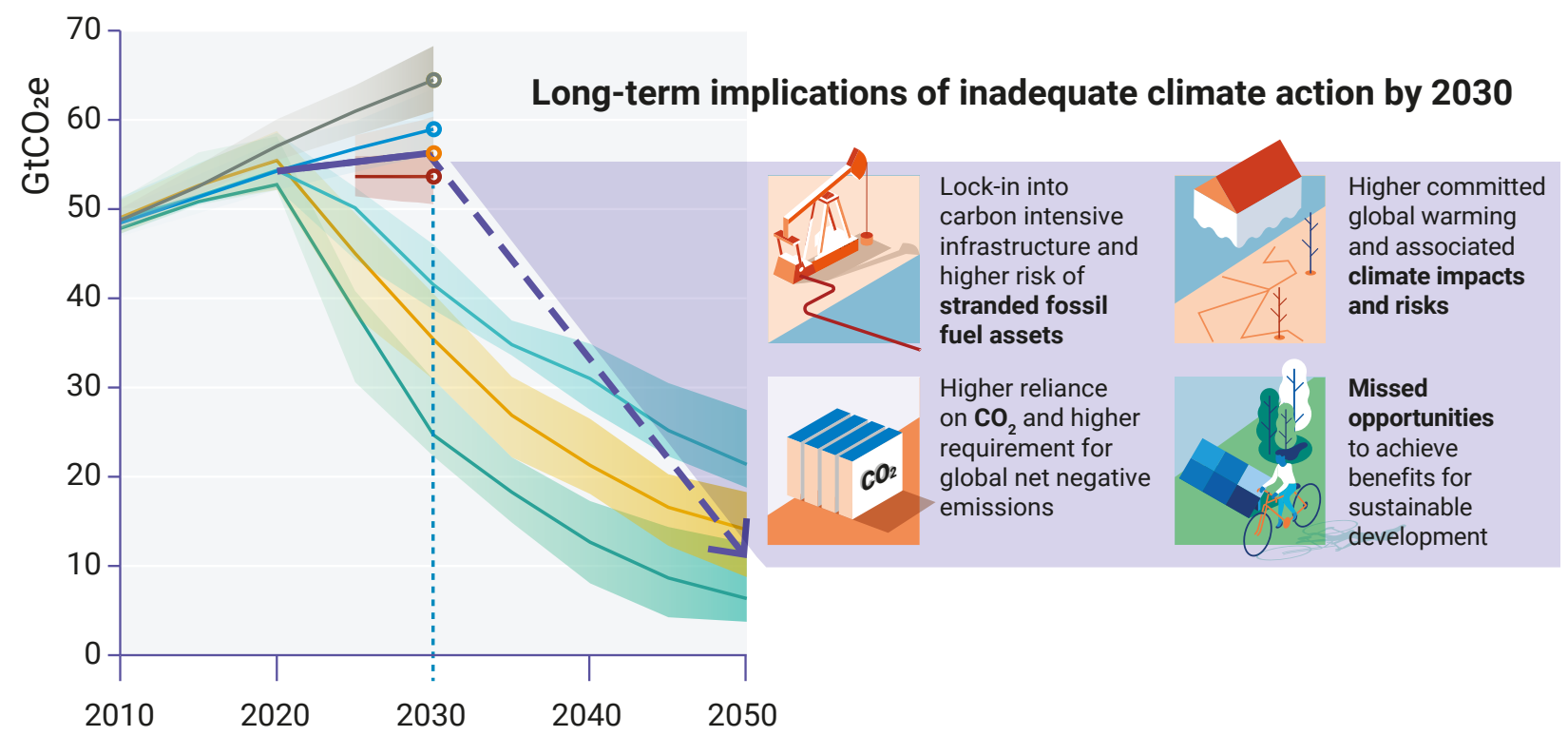

To illustrate, the six $1.5^{\circ} \mathrm{C}$ pathways available from the literature that limit the availability of biomass with carbon capture and storage (CCS) and that aim to maximize synergies with sustainable development all have GHG emission levels of at most $25 \mathrm{GtCO}_{2} \mathrm{e}$ by 2030 (Bauer et al. 2018; Bertram et al. 2018; Grübler et al. 2018; Holz et al. 2018; Huppmann et al. 2018b; Kriegler et al. 2018; Rogelj et al. 2018; van Vuuren et al. 2018).

Similar insights can be drawn for limiting warming to well below $2^{\circ} \mathrm{C}$. In the absence of significant climate action by 2030, the daunting challenge that lies beyond 2030 suggests that limiting global warming to even slightly higher levels than $1.5^{\circ} \mathrm{C}$ would effectively be out of reach - a conclusion that is also highlighted in the IPCC SR1.5 (Rogelj et al. 2018).

\subsubsection{Global warming implications}

Emissions until 2030 do not fully determine the levels of warming by the end of the century. However, the trend until 2030 can be used to estimate the projected warming based on the assumption that this trend will continue until 2100. The method used in previous Emissions Gap Reports has been followed to link $2030 \mathrm{GHG}$ emissions and their continuation until $2100^{5}$ to projected warming throughout the twenty-first century (Rogelj et al. 2016). This approach results in global warming estimates that are consistent

5 Since most scenarios that are used to inform the extension of emissions after 2030 assume exponentially increasing carbon prices throughout the century, the method applied here also implicitly assumes that climate action continues to be strengthened until 2100. 
with temperature outcomes found in the wider integrated scenario literature (Jeffery et al. 2018).

Since current policies and NDC scenarios have not changed since the 2019 report, the estimated temperature implications remain the same. The unconditional NDCs are consistent with limiting warming to no more than $3.2^{\circ} \mathrm{C}$ (range: $3.0-3.5^{\circ} \mathrm{C}$ ) by the end of the century (with 66 per cent probability). Full implementation of both conditional and unconditional NDCs would lower this estimate by about $0.2^{\circ} \mathrm{C}$. In contrast, the current policies scenario (preCOVID-19) results in greater emissions by 2030 , which if continued until the end of the century would result in a global mean temperature rise of $3.5^{\circ} \mathrm{C}$ by 2100 (range: $3.4-$ $3.9^{\circ} \mathrm{C}, 66$ per cent probability). In all cases, global warming would not be stabilized by 2100 and would continue to increase thereafter.

These global warming ranges do not consider the growing number of announced net-zero emission goals, such as China's 2060 announced net-zero carbon goal, the European Union's 2050 net-zero GHG emissions goal, the United Kingdom's legally enshrined 2050 net-zero GHG emissions goal, and South Africa's aspirational 2050 net-zero carbon emissions goal. Japan and the Republic of Korea have also announced similar goals. Although detailed studies of the temperature outcomes of these targets are not yet available, a preliminary estimate carried out for this report suggests that, collectively, these targets could further lower the temperature projections consistent with unconditional NDCs by about half a degree Celsius to around $2.7^{\circ} \mathrm{C}$. If the United States of America were to also adopt a net-zero GHG emissions target by 2050, as suggested in the Biden-Harris climate plan, the combined effect of all net-zero targets would be further strengthened. In that case, projections until the end of the century are estimated to be $2.5-2.6^{\circ} \mathrm{C}$, which is $0.6-0.7^{\circ} \mathrm{C}$ lower than the global warming estimate for current unconditional NDCs. This is consistent with other preliminary analyses (Climate Action Tracker 2020c). Once countries submit their announced net-zero targets as long-term low GHG emission development strategies to the UNFCCC, temperature projections can more formally reflect these intentions.

The 2020 analysis makes it clear that neither NDCs nor current policies are adequate to limit warming below the temperature limits included in the Paris Agreement. This inadequacy is even further emphasized when considering the cumulative $\mathrm{CO}_{2}$ emissions by 2030 as implied by current NDCs. Starting from the 2018 level of global $\mathrm{CO}_{2}$ emissions of $41.6 \mathrm{GtCO}_{2}$ (Le Quéré et al. 2018) and assuming a straight trajectory to 2030, the current unconditional NDC scenario implies cumulative emissions of about $510 \mathrm{GtCO}_{2}$ (range: 495-528 $\mathrm{GtCO}_{2}$ ) until 2030. Meanwhile, the IPCC SR1.5 estimated that the remaining carbon budget starting from 2018 and consistent with limiting warming to $1.5^{\circ} \mathrm{C}$ (with 5066 per cent probability) amounts to around $320-480 \mathrm{GtCO}_{2}$, which rises to $700 \mathrm{GtCO}_{2}$ and $1,070 \mathrm{GtCO}_{2}$ for limiting warming to $1.75^{\circ} \mathrm{C}$ and $2^{\circ} \mathrm{C}$ (with 66 per cent probability), respectively. ${ }^{6}$ Current NDCs therefore fully deplete the carbon budget consistent with limiting warming to $1.5^{\circ} \mathrm{C}$ and strongly reduce the remaining budgets for limiting warming to well below $2^{\circ} \mathrm{C}$, without making any progress towards bringing global $\mathrm{CO}_{2}$ emissions closer to net zero.

Finally, COVID-19 containment measures have resulted in a marked but temporary reduction in global GHG emissions in 2020. However, unless economic recovery is used as an opportunity to foster a low-carbon transition, this temporary blip in global GHG emissions is estimated to result in no more than a $0.01^{\circ} \mathrm{C}$ reduction of global warming by 2050, which by then is expected to have exceeded $1.5^{\circ} \mathrm{C}$ (IPCC 2018; Forster et al. 2020). NDCs to date fail to reverse the long-term upward trend in emissions, which leaves no doubt that the current NDCs are completely inadequate to achieve the climate goals of the Paris Agreement.

6 These values consider the impact of Earth system feedbacks such as permafrost thaw, as assessed in the IPCC SR1.5 


\title{
1 Bridging the gap - implications of current COVID-19 fiscal rescue and recovery measures
}

\author{
Lead authors: \\ Niklas Höhne (NewClimate Institute, Germany), Frederic Hans (NewClimate Institute, Germany), Anne Olhoff (UNEP DTU \\ Partnership, Denmark)
}

\section{Contributing authors:}

Parth Bhatia (Centre for Policy Research, India), Brian O'Callaghan (University of Oxford, UK), Sherillyn Raga (Overseas Development Institute (ODI), UK), Nigel Yau (University of Oxford, UK)

\subsection{Introduction}

The COVID-19 pandemic has brought unprecedented health and socioeconomic challenges - several of which will continue to have a profound effect on global society for many years to come. These new challenges compound many existing social and economic challenges, including widespread social inequality, rural/urban disparities and climate change. This confluence of challenges requires a considered response.

At the same time, COVID-19 rescue and recovery measures present an opening to stimulate the economy, while simultaneously accelerating a transition towards a lowcarbon economy consistent with the temperature goals of the Paris Agreement. Unless this opening is pursued, the Paris Agreement goals are likely to slip further out of reach (chapter 3).

Against this background, this chapter assesses two main questions:

What can we say about the size and extent to which COVID-19 rescue and recovery measures to date support low-carbon or high-carbon development? (sections 4.2 and 4.3)

What are the emerging lessons for governments in the pursuit of a low-carbon economic recovery? (section 4.4)

Global fiscal actions to address the impact of the COVID-19 pandemic are of an unprecedented scale. As section 4.2 shows, in September 2020, fiscal actions amounted to around US\$12 trillion, or 12 per cent of global gross domestic product (GDP). Particularly for countries with capacity to cheaply borrow funds (high 'fiscal space'), governments have been willing to spend large sums of money, often drastically increasing public debt. For nations without this fiscal space (often developing countries), public spending has been significantly lower to date.

To date, most governments have rightly focused on funding economic rescue measures to protect lives and businesses in their immediate economic response to COVID-19. As competing objectives and varied COVID-19 impact and response timelines have emerged around the world, some governments have also started sharpening their fiscal focus to funding recovery measures to reinvigorate their economies.

This chapter shows that so far, the opening to use rescue and recovery measures to support a low-carbon transition has largely been missed. Although there are examples of measures that support a transition towards a decarbonized world, most countries are currently adopting measures that support a high-carbon status quo of their economies - or even foster new high-carbon investments. This is particularly the case for rescue measures.

The jury is still out on whether COVID-19 rescue and recovery measures will lead to lower or higher global greenhouse gas ( $\mathrm{GHG}$ ) emissions in the longer run (see also chapter 3). However, this chapter illustrates that certain rescue and recovery measures can simultaneously support a rapid, employment-intensive and economically cost-effective economic recovery and a low-carbon transition. Such measures include i) support to low-carbon and renewable energy, low-carbon transport, zero-energy buildings and low-carbon industry; ii) support to research and development of zero-emissions technologies; iii) fiscal reforms of fossil fuel subsidies; and iv) nature-based solutions, including large-scale landscape restoration and reforestation.

A detailed evaluation of the appropriateness of given measures in various country contexts is required to assess the scope for rolling them out across countries, as impacts vary across different political, environmental, 
economic, business, legal, regulatory and social contexts. Well-designed spending can also tackle other pressing problems such as air pollution, natural capital deficit, wealth and income inequality, inadequate quality of life and rural/urban disparities

The future can still be shaped in a way that helps bridge the emissions gap, through the decisions yet to be made on the composition and implementation of the announced recovery packages and on future recovery actions.

\subsection{Unprecedented global fiscal spending on economic rescue and recovery measures}

Fiscal actions to address the impact of the COVID-19 pandemic are unprecedented in scale (see figure 4.1): around US\$12 trillion, or 12 per cent of global GDP, had been spent by September 2020 (International Monetary Fund [IMF] 2020a, 2020b). For some G20 members, fiscal spending has been as high as 40 per cent of GDP. However, spending profiles have not been homogeneous around the world. While the average G20 spend currently hovers at approximately 15 per cent of GDP, the average for the middle- and low-income country categories used by the International Monetary Fund (IMF) is less than 6 per cent (IMF 2020a).

Fiscal responses to the COVID-19 crisis have included both new spending measures and changes to pre-existing revenue streams. Spending measures have included direct liquidity support for businesses and not-for-profits; direct provision of cash, resources and health services for citizens; new incentive measures (for instance to restart tourism); infrastructure investment and; investment in research and development (R\&D). Revenue measures have included tax deferrals, tax cuts, and reductions in payments and rent for public services and resources.

While the recorded size of fiscal action varies slightly by institution and tracker, overall spending trends are relatively consistent. The main difference is in the scope and timing of tracking fiscal measures, monetary measures,

Figure 4.1. Discretionary fiscal response announced by G20 countries in response to the COVID-19 pandemic as at 11 September 2020, expressed as a percentage of GDP

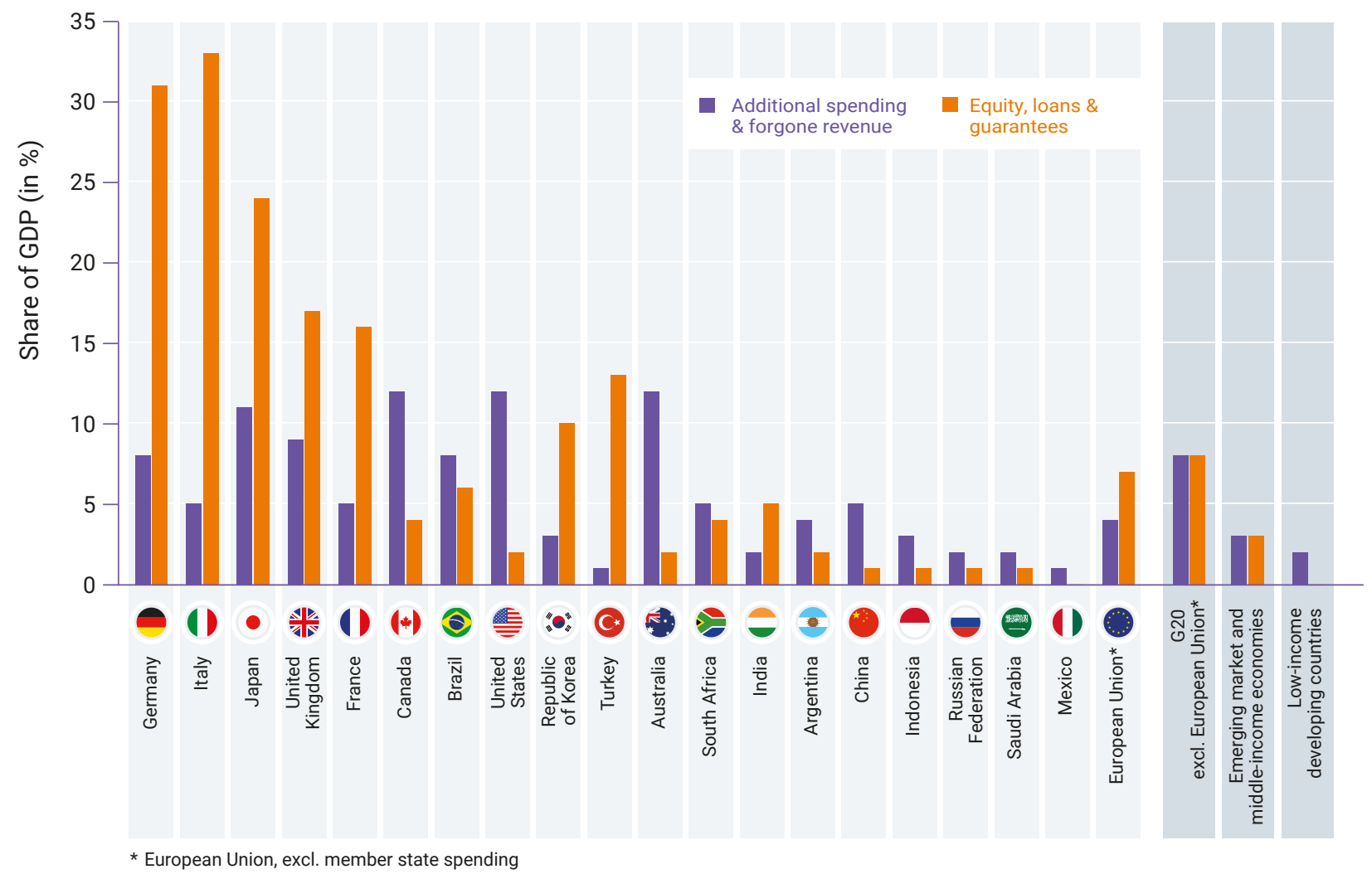

Note: Discretionary fiscal response by the European Union includes all (announced) fiscal actions at the European Union institutional level, excluding fiscal spending at the member state level. The average across all G20 members excluding the European Union represents the weighted average by country-specific GDP values. The classification according to emerging market and middle-income economies and low-income developing countries comes from the IMF's Fiscal Monitor: Policies for the Recovery of October 2020 (IMF 2020 ).

Sources: IMF (2020a); IMF (2020b) 
and deregulation initiatives. ${ }^{1}$ For instance, the Overseas Development Institute (ODI) estimates the total fiscal stimulus of G20 countries, excluding fiscal actions at the European Union institutional level, at US\$10.8 trillion as at August 2020 (Overseas Development Institute [ODI] 2020), compared with the US\$10.3 trillion estimated by the IMF as at September 2020 (IMF 2020a) and the US\$12.4 trillion estimated by the Oxford University Economic Recovery Project and the Green Fiscal Policy Network as at November 2020 (O'Callaghan et al. 2020).

If monetary liquidity stimulus provided by countries' central banks is considered in addition to fiscal spending, the share of GDP spent on COVID-19 measures increases sharply: up to 70 per cent for some G20 members (ODI 2020). The range of fiscal and monetary interventions reflects the full policy space available to each country to respond to the COVID-19 pandemic.

Since many developing countries entered the pandemic with pre-existing vulnerabilities and limited fiscal space, and given the immediate threat to lives due to the health and income impacts of COVID-19, spending in these nations has primarily targeted short-term rescue measures. Key vulnerabilities include high levels of public indebtedness, slowing economic growth rates due to subdued global demand, and trade tensions. To date, this has left little room to fund recovery strategies with a longer-term perspective. In view of this, regional development banks and the international donor community have increased their commitment of support.

At the regional level, for example, the African Development Bank initially responded by raising US\$3 billion for a 'Fight COVID-19' social bond in March 2020, the largest US-dollardenominated social bond transaction in the capital markets to date (African Development Bank [AfDB] 2020a). This was followed by its creation of a US\$10 billion response facility to assist governments and the private sector, its approval of loans and grants to individual member countries, and its support for regional efforts to combat the pandemic (AfDB 2020b; AfDB 2020c). Meanwhile for most European and Central Asian countries, the European Bank for Reconstruction and Development (EBRD) plans to devote more than half of its total COVID-19 recovery investments to the green economy (Bennett 2020).

The IMF doubled its COVID-19-related funding capacity from US\$50 billion to US\$100 billion in April 2020, had reached
US\$280 billion lending commitment by October 2020, and stands ready to deploy US\$1 trillion in lending capacity to help its member countries to weather the impact of the pandemic (IMF 2020c; IMF 2020d; IMF 2020e). Meanwhile, the World Bank Group also significantly increased its commitment for COVID-19 projects from US\$14 billion in March 2020 to US\$160 billion in April 2020 (World Bank 2020a; World Bank 2020b). The World Bank had allocated US\$43 billion of this pool as at September 2020 (World Bank 2020c). Reflecting global spending patterns, in the early stages of the COVID-19 outbreak, most World Bank projects supported emergency funding to address health priorities. More recently, the scope of funding has widened to include financial sector reform, education, governance, and market support. ${ }^{2}$ The international donor community is likely to play an important role in supporting and steering funding towards measures that support an inclusive, resilient and low-carbon economic recovery (UN Regional Commissions 2020), especially in the least developed countries.

\subsection{Fiscal COVID-19 spending has so far primarily supported the global status quo of high-carbon economic production}

This section provides a preliminary assessment of the extent to which COVID-19 fiscal rescue and recovery measures to date support low- or high-carbon development, and whether they have a positive net effect on GHG emissions. As at October 2020, COVID-19 fiscal spending had primarily supported the global status quo of high-carbon economic production. While it is understandable that immediate rescue measures were directed to incumbent industry, later rescue and recovery measures could have supported low-carbon development, without forsaking opportunities for economic gain (Hepburn et al. 2020).

Only a few countries have transformed green rhetoric into low-carbon recovery measures (that is, measures that lead to a reduction in GHG emissions). For most, recovery spending has mostly been high-carbon (that is, implying negative net effects GHG emissions) or neutral (that is, having no discernible effects on GHG emissions). Furthermore, in a number of cases, the effect on GHG emissions is still unclear. Focusing on G20 members, figure 4.2 provides an overview of climate negative, neutral and positive fiscal rescue and recovery measures

1 For example, the IMF (2020a) includes both additional spending and forgone revenue as 'above the line measures' and equity injections, loans asset purchase, debt assumptions and contingent liabilities as 'liquidity support'. The ODI (2020) includes both 'fiscal stimulus' including aid, grants and guarantees and 'monetary (liquidity) stimulus' including central banks' explicit monetary liquidity injection and expected impact from lowering policy interest rates. Vivid Economics includes deregulation measures in its Green Stimulus Index (Vivid Economics 2020a). The highest granularity pure-form fiscal spending tracker, from the Oxford University Economic Recovery Project, combines inputs from these sources with its own tracking to report and classify policies covering all fiscal stimulus measures announced by the largest 50 economies since March 2020 (O'Callaghan et al. 2020)

2 See the World Bank Group's Operational Response to COVID-19 (coronavirus) - Projects List (accessed on 11 September 2020) for a list of beneficiary countries: https://www.worldbank.org/en/about/what-we-do/brief/world-bank-group-operational-response-covid-19-coronavirusprojects-list. 
Figure 4.2. Non-exhaustive overview of total fiscal rescue and recovery measures of G20 members with high-carbon, neutral and low-carbon effects as a share of 2019 GDP

High-carbon effects

(in \%) $3 \quad 2 \quad 1 \quad 0$
Neutral/Unclear

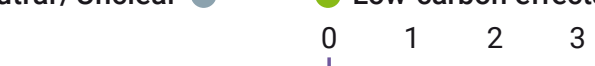

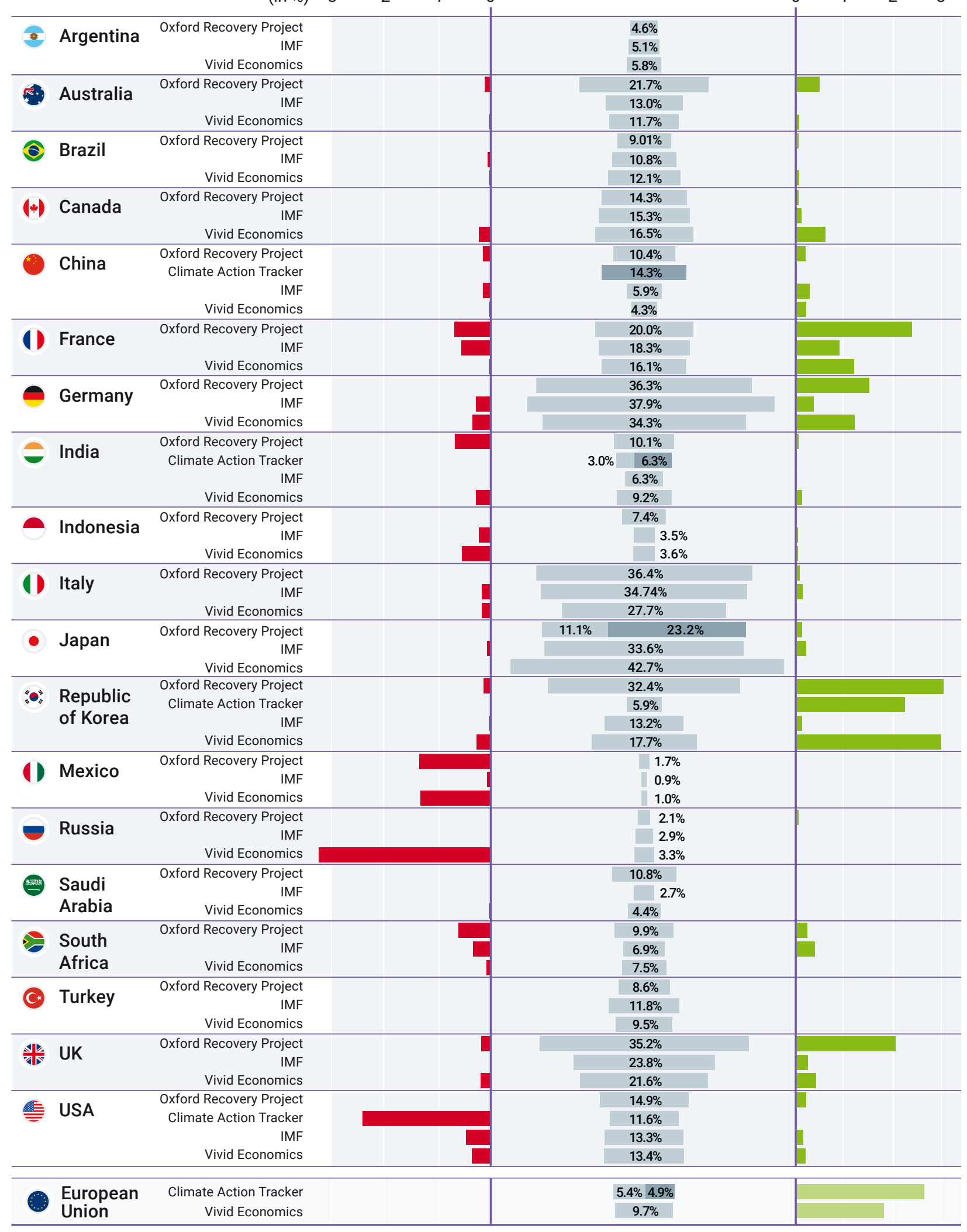

Note: Oxford Recovery Project refers to the Oxford University Recovery Project (OUERP).

All announcements by the European Council on the NextGenerationEU recovery fund and additional green climate change-related spending in the 2021-2027 Multiannual Financial Framework remain preliminary as at October 2020

Sources: Climate Action Tracker (2020); IMF (2020a); IMF (2020b); O'Callaghan et al. (2020); Vivid Economics (2020a). Climate Action Tracker data from August 2020, Vivid Economics from August 2020, IMF from September 2020 and Oxford from November 2020 
to date, based on four main trackers of COVID-19 fiscal investments. Annex II provides an overview of the methodologies underlying these four COVID-19 trackers.

For G20 members, several preliminary findings are emerging regarding the extent to which fiscal rescue and recovery measures to date have been low-carbon, neutral or high-carbon (Carnell et al. 2020; Climate Action Tracker 2020; Energy Policy Tracker 2020; IMF 2020a; Larsen et al. 2020; O'Callaghan et al. 2020; Tiftik et al. 2020; Vivid Economics 2020a):

All G20 members have implemented several immediate rescue measures in response to the COVID-19 pandemic (Climate Action Tracker 2020; Energy Policy Tracker 2020; O'Callaghan et al. 2020; Vivid Economics 2020a). These are mostly considered neutral in terms of GHG emissions impact (for example, health-care-related spending) or supporting high-carbon industries without conditions for a lowcarbon transition attached.

- Around a quarter of G20 members have dedicated shares of their packages (accounting for up to 3 per cent of GDP) explicitly to low-carbon measures as at October/November 2020 (Climate Action Tracker 2020; Energy Policy Tracker 2020; O'Callaghan et al. 2020; Vivid Economics 2020a). Several countries are spreading the announced sums across the years up to 2025

- Most G20 members have brought forward measures and packages supporting a high-carbon status quo of their economies or are even fostering new highcarbon investments (O'Callaghan et al. 2020; Vivid Economics 2020a). For some G20 members, no explicit low-carbon measures could be identified (O'Callaghan et al. 2020; Tiftik et al. 2020; Vivid Economics 2020a).

Assessments of the effects on GHG emissions are preliminary (see chapter 3 ), but will become more robust as the composition and implementation details of rescue and recovery packages become clearer.

Methodologies for identifying and quantifying the climate impacts of rescue and recovery measures and times of analysis vary slightly across institutions, bringing corresponding variance in results (figure 4.2, Annex II). However, for all trackers and across geographies, lowcarbon measures are significantly outweighed by neutral and high-carbon measures.

Preliminary analysis ${ }^{3}$ indicates that low-carbon policies have been slightly more prevalent in recovery measures than in rescue measures ( $O^{\prime}$ Callaghan et al. 2020). This is noteworthy, as the next stages of COVID-19 fiscal interventions are likely to shift a greater proportion of capital towards recovery measures, indicating prospects for increasing low-carbon measures in upcoming new recovery plans or in revisions to announced recovery plans.

\subsection{Emerging lessons and examples for governments in the pursuit of low- carbon economic recovery}

The previous sections show that the economic rescue and recovery measures announced by governments worldwide are unprecedented in scale. Although section 4.3 clearly shows that measures supporting a low-carbon transition have been limited to date, there is scope to adjust announced recovery measures to become more lowcarbon and to design future packages in a manner that supports an inclusive, resilient and low-carbon economic recovery (UN Regional Commissions 2020).

As chapter 3 illustrates, global GHG emissions are projected to be significantly reduced by 2030 only if COVID-19 economic recovery is used as an opening to pursue decarbonization. Therefore, bridging the 2030 emissions gap critically depends on the extent to which this opening is used and integrated into substantially more ambitious new or updated nationally determined contributions (NDCs). Previous editions of the Emissions Gap Report have highlighted the major long-term sectoral transformations that are needed to bridge the gap and reach net-zero GHG emissions globally and these are also relevant to consider in the context of recovery measures (box 4.1).

Governments evaluate fiscal rescue and recovery spending, taxation and regulatory options against a variety of criteria. In most instances, the ability to stabilize or stimulate the economy through a specific measure is likely the first criteria considered by policymakers. However, measures that have similar short-term economic characteristics may differ considerably in terms of their social, environmental and long-term economic impacts. Considering medium- to long-term economic, environmental and social indicators can therefore help governments maximize the long-term prosperity benefits of their recovery measures. Various studies discuss, in a global context, the benefits of aligning policy with different indicators. These are summarized in table 4.1 (Flyvbjerg 2020; Hepburn et al. 2020; International Energy Agency [IEA] 2020; Jotzo et al. 2020; O'Callaghan et al. 2020; Vivid Economics 2020b; World Bank 2020d)

For country-specific cases, detailed evaluation is required to assess the appropriateness of each measure, as impacts vary across different political, environmental, economic, business, legal, regulatory and social domains. To design 
Box 4.1. Major long-term sectoral transformations needed to reach net-zero GHG emissions globally

- Full decarbonization of the energy sector, based on renewable energy and electrification across sectors, including phasing out coal-fired power plants

- Decarbonization of the transport sector in parallel with modal shifts to public transportation, cycling and walking

- Shifts in industry processes towards electricity, (near-)zero carbon, substitution of carbonintensive products, circularity and material efficiency
Decarbonization of the building sector, including electrification and greater efficiency

Enhanced agricultural management as well as demand-side measures such as dietary shifts to more sustainable, plant-based diets and measures to reduce food waste

- Zero net deforestation and the adoption of policies to conserve and restore land carbon stocks and protect natural ecosystems, aiming for significant net $\mathrm{CO}_{2}$ uptake in this sector

Source: UNEP Emissions Gap Report 2019 - chapter 4 (Höhne et al. 2019)

optimal policy, it is important that results for each dimension are assessed and weighed against each other.

Some fiscal rescue and recovery measures are likely to perpetuate high-carbon and environmentally damaging development (see table 4.2 to table 4.7 for detailed COVID-19 examples). These include:

- fossil fuel-based infrastructure investments or fiscal incentives for high-carbon technologies and projects

- waivers or rollbacks of environmental regulations

- bailouts of fossil fuel-intensive companies without conditions for low-carbon transition or environmental sustainability: relevant industries include airlines, internal combustion automotive companies, industrial industries and fossil energy companies.

Conversely, many fiscal rescue and recovery measures can simultaneously support rapid, employment-intensive and cost-effective economic recovery and a low-carbon transition (see table 4.2 to table 4.7 for detailed examples). Broad categories include:

- support for zero-emissions technologies and infrastructure, for example, low-carbon and renewable energy, low-carbon transport, zero-energy buildings and low-carbon industry
$>$

support to research and development of zeroemissions technologies

- fossil fuel subsidies through fiscal reform

- nature-based solutions, including large-scale landscape restoration and reforestation.

Experience from early COVID-19 rescue and recovery measures can provide valuable insights for policymakers designing economic rescue and recovery measures for the immediate future. Based on an assessment of recently published literature and information from available rescue and recovery trackers, table 4.2 to table 4.7 provide case examples of low-carbon and high-carbon recovery measures organized by main sectors. All tables have been constructed based on information available in October 2020. Each table includes a set of examples that reduce GHG emissions and a set of examples that tend to increase GHG emissions or foster lock-in of high carbon emissions.

The case examples presented have all been cited by multiple sources and many incorporate relevant additional socioeconomic considerations, such as employment or social benefits (CarbonBrief 2020; Energy Policy Tracker 2020; O'Callaghan et al. 2020; Vivid Economics 2020a). Further research is required to assess the replicability of specific recovery examples in different country contexts given their different environmental, social and economic dimensions. 
Table 4.1. Non-exhaustive, simplified overview of recently published literature that proposes indicators to assess and design low-carbon, sustainable and socially inclusive economic recovery measures

\begin{tabular}{|c|c|c|c|c|c|c|}
\hline Indicators & $\begin{array}{l}\text { IEA } \\
(2020)\end{array}$ & $\begin{array}{l}\text { World } \\
\text { Bank } \\
\text { (2020d) }\end{array}$ & $\begin{array}{l}\text { Hepburn } \\
\text { et al. } \\
(2020)\end{array}$ & $\begin{array}{l}\text { Jotzo } \\
\text { et al. } \\
(2020)\end{array}$ & $\begin{array}{l}\text { O'Callaghan } \\
\text { et al. } \\
(2020)\end{array}$ & $\begin{array}{l}\text { Vivid } \\
\text { Economics } \\
(2020 \mathrm{~b})\end{array}$ \\
\hline $\begin{array}{l}\text { Timeliness (including speed of implementation } \\
\text { and timing of effects) }\end{array}$ & $\checkmark$ & $\checkmark$ & $\checkmark$ & $\checkmark$ & $\checkmark$ & $\checkmark$ \\
\hline $\begin{array}{l}\text { Employment (including scale, quality, location } \\
\text { and their distribution over time) }\end{array}$ & $\checkmark$ & $\checkmark$ & & $\checkmark$ & & $\checkmark$ \\
\hline $\begin{array}{l}\text { Economic activity (including short- and long- } \\
\text { term impact and multiplier effects) }\end{array}$ & & $\checkmark$ & $\checkmark$ & $\checkmark$ & $\checkmark$ & $\checkmark$ \\
\hline $\begin{array}{l}\text { Government budget capacity (including the } \\
\text { impact on fiscal space, e.g. producing future } \\
\text { fiscal revenues or savings to the government) }\end{array}$ & & & & $\checkmark$ & & $\checkmark$ \\
\hline $\begin{array}{l}\text { GHG emissions (including short- and long- } \\
\text { term and potential lock-in) }\end{array}$ & $\checkmark$ & $\checkmark$ & $\checkmark$ & $\checkmark$ & $\checkmark$ & $\checkmark$ \\
\hline $\begin{array}{l}\text { Other environmental benefits (including air } \\
\text { quality and water) }\end{array}$ & & $\checkmark$ & & $\checkmark$ & $\checkmark$ & \\
\hline $\begin{array}{l}\text { Social benefits (including access to public } \\
\text { resources, health, gender equity, cost-of-living } \\
\text { reductions for low-income earners or improved } \\
\text { public health) }\end{array}$ & $\checkmark$ & & & & $\checkmark$ & \\
\hline
\end{tabular}
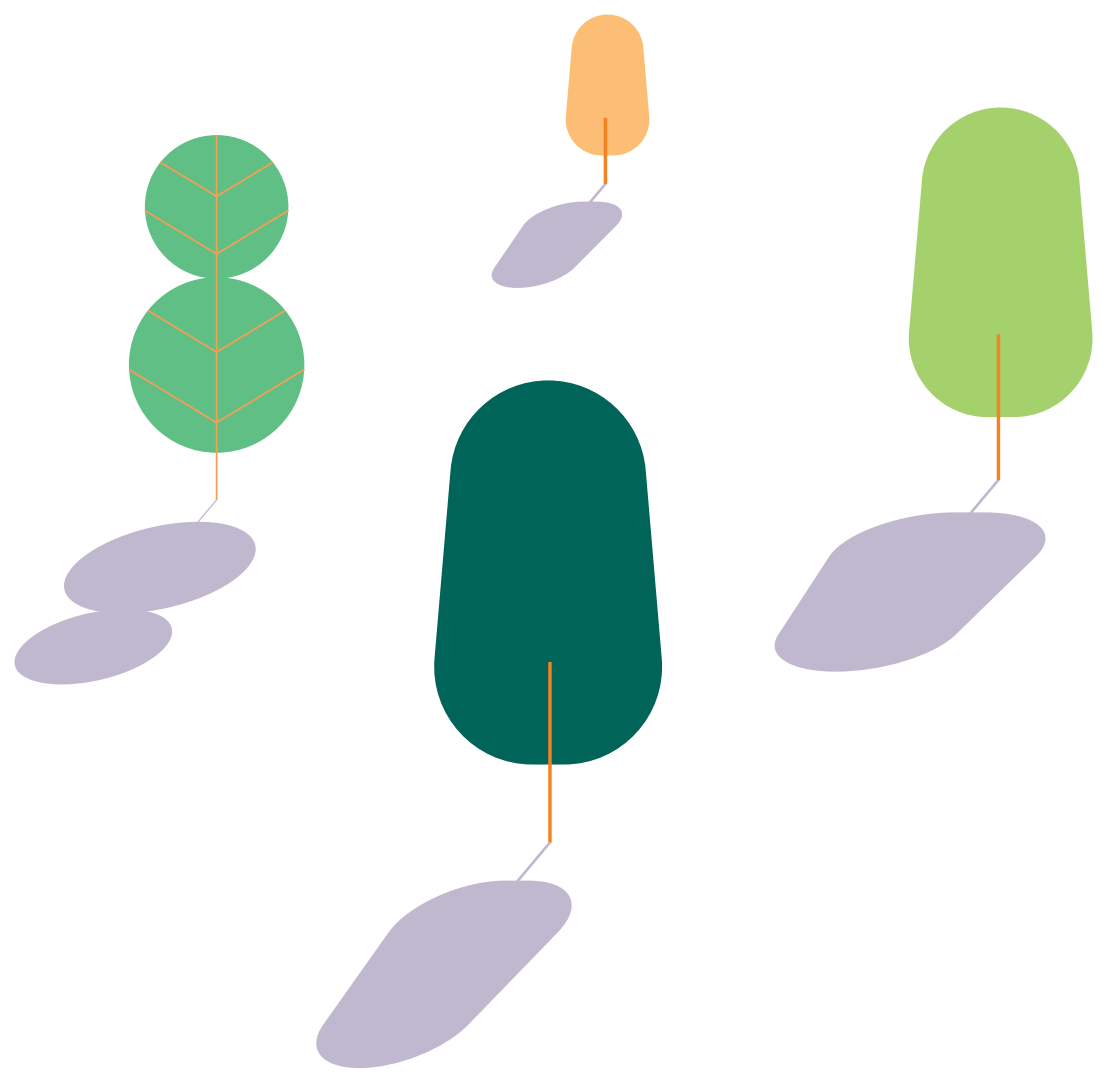
Table 4.2. Non-exhaustive overview of low-carbon and high-carbon rescue and recovery measures for the energy and electricity supply sector, and selected case examples as at October 2020

\section{ENERGY AND ELECTRICITY SUPPLY: low-carbon and high-carbon interventions}

Total of 45 low-carbon spending measures identified in 17 out of 50 countries and 32 high-carbon spending measures in 14 out of 50 countries as at October 2020 (O'Callaghan et al. 2020)
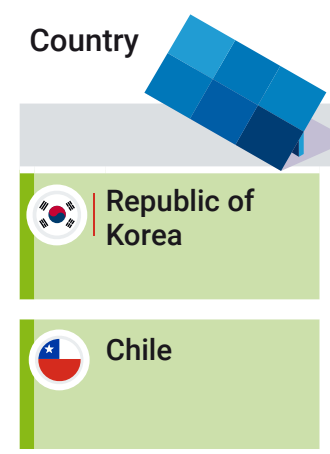

China
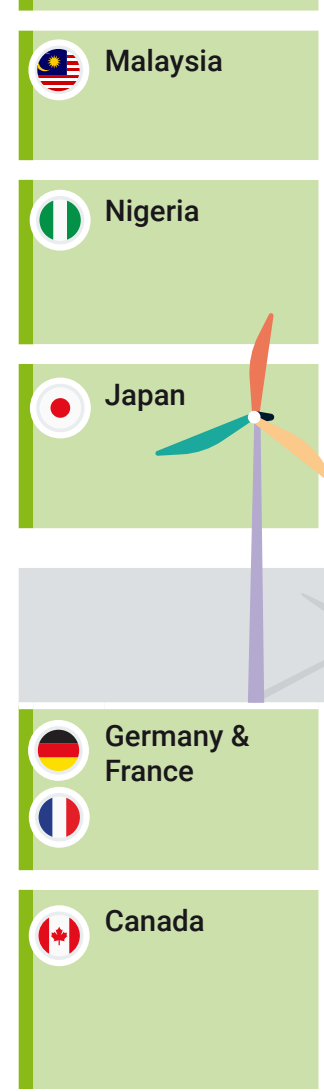

\section{Case study}

Direct support for zero-emissions energy technologies and infrastructure

Increased support for solar and wind capacity deployment in 2020-2025, with a particular focus on large-scale offshore wind parks (Republic of Korea, Ministry of Economy and Finance 2020)

Green Credit programme to make renewable energy investments of up to US\$39 million in 2020 by refinancing long-term credits granted by financial intermediaries (Government of Chile 2020; Mackenna et al. 2020)

Increase in solar and wind energy targets to $240 \mathrm{GW}$ each for 2020, implying additions of $30 \mathrm{GW}$ of wind and $36 \mathrm{GW}$ of solar in 2020 (Hove 2020)

Tender of $1 \mathrm{GW}$ solar announced as part of economic recovery efforts, with the potential to create 12,000 employment opportunities in Malaysia (Government of Malaysia 2020)

Installation of Solar Home Systems (SHS) in 5 million households currently not connected to the national grid, including a local content production requirement triggering domestic employment opportunities (Akrofi and Antwi 2020;

Government of Nigeria 2020)

Up to US\$50 million for the development of on-site renewables to support corporate power purchase agreements (PPAs) under companies' commitments to the RE100 initiative (Japan, Cabinet Office 2020; Japan, Ministry of the Environment 2020)

Support for research and development (R\&D) in zero-emission energy technologies and infrastructure, and liquidity support to energy companies with conditions for zero-emission transition

Funding for national hydrogen strategies to support R\&D in green hydrogen technologies: around US\$8.3 billion in Germany (Germany, Federal Ministry of Finance 2020) and around US\$2.4 billion in France as part of the recovery plan (France, Ministry for the Economy and Finance 2020a)

Energy companies and other corporates receiving support from the Large Employer Emergency Financing Facility (LEEFF) must commit to disclosing annual climate-related reports, including an assessment of the impact of their future operations on sustainability and climate goals (Canada, Office of the Prime Minister of Canada 2020)

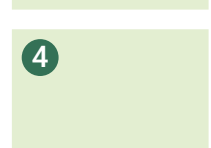

35
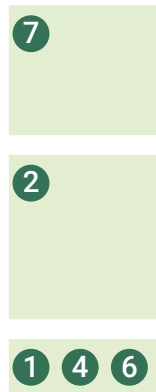

Positive

Negative
1 Vivid Economics (2020a)

5 Climate Action Tracker (2020)
2 Carbon Brief (2020)

6 Moisio et al. (2020)
3 Energy Policy Tracker (2020)

7 Martin (2020)
(2) 34

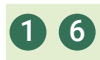

4 O'Callaghan et al. (2020)

8 Sarkar (2020) 
Table 4.2. Non-exhaustive overview of low-carbon and high-carbon rescue and recovery measures for the energy and electricity supply sector, and selected case examples as at October 2020 (continued)

\section{ENERGY AND ELECTRICITY SUPPLY: low-carbon and high-carbon interventions}

Total of 45 low-carbon spending measures identified in 17 out of 50 countries and 32 high-carbon spending measures in 14 out of 50 countries as at October 2020 (O'Callaghan et al. 2020)

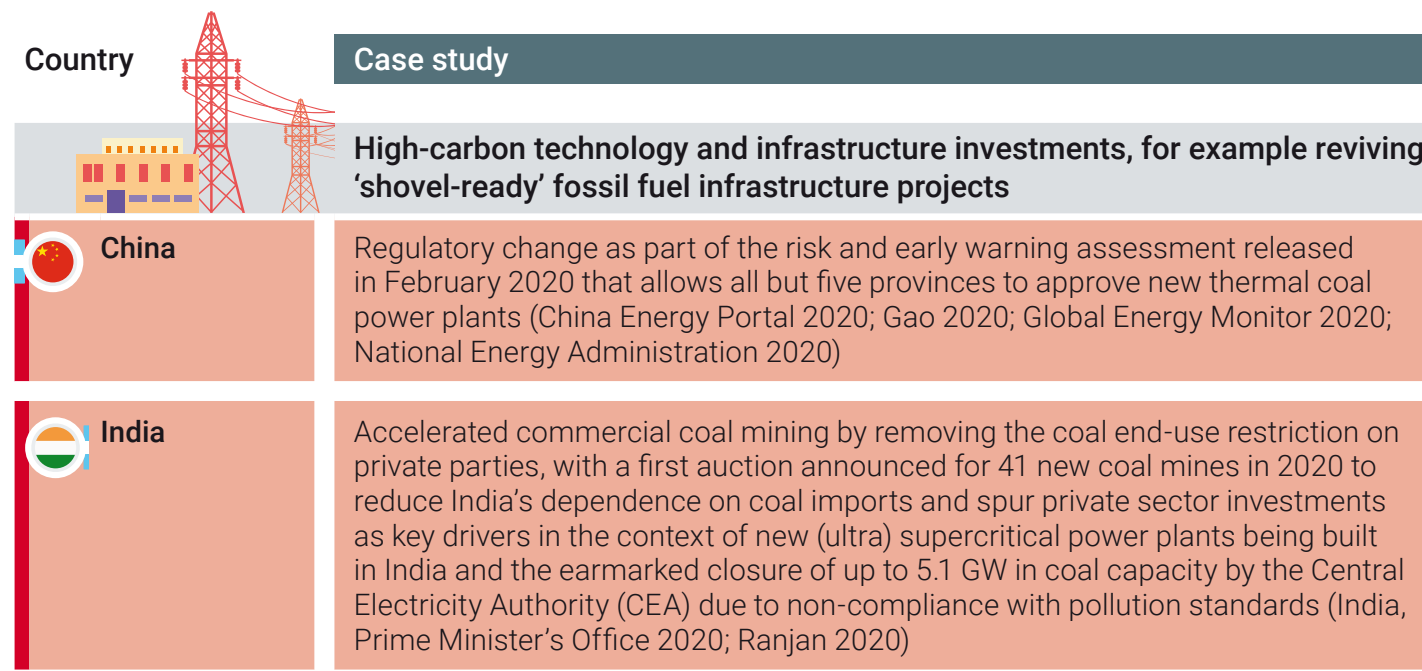

High-carbon technology and infrastructure investments, for example reviving 'shovel-ready' fossil fuel infrastructure projects power plants (China Energy Portal 2020; Gao 2020; Global Energy Monitor 2020; (2020) private parties, with a first auction announced for 41 new coal mines in 2020 to reduce India's dependence on coal imports and spur private sector investments Electricity Authority (CEA) due to non-compliance with pollution standards (India, Prime Minister's Office 2020; Ranjan 2020)

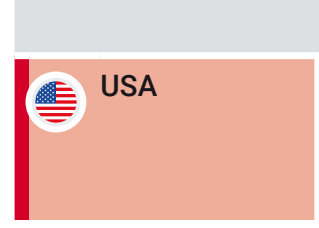

Australia (states and territories)
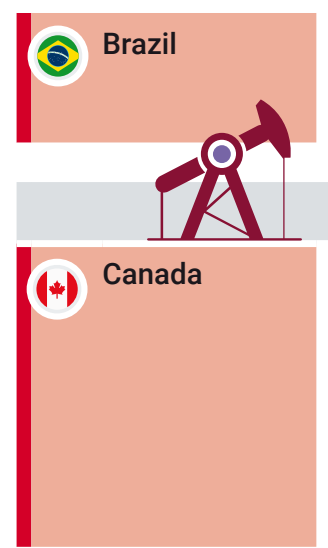

USA

Positive
Negative

1 Vivid Economics (2020a)

0)

\section{Waivers or rollback on environmental regulations for the energy industry}

Waiver of reporting requirements for fossil fuel electricity generators under the Cross-State Air Pollution Rule, Acid Rain Program and NOx State Implementation Plan (Environmental Protection Agency [EPA] 2020), and executive order waiving environmental reviews of infrastructure projects

Queensland has frozen fees and charges for coal and gas explorers until July 2021 (State Government of Queensland 2020), and South Australia has implemented a partial suspension of permitting and licensing fees in the oil, gas and mining sectors (State Government of South Australia 2020)

Reduction of royalties for small or medium-sized companies exploring, developing and producing oil and natural gas to initiate further private sector investment (Brazil, National Energy Policy Council 2020)

Bailout of fossil fuel companies without conditions for zero-emission transition

Short-term unconditional liquidity support and higher-risk financing for Canadian oil and gas companies to support operational requirements over a 12-month period of up to around US\$46 million (CAD 60 million) per company announced in April 2020 (Business Development Bank of Canada [BDC] 2020). While this specific programme does not include requirements for zero-emission transition, the Government of Canada has also announced other recovery investments in the oil and gas sectors designed at reducing emissions while stimulating the economy and creating jobs.

Paycheck Protection Program (PPP) established by the Coronavirus Aid, Relief, and Economic Security (CARES) Act and a tax loophole in the CARES Act provide financial support to oil and gas companies, without any conditions for zeroemission transition (Juhasz 2020) 
One aspect not directly considered in this chapter is the extent to which the implications of COVID-19 and associated rescue and recovery measures may influence underlying drivers of high-carbon production and consumption. Box 4.2 provides an example of how COVID-19 could compound economic and environmental incentives for a transition out of coal, using India as an illustrative example.

\section{Box 4.2. A potential opening for accelerated retirement of coal plants in India}

Coal-based power is an important part of India's immediate energy future to enable reliable and modern electricity access in a historically energy-poor nation. However, beneficial economics of an accelerated phaseout of old coal-fired power plants, and expressions of political support for doing so, offer the possibility of postCOVID recovery and both climate and air pollution gains.

India has one of the largest and youngest coal power fleets in the world, with an installed capacity of $205 \mathrm{GW}$ and average plant age of around 12 years (Malik et al. 2020). India's fleet continues to grow, with $6.7 \mathrm{GW}$ added in FY2019-20 and another 59.8 GW in the pipeline, of which $23.7 \mathrm{GW}$ are on hold for various reasons (Central Electrical Authority [CEA] 2020a). In contrast, 10 GW have been retired since April 2014 (India, Ministry of Power 2020a)

However, rapid capacity addition in recent years (nearly 60 per cent of India's coal capacity was commissioned between 2010 and 2020), lower-than-forecasted growth in demand, and competition from renewable energy have created a power surplus. The entire coal fleet is facing low utilization rates (55-60 per cent) and competition for limited coal supply. Forty GW of coal-fired projects were financially stressed in 2018 (India, Ministry of Power 2018). In addition, new pollution control norms will add costs to coal-based electricity production. Reflecting these developments, in her budget speech for 2020, the Finance Minister suggested that old thermal plants with high carbon emissions should be closed, and the Power Minister later announced that 5.1 GW had been earmarked for shutdown due to noncompliance with pollution standards. Two major states, Gujarat and Chhattisgarh, have announced that they will no longer construct new coal plants (Carbon Copy Editorial Team 2019).
In the medium term, COVID-19 is expected to cause a sustained decline in electricity demand compared with pre-COVID-19 trends (Spencer 2020). This could reinforce a move away from coal. Analysts have identified accelerated retirements of coal plants as a catalyst for reviving the power sector, while reducing air pollution and $\mathrm{GHG}$ emissions. Studies estimate that there is a strong economic and environmental case for decommissioning 27-36 GW of old, expensive or polluting plants in the short term (Fernandes and Sharma 2020; Srikanth and Krishnan 2020). This would release debt-ridden utilities from contractual fixed cost obligations and improve the utilization of younger, more efficient and cleaner plants, while also releasing lowcost coal linkages.

At the same time, it would result in considerable savings in terms of system-level costs and GHG emissions (Dang, Nuwal and Acharya 2020; Ghosh and Ruha 2020). It would also generate upstream benefits on the balance sheets of public sector banks at a critical moment. Increasing the usage of cleaner plants would avoid the cost of retrofitting old, dirty plants with air pollution control equipment. Furthermore, utilities would be free to lower their power purchase costs by replacing the lost generation with cheaper renewable energy or power exchange.

Implementing an accelerated retirement programme for old coal plants will face technical and political constraints, particularly if the promoter has not fully recovered their equity. Proposals to overcome such challenges have recently emerged, such as bundling the decommissioning costs into renewable energy auctions (Dang, Nuwal and Acharya 2020) or raising government bonds funded by ratepayer surcharges to buy out brownfield assets (known as 'securitization') (Shrimali 2020) 
Table 4.3. Non-exhaustive overview of low-carbon and high-carbon rescue and recovery measures for the land-based transport sector, and selected case examples as at October 2020

\section{LAND-BASED TRANSPORT SECTOR: low-carbon and high-carbon interventions}

Total of 35 low-carbon spending measures identified in 18 out of 50 countries and 41 high-carbon spending measures in 21 out of 50 countries as at October 2020 (O'Callaghan et al. 2020)

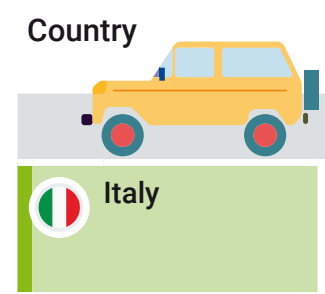

India (cities)

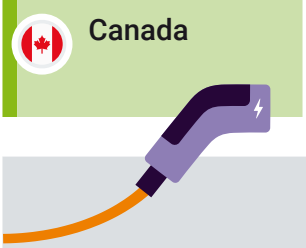

China
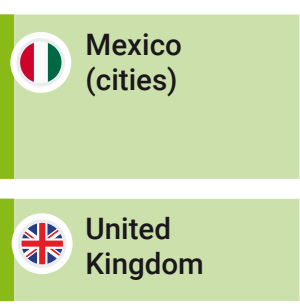

Spain
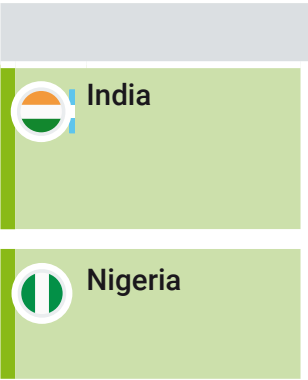

\section{Case study}

Studies

Financial incentives for zero-emission vehicles and other low-carbon transportation

Government incentives for purchase and registration of low-carbon cars has increased by US\$600 million, including budget to support installation of charging infrastructure for electric vehicles

The city government of Delhi aims to increase electric vehicles to 25 per cent of all new vehicle registrations by 2024 as part of its green stimulus package

\section{(1) 34}

Funding of US\$1.1 billion to purchase zero-emission buses and charging infrastructure provided by the Canada Infrastructure Bank

Investments in low-carbon infrastructure such as electric vehicle charging infrastructure, cycleways, and low-carbon rail or other mass transit systems

Expansion of electric vehicle charging network with an additional 200,000 charging stations to be installed in 2020, an increase of about 16.5 per cent over the year 2019 (Shen 2020)

Investment in active transport infrastructure in response to COVID-19 by investing in the expansion of Mexico City cycling network, with $54 \mathrm{~km}$ of new routes to support healthy, safe and sustainable urban mobility (City Government of Mexico City 2020; Webber 2020)

Funding of US\$2.6 billion (GBP 2 billion) for bike lanes, wider pavements and safer junctions (Government of the United Kingdom 2020a)

Investments to support green transport networks, and funding for R\&D in sustainable transport such as hydrogen-fuelled public transport (Government of Spain 2020)

\section{Fiscal reform on fossil fuel subsidies}

Temporary tax increase by INR 2 per litre for petrol and INR 4 per litre for diesel in the context of low international oil prices to create, inter alia, additional fiscal revenue streams for urgent rescue measures such as health-care provision in response to the COVID-19 pandemic (Kishore 2020; Parashar 2020)

Removal of gasoline subsidies to save a total of US\$2 billion annually will increase end-consumer prices to around US\$0.32 per litre for gasoline (Bala-Gbogbo 2020)
Positive

1 Vivid Economics (2020a)

2 Carbon Brief (2020)

5 Climate Action Tracker (2020)

6
Moisio et al. (2020)

3

7 Martin (2020)
4 O'Callaghan et al. (2020)

8 Sarkar (2020) 
Table 4.3. Non-exhaustive overview of low-carbon and high-carbon rescue and recovery measures for the land-based transport sector, and selected case examples as at October 2020 (continued)

\section{LAND-BASED TRANSPORT SECTOR: low-carbon and high-carbon interventions}

Total of 35 low-carbon spending measures identified in 18 out of 50 countries and 41 high-carbon spending measures in 21 out of 50 countries as at October 2020 ( $0^{\prime}$ Callaghan et al. 2020)
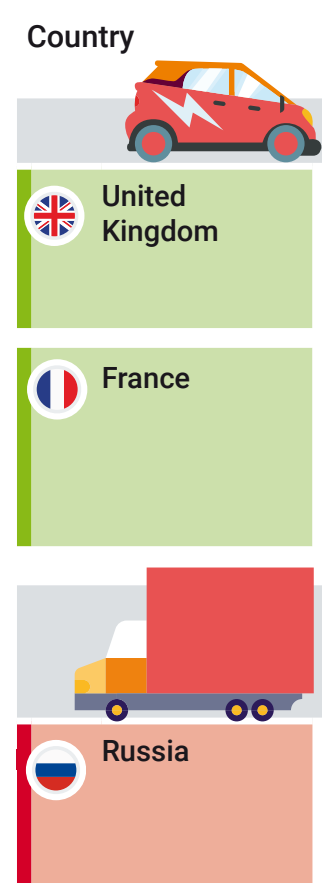

Republic of Korea
Case study

Studies

Bailout of transport and automobile companies with environmental conditions

US\$2 billion bailout to Transport for London (TfL) to cover the public

transportation company's losses, accompanied by the congestion charge in

the Ultra-Low Emission Zone (ULEZ) in London increasing to GBP 15 per day

(Government of the United Kingdom 2020b)

Government-backed loan of US\$5.4 billion for car manufacturer Renault linked to environmental conditions, although limited information on the specific conditions has been publicly communicated (Government of France 2020)

Financial incentives for high-carbon products (e.g. combustion engine vehicles), deregulation of vehicle emission standards, or automobile company bailouts without conditions for zero-emission transition

Unconditional support to the Russian automotive industry of around US\$360 million (RUB 25 billion) through state procurement and interest rate subsidies, without any conditions for zero-emission transition (Government of the Russian Federation 2020)

Reduction of car sales tax for new cars from 5 per cent to 1.5 per cent between March and June 2020 and to 3 per cent from July to December 2020, without preferential measures for electric or hydrogen vehicles (Ho-Jeong 2020), despite an additional temporary tax cut on purchases of all-electric and hydrogen fuel-cell electric cars having been extended to 2022 (Kim 2020)

\section{(1) 3}

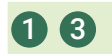


Table 4.4. Non-exhaustive overview of low-carbon and high-carbon rescue and recovery measures for the aviation sector and selected case examples as at October 2020

\section{AVIATION: low-carbon and high-carbon interventions}

Total of three low-carbon spending measures identified in 2 out of 50 countries and 48 high-carbon spending measures in 23 out of 50 countries as at October 2020 (O'Callaghan et al. 2020)

\section{Country}

.
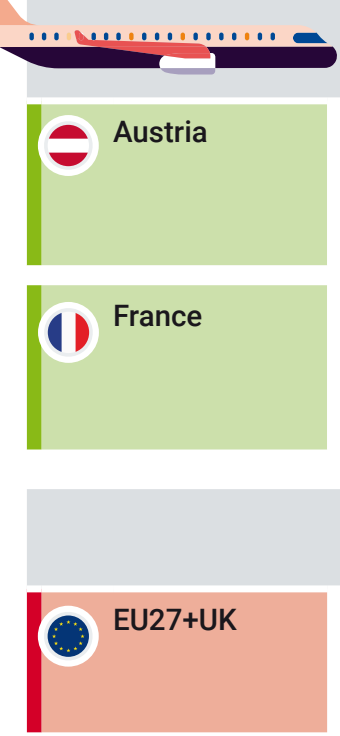

Republic of Korea

USA

\section{Case study}

Studies
Bailout of airlines or airports with conditions for zero-emission transition, and support of R\&D in zero-emission aviation technologies and infrastructure

Bailout of Austrian Airlines linked to several climate conditions such as reduction in domestic flight emissions by 2030 , end of flights where a train connection under three hours exists, and minimum price for tickets via fees and taxes (Bannon 2020a)

Bailout of Air France linked to several non-legally binding climate conditions such as fleet efficiency improvements, reduction in domestic flight emissions by 2024 and a fuel mandate by 2025 (Bannon 2020b), supplemented by US\$1.8 billion (EUR 1.5 billion) in public support directed towards developing low-carbon planes

Bailout of airlines or airports without conditions for zero-emission transition, and deregulation of environmental standards or rollback of fees and taxes

\section{Twenty-four out of $\mathbf{2 6}$ airline bailouts in EU27+UK, totalling around US\$32 billion} (EUR 26 billion), did not have any conditions for zero-emission transition as at October 2020 (Transport \& Environment 2020)

Bailouts of around US\$2.5 billion provided to Korean Air and Asiana Airlines, without any conditions attached for zero-emission transition (Yim 2020)

Financial support to airlines of around US\$60 billion, without any conditions attached for zero-emission transition, through the CARES Act (Aratani 2020)
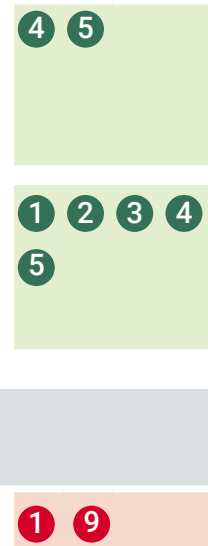

\section{Positive \\ Negative}

\section{Vivid Economics (2020a)}

5 Climate Action Tracker (2020)
2 Carbon Brief (2020)

6 Moisio et al. (2020)
3 Energy Policy Tracker (2020)

7 Martin (2020)
8 Sarkar (2020)

4 O'Callaghan et al. (2020)

9 Greenpeace (2020) 
Table 4.5. Non-exhaustive overview of low-carbon and high-carbon rescue and recovery measures for the industrial sector, and selected case examples as at October 2020

\title{
INDUSTRY: low-carbon and high-carbon interventions
}

Total of 25 low-carbon R\&D spending measures identified in 13 out of 50 countries and 47 'neutral' R\&D spending measures in 17 out of 50 countries as at October 2020 (O'Callaghan et al. 2020)

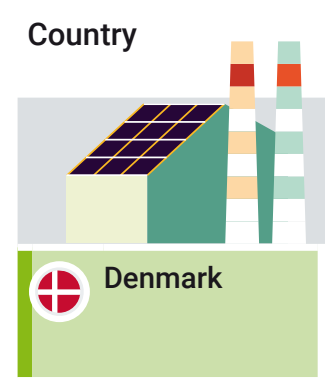

Sweden
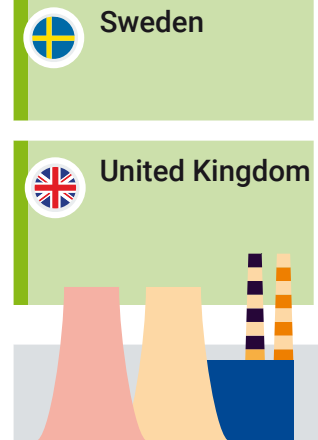

USA

G20

\section{Case study}

Financial incentives for investments in low-carbon technology, R\&D and pilot projects for difficult-to-abate sectors such as the steel and cement sector, and bailouts of industrial corporations with conditions for zero-emission transition

Grants of US\$140 million proposed to fund electrification and energy efficiency in industry between 2020 and 2024 to promote a "green transition" (Government of Denmark 2020)

Introduction of state credit guarantee programme for large-scale industrial investments that contribute to achieving the environmental and climate goals and reduce emissions (Sweden, Ministry of Finance 2020)

Around US $\$ 450$ million in funding has been provided to reduce emissions in heavy industry, for example funding to support the transition from natural gas to clean hydrogen power and the scaling-up of carbon capture and storage technology (Government of the United Kingdom 2020c)

Deregulation of environmental standards, rollback of climate measures, and bailouts of industrial corporations without conditions for zero-emission transition

Relaxation of several environmental regulations for industry and energy companies (Columbia Law School 2020), for example the Environmental Protection Agency has suspended payment of penalties for violation of environmental regulations (Friedman 2020)

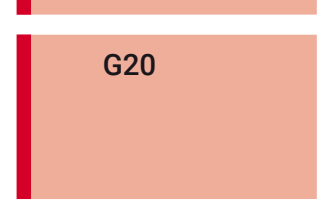

Thirteen G20 Member States have bailed out industrial corporations without conditions for zero-emission transition, or have implemented other environmentally harmful rescue and recovery measures in the industrial sector (Vivid Economics 2020a)

\section{Studies}

\section{Positive \\ Negative}

1 Vivid Economics (2020a)

5 Climate Action Tracker (2020)
2 Carbon Brief (2020)

6 Moisio et al. (2020)
3 Energy Policy Tracker (2020)

7 Martin (2020)

\section{4}

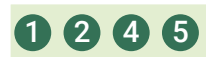

(1)

\begin{abstract}
(2020)
\end{abstract}
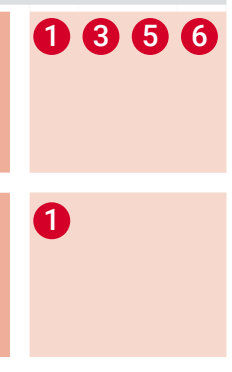
Table 4.6. Non-exhaustive overview of low-carbon and high-carbon rescue and recovery measures for the buildings and construction sector, and selected case examples as at October 2020

\section{BUILDINGS AND CONSTRUCTION SECTOR: low-carbon and high-carbon interventions}

Total of 14 low-carbon retrofit spending measures identified in 9 out of 50 countries and nine high-carbon infrastructure spending measures (excluding transport and high-carbon energy) in 5 out of 50 countries as at October 2020 (O'Callaghan et al. 2020)

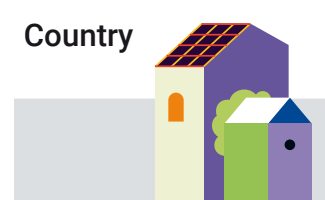

Germany
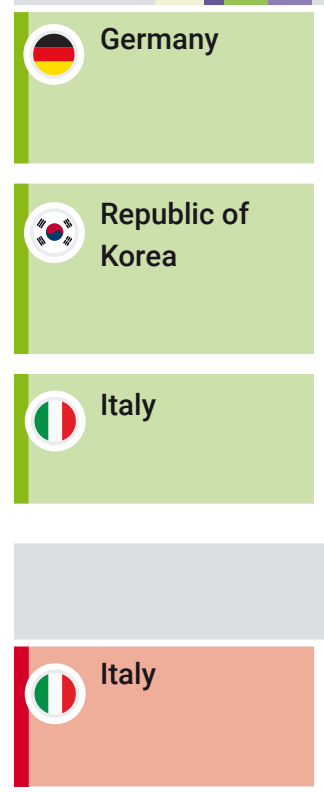

\section{Case study}

Financial and regulatory support for energy-efficient retrofits of existing buildings, and accelerated construction of low and zero-energy buildings

Additional funding of around US\$2.5 billion in 2020 and 2021 for a building renovation programme targeting energy efficiency improvements (Germany, Federal Ministry of Finance 2020)

Retrofitting of old public facilities such as day-care centres and public housing with a total investment of around US\$5.2 billion between 2020 and 2025

(Republic of Korea, Ministry of Economy and Finance 2020) and creating more than 243,000 employment opportunities

'Ecobonus' scheme providing 110 per cent tax deductions for the private installation of energy-efficient retrofits such as heat pumps (Government of Italy 2020a)

Stimulus programmes for retrofitting existing buildings or supporting new buildings without any energy efficiency criteria

Tax credits for the refurbishment and upgrade of buildings in the tourism sector (around US\$180 million per year in 2020 and 2021), without distinct conditions on energy efficiency criteria (Government of Italy 2020b)

\section{(1) 234 (5) as part of 'Package for the Future'}

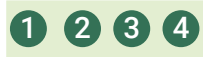
5 as part of Green New Deal

\section{(1) 234}

\section{(3) 4}
Positive
1 Vivid Economics (2020a)
2 Carbon Brief (2020)
3 Energy Policy Tracker (2020)
4 o'Callaghan et al. (2020)
Negative
5 Climate Action Tracker (2020)
6 Moisio et al. (2020)
7 Martin (2020)
8 Sarkar (2020) 
Table 4.7. Non-exhaustive overview of low-carbon and high-carbon rescue and recovery measures for the land-use and environmental protection sector, and selected case examples as at October 2020

LAND USE AND ENVIRONMENTAL PROTECTION: low-carbon and high-carbon interventions

Total of 25 low-carbon spending measures identified as green spaces and natural infrastructure investment identified in 11 out of 50 countries as at October 2020 (O'Callaghan et al. 2020)
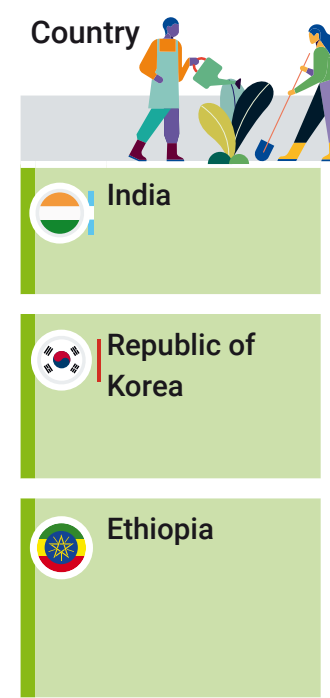

Pakistan
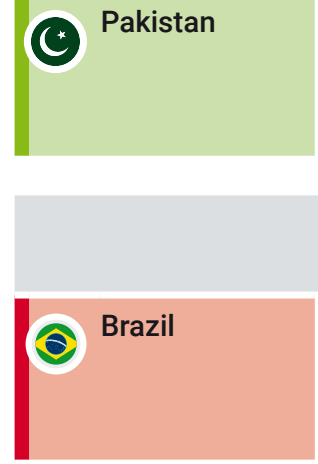

\section{Case study}

Large-scale landscape restoration and reforestation efforts ('nature-based solutions')

Additional funding (approx. US\$780) through the Compensatory Afforestation Fund Management and Planning Authority (CAMPA) to support plantation work, forest management and wildlife conservation (Government of India 2020)

Funding component of around US\$2.1 billion as part of the Green New Deal for 2020-2025 to restore the terrestrial, marine and urban ecosystems, involving the creation of more than 100,000 employment opportunities (Republic of Korea, Ministry of Economy and Finance 2020)

Ethiopia and the United Nations Economic Commission for Africa signed a Memorandum of Understanding on a four-year US\$3.6 million project on naturebased solutions for water resources infrastructure and community resilience to support Ethiopia's green recovery (United Nations Economic Commission for Africa 2020)

Three-phased approach to natural ecosystems restoration focusing on local employment creation, for example aiming to provide around 65,000 employment opportunities as part of the first stage of the 10 Billion Trees Tsunami project (Khan 2020)

Deregulation of environmental standards and rollback of environmental regulations, and dismantling enforcement of state protection for natural habitats

Changes in rules and procedures on land use regulation and law enforcement in the Amazon, Cerrado, and Mata Atlântica areas to stimulate economic activity without safeguards for environmental protection (De Freitas Paes 2020; Gonzales 2020; Observatório de Clima 2020)

Australia (states and territories)
Suspension of conservation laws in the logging industry for the next decade by the State of Victoria, as part of the Regional Forestry Agreement which exempts loggers from having to comply with certain federal conservation laws (Morton 2020)

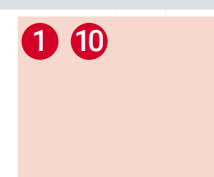

(1)

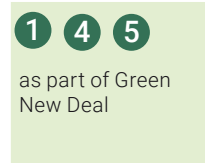

6

(4) . 


\title{
5 Bridging the gap - the role of international shipping and aviation
}

\author{
Lead authors: \\ Jasper Faber (CE Delft, the Netherlands) and David S. Lee (Manchester Metropolitan University, UK)
}

\section{Contributing authors:}

Susanne Becken (Griffith University, Australia), James J. Corbett (Energy and Environmental Research Associates, USA), Nick Cumpsty (Imperial College London, UK), Gregg Fleming (Volpe Center, U.S. Department of Transportation, USA), Tore Longva (DNV GL, Norway), Marianne Tronstad Lund (Center for International Climate Research - CICERO, Norway), Tristan Smith (University College London, UK)

\subsection{Introduction and framing}

Emissions from the shipping and aviation sectors have increased in the past decades (though they reduced in 2020 due to the COVID-19 pandemic) and accounted for approximately $2 \mathrm{GtCO}_{2}$ in 2019 (International Maritime Organization [IMO] 2020; Lee et al. in press). About twothirds of these emissions are international, meaning they are not included in national totals reported to the United Nations Framework Convention on Climate Change (UNFCCC) and are instead added as memo items. Although international emissions are not covered under the nationally determined contributions (NDCs) of most signatories to the Paris Agreement, article 4 commits its signatories to reducing all anthropogenic greenhouse gas (GHG) emissions. No sector is exempt from this commitment. At present, the International Civil Aviation Organization (ICAO) and the International Maritime Organization (IMO) are the specialized United Nations agencies tasked with addressing international GHG emissions. Shipping and aviation both largely depend on liquid fossil fuels and have inherently long technology development and fleet turnover times, which make it difficult for the sectors to decarbonize. In addition to $\mathrm{GHG}$ emissions, both sectors emit other emissions that contribute to climate change, such as nitrogen oxides $\left(\mathrm{NO}_{x}\right)$, water vapour, back carbon (soot) and sulphur dioxide $\left(\mathrm{SO}_{2}\right)$ (Eyring et al. 2010; Eide et al. 2013; Lee et al. in press).

This chapter presents current and projected emissions to assess how much the international transport sectors are contributing to the emissions gap (section 5.2). Section 5.3 analyses the technical, operational and fuel options available to decarbonize shipping and aviation. Section 5.4 contrasts the projected emissions with global emissions pathways required to meet the Paris Agreement temperature goals in order to assess when, and to what extent, the decarbonization options should be implemented, while also evaluating the current policy goals in the context of the Paris Agreement. Section 5.5 concludes the findings.

\subsection{Current emissions, projections and drivers}

Increased globalization and diversified economies have led to a rapid growth in human mobility and the transport of goods. In turn, increasingly connected and affordable transport systems have further enabled globalization and associated economic development, bringing socioeconomic benefits to parts of the population. In addition to rising global average incomes, this has caused an increase in consumer demand for travel and traded goods, reaching record levels in 2019 with 1.4 billion international tourists (World Tourism Organization [WTO] 2019), 4.5 billion passengers, 61.3 million tons of air freight (International Air Transport Association [IATA] 2020a) and 11 billion tons of world seaborne trade recorded (United Nations Conference on Trade and Development [UNCTAD] 2019).

\subsubsection{Shipping}

GHG emissions from shipping, principally carbon dioxide $\left(\mathrm{CO}_{2}\right)$, totalled approximately $1 \mathrm{GtCO}_{2}$ in 2018 , the latest year for which detailed data are available (IMO 2020), with small additional emissions of methane $\left(\mathrm{CH}_{4}\right)$ and nitrous oxide $\left(\mathrm{N}_{2} \mathrm{O}\right) . \mathrm{CH}_{4}$ emissions have risen in recent years (albeit from a low base), due to the increased number of liquified natural gas (LNG)-fuelled ships. Shipping also emitted around 100,000 tons of black carbon (soot) in 2018, which is a short-lived climate pollutant that contributes to warming (Comer et al. 2017; IMO 2020). Other non- $\mathrm{CO}_{2}$ emissions (such as $\mathrm{NO}_{x}$ and $\mathrm{SO}_{2}$ ) cause net cooling effects, largely through the formation of low-level clouds from $\mathrm{SO}_{2}$ emissions (Fuglestvedt et al. 2009; Peters et al. 2012), although in January 2020, new air quality protection regulations for shipping entered into force, with the aim of reducing these emissions (Sofiev et al. 2018). 
In 2018, international voyages (those between ports in different countries) were responsible for 71 per cent of the sector's $\mathrm{CO}_{2}$ emissions (IMO 2020). ${ }^{1}$ Many of the ships that undertake international voyages also undertake domestic voyages. For example, a ship may load cargo in a port in one country, sail to a second port in that same country to load more cargo, and then sail to a port in another country to discharge cargo.

$\mathrm{CO}_{2}$ shipping emissions in 2018 were lower than in 2008, which was the historic peak. As shown in figure 5.1, seaborne trade and emissions were closely correlated between 1990 and 2008. At the end of 2007, an oversupply of ships led ships to reduce their speed in order to ensure optimal utilization of their cargo capacity, which consequently reduced emissions. This became even more prominent in 2008 due to the decline in transport demand caused by the global financial crisis. After 2008, ships permanently reduced their speed by about 10-20 per cent compared with their pre-2008 speed, and the average size of bulkers and container ships increased, resulting in further efficiency improvements.

Figure 5.1. Historical and projected international shipping emissions and trade metrics, indexed in 2008, for 1990-2050

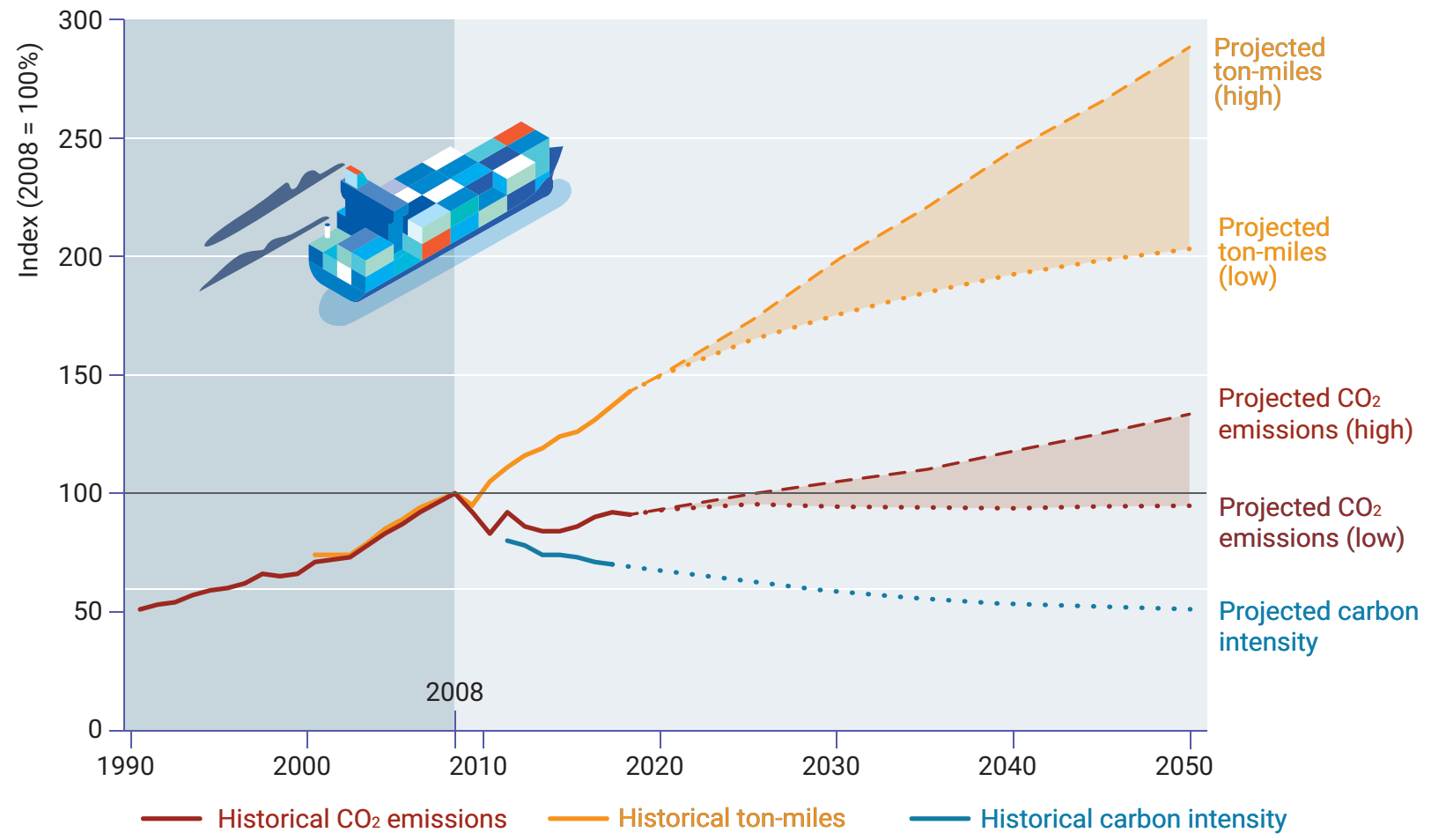

Note: The effect of COVID-19 is not included.

Source: IMO (2020)

In future decades, $\mathrm{CO}_{2}$ emissions from shipping are projected to increase by 4-50 per cent from 2018 levels according to a range of plausible business-as-usual (BAU) scenarios that assume no further policy intervention on shipping emissions. This is due to the projected $40-100$ per cent increase in transport demand, despite projected fuel efficiency improvements in some scenarios (Faber et al. 2016; IMO 2020). The main driver of the increase in transport demand is the projected growth in wealth, as there is a strong positive correlation between gross domestic product (GDP) per capita and maritime transport demand.

DNV GL (2020) estimates that COVID-19 will cause the total demand for seaborne transportation to decline by approximately 8 per cent in 2020, which will vary between cargo segments. By May 2020, some segments had seen an increase in activity compared with the same period in 2019, though container shipping capacity reduced by 6 per cent. Manufacturing is typically more affected in an economic downturn, which in turn reduces the demand for seaborne trade of manufactured products and base materials. IMO (2020) did not foresee COVID-19 as impacting emissions projections for 2030 and beyond.

\subsubsection{Aviation}

In 2018, global $\mathrm{CO}_{2}$ aviation emissions were approximately $1 \mathrm{Gt}$ (Lee et al. in press), of which about 65 per cent were international and 35 per cent domestic (Fleming and de

1 According to another definition of international shipping emissions, which refers to ship types rather than to voyages, 87 per cent of emissions are international (IMO 2020). 
Lépinay 2019). ${ }^{2}$ Emissions have increased by around 27 per cent over the last five years (an average annual increase of 4.6 per cent based on International Energy Agency (IEA) data), while passenger numbers have grown by 38 per cent (based on International Air Transport Association (IATA) data).

Despite increased access to mobility, aviation remains the preserve of high-income earners. Over 60 per cent of demand for aviation comes from inhabitants of highincome countries (Becken and Pant 2019). According to Gössling and Humpe (2020), approximately 1 per cent of the world's population account for more than half of the total emissions from passenger air travel, thus revealing a strong equity dimension to aviation as a consumer sector. Chapter 6 discusses some of the demand-side issues related to aviation emissions and how these can be managed and reimagined in a post-pandemic future.

$\mathrm{CO}_{2}$ emissions from international aviation, along with related non- $\mathrm{CO}_{2}$ emissions from water vapour, NOx and soot/ aerosol particles have a net warming impact on climate, with the total impact of both types of emission estimated at 3.5 per cent of all drivers of climate change from human activities (Lee et al. in press). Historical $\mathrm{CO}_{2}$ emissions from global aviation result in approximately 34 per cent of present-day aviation-related effective radiative forcing (ERF), with non- $\mathrm{CO}_{2}$ impacts accounting for approximately 66 per cent of ERF from (global) aviation (Lee et al. in press).

The aviation industry expects emissions to increase in the coming decades, despite the current COVID-19 pandemic, which is currently estimated to impact traffic until at least 2024 (IATA 2020b). The latest emissions projections from the eleventh meeting of the ICAO Committee on Aviation Environmental Protection (CAEP/11) (figure 5.2, prepared prior to the pandemic) suggest that emissions of international aviation will increase from about $0.5 \mathrm{GtCO}_{2}$ of emissions (2015) to 1.2-1.9 $\mathrm{GtCO}_{2}$ by 2050 (Fleming and de Lépinay 2019). Revenue ton-kilometres (a metric for transport work in the aviation sector) are also expected to increase fourfold in the same period.

Figure 5.2. Projections of $\mathrm{CO}_{2}$ emissions for international aviation

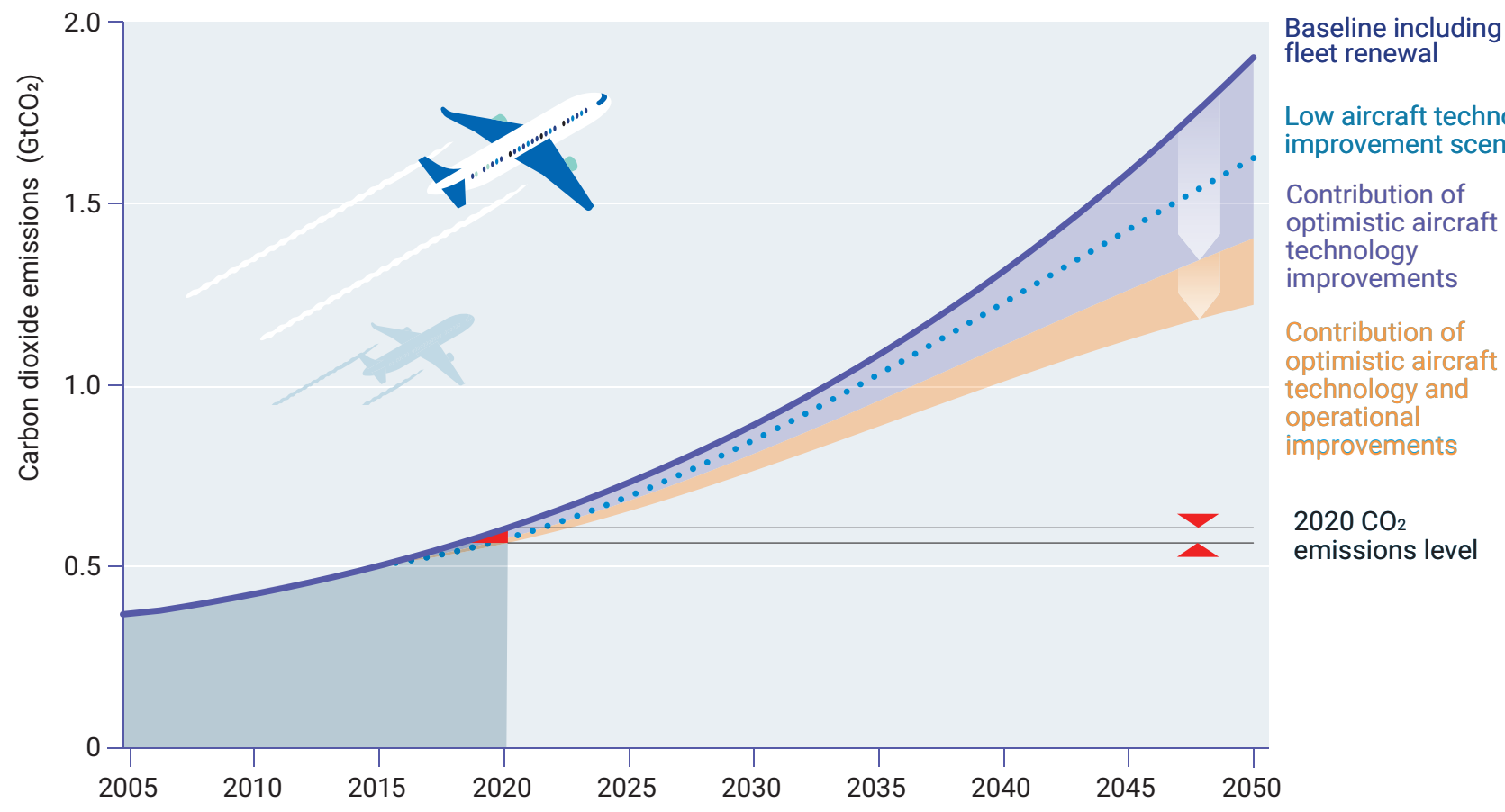

Note: Projections were made prior to the COVID-19 global pandemic.

Source: Fleming and de Lépinay (2019)

Figure 5.2 shows projections of $\mathrm{CO}_{2}$ emissions for international aviation to 2050, and incorporates projected improvements in technology, operations and infrastructure use. These trends assume that growth is unconstrained by airport infrastructure or airspace operational constraints. A wide range of factors, such as fluctuations in fuel prices and global economic conditions, can affect such trends.

The current COVID-19 pandemic has severely affected demand for aviation transport, with 2020 passenger numbers expected to be 55 per cent lower than 2019 levels, and air cargo 12-15 per cent lower (IATA 2020b; IATA 2020c), though it is too early to tell what this will mean in terms of emissions. Current IATA forecasts suggest that short-haul traffic will recover more quickly than long-haul

2 Different data sources and emissions estimation methodologies are used in the literature, which may result in some differences. For example, 'topdown' methodologies are used for IEA data, while Fleming and de Lépinay (2019) use a 'bottom-up' approach for their emissions models. 
traffic. Market analysts suggest that some of the reductions in corporate travel could be permanent, which is supported by the Global Business Travel Association's ongoing polling (Global Business Travel Association [GBTA] 2020). Overall, emissions are likely to increase as traffic recovers, but there is significant uncertainty over the rate of recovery and impact on long-term projections.

\subsubsection{International shipping and aviation emissions and the goals of the Paris Agreement}

Unless States choose to include international shipping and aviation GHG emissions in their initial NDCs, these emissions are not addressed by national policies. The emissions trajectories from the Intergovernmental Panel on Climate Change (IPCC) Special Report on Global Warming of $1.5^{\circ} \mathrm{C}$ (SR1.5) (2018) indicate that global temperature increase can only be limited to no more than $1.5^{\circ} \mathrm{C}$ if $\mathrm{CO}_{2}$ emissions reach net zero by 2050 (interquartile range: 2045-2055), with active permanent removal of $\mathrm{CO}_{2}$ from the atmosphere thereafter. To limit global warming to below $2^{\circ} \mathrm{C}, \mathrm{CO}_{2}$ emissions need to reach net zero by 2070 (66 per cent probability). Based on these pathways, it is clear that international shipping and aviation must be completely decarbonized by around 2050 for $1.5^{\circ} \mathrm{C}$ and by 2070 for $2^{\circ} \mathrm{C}$.

This is illustrated in figure 5.3, which shows combined $\mathrm{CO}_{2}$ emissions from international shipping and aviation as percentages of the available $\mathrm{CO}_{2}$ budget, relative to IPCC illustrative $1.5^{\circ} \mathrm{C}$ scenarios. Without further mitigation action, combined international emissions will consume around 60-220 per cent of the available global $\mathrm{CO}_{2}$ budget by 2050 . This remains the case even when the benefits of technology are included to arrive at the 'low' estimates for fuel usage.

Figure 5.3. Global emissions pathways of $\mathrm{CO}_{2}$ limiting global warming to $1.5^{\circ} \mathrm{C}$ under IPCC illustrative $1.5^{\circ} \mathrm{C}$ scenarios

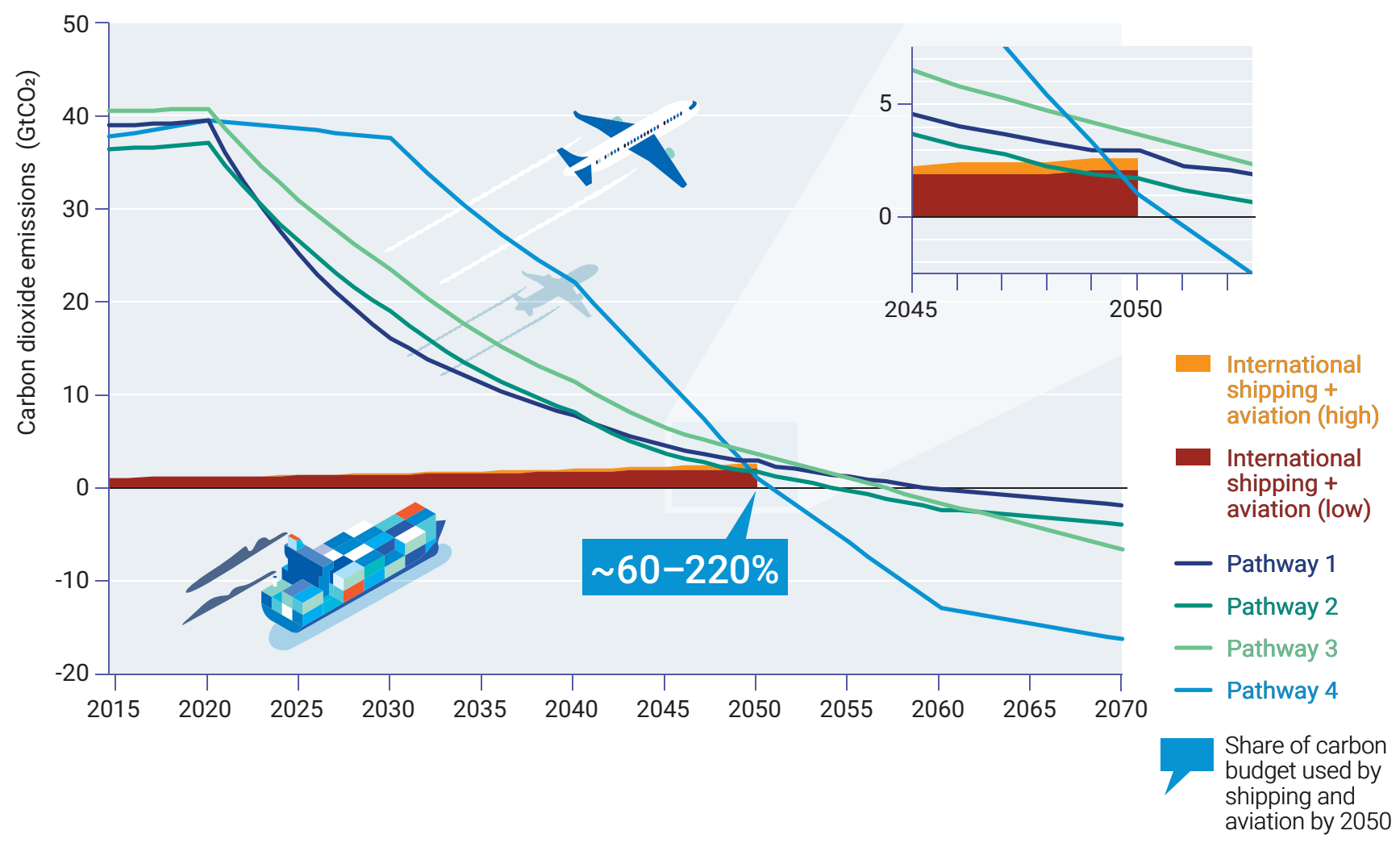

Sources: Pathways redrawn from figure SPM3a, IPCC (2018); international aviation + shipping emissions of $\mathrm{CO}_{2}$ from Fleming and de Lépinay (2019)

\subsection{Mitigation options}

\subsubsection{Shipping}

\section{Improving supply chains and logistics}

There is significant potential to improve efficiencies throughout transport networks, aligning transport demand with size, operations and functionality of ships as well as land-based infrastructure and logistics systems. Improving fleet efficiency can be achieved through increased utilization (for example, reducing ballast leg using larger vessels assuming the increased capacity is utilized), alternative sea routes that have shorter distances, and reduced speed (DNV GL 2019).

Reducing ships' speed has large emissions reduction potential. The required propulsion power of a ship increases approximately to the third power of its speed. Since 2008, the shipping fleet has reduced its average speed and significantly reduced its emissions, though further reductions are possible (IMO 2020). Reducing the speed of large tankers from 12 knots to 11 knots for example, 
reduced emissions per ton-mile by around 8 per cent. Below 7 knots, the emissions begin to increase again (Lindstad and Eskeland 2015).

\section{Improving ship design and operation}

The newest generation of ships (built after 2015) are typically about 10-15 per cent more efficient than older ships, mainly due to optimized hull design and propeller efficiency and reduced auxiliary loads. This was at least partly driven by regulation on the Energy Efficiency Design Index (EEDI), an IMO efficiency standard that applies to new ships contracted from 2013 (Faber and 't Hoen 2016). Ships built in the next five years may improve by another 15-25 per cent through improved machinery and electricity systems, which could include measures such as hybridization (peak load shaving in conjunction with batteries) and waste heat recovery. Later generations could include a full-scale application of sails and kites, air lubrication and more advanced waste heat recovery, with another 5-10 per cent improvement on average (DNV GL 2017). Operational measures could reduce emissions by a further 5-10 per cent (DNV GL 2017; IMO 2020).

The total potential of improving the energy efficiency of shipping up to 2050, including logistics and supply chain improvements, speed reduction and ship design and operation, ranges from 35 to 55 per cent compared with 2018 (DNV GL 2019; Balcombe et al. 2020; IMO 2020). Most measures are expected to be cost-efficient with current fuel prices, though wind power, solar panels, air lubrication and waste heat recovery, which require significant investment, need a higher fuel price to be cost-efficient (IMO 2020).

\subsubsection{Aviation}

\section{Technological improvements - engine and airframe}

A recent review (ICAO 2019a) requested by ICAO using independent experts examined the two types of aircraft that burn the overwhelming majority of fuel, the single-aisle (such as the Boeing 737 and Airbus A320) and the twin-aisle (such as the Boeing 777 and 787, and Airbus A330 and A350), and estimated their performance in 10 and 20 years (2027 and 2037). According to the review, radical alteration in aircraft shape is unlikely by 2037, with improvements limited to 'tube and wing' type aircraft. The following targets were deemed challenging but possible by 2037: reductions in fuel burn for single-aisle and twin-aisle aircraft of 21.6 per cent and 21.0 per cent, respectively, which are annual improvements of 1.22 and 1.28 per cent. Prior to the COVID-19 pandemic, in October 2018, IATA forecasted compound annual growth in air travel of 3.5 per cent, which equates to a doubling over 20 years and is considerably greater than the reductions likely to follow from technological improvements.

In the ICAO/CAEP report, independent experts accepted the constraints on design that are currently imposed. In line with current practice, aeroplanes are designed for longer ranges than required, as this gives flexibility in terms of operations and makes resale easier, though at the expense of potential fuel-burn reductions. In a 2010 ICAO review (ICAO 2010), the following additional, but relatively small, savings were identified from changing design constraints:

- reducing the cruise Mach number from $M=0.84$ to 0.78 would give potential savings of around 4 per cent for twin-aisle aircraft

- increasing wingspan for some designs would reduce fuel burn, though this would require wider gates at airports or folding wings (as on the Boeing 777X)

injecting water into engines to mitigate the hightemperature problems experienced at take-off would improve engine performance during cruise as less turbine cooling air would be required

restricting top-of-climb performance (to make the clime rate smaller) would allow for better optimization of engines.

The independent experts also looked at advanced alternative aircraft types, such as the blended wing body (a design that merges fuselage with a large delta wing), and configurations with wider bodies, smaller wings and engines at the rear of the aeroplane. For the blended wing body, the fuel-burn reduction was 10-12 per cent compared with advanced conventional aircraft. Another alternative design, the Aurora D8, which was studied at the Massachusetts Institute of Technology (MIT) with support from the National Aeronautics and Space Administration (NASA), has wings and a separate fuselage, and offers roughly a 13 per cent improvement. Chen et al. (2019) estimate that blended wing bodies will be 31.5 per cent more efficient in terms of fuel burn than current aircraft. In general, there are likely to be improvements in aircraft airframes and engines in the next 20 or so years, which will improve the burn-fuel metric by around 1.2 per cent per year. However, the crucial conclusion is that the sum of the potential improvements does not come near to matching the projected growth in aviation, let alone to reducing emissions from the current level.

\section{Operational improvements}

In practice, the operation of aircraft is generally less than optimal as they often fly below full capacity and cannot take the best flight route due to diversions and holding patterns. Improved operations could be achieved from, for example, single-engine taxi procedures and ground holds in the terminal area, reduced or de-rated thrust on departure, more direct routing and weather-optimized routing en route, and continuous descent approach (CDA) during arrival. A recent ICAO study calculated that routing inefficiencies currently total 2-6 per cent (Brain and Voorbach 2019). Clearly, the scope for operational improvements to reduce $\mathrm{CO}_{2}$ emissions is limited.

\subsubsection{Alternative fuels}

For both the aviation and shipping sectors, decarbonization cannot occur without a transition away from the fossil fuels 
that they currently burn to alternative fuels. Such fuels could include synthetic hydrocarbon fuels 3 produced from biomass, waste products or $\mathrm{CO}_{2}$ direct air capture (DAC) from the atmosphere (The Royal Society 2019), zero-carbon fuels and energy carriers, such as hydrogen and ammonia (as long as they are produced without generating additional GHG emissions). This section discusses non-fossil alternative fuels for shipping and aviation that have low, zero or negative GHG emissions throughout their life cycle.

\section{Biofuels}

Various biofuels are currently used in shipping and aviation, albeit on a small scale, with estimates suggesting that these will comprise less than 1 per cent of total aviation fuel by 2024 (International Energy Agency [IEA] 2019). While biofuels can have lower life cycle emissions, assessing their merits is complex, as gains towards 'carbon neutrality' depend heavily on their feedstocks and processes, as well as on their direct and indirect emissions, particularly those resulting from land-use change (LUC) from biofuel production. Assuming that biofuel combustion is carbon neutral is therefore a fundamental accounting error that rests on implicit spatiotemporal boundaries and assumptions (Searchinger et al. 2009), as for many biofuels, the energy return on investment is comparatively low or possibly negative (Hall, Lambert and Balogh 2014; Chiriboga et al. 2020). The availability of land and water is also a key and potentially ethical constraint on the availability of biofuel (Nuffield Council on Bioethics 2011).

For shipping, biofuels are currently three to five times as expensive as conventional fuels (CE Delft and Ecorys forthcoming) and are of similar magnitudes for aviation (IEA 2018).

\section{E-fuels from renewable energy}

Other pathways have been discussed for the production of synthetic hydrocarbon fuels, such as power-to-liquid 'electro-fuels' (e-fuels) (Schmidt et al. 2018), or more broadly 'power-to-x pathways' (Kober et al. 2019) (for example, by incinerating municipal waste). The generation of such fuels critically requires the availability of renewable electricity, $\mathrm{CO}_{2}$ and water to synthesize hydrocarbon fuels. To create carbon-neutral fuels, hydrogen needs to be produced via electrolysis powered by renewable energy, while $\mathrm{CO}_{2}$ needs to be taken directly from the atmosphere by DAC and used in Fischer-Tropsch, methanation or methanol synthesis processes. DAC still represents a significant challenge, although some $\mathrm{CO}_{2}$ may be captured from residual emissions, which includes processes such as fermentation and cement manufacturing.

In terms of environmental performance, e-fuels have much smaller land requirements than biofuel and do not depend on arable land (Schmidt et al. 2018), though they do require significant renewable electricity (Fuhrman et al. 2020). Notwithstanding the significant barriers of sufficient available renewable energy and $\mathrm{CO}_{2}$ from $\mathrm{DAC}$, creating synthetic fuel is technologically feasible, though at much greater costs than direct fossil fuel extraction and refining.

In the case of aviation, the use of renewably-generated synthetic fuels (or biofuels) would also benefit the climate through reducing contrail-related warming, due to their absence of soot particles (which are formed from fossil kerosene aromatics and cause the formation of contrails) (Bier et al. 2017; Bier and Burkhardt 2019).

\section{Hydrogen and ammonia}

Hydrogen can be used as a zero-carbon fuel, either in combustion engines or fuels cells. To ensure that hydrogen is carbon neutral, it must be generated from renewable energy sources or reformation of fossil fuels during carbon capture and storage (CCS).

Although liquid hydrogen $\left(\mathrm{LH}_{2}\right)$ has an energy density per unit mass approximately three times greater than aviation kerosene, it has a much lower energy density per unit volume. Thick layers of insulation are also required, which further increases the effective volume. Its use in aviation would therefore require radical aircraft design changes (McKinsey and Company 2020). Similarly, for ships, hydrogen requires about seven times the space of diesel tanks (DNV GL 2019) and would result in a loss of revenue and range. There are also many infrastructural barriers to $\mathrm{LH}_{2}$-powered aircraft or ships, such as generation and distribution, meaning its development is only likely under a larger-scale hydrogenoriented energy economy.

The energy content of hydrogen may be obtained without the problems of cryogenic or high-pressure storage by using a hydrogen-containing compound as a carrier. This is done with hydrocarbons but can also be done with nitrogen to form ammonia. Burning ammonia releases the energy of hydrogen on combustion without producing $\mathrm{CO}_{2}$. Ammonia requires a volume of around 3.5 times the space of traditional fuel tanks (DNV GL 2019). Internal combustion engines can be modified to run on ammonia, though research and development are needed, including on ways to limit emissions of $\mathrm{N}_{2} \mathrm{O}$, a potent $\mathrm{GHG}$ (Valera-Medina et al. 2018).

\section{Full-electric propulsion}

Full-electric propulsion can be carbon neutral if the electricity is generated without emitting $\mathrm{CO}_{2}$ (Epstein and O'Flarity 2019). However, a major barrier in both aviation and shipping is that the energy stored in batteries per unit mass is around $250 \mathrm{~W}-\mathrm{hr} / \mathrm{kg}$, whereas hydrocarbon fuel has a calorific value of around 12,000 W-hr/kg. In addition, electrical machinery and control units are heavy and large.

3 Meaning hydrocarbon fuels generated from non-fossil fuel feedstocks and with renewable electricity in the manufacturing process (and avoiding an increase in fossil-powered electricity generation because of the increase in demand for electricity) 
For aircraft, the heaviness of batteries means that batterypropelled aircraft will be limited to shorter ranges. A recent paper by Langford and Hall (2020) states that electric propulsion makes economic sense for ranges between 50 and 200 miles, meaning it will only slightly contribute to reductions in aviation sector emissions. Similarly, batteries can be used as propulsion energy for ships undertaking short voyages, most obviously ferries, but not long voyages unless radical improvements are made.

\section{Implications and key challenges: a focus on price signals and economic incentives}

There are several options that the shipping sector can take to transition away from fossil fuels. Techno-economic analyses from the last two years (Ash and Scarbrough, 2019; Lloyd's Register [LR] and University Maritime Advisory Services [UMAS] 2019; DNV GL 2020; IEA 2020) all indicate that sustainable ammonia is the cheapest decarbonization option for shipping in many scenarios, and would only require a small evolution in current on-board machinery. However, the technology is just in development and full-scale pilots are unlikely for another three years, thus prolonging the period of uncertainty in least-cost fuels.

Non-hydrocarbon fuel options for aviation require radical airframe/engine and infrastructural changes. In contrast, 'drop-in' fuel options, which include alternative hydrocarbon fuels such as biofuels and e-fuels, require little or no changes to aircraft, though they still emit $\mathrm{CO}_{2}$ when combusted in engines. Despite this, drop-in fuels achieve greater climate benefits compared with the life cycle of conventional jet fuel.

The use of alternative low- or zero-carbon fuels will involve massive investment, most of which (90 per cent) will finance the production and distribution infrastructure required, with far less required for on-board engines and fuel storage (Carlo et al. 2020). For operators, this will be reflected in the cost of fuel, which is significant for both shipping and aviation. Future carbon-neutral and zero-carbon fuel prices are estimated to cost in the range of US\$20-100/GJ, which is significantly higher than current aviation fuel costs of around US\$7.5/GJ. IEA estimated that the mean production costs of aviation biofuels in 2018 were approximately two to three times that of fossil jet kerosene (IEA 2018). The major uncertainty lies in the cost and availability of the primary energy sources, such as sustainable biomass and renewable electricity (DNV GL 2020; IMO 2020; LR and UMAS 2020). Shipping fuels traded at around US\$8-9/GJ in summer 2020 (Ship \& Bunker undated), although recent prices have reached over US\$16/GJ.

A shift to fuels that emit low GHG emissions and are renewable provides a very strong economic signal that will further affect the fundamental inputs to fleet growth scenarios. If higher fuel costs translate into airfares, demand will reduce according to price elasticities, assuming all other factors remain equal. Elasticities for passenger air travel vary considerably (Smyth and Pearce 2008) but could average in the order of -1.1 across travel classes
(Becken and Carmignani 2020). In the case of shipping, supply chains that adapt to these new economic conditions may enable fleets using renewable fuels to modify their services and modernize their technologies in such a way that allows GHG targets to be met with minimal impacts on the growth in demand for shipping services (Halim, Smith and Englert 2019).

Ultimately, the price gap between incumbent fossil fuels and post-fossil fuels represents a key challenge that prevents investment both in the sectors and infrastructure on land. Without sufficiently stringent regulation in place to force or enable a business case for zero-carbon fuel use, these investments are unlikely to flow at the required scale until there is either a customer preference or a price premium for zero-carbon shipping services.

\subsection{Pathways to lower emissions}

Section 5.2 shows that projected emissions from shipping and aviation are incompatible with emissions pathways that are consistent with the Paris Agreement temperature goals, given projected increases and the lack of permanent $\mathrm{CO}_{2}$ removals. This means that the decarbonization options presented in section 5.3 need to be implemented despite their high costs. This section discusses the agreed policy goals for both sectors, concludes that they are not sufficient to achieve full decarbonization by 2050 or well before 2070 and discusses how policies could be intensified.

\subsubsection{Current shipping policies}

In 2011, the IMO adopted mandatory technical and operational energy efficiency measures that were expected to significantly reduce the amount of $\mathrm{CO}_{2}$ emissions from international shipping. These mandatory measures (EEDI/ Ship Energy Efficiency Management Plan - SEEMP) entered into force on 1 January 2013. In 2016, additional amendments were adopted to mandate the collection and reporting of ships' fuel oil consumption data. The IMO's Marine Environment Protection Committee (MEPC) adopted the Initial IMO Strategy on reduction of GHG emissions from ships in 2018, which sets out levels of ambition for shipping emissions. These are stated in the strategy as:

phase out GHG emissions from international shipping as soon as possible through strengthened energy efficiency design requirements for ships

improve the carbon intensity $\left(\mathrm{CO}_{2}\right.$ emissions per unit of transport work) of international shipping by at least 40 per cent in 2030 and 70 per cent by 2050, both relative to 2008

set GHG emissions from international shipping on a declining pathway as soon as possible, reducing the total annual GHG emissions of international shipping by at least 50 per cent by 2050 compared with 2008 as a point on a pathway of emissions 
reductions consistent with the Paris Agreement temperature goals.

The IMO is due to agree on a Revised GHG Strategy in 2023, which will be a key opportunity to update the quantitative targets in line with the latest science, and to remove current ambiguities on their alignment to the Paris Agreement temperature goals. Currently, $\mathrm{CO}_{2}$ emissions from domestic shipping are generally not addressed in NDCs.

\section{Role of non-State actors and national strategies}

The system change required for shipping to decarbonize is considerable and demands industry regulation in order to overcome a range of market barriers and failures. The IMO's most common regulatory target is ships and therefore shipowners, though significant evidence shows that there are many additional energy efficiency barriers and failures (Faber et al. 2012; Rehmatulla and Smith 2015).

Private standards and initiatives to reduce GHG emissions from shipping include the following:

Getting to Zero Coalition: a collaboration of approximately 140 corporations focused on achieving the goal of establishing scalable zero-carbon energy solutions for international shipping from 2030 (Global Maritime Forum 2020).

Poseidon Principles: a commitment to transparent annual reporting of portfolio operational carbon intensity relative to an interpretation of the Initial IMO Strategy by financial institutions representing approximately 30 per cent of the capital invested in international shipping (Poseidon Principles undated)

Sea Cargo Charter: a commitment to transparent annual reporting of supply chain operational carbon intensity relative to an interpretation of the Initial IMO Strategy by charterers and cargo owners (Sea Cargo Charter undated).

Altogether, these create a growing set of decarbonizationaligned initiatives that will move capital and purchasing decisions and hold organizations accountable to the Paris Agreement temperature goals. Their connection to the Initial IMO Strategy and Paris Agreement temperature goals indicates that a clarification of the IMO's ambitions within its Revised Strategy could be easily translated into further private sector action.

\subsubsection{Current aviation policies}

ICAO, as a specialized United Nations organization, has the lead role in steering the aviation industry's response to climate change goals. It has developed two global aspirational climate change goals for international aviation, which are to improve fuel efficiency by 2 per cent per year until 2050, and to achieve carbon-neutral growth from 2020 onward. ICAO Member States have identified four main elements in a 'basket of measures' to achieve these goals: aircraft technologies, operational improvements, sustainable alternative fuels and a market-based mechanism. Member States are also exploring the feasibility of a long-term aspirational goal for international aviation (ICAO 2016; ICAO 2019b).

The means of in-sector reductions include aircraft technology improvements through the Aeroplane $\mathrm{CO}_{2}$ Standard (ICAO undated a), along with guidance on operational improvement measures to minimize fuel burn (ICAO undated b) and sustainability criteria for aviation fuels. The Aeroplane $\mathrm{CO}_{2}$ Standard is expected to deliver incremental reductions in line with historic improvements in efficiency. Recent reports suggest that about 1.2-1.4 per cent in fleet efficiency gain is possible per year (ICAO 2019; Fleming and de Lépinay 2019), which falls short of the ICAO target of 2 per cent per year and is significantly less than the projected annual growth in aviation.

The route taken by ICAO to achieve carbon-neutral growth is being predominantly pursued via out-of-sector measures, in particular through the offsetting element of the Carbon Offsetting and Reduction Scheme for International Aviation (CORSIA), which sets a target of not increasing net $\mathrm{CO}_{2}$ emissions from international aviation over average 20192020 levels for the 2021-2035 period (ICAO 2020). ${ }^{4}$ CORSIA will require airlines to purchase eligible units to offset emissions above the baseline. Airlines can reduce their offsetting requirement by claiming emission reductions from CORSIA eligible fuels, thus incentivizing the use of fuels with a lower carbon footprint. It is crucial that the UNFCCC and Member States provide clarity on mechanisms to avoid double counting of units. The nature of offsetting means that there will be no absolute reductions in the aviation sector itself through the use of such credits, and could in fact result in a potential increase in $\mathrm{CO}_{2}$ emissions. Instead, aviation relies on other sectors' avoidance or removal of carbon. By not only continuing to emit but potentially increasing emissions, the net effect will be that no overall reductions can be achieved. This outcome is in stark contrast with the reduction pathway necessary for limiting warming to within $1.5^{\circ} \mathrm{C}$ (Becken and Mackey 2017). Furthermore, the ambiguity of international aviation's $\mathrm{CO}_{2}$ emissions in the Paris Agreement is a constraint to multilateral regulation.

Regardless of concerns around the net benefit of offsetting, Scheelhaase et al. (2018) estimate that CORSIA will result in the offset of only 12 per cent of total international and domestic aviation emissions by $2030 .{ }^{5}$ Currently, offsets

4 This only refers to growth over and above the 2019-2020 levels. Owing to COVID-19 air travel disruptions, the ICAO Council has changed the baseline for the CORSIA pilot period to 2019 levels.

5 CORSIA only addresses international emissions. 
are almost exclusively provided by emissions avoidance. At a hypothetical maximum, if additionality is assumed, only 50 per cent of the emissions will be 'offset' (Becken and Mackey 2017) as the 'baseline' is an intention to emit two units of $\mathrm{CO}_{2}$; if the avoidance is achieved, aviation still emits one unit. However, additionality is controversial as it inherently cannot be proven (Warnecke et al. 2019). More speculatively, it is possible that in the future, offsets particularly sequestration offsets such as afforestation/ reforestation - may become scarce as States use them in their NDC accounting (which also presents a potential double-counting issue).

CORSIA sits alongside several other policies, most notably the European Union Emissions Trading Scheme (EU ETS) that currently includes intra-European flights. How European flights will be treated in terms of compliance with both the EU ETS and CORSIA remains a point of uncertainty (Erling 2018; Scheelhaase et al. 2018; Maertens et al. 2019).

\subsubsection{Intensifying policy measures to achieve decarbonization}

The previous section shows that decarbonization of shipping and aviation in line with the Paris Agreement is very challenging but necessary and feasible. It requires policies that specify energy consumption reduction targets for existing fleets, along with policies that aim to achieve a rapid transition away from fossil fuels to alternative fuels with a lower carbon footprint. Policy instruments related to the introduction of new fuels should incentivize an early adoption phase this decade and take a full life cycle approach to emissions accountancy (DNV GL 2020). Policies should aim to rapidly scale the deployment of new fuels as soon as possible (given the long lifetimes of assets), encourage investment in production processes and ramp up the required generation of renewable electricity.

Suitable regulation to bridge the fuel pricing gap could start at the domestic or regional levels. Satellite observations of shipping activity reveal that an estimated 30 per cent of total shipping emissions fall directly within the responsibility of national governments, which is twice the magnitude previously estimated (UCL 2020). Governments could therefore take action on this policy area as part of their NDCs. Domestic or regional actions towards regulating shipping emissions could also prompt ambitious action at the international level (known as 'autonomous interaction' in international law) and serve as a signal to the industry (Martinez Romera 2016).

Given that supply and demand are interlinked, and because investors need to have confidence that fuels will find a market or that ships or aircraft will be able to purchase the type of fuel they require, it takes time to make a transition. Due to these various lag effects, it is important to start the transition early and gradually, taking into account all United Nations Sustainable Development Goals (SDGs).

\subsection{Conclusions}

1. If left unabated, the international shipping and aviation sectors are projected to emit increasing amounts of $\mathrm{CO}_{2}$ and other $\mathrm{GHG}$ emissions in the coming decades. BAU scenarios indicate that international emissions from these sectors will consume between 60-220 per cent of allowable $\mathrm{CO}_{2}$ emissions under the IPCC SR1.5 illustrative scenarios by 2050 .

2. Current policy frameworks are insufficient and additional policies are therefore required to bridge the gap between the sectors' current BAU trajectories and GHG pathways consistent with the Paris Agreement temperature goals.

3. Improvements in technology and operations can increase the fuel efficiency of transport if further policies incentivize them. However, due to expected increases in demand (even considering the potential impacts of the current global COVID-19 pandemic), improvements are unlikely to result in decarbonization and absolute reductions of $\mathrm{CO}_{2}$ for either the shipping or aviation sectors.

4. Both sectors will therefore need to combine a maximization of energy efficiency with a rapid transition away from fossil fuel. Fossil fuel substitutes will need to be produced without combustion of fossil fuels, which will require a decarbonization (and rapid scale-up) of new production and supply chains.

5. International aviation currently intends to meet its ICAO goals through heavily relying on carbon offsets, which do not represent absolute reductions, but at best, provide time to transition to low-carbon fuels and introduce energy efficiency improvements. At worst, offsets create a disincentive for investment in in-sector decarbonization and delay the necessary transition. Current carbon offsetting is clearly not a long-term solution and therefore needs to be minimized and eventually phased out. ICAO recognizes this through the CORSIA review scheduled for 2032.

6. For the next few decades it is highly likely that aircraft will be fuelled with hydrocarbons due to their inherent advantages as fuels. Compared with aeroplanes, ships have a less constrained design in terms of volume and mass of fuel, and therefore have greater options, including ammonia.

7. Biofuels can have a lower carbon footprint than fossil hydrocarbon fuels, but this is sensitive to induced LUC emissions, either direct or indirect, which are difficult to quantify. Large-scale production of fossil fuel substitutes will be difficult, expensive and potentially detrimental to the environment. 
8. The hydrogen feedstock used in ammonia and synthetic hydrocarbon fuel will only present net benefits if the production is powered by renewable electricity and if large amounts of $\mathrm{CO}_{2}$ are available without additional combustion of carbon-containing material. The use of synthetic fuels and biofuels in aviation would help reduce warming from contrail cirrus.

9. Although there are large uncertainties surrounding demand and price, the cost of fuel could increase severalfold, regardless of the feedstock and process. Any increases in the cost of fuel will raise the cost of both aviation and shipping. This will likely supress demand, especially for aviation, which may ultimately be the most effective means to manage the sector's emissions.

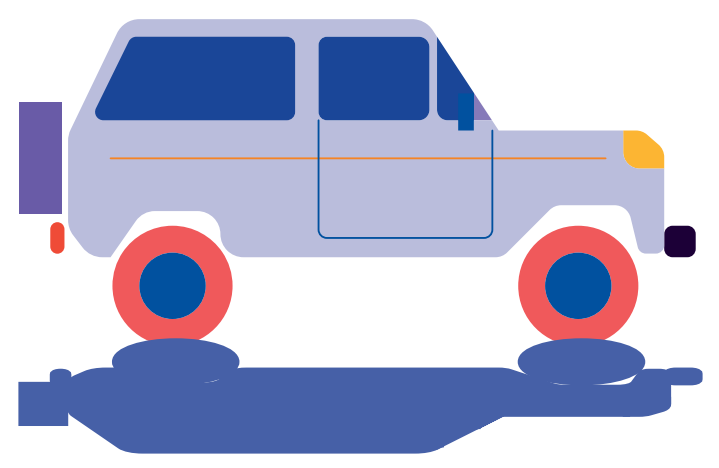




\title{
6 Bridging the gap - the role of equitable low-carbon lifestyles
}

\author{
Lead authors: \\ Stuart Capstick (Cardiff University, Centre for Climate Change and Social Transformations, Tyndall Centre for Climate \\ Change Research, UK), Radhika Khosla (University of Oxford, UK) and Susie Wang (Climate Outreach, UK)
}

\section{Contributing authors:}

Nicole van den Berg (Utrecht University, the Netherlands), Diana Ivanova (University of Leeds, UK), Ilona M. Otto (Wegener Center for Climate and Global Change, University of Graz, and Potsdam Institute for Climate Impact Research, Germany), Timothy Gore (Oxfam International, UK), Adam Corner (Climate Outreach, Centre for Climate Change and Social Transformations, UK), Lewis Akenji (Hot or Cool Institute, Germany), Claire Hoolohan (University of Manchester, Centre for Climate Change and Social Transformations, Tyndall Centre for Climate Change Research, UK), Kate Power (KR Foundation, Denmark), Lorraine Whitmarsh (University of Bath, Centre for Climate Change and Social Transformations, Tyndall Centre for Climate Change Research, UK)

\subsection{The consumption problem and why lifestyles are critical to tackling climate change}

Minimizing the impacts of climate change requires rapid transitions in people's lifestyles and how we organize our societies, institutions and infrastructure. This is underscored by the fact that household consumption accounts for around two-thirds of global greenhouse gas (GHG) emissions; Ivanova et al. (2016) estimate lifestyle and consumption emissions at 65 per cent of the global total, while Hertwich and Peters (2009) suggest the proportion to be around 72 per cent of total emissions. ${ }^{1}$ On an aggregate level, compliance with the $1.5^{\circ} \mathrm{C}$ goal of the Paris Agreement will require reducing consumption emissions to a per capita lifestyle carbon footprint of around 2 to 2.5 tons of $\mathrm{CO}_{2}$ e by 2030, and an even smaller 0.7 tons by 2050 (Intergovernmental Panel on Climate Change [IPCC] 2018; Institute for Global Environment Strategies [IGES] et al. 2019; Ivanova et al. 2020). Most climate mitigation pathways that seek to keep temperature rise to within $1.5^{\circ} \mathrm{C}$ envisage a major role for lifestyle change (IPCC 2018). The International Energy Agency (IEA 2020) has likewise concluded that behaviour change is an integral part of emissions reduction strategies that accomplish net-zero emissions by 2050 , emphasizing in particular the need for changes to domestic energy use, as well as reductions in car use and passenger aviation (see chapter 5).

Understanding the distribution of lifestyle emissions among populations and by activities is important for equitable targeting of mitigation measures, in order to encourage reductions from households with high consumption emissions and to avoid regressive impacts associated with imposing burdens on the poor (Rao et al. 2017; Roberts et al. 2020; Wiedman et al. 2020). Average consumption emissions vary substantially between countries. For example, current per capita consumption emissions in the United States of America are approximately 17.6 tons $\mathrm{CO}_{2}$ e per capita, around 10 times that of India at 1.7 tons per capita. By contrast, the European Union and the United Kingdom together have an average footprint of approximately 7.9 tons per capita (see chapter 2).

A range of estimates point to a strong correlation between income and emissions, with a highly unequal global distribution of consumption emissions. Such studies estimate that the emissions share of the top 10 per cent of income earners is around 36-49 per cent of the global total, whereas the lowest 50 per cent of income earners account for around 7-15 per cent of all emissions (Chakravarty et al. 2009; Chancel and Piketty 2015; Oxfam 2015; Hubacek et al. 2017; Dorband et al. 2019; Oxfam and Stockholm Environment Institute [SEI] 2020). This disparity is particularly stark where studies have estimated footprints among the very highest-income, highest emitters: the combined emissions share of the top 1 per cent of income earners has been found to very likely be larger than - and perhaps double - that of the bottom 50 per cent (Chancel and Piketty 2015; Oxfam and SEI 2020). Around half the consumption emissions of the global top 10 per cent and 1 per cent are associated with citizens of high-income countries, and most

1 Calculated using consumption-based accounting, encompassing GHG emissions associated with the production and use of products and services used by households. 
of the other half with citizens in middle-income countries (Chancel and Piketty 2015; Oxfam and SEI 2020). One study estimates that the 'super-rich' top 0.1 per cent of earners have per capita emissions of around $217 \mathrm{tCO}_{2}-$ several hundred times greater than the average of the poorest half of the global population (Oxfam and SEI 2020).

Estimates of the per capita $\mathrm{CO}_{2}$ consumption emissions of different global income groups are shown in figure 6.1, based on Oxfam and SEI (2020). This analysis estimates per capita $\mathrm{CO}_{2}$ emissions rather than $\mathrm{CO}_{2}$-equivalent, and allocates all consumption emissions to individuals rather than just those associated with household consumption. To indicate the relative scale of lifestyle emission changes required, a target for global average per capita consumption emissions of $2.1 \mathrm{tCO}_{2}$ per capita in 2030 is also shown, as implied by $1.5^{\circ} \mathrm{C}$-consistent pathways estimated by Oxfam (2020). Estimates in figure 6.1 show that per capita consumption emissions of those in the global top 10 per cent of income earners would need to be reduced to about one-tenth of their current level by 2030 and those of the top 1 per cent by at least a factor of 30 , while those of the poorest 50 per cent could increase by around three times their current level.

Figure 6.1. Per capita and absolute $\mathrm{CO}_{2}$ consumption emissions by four global income groups in 2015

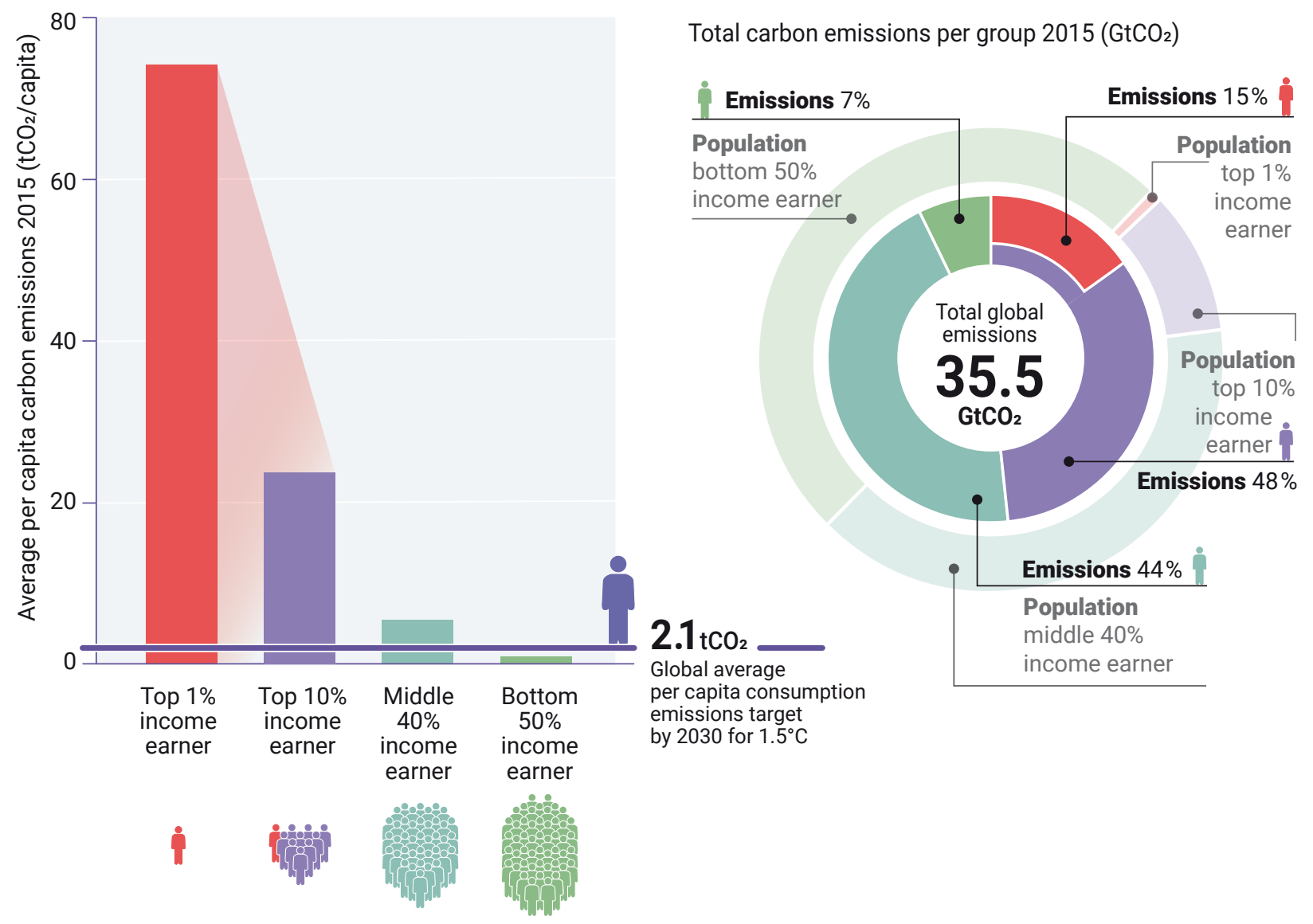

Note: Per capita $\mathrm{CO}_{2}$ consumption emissions, and absolute $\mathrm{CO}_{2}$ consumption emissions by four global income groups in 2015, compared with emissions reduction targets for 2030 for limiting warming to $1.5^{\circ} \mathrm{C}$. Income thresholds in 2015 are according to US\$ purchasing power parity in 2011: 1 per cent > US $\$ 109,000 ; 10$ per cent > US $\$ 38,000$; middle 40 per cent > US $\$ 6,000$; poorest 50 per cent $<$ US\$6,000.

Other estimates also affirm wide disparities in emissions by income bracket. Oswald et al. (2020) estimate that households of the global top 10 per cent of income earners use around 45 per cent of all energy for land transport and around 75 per cent of all energy for aviation, compared with 10 per cent and 5 per cent respectively for the poorest 50 per cent of households. Similarly, Ivanova and Wood (2020) find that a large share of the emissions of the topemitting European Union households are transport-related.
To design equitable low-carbon lifestyle approaches, it is important to consider these consumption inequities and identify populations with very high and very low carbon footprints. Central to addressing consumption inequities is reframing the meaning of 'progress' and 'affluence' away from the accumulation of income or energy-intensive resources to the achievement of well-being and quality of life. Studies show that a comprehensive idea of well-being that includes basic needs for all people can be attained with 


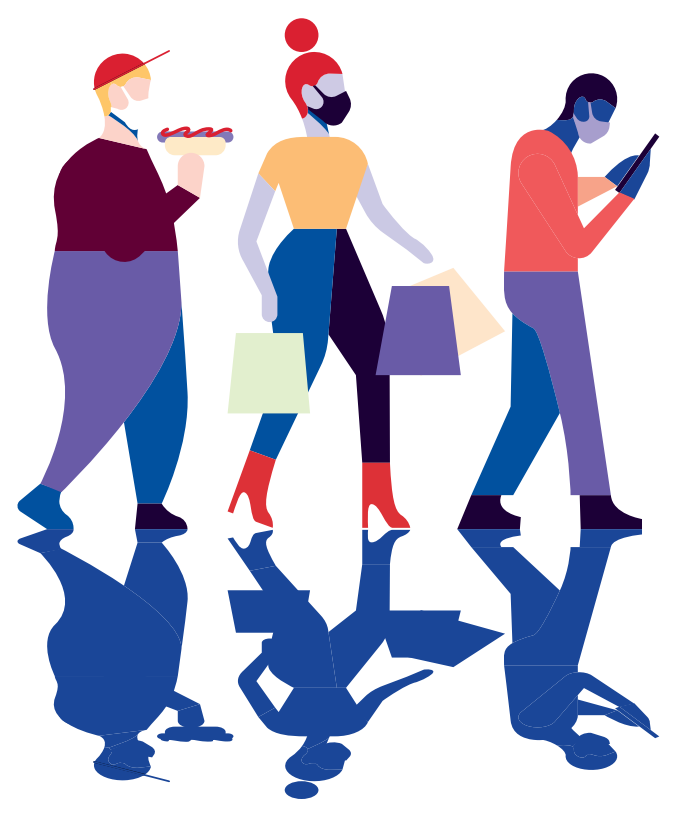

a much-reduced level of energy consumption (Rao et al. 2019; Millward-Hopkins et al. 2020).

\subsection{Achieving lifestyle emissions reduction by sector}

To help understand the options available to reduce lifestyle emissions, the Avoid-Shift-Improve (ASI) framework (Creutzig et al. 2018; van den Berg et al. 2019) provides a useful conceptual categorization. This framework does not articulate how lifestyle change occurs, but provides distinctions around the types of possible emissions reduction. In this chapter, we emphasize emissions reduction from mobility, residential energy use and food, as these constitute key sectors through which lifestyle change can enable climate mitigation, comprising approximately 17 per cent, 19 per cent and 20 per cent of lifestyle emissions respectively (Hertwich and Peters 2009).

The Avoid category refers to the reduction in energy or carbon demand by foregoing some aspect of consumption (for example, reduced travel, fewer appliances). The Shift category includes shifts in behaviour to less carbonintensive modes of consumption (for example, opting for walking, cycling or public transport instead of private vehicles; plant-based diets). The Improve category refers to reducing $\mathrm{GHG}$ emissions through improving efficiency or replacing technologies with lower-carbon ones, without changing the underlying consumption activity; this category includes increased vehicle efficiency and switching to battery electric vehicles (BEVs), efficient domestic appliances, household renewable energy and consumption of organically grown food

Figure 6.2 shows boxplots for options of varying carbon mitigation potential, aggregated by different sectors and ASI categories, based on a meta-review of 53 lifecycle assessment studies by Ivanova et al. (2020). ${ }^{2}$ These studies included the supply chain impacts that may occur elsewhere than the country of consumption. Also shown in figure 6.2 are illustrative examples of impactful changes across sectors, based on median emissions reduction potential across studies.

2 For more detail on the results included in this chapter, please see Annex III. For more detail on the searches, procedure and inclusion criteria, please see Ivanova et al. 2020 
Figure 6.2. Carbon mitigation potential of Avoid, Shift and Improve consumption options within domains

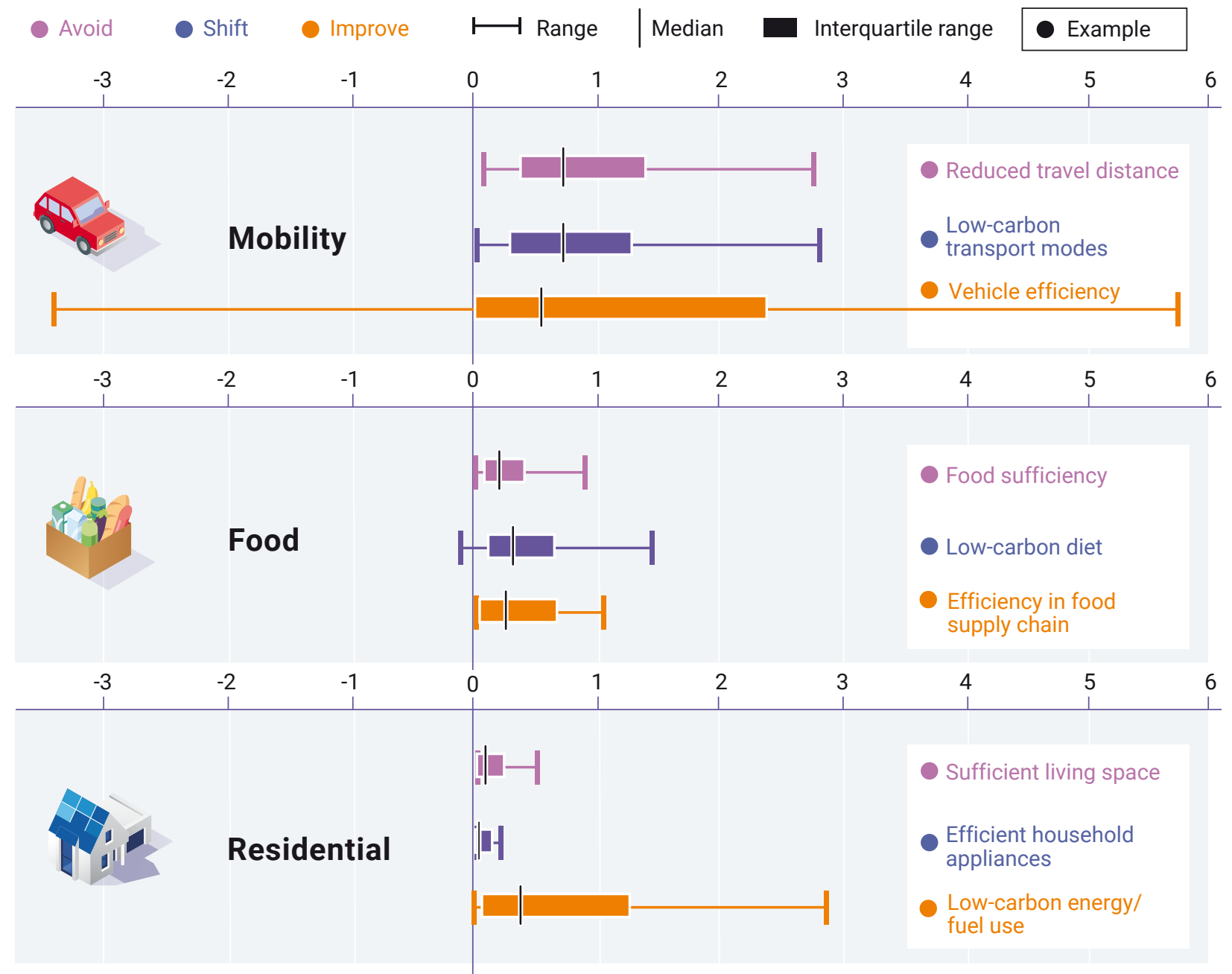

Mitigated $\mathrm{tCO}_{2} \mathrm{e}$ per capita, per year

Note: Aggregated consumption options per sector and per ASI category. The error bars represent the minimum and maximum values of estimates (excluding outliers, which are classed as greater than 1.5x the interquartile range), the boxes represent the interquartile range, and the middle line represents the median values of the consumption options. Examples for each ASI category per sector are given. For a detailed breakdown of consumption options included, see Annex III and Ivanova et al. 2020.

Building on the types of changes identified in figure 6.2, tables 6.1 to 6.3 offer examples from different countries on approaches to encourage low-carbon lifestyles for mobility, residential energy use and food, covering both hypothetical and implemented cases, as well as a range of mechanisms (for example, city-based projects, national policies and citizen-led initiatives). We discuss in more detail the range of mechanisms by which lifestyle change can be accomplished in section 6.3.

In terms of mobility (table 6.1), there is substantial mitigation potential to reduce emissions by avoiding and curtailing travel. Reducing long-haul flights has strong potential to reduce emissions in an equitable manner: air travel accounts for around 41 per cent of the carbon footprint of the highestemitting 1 per cent of households in the European Union, but less than 1 per cent of the emissions of the poorest 50 per cent of households. Although this mitigation option is available only to primarily wealthier people who fly, it has the potential for substantial emissions reduction, at around
$1.9 \mathrm{tCO}_{2} \mathrm{e}$ per avoided long-haul return flight (see chapter 5 for a more detailed discussion of technology-centric options to reduce aviation-sector emissions).

Emissions from mobility can also be reduced through more active travel such as cycling and walking, and greater use of public transport. Further options to improve mobility emissions include greater vehicle efficiency or the adoption of BEVs. Overall, consumption options in the mobility sector show high mitigation potential and high income-elasticity of demand (i.e. there is a strong link between income and mobility emissions; Ivanova and Wood 2020; Oswald et al. 2020). This suggests that emissions reduction measures across this sector can be relatively impactful and equitable, as they concern limiting luxury consumption by higherincome households. 
Table 6.1. High energy intensity (energy footprint/money spent by consumer), high income-elasticity of demand (luxury consumption)

\begin{tabular}{|c|c|c|c|}
\hline $\begin{array}{l}\text { Most } \\
\text { impactful } \\
\text { changes }\end{array}$ & $\begin{array}{l}\text { Annual GHG } \\
\text { emissions } \\
\text { reduction } \\
\text { potential } \\
\text { Mean (min/ } \\
\text { max) } \mathrm{tCO}_{2} \mathrm{e} / \\
\text { cap }\end{array}$ & Mechanisms for lifestyle change & Practical examples \\
\hline $\begin{array}{l}\text { Reducing } \\
\text { use of long- } \\
\text { haul flights/ } \\
\text { medium-haul } \\
\text { flights }\end{array}$ & $\begin{array}{l}\text { One less long- } \\
\text { haul return } \\
\text { flight: } \mathbf{1 . 9} \\
(0.7 / 4.5) \\
\text { One less } \\
\text { medium-haul } \\
\text { return flight: } \\
\mathbf{0 . 6}(0.2 / 1.5)\end{array}$ & $\begin{array}{l}\text { Economic policies: end kerosene tax } \\
\text { exemptions; implement frequent flyer } \\
\text { levy; incentivize domestic tourism } \\
\text { Legal frameworks: restrict airline and } \\
\text { flight advertising; legal challenges to } \\
\text { airport expansion } \\
\text { Transport infrastructure: end further } \\
\text { airport expansion in high-income } \\
\text { countries; improve surface transport } \\
\text { alternatives to aviation } \\
\text { Social norms and social movements: } \\
\text { changing desirability of air travel } \\
\text { Social conventions: growing } \\
\text { professional use of virtual meetings }\end{array}$ & $\begin{array}{l}\text { Airport expansion plans in the UK legally } \\
\text { rejected in their current form on climate } \\
\text { grounds (Mitchell 2020) } \\
\text { Domestic Austrian flights replaced } \\
\text { with intercity rail between Vienna and } \\
\text { Salzburg (Railway Gazette 2020) } \\
\text { Tax exemptions for domestic tourism } \\
\text { in India encourage land-based travel } \\
\text { (Kumar 2016) } \\
\text { Frequent flyer levy could reduce flying } \\
\text { among the wealthy (Fouquet and O'Garra } \\
\text { 2020) } \\
\text { Changing norms around flying: 'flight } \\
\text { shame' (Gössling et al. 2020) } \\
\text { Rapid uptake and normalization of online } \\
\text { work practices in response to COVID-19 } \\
\text { (Carroll and Conboy 2020) }\end{array}$ \\
\hline $\begin{array}{l}\text { Reduced car } \\
\text { use, increased } \\
\text { public } \\
\text { transport } \\
\text { and active } \\
\text { travel (bicycle, } \\
\text { walking) }\end{array}$ & $\begin{array}{l}\text { Living car-free: } \\
\mathbf{2 . 1}(0.6 / 3.6) \\
\text { Reducing car } \\
\text { usage: } \mathbf{0 . 8} \\
(0.1 / 1.6) \\
\text { Car-pooling: } \mathbf{0 . 3} \\
(0.0 / 1.0) \\
\text { Shift to active } \\
\text { transport: } \\
\mathbf{0 . 8}(0.01 / 2.8)\end{array}$ & $\begin{array}{l}\text { Economic policies: subsidized public } \\
\text { transport; incentives for cycling } \\
\text { and cycle purchases; road toll and } \\
\text { congestion charges; vehicle quota } \\
\text { policies } \\
\text { Legal framework: ban on petrol and } \\
\text { diesel vehicle sales; parking and zoning } \\
\text { restrictions; green public procurement } \\
\text { Transport infrastructure: tackle } \\
\text { peak demand e.g. through car-pool } \\
\text { lanes; expand cycle networks; open } \\
\text { dedicated cycle lanes; introduce car- } \\
\text { free residential zones; expand public } \\
\text { transport provision } \\
\text { Interpersonal influence: personal } \\
\text { action contributes to visibility and } \\
\text { mainstreaming of active travel } \\
\text { Habit disruption: targeted } \\
\text { interventions when people move house }\end{array}$ & $\begin{array}{l}\text { Integrated policies and infrastructure } \\
\text { to enable cycling in Colombia, the } \\
\text { Netherlands, Germany and Denmark } \\
\text { (Cervero et al. 2009; Pucher and Buehler } \\
\text { 2008) } \\
\text { Car-free settlements in Austria } \\
\text { (Ornetzeder et al. 2008) } \\
\text { USA car-sharing facilitates large } \\
\text { reductions in household emissions } \\
\text { (Martin and Shaheen 2011) } \\
\text { Global provision of public bike-sharing } \\
\text { programmes (Meddin et al. 2020; United } \\
\text { Nations Environment Programme [UNEP] } \\
\text { 2016) } \\
\text { Workplace provision of e-bikes (Page and } \\
\text { Nilsson } 2017 \text { ) } \\
\text { Increased cycling through 'pop-up' bike } \\
\text { lanes across Europe in response to } \\
\text { COVID-19 (Kraus and Koch 2020) }\end{array}$ \\
\hline
\end{tabular}




\begin{tabular}{|c|c|c|c|}
\hline $\begin{array}{l}\text { Reduced car } \\
\text { use, increased } \\
\text { public } \\
\text { transport } \\
\text { and active } \\
\text { travel (bicycle, } \\
\text { walking) }\end{array}$ & $\begin{array}{l}\text { Shift to public } \\
\text { transport: } \\
\mathbf{1 . 0}(0.2 / 2.2)\end{array}$ & $\begin{array}{l}\text { Attitude and awareness: cycle safety } \\
\text { and promotion campaigns; carbon } \\
\text { labelling at point of sale for vehicle fuel } \\
\text { Social norms: increase convenience } \\
\text { and attractiveness of active travel and } \\
\text { car-pooling options e.g. via car clubs or } \\
\text { shared neighbourhood vehicles }\end{array}$ & $\begin{array}{l}\text { Incentives for bicycle purchase and repair } \\
\text { - tax cuts for cycling in the EU (Fleming } \\
\text { 2019) and UK (Swift et al. 2016) } \\
\text { Citizen activism in India pushed for } \\
\text { prioritizing non-motorized vehicles } \\
\text { (Roy 2015) and advocacy groups } \\
\text { accelerate uptake of cycling in Colombia } \\
\text { and Denmark (Rosas-Satizábal and } \\
\text { Rodriguez-Valencia 2019; Carstensen et } \\
\text { al. 2015) }\end{array}$ \\
\hline $\begin{array}{l}\text { Smaller, } \\
\text { more- efficient } \\
\text { vehicles }\end{array}$ & $\mathbf{0 . 4}(0.0 / 1.1)$ & $\begin{array}{l}\text { Economic policies: differentiated } \\
\text { vehicle tax based on emissions } \\
\text { Legal framework and attitude } \\
\text { change: ban advertising of large, high- } \\
\text { carbon private vehicles } \\
\text { Social norms and social movements: } \\
\text { change desirability of large and high- } \\
\text { emission vehicles } \\
\text { Attitude and awareness: carbon/eco- } \\
\text { labelling at point of sale for vehicle fuel }\end{array}$ & $\begin{array}{l}\text { Differentiated tax in Norway reduced } \\
\text { high-emission car purchases but also led } \\
\text { to more diesel cars (Ciccone 2018) } \\
\text { Campaign to ban advertising of sports } \\
\text { utility vehicles (SUVs) and high-emission } \\
\text { vehicles (Beevor et al. 2020) } \\
\text { Emissions standards to encourage } \\
\text { smaller vehicles in Italy (Shindell et al. } \\
\text { 2011) } \\
\text { Health warnings and eco-labels for fossil } \\
\text { fuel purchases (e.g. at petrol pumps) to } \\
\text { prompt behaviour change (Gill et al. 2020) }\end{array}$ \\
\hline $\begin{array}{l}\text { Battery electric } \\
\text { vehicle } \\
\text { (BEV), fuel cell } \\
\text { vehicle (FCV), } \\
\text { hybrid vehicles }\end{array}$ & $\begin{array}{l}\text { BEV: } \mathbf{2 . 0} \\
(-1.9 / 5.4) \text { (varies } \\
\text { with electricity } \\
\text { mix) } \\
\text { FCV: } \mathbf{0 . 0} \\
(-3.4 / 5.8) \\
\text { Hybrid: } \mathbf{0 . 7} \\
(-0.2 / 3.1)\end{array}$ & $\begin{array}{l}\text { Transport infrastructure: network of } \\
\text { charging stations; priority parking and } \\
\text { bus lane access for electric vehicles; } \\
\text { public transport e-mobility options } \\
\text { such as electrobuses } \\
\text { Economic policies: tax and fee } \\
\text { exemptions for electric vehicle usage; } \\
\text { grants and incentives for electric } \\
\text { vehicle purchase } \\
\text { Interpersonal influence: household } \\
\text { uptake and conversations contribute to } \\
\text { diffusion of electric vehicles } \\
\text { Attitude change: social marketing of } \\
\text { electric vehicles that highlights vehicle } \\
\text { performance and addresses range } \\
\text { anxiety } \\
\text { *To optimize impact from these } \\
\text { mechanisms, it is also important to } \\
\text { decarbonize the electricity mix. Supply } \\
\text { side: moratoriums, bans on fossil fuel } \\
\text { exploration and extraction }\end{array}$ & $\begin{array}{l}\text { Bus lane access and reduction of, and } \\
\text { exemptions from, fees and taxes led to } \\
\text { BEV uptake in Norway (Aasness and } \\
\text { Odeck 2015); consolidated by social } \\
\text { influence between citizens (Figenbaum } \\
\text { 2017) } \\
\text { Restrictions on petrol cars, plus financial } \\
\text { incentives, led to BEV uptake in China (Li } \\
\text { et al. 2019) } \\
\text { Oil exploration moratoriums in Costa } \\
\text { Rica, Belize, Mexico (Tudela 2019), New } \\
\text { Zealand (2019) and France (2017) }\end{array}$ \\
\hline
\end{tabular}

Note: Emissions reduction calculations for all tables based on a meta-review by Ivanova et al. (2020). See the meta-review for emission reduction ranges and more details. The absolute minimum and maximum emissions mitigation ranges are included in parentheses. 
For the residential sector (table 6.2), there is substantial mitigation potential to reduce emissions through measures such as low-carbon heating and renewable energy use by households, as well as energy-efficient construction and renovations. Further options include reducing emissions through smaller living spaces and adjustments to room temperature. Overall, residential consumption options show relatively high mitigation potential, although much lower income-elasticity of demand (involving basic or essential consumption), with these highly context-dependent by socioeconomic group and region (Oswald 2020).

Table 6.2. Residential High energy intensity, low income-elasticity of demand (basic or essential consumption)

\begin{tabular}{|c|c|c|c|}
\hline $\begin{array}{l}\text { Most } \\
\text { impactful } \\
\text { changes }\end{array}$ & $\begin{array}{l}\text { Annual GHG } \\
\text { emissions } \\
\text { reduction } \\
\text { potential } \\
\text { Mean (min/max) } \\
\mathrm{tCO}_{2} \mathrm{e} / \mathrm{cap}\end{array}$ & Mechanisms for lifestyle change & Practical examples \\
\hline $\begin{array}{l}\text { Better energy } \\
\text { efficiency of } \\
\text { appliances } \\
\text { and heat } \\
\text { pumps; } \\
\text { better } \\
\text { insulation } \\
\text { and } \\
\text { construction }\end{array}$ & $\begin{array}{l}\text { Refurbishment/ } \\
\text { renovation: } \mathbf{0 . 9} \\
(0.0 / 1.9) \\
\text { Heat pumps: } \mathbf{0 . 9} \\
(0.0 / 1.8)\end{array}$ & $\begin{array}{l}\text { Economic policies: retrofitting recovery } \\
\text { packages; incentives to increase benefits of } \\
\text { retrofitting for landlords and homeowners; } \\
\text { incentives to purchase new energy-efficient } \\
\text { appliances } \\
\text { Physical infrastructure: energy-efficient } \\
\text { construction and stricter building standards; } \\
\text { wood-based construction } \\
\text { Behaviour change: reduce barriers to action } \\
\text { for retrofitting; make it easier for households } \\
\text { to invest in energy efficiency } \\
\text { Information-based policies: standards and } \\
\text { labels for energy-efficient products }\end{array}$ & $\begin{array}{l}\text { Improved residential energy } \\
\text { efficiency in USA; retrofitting } \\
\text { public housing after economic } \\
\text { downturn (Climate Action } \\
\text { Tracker 2020) } \\
\text { India's residential light-emitting } \\
\text { diode (LED) purchase scheme } \\
\text { (Kamat et al. 2020) } \\
\text { Legislation improving } \\
\text { environmental performance } \\
\text { of products; eco-design and } \\
\text { energy labelling in the EU } \\
\text { (Casamayor and Su 2020; } \\
\text { European Commission 2020a) } \\
\text { Energy-efficiency standards for } \\
\text { energy-intensive products in } \\
\text { Japan (Asia Energy Efficiency } \\
\text { and Conservation Collaboration } \\
\text { Center 2020) }\end{array}$ \\
\hline $\begin{array}{l}\text { Household } \\
\text { use of } \\
\text { grid-based } \\
\text { and on-site } \\
\text { renewable } \\
\text { electricity; } \\
\text { heat pumps; } \\
\text { district } \\
\text { heating and } \\
\text { cooling; } \\
\text { combined } \\
\text { heat and } \\
\text { power }\end{array}$ & $\begin{array}{l}\text { Renewable } \\
\text { electricity use } \\
\text { in homes: } \mathbf{1 . 5} \\
(0.3 / 2.5)\end{array}$ & $\begin{array}{l}\text { Physical infrastructure: provide renewable } \\
\text { electricity and related infrastructure for } \\
\text { household renewable energy production } \\
\text { Economic policies: incentives to invest in } \\
\text { and consume renewable electricity } \\
\text { Legal framework: restrictions on fossil-fuel- } \\
\text { based provision of home energy } \\
\text { Social influence: harness social diffusion } \\
\text { of solar panels via aggregate/community } \\
\text { pricing options; emphasize presence of } \\
\text { renewables through visible signposts; launch } \\
\text { community engagement initiatives }\end{array}$ & $\begin{array}{l}\text { Renewable energy defaults } \\
\text { led to higher uptake of green } \\
\text { home energy tariffs (Schonau, } \\
\text { Germany; several states in USA; } \\
\text { Kaiser et al. 2020; Kennedy and } \\
\text { Rosen 2020) }\end{array}$ \\
\hline
\end{tabular}




\begin{tabular}{l|l|l|l}
$\begin{array}{l}\text { Technology } \\
\text { to encourage } \\
\text { shifts } \\
\text { towards } \\
\text { lower energy } \\
\text { use }\end{array}$ & $\begin{array}{l}\text { Lower room } \\
\text { temperature: } \mathbf{0 . 1} \\
(0.0 / 0.4)\end{array}$ & $\begin{array}{l}\text { Economic policies: incentivize lower usage } \\
\text { and energy-efficient heating and cooling } \\
\text { devices; loans for passive homes and net- } \\
\text { zero buildings }\end{array}$ & $\begin{array}{l}\text { Smart meters reduced gas } \\
\text { consumption by 22.0 per cent } \\
\text { overall and by 27.2 per cent } \\
\text { in high consumers in the UK } \\
\text { (Mogles et al. 2017) }\end{array}$ \\
\hline $\begin{array}{l}\text { Technology } \\
\text { to encourage } \\
\text { shifts } \\
\text { towards } \\
\begin{array}{l}\text { lower energy } \\
\text { use } \\
\text { (continued) }\end{array}\end{array}$ & $\begin{array}{l}\text { Smart metering: } \\
\mathbf{0 . 2}(0.0 / 1.1)\end{array}$ & $\begin{array}{l}\text { Infrastructure: provide smart meters; use } \\
\text { shading; insulate walls and windows; use } \\
\text { high reflecting surfaces on areas such as } \\
\text { roofs and walls; increase ventilation; install } \\
\text { occupancy sensors } \\
\text { Behaviour change: green energy tariffs by } \\
\text { default to encourage uptake; reduce energy } \\
\text { use through information and feedback }\end{array}$ & $\begin{array}{l}\text { Normative feedback reduces } \\
\text { energy consumption in some } \\
\text { circumstances (Schultz et al. } \\
\text { 2007; Jain et al. 2013) }\end{array}$ \\
\hline
\end{tabular}

Note: Emissions reduction calculations for all tables based on a meta-review by Ivanova et al. (2020). See the meta-review for emission reduction ranges and more details. The absolute minimum and maximum emissions mitigation ranges are included in parentheses.

For food (table 6.3), a shift towards vegetarian or vegan diets offers substantial potential for carbon mitigation. Further options for emissions reductions include consumption of locally grown and organic food and use of improved cooking equipment. ${ }^{3}$ While the avoidance of excess consumption and food waste reduction show substantial mitigation potential, these options are mostly applicable to higherincome households.

Table 6.3. Food Low energy intensity, low income-elasticity (basic or essential consumption)

\begin{tabular}{|c|c|c|c|}
\hline $\begin{array}{l}\text { Most } \\
\text { impactful } \\
\text { changes }\end{array}$ & $\begin{array}{l}\text { Annual GHG } \\
\text { emissions } \\
\text { reduction } \\
\text { potential } \\
\text { Mean (min/max) } \\
\mathrm{tCO}_{2} \mathrm{e} / \mathrm{cap}\end{array}$ & Mechanisms for lifestyle change & Practical examples \\
\hline $\begin{array}{l}\text { Vegan/ } \\
\text { vegetarian } \\
\text { diet }\end{array}$ & $\begin{array}{l}\text { Vegan: } \mathbf{0 . 9} \\
(0.4 / 2.1) \\
\text { Vegetarian: } \\
\mathbf{0 . 5}(0.0 / 1.5)\end{array}$ & $\begin{array}{l}\text { Legal framework: restrict advertising of } \\
\text { high-carbon food items; stronger protection } \\
\text { of forest land to withstand pressure from } \\
\text { cattle ranches; trade policy that ensures } \\
\text { sustainable supply chains } \\
\text { Economic policies: end incentives for } \\
\text { unsustainable food industries and offer } \\
\text { support for alternatives } \\
\text { Supply chains: influence provision systems } \\
\text { e.g. better availability of sustainable } \\
\text { products (e.g. plant-based alternatives) in } \\
\text { supermarkets and retail outlets }\end{array}$ & $\begin{array}{l}\text { Finnish policies to reduce dairy } \\
\text { consumption using behaviour } \\
\text { campaigns, school meals and } \\
\text { training for health care workers } \\
\text { (Pietinen et al. 1988) } \\
\text { Growth of veganism in Austria } \\
\text { through social diffusion (Ploll et } \\
\text { al. 2020) } \\
\text { European 'farm to fork' initiative } \\
\text { aims to ensure sustainable diets } \\
\text { are affordable and accessible; } \\
\text { proposed legislation to address } \\
\text { food linked to deforestation } \\
\text { (European Commission 2020b) }\end{array}$ \\
\hline
\end{tabular}




\begin{tabular}{|c|c|c|c|}
\hline & & $\begin{array}{l}\text { Social influence: cultural and societal } \\
\text { changes via media }\end{array}$ & $\begin{array}{l}\text { Provision of meat-free meals } \\
\text { in schools in UK (Leeds City } \\
\text { Council 2020) and 'Meatless } \\
\text { Monday' in Norwegian armed } \\
\text { forces (Milford et al. 2019) }\end{array}$ \\
\hline $\begin{array}{l}\text { Sufficiency } \\
\text { (eating only } \\
\text { what is } \\
\text { needed) and } \\
\text { food waste } \\
\text { reduction }\end{array}$ & $\mathbf{0 . 3}(0.0 / 1.3)$ & $\begin{array}{l}\text { Economic policies: penalties on food waste } \\
\text { in supermarkets, dis-incentivize buffets and } \\
\text { package deals } \\
\text { Infrastructure: schemes encouraging } \\
\text { reuse/charitable donation of leftover food in } \\
\text { restaurants } \\
\text { Attitudes: campaigns against food waste } \\
\text { and unnecessary stockpiling }\end{array}$ & $\begin{array}{l}\text { France implemented national } \\
\text { policies against food waste } \\
\text { in supermarkets (Mourad } \\
\text { 2016); Italy implemented a } \\
\text { law to reduce food waste and } \\
\text { encourage donation of leftover } \\
\text { food to charity (Gazetta Uficiale } \\
\text { della Republica Italiana 2016) }\end{array}$ \\
\hline $\begin{array}{l}\text { Local, } \\
\text { organic } \\
\text { foods }\end{array}$ & $\begin{array}{l}\text { Organic food: } \mathbf{0 . 5} \\
(0.0 / 0.9) \\
\text { Regional/local } \\
\text { food: } \\
\mathbf{0 . 4}(0.01 / 1.1)\end{array}$ & $\begin{array}{l}\text { Legal framework: policy support for organic } \\
\text { production; stronger standards for the use of } \\
\text { pesticides } \\
\text { Economic policies: incentivize local, organic } \\
\text { options to ensure affordability } \\
\text { Social influence: work with communities, } \\
\text { public kitchens and schools to diffuse change } \\
\text { Information sharing: knowledge transfer } \\
\text { of resource-efficient agricultural practices } \\
\text { between developed and developing countries }\end{array}$ & $\begin{array}{l}\text { Danish Organic Action Plan } \\
\text { led to increased provision of } \\
\text { organic food in state-linked } \\
\text { outlets (Sørensen et al. 2016) } \\
\text { Urban household vegetable } \\
\text { gardens have potential to } \\
\text { reduce GHG emissions } \\
\text { (Cleveland et al. 2017) } \\
\text { Food-growing households } \\
\text { in Czech Republic reduce } \\
\text { household emissions (Vávra et } \\
\text { al. 2018) } \\
\text { Legal exceptions granted for } \\
\text { agricultural zones in Quezon } \\
\text { City, Philippines, to ensure more } \\
\text { self-reliant food production } \\
\text { (C40 Cities Network 2020) }\end{array}$ \\
\hline
\end{tabular}

Note: Emissions reduction calculations for all tables based on a meta-review by Ivanova et al. (2020). See the meta-review for emission reduction ranges and more details. The absolute minimum and maximum emissions mitigation ranges are included in parentheses.

While the estimates considered here are drawn from a range of geographical regions, evidence of mitigation from lifestyle change from developing countries are typically lacking in the literature relative to European and North American studies. Approaches to promote low-carbon lifestyle measures in developing countries are critical, however, with structural transitions offering opportunities to align development and climate objectives (McCauley and Heffron 2018). Many developing countries' economies are growing quickly, and infrastructure and policy decisions taken now have the potential to lock in high- or low-carbon lifestyles (the latter with multiple benefits) for the long-term. For instance, an estimated 3 billion people worldwide currently rely on highly polluting and unhealthy traditional solid fuels for household cooking and heating (Yadama 2013). Shifting these energy sources to electricity and clean fuels could heavily influence residential emissions reductions and provide multiple development outcomes (Creutzig et al. 2016; Mulugetta et al. 2019)

\subsection{Realizing lifestyle change: which mechanisms encourage low-carbon lifestyles?}

The evidence presented so far shows that rising emissions are underpinned by contemporary lifestyles. Major reductions in emissions require substantial changes to these patterns of consumption and behaviours - especially among the global rich (Davis and Caldeira 2010; Liobikiene and Dagiliūtè 2016; Oswald et al. 2020; Oxfam and SEI 2020).

A person's choices operate within broader contexts that enable or constrain action (Akenji and Bengtsson 2014; Walker 2014) - including physical environments, cultural conventions, social norms and financial and policy frameworks - and are inseparable from income levels and access to resources. Even so, individuals can exercise environmental citizenship to bring about societal change through the various roles they occupy: including as 
consumers, members of organizations and communities, citizens participating in social movements and deliberative processes, or as owners of assets and investments (Stern 2000). These types of personal action can influence not only the underlying social conditions that shape lifestyles, but also the actions of governments and businesses
(Otto et al. 2020a; Nielsen et al. 2020; Amel et al. 2017). The interaction between structural conditions and how people live is dynamic: personal choices have consequences for the contexts within which they are made, which in turn reinforce or challenge the contribution of lifestyles to climate change (see figure 6.3)

Figure 6.3. Mechanisms to change lifestyles

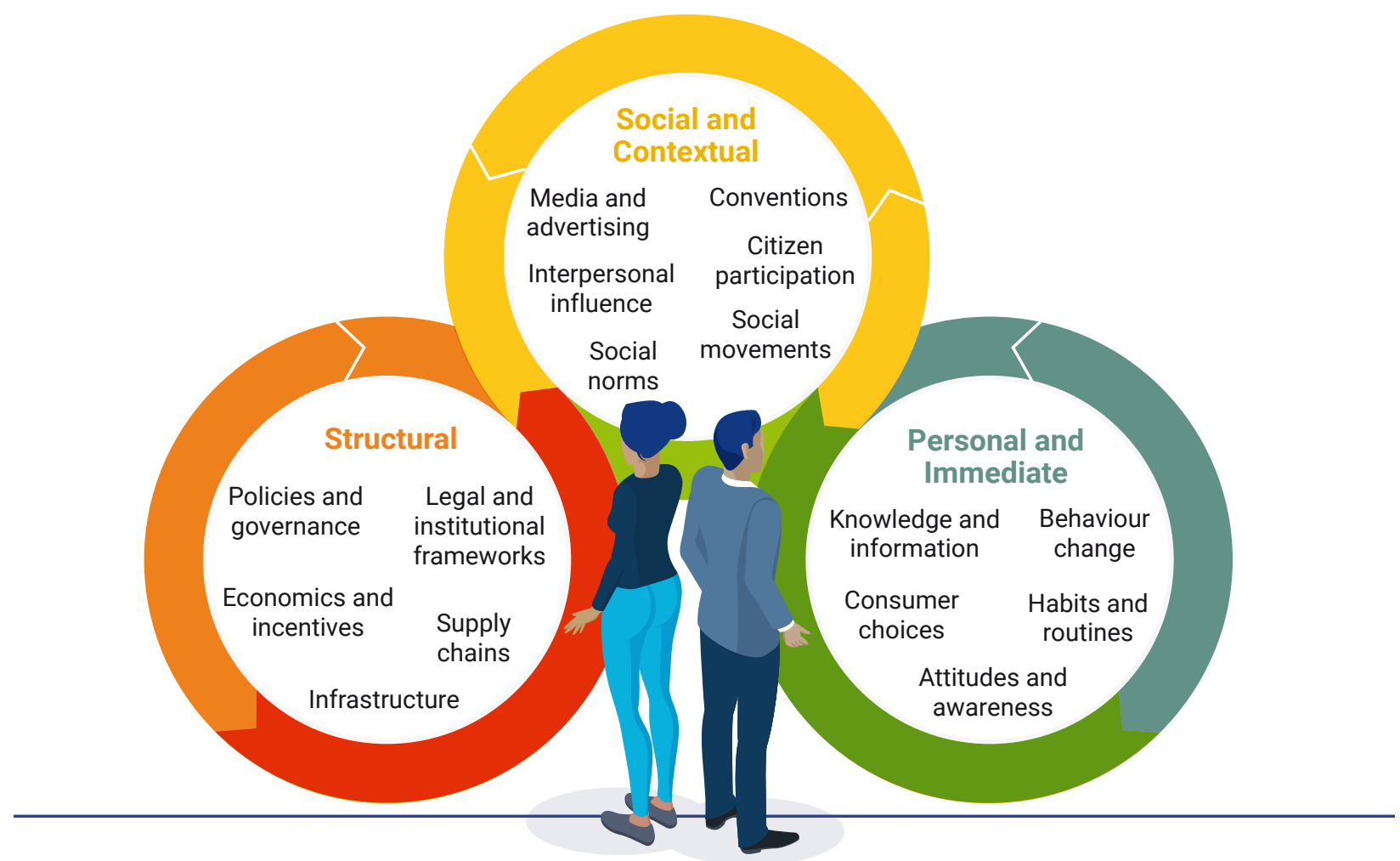

Note: Personal, social and contextual, and structural factors affecting lifestyle consumption options.

\subsubsection{Incentives, information and choice provision}

Approaches that encourage voluntary behaviour change (for example, information provision, economic incentives) have been a dominant means by which policy has attempted to influence lifestyles (Pykett et al. 2011). Economic policies such as renewable energy incentives have stimulated uptake of solar voltaic panels (Briguglio and Formosa 2017; Mundaca and Samahita 2020) and changed the competitiveness of renewable energy compared with fossil fuels. Market-oriented policies can also increase the behavioural plasticity (i.e. how responsive behaviours are to changes in external conditions) of actions for carbon emissions reduction (Dietz et al. 2009), which can be crucial in increasing access to low-carbon lifestyle options.

Targeted information (energy efficiency information, carbon labelling) can also shift consumer decision-making towards more efficient and low-carbon products (Langley et al. 2012; Kunreuther and Weber 2014; Khosla et al. 2019; Whittle et al. 2019) and often has broad public support (Carbon Trust 2020). Adjustments to the contexts under which decisions are made can also be influential, by offering low-carbon products and services as the default option (Kaiser et al. 2020).

While information and incentives can be useful, there are limits to approaches that seek to 'nudge' behavioural change, as they rely on individual responsibility to bring about change. Such approaches risk 'scapegoating' citizens (Akenji 2012) and may not be enough to overcome inertia (Kaiser et al. 2020). Historically, sustainable transitions have not been strongly driven by voluntary consumer choices (Organisation for Economic Co-operation and Development [OECD] 2003), but by factors such as social norms and by changing the options available to consumers (Sustainable Consumption Roundtable 2006).

While there have been calls for integrated policy that combines more assertive and restrictive policies with voluntary ones (Moberg et al. 2018), public acceptability is key for both approaches, with the risk that policies that unfairly burden households will receive backlash (Sovacool et al. 2017; Moberg et al. 2018). 


\subsubsection{Infrastructure and conventions of everyday life}

Patterns of everyday life - the way we eat, travel and occupy our homes - are shaped and directed by the built environment, how services are provided, and expectations of normal conduct (Breadsell et al. 2019). In many developed nations, the dominance of the car has been enabled through urban infrastructure that is car-dependent, spatial planning that has led people to live far from workplaces and essential services, and a 'car culture' that favours this mode of transport (Mattioli et al. 2020). Likewise, high-carbon diets have become established through supply chains and market liberalization that has promoted convenience foods, bulkbuying and meat-based meals (Hoolohan et al. 2016; Xiong et al. 2020).

Attempts to reduce lifestyles emissions are more likely to be effective if they address the infrastructures on which highcarbon lifestyles depend and enable knock-on effects to other carbon-intensive practices. For example, high-speed rail networks may lower demand for domestic aviation (Clewlow et al. 2014). Conversely, infrastructural changes that do not anticipate how decisions might influence wider patterns of daily life may result in failure or unintended increases in emissions.

\subsubsection{Social influence}

Where lifestyle change is accomplished - by one person, household or community - this can act as a catalyst to promote wider change, spreading behaviours through peer influence and reconfiguring what is typical or expected (Shwom and Lorenzen 2012; Guilbeault et al. 2018; Wolske et al. 2020).

Social influence has contributed to wider uptake of rooftop solar panels (Bollinger and Gillingham 2012; Richter 2013; Graziano and Gillingham 2015), transport modal shift (Feygin and Pozdnoukhov 2018), transitioning to plantbased diets (Cherry 2006) and purchase of energy-efficient products (Wolske et al. 2020).

At the interpersonal level, people follow the example of others who are similar to themselves (Welsch and Kühling 2009; Abrahamse and Steg 2013; Amel et al. 2017). At a larger scale, the actions of a committed minority of people can comprise a 'critical mass' that is able to prompt broader change in patterns of behaviour, leading to a tipping point whereby social conventions change rapidly towards a new normal (Centola et al. 2018; Otto et al. 2020a). Actions taken by key individuals can lead to greater uptake of similar choices by others. The social influence of highemitting groups, especially those in prestigious or influential positions, may be particularly important in shaping what is desirable and affect people's willingness to cooperate on shared problems (Anderson 2011; Henrich et al. 2015). Additionally, climate communicators, advocates and researchers are seen as more convincing - and their advice more likely to be acted upon - if they themselves pursue low-carbon lifestyles (Attari et al. 2016; Attari et al. 2019; Sparkman and Attari 2020).

\subsubsection{Citizen participation}

Social movements can give individually disempowered people a strong voice if they act collectively (Kashwan 2016; Otto et al. 2020b). The example of the Fridays for Future youth climate protests has demonstrated collective agency among individuals - many of whom do not even have voting rights - with the movement becoming widely established across Europe, Africa, South America and Asia (Marquardt 2020).

The involvement of people in bringing about change is enshrined in article 6 of the UNFCCC Doha Convention and article 12 of the Paris Agreement. Citizen participation can range from formal processes to shape policy, to participation in social movements. Where processes exist that enable individuals to directly shape policy - including citizens' juries and assemblies - they have led to the proposal of measures that have confronted the structural determinants of high-carbon lifestyles (Kythreotis et al. 2019; Devaney et al. 2020). For example, Ireland's citizens' assembly advocated higher taxes across carbon-intensive activities (Torney and O'Gorman 2019; Muradova et al. 2020) whereas in France, participants proposed a change to the country's Constitution and a new law of 'ecocide' as ways to hold policymakers and other actors to account (Convention Citoyenne pour le Climat 2020). The 2015 World Wide Views deliberation across 76 countries likewise found that most citizens supported strong action on climate change (Dryzek and Niemeyer 2019).

Advocacy of inclusive solutions has often been driven by poorer communities able to demonstrate best practice in climate mitigation (Roy 2015). For example, Project 90 in South Africa advocates for a 90 per cent reduction in emissions by 2030 through youth leadership programmes and community engagement (Kyle 2020), while Bold Nebraska brought together farmers, Native Americans and other concerned citizens to build community action that successfully opposed the construction of the Keystone $\mathrm{XL}$ pipeline (Ordner 2017).

\subsubsection{Disrupting habits}

Much of our behaviour is habitual - unconscious routines triggered by contextual cues (such as time of day), rather than a conscious intention to act (Kurz et al. 2015). Habits are a substantial barrier to lifestyle change, as they lock in individual behaviour and maintain its automatic repetition over time (Maréchal and Lazaric 2011). However, since habits develop in, and are cued by, stable contexts (Wood et al. 2005), changes in context can in turn provide opportunities to disrupt well-established routines (Verplanken et al. 2008; Kurz et al. 2015).

'Moments of change' - defined as occasions when an individual's circumstances change considerably within 
a short time frame (Thompson et al. 2011) - have been identified as an important lever for lifestyle change (Capstick et al. 2014). Research shows that disruptions whether concerning a person's life-course (such as moving house) or structural changes (such as economic growth or downturn) - can provide opportunities to recraft lifestyles in new directions (Birkmann et al. 2010; Verplanken et al. 2018), such as shifting from commuting by car to home-working (Marsden et al. 2020) or investing in energy-efficient housing and the use of LEDs in the home (Khosla et al. 2019; Kamat et al. 2020)

\subsubsection{Lessons from COVID-19: opportunity to lock in positive changes}

COVID-19 has impacted everyday life around the world, disrupting many established patterns of behaviour. As noted in chapter 2 of this report, an unintended side effect of lockdown policies was a sharp, unprecedented drop in carbon emissions (Le Quéré et al. 2020), representing the largest relative reduction globally since WWII. However, policies to contain COVID-19 differ from those needed to curb carbon emissions in important ways, and there are risks in drawing simplistic parallels between these very different issues. Lockdown policies were enacted quickly and designed to be temporary disruptions to the status quo. By contrast, lifestyle changes to address climate change entail carefully managed and long-term transitions away from the status quo towards more sustainable and equitable practices (Howarth et al. 2020). Nonetheless, COVID-19 has shown that rapid, extensive and profound changes in lifestyles are possible with the coordination of governments and civil society. The lessons for climate mitigation from COVID-19 are less about the magnitude or longevity of the drop in emissions observed, and more about the insights gained into how rapid lifestyle changes can happen.

First, governments must lead the way and create conditions under which lifestyle changes are possible (for example, economic measures that enable workers to remain at home). Second, positive social norms and a sense of collective agency are important for behavioural change. Finally, infrastructure to lock in behaviour changes is critical - for example in the case of cities that, in response to COVID-19, took action to promote walking and cycling and encourage local food production (C40 Cities Network 2020). New habits take around two to three months to form (Lally et al. 2010), meaning the lockdown period in many countries may be long enough to establish new, enduring routines, if these are supported by longer-term measures.

In planning the recovery from COVID-19, governments have an opportunity to catalyse low-carbon lifestyle changes by disrupting entrenched practices, rethinking infrastructure and protecting environmental standards (Büchs et al. 2020, see also chapter 4).

\subsection{Integrated policies in each sector}

Drawing on the mechanisms described above, the following sections outline integrated approaches to lifestyle change across the mobility, residential and food sectors, providing practical examples of measures that have been implemented, as well as potentially effective approaches.

\subsubsection{Towards low-carbon mobility}

Approaches to enable lifestyle change for the mobility sector include assertive policies that prioritize active travel, incentivize shifts to low-carbon modes of transport and discourage non-essential travel, particularly among highconsuming groups

Around the world, changes to mobility options and practices have been made as a direct response to the COVID-19 pandemic. The $\mathrm{C} 40$ group of around 100 large cities has called for a green and just recovery from the economic impacts of COVID-19 (C40 Cities Network 2020), including a worldwide initiative to pursue urban planning that enables most residents to access everyday needs within a 15-minute journey by walking or cycling.

Social influence is important when shaping mobility lifestyle decisions. For example, near-exponential growth in electric vehicle ownership in Norway that has strongly aligned with climate policy conferring price advantages has been consolidated by peer-to-peer communication (Figenbaum 2017), as well as neighbourhood effects (for example, visibility in residential areas) and perceptions of what is expected and desirable (Pettifor et al. 2017). Similarly, there is a role for social influence in shaping norms around the desirability of flying ('flight shaming'; Gössling et al. 2020), potentially in conjunction with policies such as frequent flyer levies (Fouquet and O'Garra 2020).

Citizen participation can also mobilize support for low-carbon mobility policy. For example, in Leeds, United Kingdom, the city's citizens' jury recommended halting local airport expansion (Place-based Climate Action Network [PCAN] 2019); the French Convention Citoyenne proposed the prohibition of both new airports and the extension of existing airports, as well as ceasing most domestic flights by 2025 (Convention Citoyenne pour le Climat 2020) and the Switch ON organization in India has mobilized concerned citizens to push back against planned restrictions on bicycles and non-motorized transport (Roy 2015).

Assertive policies around the world have challenged the social status of the car. For instance, in Bogotá the reallocation of street space, construction of off-street bike paths and car-free days has encouraged a shift towards cycling and walking (Rosas-Satizábala and RodriguezValencia 2019). Such measures can be achieved equitably: in the Netherlands, Germany and Denmark, cycling is distributed evenly across income, gender and age groups (Pucher and Buehler 2008). In China, BEV uptake has been encouraged using a combination of mandatory restrictions 
on petrol cars (limiting their purchase and use) and marketoriented policies (government subsidies, tax exemptions, and dedicated licence plates that afford parking benefits, as well as having symbolic value; Li et al. 2019). Health practitioners have also argued for warning labels at point of sale for fossil fuels (for example, at petrol stations) and in the context of high-carbon services (for example, on airline tickets; Gill et al. 2020)

In developing nations, there are opportunities to leapfrog the car-dependent, carbon-intensive infrastructure that dominates many developed nations. High-density, mixeduse urban forms that emphasize access by modes of transport other than cars are beneficial from an emissions perspective, and also enable more equitable participation in employment, cultural and entertainment activities (Kenworthy 2006). Such modal shifts also reduce local air pollution, thereby emphasizing the multiple benefits of more active, less carbon-intensive mobility options.

\subsubsection{Towards a low-carbon residential sector}

Policies that enable residential lifestyle change - particularly low-carbon technologies operating at the individual or household level (for example, energy-efficient building envelopes, heat pumps, electric vehicle charging points, household solar) - have been shown to lead to more rapid diffusion of technology and more widespread social returns (such as job creation) than in the case of larger-scale energy investments (Wilson et al. 2020).

Incentives, information and changes to how choices are presented (behavioural 'nudges') have met with some success, especially in terms of enabling equitable access to low-carbon options. Green defaults (whereby new customers are automatically assigned green energy tariffs) have been shown to dramatically increase their uptake (Ebeling and Lotz 2015; Kaiser et al. 2020). In 2017, around 5 million customers in California, United States of America, were able to access greater renewable energy at lower cost through the green default provided by the stateenabled Community Choice Aggregation programmes (O'Shaughnessy et al. 2019).

More broadly, successful residential lifestyle changes require anticipating how policies will impact daily life. Financial incentives to encourage uptake of efficient and improved cookstoves in developing countries show that policies also need to account for ongoing costs of use and maintenance (Pattanayak et al. 2019), the role of female empowerment, as well as attachment to traditional cooking techniques (Lewis and Pattanayak 2012).

The residential sector offers significant mitigation opportunities and risks as it is one of the longest-lived components of the economy. In many developing countries, rapid urbanization and population growth are outpacing the provision of adequate, affordable housing (United Nations 2017). Studies estimate that ongoing upgrade and construction of infrastructure to connect communities and enable urban development could result in additional emissions of $226 \mathrm{GtCO}_{2}$ by 2050 (Müller et al. 2013; Bai et al. 2018). Analogously, the predicted growth in ownership of air-conditioning technologies (equivalent to 10 new air conditioners being purchased every second for the next 30 years), especially in China, India and Indonesia, affirms the need for low-energy and low-carbon cooling options (IEA 2019). Infrastructural changes can moderate this growth: for instance, in Viet Nam and India, successful examples of vernacular architecture (buildings designed using local knowledge and materials for local needs) require much lower energy inputs (Creutzig et al. 2016)

In the past, recovery measures during economic downturn have been used to incentivize sustainable changes to households (for example, enabling retrofitting, solar panels and insulation; Climate Action Tracker 2020). Such policies bring multiple benefits by hastening the energy transition, enabling low-income households greater access to lowcarbon living, stimulating the economy and reducing income burdens from high energy costs.

\subsubsection{Towards low-carbon diets}

In comparison to current average diets, full or partial vegetarianism has the potential to reduce emissions from food consumption by around 31 per cent, with a pescatarian diet leading to an approximately 27 per cent reduction (Aleksandrowicz et al. 2016). However, attempts to encourage more sustainable diets have tended to be limited to information and awareness campaigns, which typically have marginal effects (Traill et al. 2014; Schanes et al. 2016; Bianchi et al. 2018). Recent modelling shows that for the best outcome for emissions, global well-being, land-use and other factors, food policies should provide food to the undernourished while simultaneously reducing overconsumption and food waste in high-consumption regions (Hasegawa et al. 2019).

Placing costs on emissions-intensive foods such as beef and lamb, in conjunction with financial support to encourage healthy fruit and vegetable consumption, can shift demand and reduce food-related emissions by nearly 10 per cent globally (Springmann et al. 2017). Low-carbon diets also tend to be those that are healthier, thus providing opportunities for health and climate policy to be aligned (Aleksandrowicz et al. 2016; Willett et al. 2019). In Latin America, North America, Europe and many parts of Asia, consumption of red meat is at much higher levels than is recommended for a healthy, low-carbon diet (Willett et al. 2019). While it is not easy to shift notions of normal and culturally acceptable ways of eating (Bailey et al. 2014; Mozaffarian et al. 2018), recent history shows that this can occur rapidly and that diets in many parts of the world are in flux (Vermeulen et al. 2019).

Comparable measures have been effective in influencing purchasing choices, such as taxes on unhealthy foods (Colchero et al. 2016) and subsidies for fruit and vegetables (for example, through food assistance programmes in the United States of America; Olsho et al. 2016). Complementary 
measures such as restricting advertising of high-carbon foods (Hyseni et al. 2017), while improving access to lowcarbon foods, such as by increasing vegetarian meals in cafeterias and other food outlets, has the potential to enable dietary change (Garnett et al. 2019). Globally, close to onethird of global food sales are from just 10 supermarket chains (IPES-Food 2017): major retailers have the ability to influence consumer practices, for example by encouraging alternatives to meat protein through ensuring their availability and prominence in stores (Gravely and Fraser 2018).

Policies against food waste offer benefits such as saving consumers money without reducing the quantity consumed (Hasegawa et al. 2019). Food waste bans and other policies can also allow providers of fresh fruit and vegetables to better address the needs of underserved or deprived communities (Pearson and Wilson 2013). Where authorities have direct control over food provision, including in the public sector, its carbon footprint can be cut: for example, the city of Leeds in the United Kingdom introduced meat-free and vegan catering into 182 primary schools for climate mitigation (Leeds City Council 2020). In Quezon City, Philippines, legislation is being developed for urban agricultural zones, with a scheme termed Fresh Market on Wheels delivering fresh produce from local farms to vulnerable communities around the city (C40 Cities Network 2020). However, as large segments of the global population still lack sufficient food (Willett et al. 2019), acknowledging divisions in terms of income and access are important if food sector emissions are to be reduced while meeting basic human needs.

\subsection{Looking forward}

\subsubsection{Communicating lifestyle change}

Popular debate has often pitted 'behaviour change' and 'system change' against each other, presented as a trade-off between two choices. As this chapter illustrates, however, system change and behaviour change are two sides of the same coin. When communicating about lifestyle change, it is important to recognize the constant interplay between the lifestyles of individuals and the social, cultural, political and economic systems in which they live and which they help shape.

There is a central role for communication and public engagement to change the way sustainable lifestyles are discussed in public forums and to emphasize the dynamic and complex relationship between systems and behaviour. Recognizing the role of interpersonal influence can also help emphasize the social and collective nature of lifestyle change, and is potentially more empowering than a view of personal actions that occur in isolation or that are negligible compared to the need for large-scale climate mitigation (Maniates 2001; Capstick 2013; Kubitt 2020). Communicating where actions would be most impactful, and that changes to lifestyles are a necessary component to meeting global emissions reduction targets, is a powerful tool that can be wielded by a diverse range of actors.

\subsubsection{Overcoming barriers and accomplishing long- lasting change}

In seeking to shift focus from economic growth towards equity and well-being within ecological limits, a move towards sustainable lifestyles is likely to challenge powerful vested interests. For example, the focus of the global economy on paid employment - and the devaluation of unpaid care work that sustains it - is an overlooked barrier to low-carbon lifestyles. Higher income tends to be correlated with higher emissions; by contrast, an alternative economic system that places caring responsibilities and well-being at the centre of community and economic life (for example, through a shorter working week and fairer distribution of care work) has the potential to reduce emissions. With enabling policies in place, such an approach could reduce emissions and gender and income inequality, while improving standards of living (Coote et al. 2010; Biesecker et al. 2014; Gottschlich and Bellina 2017; Wiedenhofer et al. 2018; Fremstad and Underwood 2019). On the other hand, an approach of this kind is poorly aligned with the current economic and political system in many parts of the world, in which large corporations are increasingly determining how private and social needs are met and shaping the conditions of everyday life (Dauvergne and Lister 2013).

Changes to underlying social and cultural norms are more difficult to accomplish than transitory behavioural changes, but once established they are likely to be more durable and to support a wider range of low-carbon lifestyles (De Young 2011). By contrast, the process of changing laws and written codes of behaviour and conduct can occur in only a few years (Williamson 1998), and large infrastructural projects can enable and disable choices of citizens for decades or longer (Seto et al. 2016; Otto et al. 2020b).

One example that seeks to redress the balance of power towards long-term sustainable societies is an ombudsman for future generations (Beckman 2016) who intervenes in public policy design and investments that present structural barriers to a low-carbon transition. Such an approach has already been implemented in Wales, United Kingdom (Davidson 2020) and in Hungary (Vincent 2012). From a cross-European study of demand-side options in line with $1.5^{\circ} \mathrm{C}$ pathways, Moberg et al. (2018) conclude that while current policies are insufficient to achieve emissions reduction in line with this, households are keen to see stronger government intervention, with high public acceptability of 'command-and-control' measures across mitigation options.

Ultimately, the accomplishment of low-carbon lifestyles will require deep-rooted changes to socioeconomic systems and cultural conventions. The participation of actors and groups across civil society, as well as government, is needed to ensure this happens in a way that preserves people's well-being while achieving substantial and rapid cuts in GHG emissions. 


\section{References}

\section{Chapter 1}

C CarbonBrief (2020). State of the climate: 2020 on course to be the warmest year on record, 23 October. https:// www.carbonbrief.org/state-of-the-climate-2020-on-course-to-be-warmest-year-on-record. Accessed 23 November 2020.

F

Forster, P.M., Forster, H.I., Evans, M.J., Gidden, M. J., Jones, C. D., Keller, C. A. et al. (2020). Current and future global climate impacts resulting from COVID-19. Nature Climate Change 10, 913-919. https://doi.org/10.1038/ s41558-020-0883-0.

$\mathbf{N}$

National Aeronautics and Space Administration (2020). 2020 Arctic sea ice minimum at second lowest on record, 21 September. https://climate.nasa.gov/news/3023/2020-arctic-sea-ice-minimum-at-second-lowest-onrecord/. Accessed 23 November 2020.

National Oceanic and Atmospheric Administration (2020). Billion-dollar weather and climate disasters: Overview. https://www.ncdc.noaa.gov/billions/. Accessed 23 November 2020.

U

United Nations (2020). Climate change and COVID-19: UN urges nations to 'recover better', 22 April. https:// www.un.org/en/un-coronavirus-communications-team/un-urges-countries-\%E2\%80\%98build-backbetter\%E2\%80\%99. Accessed 23 November 2020.

United Nations Framework Convention on Climate Change (2020). An economic recovery that builds a greener future, 13 July. https://unfccc.int/news/an-economic-recovery-that-builds-a-greener-future. Accessed 23 November 2020.

World Meteorological Organization (2020). United in Science. High-level Synthesis Report of Latest Climate Science Information Convened by the Science Advisory Group of the UN Climate Action Summit 2019. https://library. wmo.int/doc_num.php?explnum_id=9937.

\section{Chapter 2}

B

Biden, J. (2020). The Biden Plan for a Clean Energy Revolution and Environmental Justice. https://joebiden.com/ climate-plan/. Accessed 15 November 2020

Blanco, G., Gerlagh, R., Suh, S., Barrett, J., de Coninck, H.C., Diaz Morejon, C.F. et al. (2014). Drivers, trends and mitigation. In Climate Change 2014: Mitigation of Climate Change. Contribution of Working Group III to the Fifth Assessment Report of the Intergovernmental Panel on Climate Change. Edenhofer, O., Pichs-Madruga, Y., Sokona, E., Farahani, S., Kadner, K. et al. (eds.). Cambridge, United Kingdom and New York, United States of America: IPCC. Chapter 5. 351-411.

BP (2020). Statistical Review of World Energy 2020. https://www.bp.com/content/dam/bp/business-sites/ en/global/corporate/pdfs/energy-economics/statistical-review/bp-stats-review-2020-full-report.pdf. Accessed 20 November 2020

C

Chai, Q., Fu, S., Xu, H., Li, W. and Zhong, Y. (2017). The gap report of global climate change mitigation, finance, and governance after the United States declared its withdrawal from the Paris Agreement. Chinese Journal of Population Resources and Environment 15(3), 196-208. https://doi.org/10.1080/10042857.2017.1365450.

Cheong Wa Dae (2020). Address by President Moon Jae-in at National Assembly to propose government budget for 2021, 28 October. http://english1.president.go.kr/BriefingSpeeches/Speeches/898. Accessed 13 November 2020

Climate Action Tracker (2019). Countries. https://climateactiontracker.org/countries/. Accessed 13 August 2019. 
(2020a). Biden's election could bring a tipping point putting Paris Agreement 1.5 degree limit "within striking distance", 7 November. https://climateactiontracker.org/press/bidens-election-couldbring-a-tipping-point-putting-paris-agreement-15-degree-limit-within-striking-distance/. Accessed 10 November 2020.

(2020b). USA, 30 July. https://climateactiontracker.org/countries/usa/. Accessed 30 September 2020.

(2020c). Pandemic Recovery: Positive Intentions vs Policy Rollbacks, with Just a Hint of Green. https://climateactiontracker.org/documents/790/CAT_2020-09-23_Briefing_GlobalUpdate_Sept2020.pdf. Accessed 1 October 2020.

Climate Transparency (2020). Climate Transparency Report: Comparing G20 Climate Action and Responses to the COVID-19 Crisis. http://climate-transparency.org.

ClimateWorks Australia (2018). Tracking Progress to Net Zero Emissions: National Progress on Reducing Emissions across the Australian Economy and Outlook to 2030. https://climateworksaustralia.org/wp-content/ uploads/2018/09/climateworksaustralia-tracking-progress-report-2018-1.pdf.

Commonwealth of Australia (2019). Australia's Emissions Projections 2019. Department of the Environment and Energy. https://industry.gov.au/sites/default/files/2020-07/australias-emissions-projections-2019report.pdf.

Crippa, M., Guizzardi, D., Muntean, M., Schaff, E., Solazzo, E., Monforti-Ferrario, F. et al. (2020). Fossil $\mathrm{CO}_{2}$ Emissions of all World Countries: 2020 Report. Luxembourg: Publications Office of the European Union. https://publications.jrc.ec.europa.eu/repository/handle/JRC121460.

Croatian Presidency of the Council of the European Union and the European Commission (2020). Submission by Croatia and the European Commission on behalf of the European Union and its Member States. Longterm low greenhouse gas emission development strategy of the European Union and its Member States. 6 March. Zagreb. https://unfccc.int/sites/default/files/resource/HR-03-06-2020\%20EU\%20Submission\%20 on\%20Long\%20term\%20strategy.pdf.

D

den Elzen, M., Kuramochi, T., Höhne, N., Cantzler, J., Esmeijer, K., Fekete, H. et al. (2019). Are the G20 economies making enough progress to meet their NDC targets? Energy Policy 126, 238-250. https://doi.org/10.1016/j. enpol.2018.11.027.

Dubash, N., Khosla, R., Rao, N.D. and Bhardwaj, A. (2018). India's energy and emissions future: an interpretive analysis of model scenarios. Environmental Research Letters 13(7). https://doi.org/10.1088/17489326/aacc74.

Enerdata (2020). Global Energy Trends 2020 Edition. https://enerdata.net/system/files/publications/globalenergy-trends-2020-edition-enerdata.pdf.

Energy and Climate Intelligence Unit (2020). Net Zero Tracker. https://eciu.net/netzerotracker. Accessed 30 October 2020.

Environment and Climate Change Canada (2020a). Progress Towards Canada's Greenhouse Gas Emissions Reduction Target. Gatineau. https://canada.ca/en/environment-climate-change/services/environmentalindicators/progress-towards-canada-greenhouse-gas-emissions-reduction-target.html.

(2020b). Canada's 4th Biennial Report to the United Nations Framework Convention on Climate Change (UNFCCC). Gatineau. https://unfccc.int/documents/209928.

European Commission (2018). In-depth Analysis in Support of the Commission Communication COM(2018) 773: A Clean Planet for All - A European Strategic Long-term Vision for a Prosperous, Modern, Competitive and Climate Neutral Economy. Brussels. https://knowledge4policy.ec.europa.eu/publication/depth-analysissupport-com2018-773-clean-planet-all-european-strategic-long-term-vision_en.

(2020a). An EU-wide Assessment of National Energy and Climate Plans: Driving Forward the Green Transition and Promoting Economic Recovery through Integrated Energy and Climate Planning. Brussels. https://eur-lex.europa.eu/legal-content/EN/TXT/PDF/?uri=CELEX:52020DC0564\&from=EN.

(2020b). Impact Assessment: Stepping up Europe's 2030 Climate Ambition - Investing in a Climateneutral Future for the Benefit of our People. Brussels. https://ec.europa.eu/clima/policies/eu-climateaction/2030_ctp_en.

European Environment Agency (2019). Trends and Projections in Europe 2019: Tracking Progress Towards Europe's Climate and Energy Targets. EEA Report No. 15/2019. Luxembourg: Publications Office of the European Union. https://eea.europa.eu/publications/trends-and-projections-in-europe-1.

Fawcett, A.A., Iyer, G.C., Clarke, L.E., Edmonds, J.A., Hultman, N.E., McJeon, H.C. et al. (2015). Can Paris pledges avert severe climate change? Science 350(6265), 1168-1169. https://doi.org/10.1126/science.aad5761. 
Forster, P.M., Forster, H.I., Evans, M.J., Gidden, M.J., Jones, C.D., Keller, A. et al. (2020). Current and future global climate impacts resulting from COVID-19. Nature Climate Change 10, 913-919. https://doi.org/10.1038/ s41558-020-0883-0.

Fransen, T. and Höhne, N. (2018). Bridging the gap: strengthening NDCs and domestic policies. In Emissions Gap Report 2018. Nairobi: UNEP. Chapter 4.

Friedlingstein, P., Jones, M.W., O'Sullivan, M., Andrew, R.M., Hauck, J., Peters, G.P. et al. (2019). Global Carbon Budget 2019. Earth System Science Data 11, 1783-1838. https://doi.org/10.5194/essd-11-1783-2019.

Friedlingstein, P., O'Sullivan, M., Jones, M.W., Andrew, R.M., Hauck, J., Olsen, A. et al. (in review). Global Carbon Budget 2020. Earth System Science Data. https://doi.org/10.5194/essd-2020-286.

Fu, S., Zou, J. and Liu, L. (2017). An Analysis of China's INDC (Updated Analysis 2017). MILES Report. Beijing: National Center for Climate Change Strategy and International Cooperation (NCSC).

Government of Argentina (2016). First Revision of its Nationally Determined Contribution. www4.unfccc.int/sites/ ndcstaging/PublishedDocuments/Argentina\%20First/Traducci\%C3\%B3n\%20NDC_Argentina.pdf.

Government of Japan (2019a). Japan's Fourth Biennial Report under the United Nations Framework Convention on Climate Change. Tokyo.

(2019b). The Long-term Strategy under the Paris Agreement. https://unfccc.int/sites/default/files/ resource/The Long-term Strategy under the Paris Agreement.pdf.

Government of Mexico (2015). First Biennial Update Report to the United Nations Framework Convention on Climate Change. https://unfccc.int/files/national_reports/non-annex_i_parties/ica/technical_support_for_ the_ica_process/application/pdf/executive_summary.pdf.

Governor General of Canada (2020). A Stronger and More Resilient Canada: Speech from the Throne to Open the Second Session of the Forty-third Parliament of Canada. https://canada.ca/content/dam/pco-bcp/ documents/pm/SFT_2020_EN_WEB.pdf.

Grassi, G., House, J., Kurz, W.A., Cescatti, A., Houghton, R.A., Peters, G.P. et al. (2018). Reconciling global-model estimates and country reporting of anthropogenic forest $\mathrm{CO}_{2}$ sinks. Nature Climate Change 8, 914-920. https://doi.org/10.1038/s41558-018-0283-x.

H Hanna, R., Xu, Y. and Victor, D.G. (2019). After COVID-19, green investment must deliver jobs to get political traction. Nature 582(7811), 178-180. https://doi.org/10.1038/d41586-020-01682-1.

Hansis, E., Davis, S.J. and Pongratz, J. (2015). Relevance of methodological choices for accounting of land use change carbon fluxes. Global Biogeochemical Cycles 29(8), 1230-1246. https://doi.org/10.1002/2014GB004997.

Höhne, N., Fransen, T., Hans, F., Bhardwaj, A., Blanco, G., den Elzen, M. et al. (2019). Bridging the Gap - Enhancing Mitigation Ambition and Action at G20 Level and Globally: Pre-release Version of a Chapter in the forthcoming UNEP Emissions Gap Report 2019. Nairobi: United Nations Environment Programme (UNEP).

Höhne, N., den Elzen, M., Rogelj, J., Metz, B., Fransen, T., Kuramochi, T. et al. (2020). Emissions: world has four times the work or one-third of the time. Nature, 579(7797), 25-28. https://doi.org/10.1038/d41586-020-00571-x.

Houghton, R.A. and Nassikas, A.A. (2017). Global and regional fluxes of carbon from land use and land cover change 1850-2015. Global Biogeochemical Cycles 31(3), 456-472. https://doi.org/10.1002/2016GB005546.

International Energy Agency (2020a). Global CO 2 emissions in 2019, 11 February. https://www.iea.org/articles/ global-co2-emissions-in-2019.

(2020b). Global Energy Review 2020. Paris. https://www.iea.org/reports/global-energy-review-2020. (2020c). Sustainable Recovery. World Energy Outlook Special Report in Collaboration with the International Monetary Fund. Paris. https://www.iea.org/reports/sustainable-recovery.

(2020d). World Energy Investment 2020. Paris. https://www.iea.org/reports/world-energyinvestment-2020.

(2020e). World Energy Outlook 2020. Paris. https://www.iea.org/reports/world-energy-outlook-2020.

J Journal officiel de la République Française (2019). LOI n 2019-1147 du 8 novembre 2019 relative à l'énergie et au climat (1) [Law No. 2019-1147 of 8 November 2019 on energy and the climate]. https://legifrance.gouv.fr/eli/ loi/2019/11/8/TREX1911204L/jo/texte.

King Abdullah University of Science and Technology (2014). Appraisal and Evaluation of Energy Utilization and Efficiency in the Kingdom of Saudi Arabia. http://studylib.net/doc/8408427/appraisal-and-evaluation-ofenergy-utilization-and-effici.... 
Keesler, D., Orifici, L. and Blanco, G. (2019). Situación actual y proyección de emisiones de gases de efecto invernadero en la Argentina [Current Status and Projection of Greenhouse Gas Emissions in Argentina]. Buenos Aires: Universidad Nacional del Centro de la Provincia de Buenos Aires. https://fio.unicen.edu.ar/ images/pdf/2019/Informe_GREENPEACE_-_CTAE-FIO-UNICEN.pdf.

Keramidas, K., Diaz Vazquez, A., Weitzel, M., Vandyck, T., Tamba, M., Tchung-Ming, S. et al. (2020). Global Energy and Climate Outlook 2019: Electrification for the Low-carbon Transition. Luxembourg: Publications Office of the European Union.

Kuramochi, T., Nascimento, L., Jose de Villafranca Casas, M., Fekete, H., de Vivero, G., Lui, S. et al. (2019). Greenhouse Gas Mitigation Scenarios for Major Emitting Countries. Analysis of Current Climate Policies and Mitigation Commitments: 2019 Update. NewClimate Institute, PBL Netherlands Environmental Assessment Agency and International Institute for Applied Systems Analysis (IIASA). https://newclimate.org/wp-content/ uploads/2019/12/GHG-Mitigation-Scenarios-Dec2019.pdf.

Larsen, K., Pitt, H., Larsen, J., Herndon, W., Houser, T., Kolus, H. et al. (2020). Taking Stock 2020: The COVID-19 Edition. Rhodium Group. https://rhg.com/research/taking-stock-2020/.

Le Quéré, C., Korsbakken, J.I., Wilson, C., Tosun, J., Andrew, R., Andres, R.J. et al. (2019). Drivers of declining $\mathrm{CO}_{2}$ emissions in 18 developed economies. Nature Climate Change 9, 213-217. https://doi.org/10.1038/s41558019-0419-7.

Le Quéré, C., Jackson, R.B., Jones, M.W., Smith, A.J.P., Abernethy, S., Andrew, R.M. et al. (2020). Temporary reduction in daily global $\mathrm{CO}_{2}$ emissions during the COVID-19 forced confinement. Nature Climate Change 10, 647-653. https://doi.org/10.1038/s41558-020-0797-x.

Levin, K. and Fransen, T. (2019). Climate Action for Today and Tomorrow: The Relationship Between NDCs and LTSs. https://wriorg.s3.amazonaws.com/s3fs-public/wri-commentary-climate-action-today.pdf.

Levin, K., Rich, D., Ross, K., Fransen, T and Elliott, C. (2020). Designing and Communicating Net-Zero Targets. Washington, DC: World Resources Institute. www.wri.org/design-net-zero.

Liu, Z., Ciais, P., Deng, Z., Lei, R., Davis, S.J., Feng, S. et al. (2020). COVID-19 causes record decline in global $\mathrm{CO}_{2}$ emissions. http://arxiv.org/abs/2004.13614.

M Meinshausen, M. and Alexander, R. (2017). NDC \& INDC factsheets. http://climatecollege.unimelb.edu.au/ndcindc-factsheets.

Ministry of Foreign Affairs of Japan (2020). Press conference by Foreign Minister MOTEGI Toshimitsu, 27 October. https://www.mofa.go.jp/press/kaiken/kaiken4e_000862.html. Accessed 2 November 2020.

Ministry of Foreign Affairs of the People's Republic of China (2020). Statement by H.E. Xi Jinping President of the People's Republic of China at the general debate of the 75th session of the United Nations General Assembly, 22 September. https://www.fmprc.gov.cn/mfa_eng/zxxx_662805/t1817098.shtml. Accessed 25 September 2020.

Mitra, A., Ross, K., Latamirano, J.-C., Fransen, T., Citkara, P., Singh, M. et al. (2017). Pathways For Meeting India's Climate Goals. Washington, DC: World Resources Institute. https://wri.org/publication/meeting-indiasclimate-goals.

Moisio, M., Nascimento, L., de Vivero, G., Gonzales, S., Hans, F., Lui, S. et al. (2020). Overview Of Recently Adopted Mitigation Policies and Climate-relevant Policy Responses to COVID-19: 2020 Update. NewClimate Institute, PBL Netherlands Environmental Assessment Agency and International Institute for Applied Systems Analysis (IIASA).

NBC News (2020). U.S. Presidential Election Results 2020: Biden wins. https://nbcnews.com/politics/2020elections/president-results. Accessed 15 November 2020.

Olivier, J.G.J. and Peters, J.A.H.W. (2019). Trends in Global $\mathrm{CO}_{2}$ and Total Greenhouse Gas Emissions: Summary of the 2019 Report. The Hague: PBL Netherlands Environmental Assessment Agency. https://pbl.nl/sites/ default/files/downloads/pbl-2019-trends-in-global-co2-and-total-greenhouse-gas-emissions-summary-otthe-2019-report_4004.pdf.

Olivier, J.G.J. and Peters, J.A.H.W. (2020, in preparation). Trends in Global $\mathrm{CO}_{2}$ and Total Greenhouse Gas Emissions: 2019 Report. The Hague: PBL Netherlands Environmental Assessment Agency. https://pbl.nl/ sites/default/files/downloads/pbl-2020-trends-in-global-co2-and-total-greenhouse-gas-emissions-2019report_4068.pdf.

Olivier, J.G.J., Schure, K.M. and Peters, J.A.H.W. (2017). Trends in $\mathrm{Global} \mathrm{CO}_{2}$ and Total Greenhouse Gas Emissions: 2017 Report. The Hague: PBL Netherlands Environmental Assessment Agency. http://pbl.nl/en/publications/ trends-in-global-co2-and-total-greenhouse-gas-emissions-2017-report. 
Pan, C., Peters, G.P., Andrew, R.M., Korsbakken, J.I., Li, S., Zhou, D. et al. (2017). Emissions embodied in global trade have plateaued due to structural changes in China. Earth's Future 5(9), 934-946. https://doi. org/10.1002/2017EF000625.

PBL (2020). PBL Climate Pledge NDC tool. www.pbl.nl/indc. Accessed 17 June 2020.

People's Republic of China (2016). 中华人民共和国气候变化 第一次两年更新报告 [First Biennial Update Report on Climate Change of the People's Republic of China]. http://unfccc.int/files/national_reports/non-annex_i_ parties/biennial_update_reports/submitted_burs/application/pdf/chnbur1.pdf.

Peters, G.P., Marland, G., Le Quéré, C., Boden, T., Canadell, J.G. and Raupach, M.R. (2012). Rapid growth in $\mathrm{CO}_{2}$ emissions after the 2008-2009 global financial crisis. Nature Climate Change 2, 2-4. https://doi.org/10.1038/ nclimate1332.

Peters, G.P., Andrew, R.M., Canadekk, J.G., Friedlingstein, P., Jackson, R.B., Korsbakken, J.I. et al. (2020). Carbon dioxide emissions continue to grow amidst slowly emerging climate policies. Nature Climate Change 10, 3-6. https://doi.org/10.1038/s41558-019-0659-6.

R Republic of South Africa (2020). South Africa's Low-emission Development Strategy 2050. https://www. environment.gov.za/sites/default/files/docs/2020lowemission_developmentstrategy.pdf.

Republic of South Africa, Department of Energy (2019). Integrated Resource Plan (IRP2019). https://gov.za/sites/ default/files/gcis_document/201910/42778gon1359.pdf.

Rochedo, P.R.R., Soares-Filho, B., Schaeffer, R., Viola, E., Szklo, A., Lucena, A.F.P. et al. (2018). The threat of political bargaining to climate mitigation in Brazil. Nature Climate Change 8, 695-699. https://doi.org/10.1038/ s41558-018-0213-y.

Roelfsema, M., van Soest, H.L., Harmsen, M., van Vuuren, D.P., Bertram, C., den Elzen, M. et al. (2020). Taking stock of national climate policies to evaluate implementation of the Paris Agreement. Nature Communications 11, 2096. https://doi.org/10.1038/s41467-020-15414-6.

Shukla, P.R., Skea, J., Calvo Buendía, E., Masson-Delmotte, V., Pörtner, H.-O., Roberts, D. et al. (2019). Summary for Policymakers, Climate Change and Land: An IPCC Special Report on climate change, desertification, land degradation, sustainable land management, food security, and greenhouse gas fluxes in terrestrial ecosystems. Intergovernmental Panel on Climate Change (IPCC). https://www.ipcc.ch/site/assets/uploads/ sites/4/2020/02/SPM_Updated-Jan20.pdf.

Tavoni, M., Kriegler, E., Riahi, K., van Vuuren, D.P., Aboumahboub, T., Bowen, A. et al. (2014). Post-2020 climate agreements in the major economies assessed in the light of global models. Nature Climate Change 5, 119-126. https://doi.org/10.1038/nclimate2475.

Tubiello, F. N., Pekkarinen, A., Marklund, L., Wanner, N., Conchedda, G., Federici, S. et al. (in review). Carbon emissions and removals by forests: new estimates 1990-2020. Earth System Science Data. https://doi. org/10.5194/essd-2020-203.

U.S. Department of State (2016). Second Biennial Report of the United States of America under the United Nations Framework Convention on Climate Change. http://unfccc.int/national_reports/biennial_reports_and_iar/ submitted_biennial_reports/items/7550.php.

U.S. Energy Information Administration (2020). Short-term energy outlook, 9 September.https://eia.gov/ outlooks/steo/.

United Kingdom (2019). The Climate Change Act 2008 (2050 Target Amendment) Order 2019. https://www. legislation.gov.uk/uksi/2019/1056/contents/made.

United Nations Department of Econimic and Social Affairs (2019). World population prospects 2019. https:// population.un.org/wpp/Download/Standard/Population/. Accessed 13 August 2019.

United Nations Environment Programme (2015). The Emissions Gap Report 2015: A UNEP Synthesis Report. Nairobi. https://newclimateinstitute.files.wordpress.com/2015/12/unep-emissions-gap-report-2015.pdf.

United Nations Framework Convention on Climate Change (2017). INDCs as communicated by Parties. https:// www4.unfccc.int/sites/submissions/INDC/Submission\%20Pages/submissions.aspx. Accessed 10 September 2019.

(2019). Climate Ambition Alliance: Nations renew their push to upscale action by 2020 and achieve net zero $\mathrm{CO}_{2}$ emissions by 2050, 11 December. https://unfccc.int/news/climate-ambition-alliance-nationsrenew-their-push-to-upscale-action-by-2020-and-achieve-net-zero. Accessed 30 September 2020

(undated a). NDC Registry (interim). www4.unfccc.int/ndcregistry/Pages/Home.aspx.

(undated b). Progress towards achieving the target - mitigation actions. www4.unfccc.int/sites/br-di/ Pages/MitigationActions.aspx. 
Weitzel, M., Vandyck, T., Keramides, K., Amann, M., Capros, P., den Elzen, M. et al. (2019). Model-based assessments for long-term climate strategies. Nature Climate Change 9(5), 345-347. https://doi.org/10.1038/s41558019-0453-5.

\section{Chapter 3}

Amador-Jiménez, M., Millner, N., Palmer, C., Pennington, R.T. and Sileci, L. (2020). The unintended impact of Colombia's Covid-19 lockdown on forest fires. Environmental and Resource Economics 76, 1081-1105. https://doi.org/10.1007/s10640-020-00501-5.

Azevedo, T. (2020). Impacto da pandemia de Covid-19 nas emissões de gases de efeito estufa no Brasil [Impact of the COVID-19 Pandemic on Greenhouse Gas Emissions in Brazil]. SEEG. https://seeg-br.s3.amazonaws. com/OC_nota_tecnica_FINAL.pdf.

Bauer, N., Rose, S.K., Fujimori, S., van Vuuren, D.P., Weyant, J., Wise, M. et al. (2018). Global energy sector emission reductions and bioenergy use: overview of the bioenergy demand phase of the EMF-33 model comparison. Climatic Change. https://doi.org/10.1007/s10584-018-2226-y.

Clarke, L., Jiang, K., Akimoto, K., Babiker, M., Blanford, G., Fisher-Vanden, K. et al. (2014). Assessing transformation pathways. In Climate Change 2014: Mitigation of Climate Change. Contribution of Working Group III to the Fifth Assessment Report of the Intergovernmental Panel on Climate Change. Edenhofer, O., Pichs-Madruga, R., Sokona, Y., Farahani, E., Kadner, S., Seyboth, A. et al. (eds). Cambridge, United Kingdom and New York, United States of America: Cambridge University Press. Chapter 6. 413-510.

Climate Action Tracker (2019). Warming Projections Global Update: December 2019. https://climateactiontracker. org/documents/698/CAT_2019-12-10_BriefingCOP25_WarmingProjectionsGlobalUpdate_Dec2019.pdf. (2020a). Warming Projections Global Update: September 2020. https://climateactiontracker.org/ documents/790/CAT_2020-09-23_Briefing_GlobalUpdate_Sept2020.pdf.

(2020b). A government roadmap for addressing the climate and post COVID-19 economic crises, 27 April. https://climateactiontracker.org/publications/addressing-the-climate-and-post-covid-19-economiccrises/. Accessed 25 November 2020.

(2020c). Biden's election could bring a tipping point putting Paris Agreement 1.5 degree limit "within striking distance", 7 November. https://climateactiontracker.org/press/bidens-election-couldbring-a-tipping-point-putting-paris-agreement-15-degree-limit-within-striking-distance/. Accessed 26 November 2020.

Dafnomilis, I., den Elzen, M.G.J., van Soest, H., Hans, F., Kuramochi, T. and Höhne, N. (2020). Exploring the Impact of the COVID-19 Pandemic on Global Emission Projections: Assessment of Green versus Non-green Recovery. PBL Netherlands Environmental Assessment Agency and NewClimate Institute. https://www. pbl.nl/en/news/2020/long-term-impact-of-covid-19-on-co2-emissions-dependent-on-greenness-ofrecovery-packages.

den Elzen, M., Kuramochi, T., Höhne, N., Cantzler, J., Esmeijer, K., Fekete, H. et al. (2019). Are the G20 economies making enough progress to meet their NDC targets? Energy Policy 126, 238-250.

Emmerling, J., Drouet, L., Reis, L., Bevione, M., Berger, L., Bosetti, V. et al. (2019). The WITCH 2016 model Documentation and implementation of the Shared Socioeconomic Pathways. Working Paper 42.2016. https:// papers.ssrn.com/sol3/papers.cfm?abstract_id=2800970.

Food and Agriculture Organization of the United Nations (2020). Food Outlook: Biannual Report on Global Food Markets. Rome. http://fao.org/3/ca9509en/ca9509en.pdf.

Forster, P.M., Forster, H.I., Evans, M.J., Gidden, M.J., Jones, C.D., Keller, C.A. et al. (2020a). Current and future global climate impacts resulting from COVID-19. Nature Climate Change 10, 1-7. https://doi.org/10.1038/ s41558-020-0883-0.

Fricko, O., Havlik, P., Rogelj, J., Klimont, Z., Gusti, M., Johnson, N. et al. (2017). The marker quantification of the Shared Socioeconomic Pathway 2: a middle-of-the-road scenario for the 21st century. Global Environmental Change 42, 251-267.

Fujimori, S., Hasegawa, T., Masui, T., Takahashi, K., Herran, D.S., Dai, H. et al. (2017). SSP3: AIM implementation of Shared Socioeconomic Pathways. Global Environmental Change 42, 268-283. 
Grübler, A., Wilson, C., Bento, N., Boza-Kiss, B., Krey, V., McCollum, D.L. et al. (2018). A low energy demand scenario for meeting the $1.5^{\circ} \mathrm{C}$ target and sustainable development goals without negative emission technologies. Nature Energy 3, 515-527. https://doi.org/10.1038/s41560-018-0172-6.

Höhne, N., den Elzen, M., Rogelj, J., Metz, B., Fransen, T., Kuramochi, T. et al. (2020). Emissions: world has four times the work or one-third of the time. Nature 579, 25-28. https://doi.org/10.1038/d41586-020-00571-x.

Holz, C., Siegel, L.S., Johnston, E., Jones, A.P. and Sterman, J. (2018). Ratcheting ambition to limit warming to $1.5^{\circ} \mathrm{C}$-trade-offs between emission reductions and carbon dioxide removal. Environmental Research Letters 13(6), 064028. https://doi.org/10.1088/1748-9326/aac0c1.

Huppmann, D., Rogelj, J., Kriegler, E., Krey, V. and Riahi, K. (2018a). A new scenario resource for integrated $1.5^{\circ} \mathrm{C}$ research. Nature Climate Change 8, 1027-1030. https://doi.org/10.1038/s41558-018-0317-4.

Huppmann, D., Kriegler, E., Krey, V., Riahi, K., Rogelj, J., Rose, S.K. et al. (2018b). IAMC $1.5^{\circ} \mathrm{C}$ Scenario Explorer and Data hosted by IIASA. https://data.ene.iiasa.ac.at/DOI/SR15/08-2018.15429/. Accessed 25 November 2020.

International Energy Agency (2019). World Energy Outlook 2019. Paris. (2020a). Sustainable Recovery. World Energy Outlook Special Report in Collaboration with the International Monetary Fund. Paris. https://www.iea.org/reports/sustainable-recovery. (2020b). World Energy Outlook 2020. Paris. https://www.iea.org/reports/world-energy-outlook-2020. International Monetary Fund (2020). World Economic Outlook Update, June 2020. Washington, D.C. Intergovernmental Panel on Climate Change (2018). Summary for policymakers. In Global Warming of $1.5^{\circ} \mathrm{C}$ : An IPCC Special Report on the Impacts of Global Warming of $1.5^{\circ} \mathrm{C}$ above Pre-industrial Levels and Related Global Greenhouse Gas Emission Pathways, in the Context of Strengthening the Global Response to the Threat of Climate Change, Sustainable Development, and Efforts to Eradicate Poverty. Masson-Delmotte, V., Zhai, P., Pörtner, H.-O., Roberts, D., Skea, J., Shukla, P. R. et al. (eds.). Geneva.

Jeffery, M.L., Gütschow, J., Rocha, M.R. and Gieseke, R. (2018). Measuring success: improving assessments of aggregate greenhouse gas emissions reduction goals. Earth's Future 6(9), 1260-1274. https://doi. org/10.1029/2018ef000865.

Kaya, Y. (1990). Impact of carbon dioxide emission control on GNP growth: interpretation of proposed scenarios. Paper presented to the Intergovernmental Panel on Climate Change (IPCC) Energy and Industry Subgroup, Response Strategies Working Group.

Keramidas, K., Diaz Vazquez, A., Weitzel, M., Vandyck, T., Tamba, M., Tchung-Ming, S. et al. (2020). Global Energy and Climate Outlook 2019: Electrification for the Low-carbon Transition. Luxembourg: Publications Office of the European Union.

Kriegler, E., Bertram, C., Kuramochi, T., Jakob, M., Pehl, M., Stevanović, M. et al. (2018). Short term policies to keep the door open for Paris climate goals. Environmental Research Letters 13(7), 074022. https://doi. org/10.1088/1748-9326/aac4f1

Kuramochi, T., Nascimento, L., Jose de Villafranca Casas, M., Fekete, H., de Vivero, G., Lui, S. et al. (2019). Greenhouse Gas Mitigation Scenarios for Major Emitting Countries. Analysis of Current Climate Policies and Mitigation Commitments: 2019 Update. NewClimate Institute, PBL Netherlands Environmental Assessment Agency and International Institute for Applied Systems Analysis (IIASA). https://newclimate.org/wp-content/ uploads/2019/12/GHG-Mitigation-Scenarios-Dec2019.pdf.

Le Quéré, C., Andrew, R.M., Friedlingstein, P., Sitch, S., Pongratz, J., Manning, A.C. et al. (2018). Global Carbon Budget 2017. Earth System Science Data 10, 405-448. https://doi.org/10.5194/essd-10-405-2018.

Le Quéré, C., Jackson, R.B., Jones, M.W., Smith, A.J.P., Abernethy, S., Andrew, R.M. et al. (2020). Temporary reduction in daily global $\mathrm{CO}_{2}$ emissions during the COVID-19 forced confinement. Nature Climate Change 10, 647-653. https://doi.org/10.1038/s41558-020-0797-x.

López-Feldman, A., Chávez, C., Vélez, M.A., Bejarano, H., Chimeli, A., Feres, J. et al. (2020). Environmental impacts and policy responses to Covid-19: a view from Latin America. Environmental and Resource Economics, 1-6.

Luderer, G., Leimbach, M., Bauer, N., Kriegler, E., Baumstark, L., Bertram, C. et al. (2015). Description of the REMIND Model (Version 1.6). Potsdam. https://ssrn.com/abstract=2697070.

Luderer, G., Rogelj, J., den Elzen, M.G.J., Jiang, K. and Huppmann, D. (2018). The emissions gap. In Emissions Gap Report 2018. Nairobi: United Nations Environment Programme (UNEP). Chapter 3. 16-22. for fulfilling the Paris Agreement and achieving the Sustainable Development Goals. Nature Energy 3(7), 589-599. https://doi.org/10.1038/s41560-018-0179-z. 
Meinshausen, M., Raper, S.C.B., and Wigley, T.M.L. (2011). Emulating coupled atmosphere-ocean and carbon cycle models with a simpler model, MAGICC6 - Part 1: Model description and calibration. Atmospheric Chemistry and Physics 11, 1417-1456. https://doi.org/10.5194/acp-11-1417-2011.

Miosio, M., Nascimiento, L., de Vivero, G., Gonzales, S., Hans, F., Lui, S. et al. (2020). Overview of Recently Adopted Mitigation Policies and Climate-relevant Policy Responses to COVID-19: 2020 Update. https://newclimate.org/ wp-content/uploads/2020/10/NewClimate_PBL-CLIMA_20200ctUpdate.pdf.

Organisation for Economic Co-operation and Development (2020a). Economic Outlook No 107 - June 2020 Double-hit scenario. https://stats.oecd.org/viewhtml.aspx?datasetcode=E0107_INTERNET_2. Accessed 25 November 2020.

(2020b). Economic Outlook No 107 - June 2020 - Single-hit scenario. https://stats.oecd.org/Index. aspx?DataSetCode=E0107_INTERNET_1\#. Accessed 25 November 2020.

_- (2020c). OECD Economic Outlook, Interim Report September 2020. Paris. https://doi. org/10.1787/34ffc900-en.

P PBL (2020). PBL Climate Pledge NDC tool. www.pbl.nl/indc. Accessed 17 June 2020.

R Rochedo, P.R.R., Soares-Filho, B., Schaeffer, R., Viola, E., Szklo, A., Lucena, A.F.P. et al. (2018). The threat of political bargaining to climate mitigation in Brazil. Nature Climate Change 8, 695-699. https://doi.org/10.1038/ s41558-018-0213-y.

Roelfsema, M., van Soest, H.L., Harmsen, M., van Vuuren, D.P., Bertram, C., den Elzen, M. et al. (2020). Taking stock of national climate policies to evaluate implementation of the Paris Agreement. Nature Communications 11, 2096. https://doi.org/10.1038/s41467-020-15414-6.

Rogelj, J., den Elzen, M., Höhne, N., Fransen, T., Fekete, H., Winkler, H. et al. (2016). Paris Agreement climate proposals need a boost to keep warming well below $2{ }^{\circ} \mathrm{C}$. Nature 534, 631-639. https://doi.org/10.1038/ nature18307.

Rogelj, J., Shindell, D., Jiang, K., Fifita, S., Forster, P., Ginzburg, V. et al. (2018). Mitigation pathways compatible with $1.5^{\circ} \mathrm{C}$ in the context of sustainable development. In Global Warming of $1.5^{\circ} \mathrm{C}$ : An IPCC Special Report on the Impacts of Global Warming of $1.5^{\circ} \mathrm{C}$ above Pre-Industrial Levels and Related Global Greenhouse Gas Emission Pathways, in the Context of Strengthening the Global Response to the Threat of Climate Change, Sustainable Development, and Efforts to Eradicate Poverty. Masson-Delmotte, V., Zhai, P., Pörtner, H.-O., Roberts, D., Skea, J., Shukla, P.R. et al. (eds.). Geneva: IPCC. Chapter 2. 93-174.

Rondeau, D., Perry, B. and Grimard, F. (2020). The consequences of COVID-19 and other disasters for wildlife and biodiversity. Environmental and Resource Economics 76, 945-961. https://doi.org/10.1007/s10640020-00480-7.

S Schleussner, C.-F., Rogelj, J., Schaeffer, M., Lissner, T., Licker, R. et al. (2016). Science and policy characteristics of the Paris Agreement temperature goal. Nature Climate Change 6, 827-835. https://doi.org/10.1038/ nclimate3096.

U United Nations Framework Convention on Climate Change (2015). Adoption of the Paris Agreement. 12 December. FCCC/CP/2015/L.9/Rev.1.

United Nations Environment Programme (2019). Emissions Gap Report 2019. Nairobi.

van Vuuren, D.P., Stehfest, E., Gernaat, D.E.H.J., van den Berg, M., Bijl, D.L., de Boer, H.S. et al. (2018). Alternative pathways to the $1.5^{\circ} \mathrm{C}$ target reduce the need for negative emission technologies. Nature Climate Change 8, 391-397. https://doi.org/10.1038/s41558-018-0119-8.

Vivid Economics (2020). Green Stimulus Index: An Assessment of the Orientation of COVID-19 Stimulus in Relation to Climate Change, Biodiversity and Other Environmental Impacts. https://www.vivideconomics.com/ casestudy/greenness-for-stimulus-index/.

\section{Chapter 4}

A African Development Bank (2020a). African Development Bank launches record breaking \$3 billion "Fight COVID-19" Social Bond, 27 March. https://www.afdb.org/en/news-and-events/press-releases/africandevelopment-bank-launches-record-breaking-3-billion-fight-covid-19-social-bond-34982. Accessed 12 November 2020. 
(2020b). African Development Bank Group unveils \$10 billion Response Facility to curb COVID-19, 8 April. https://www.afdb.org/en/news-and-events/press-releases/african-development-bank-group-unveils10-billion-response-facility-curb-covid-19-35174. Accessed 12 November 2020.

(2020c). African Development Fund approves \$9.52 million to enhance coordinated COVID-19 response in East and Horn of Africa and the Comoros, 30 June. https://www. afdb.org/en/news-and-events/ press-releases/african-development-fund-approves-952-million-enhance-coordinated-covid-19-responseeast-and-horn-africa-and-comoros-36627. Accessed 12 November 2020

Akrofi, M.M.C., and Antwi, S.H. (2020). COVID-19 energy sector responses in Africa: A review of preliminary government interventions. Energy Research \& Social Science 68, 101681. https://doi.org/10.1016/j. erss.2020.101681

Aratani, L. (2020). Treasury begins payments to airlines for coronavirus-related relief, 21 April 2020. https://www. washingtonpost.com/transportation/2020/04/20/treasury-officials-finalize-agreements-with-airlinescoronavirus-related-relief/. Accessed 17 November 2020.

Bala-Gbogbo, E. (2020). Oil crash spurs Nigeria to end fuel subsidies, risk backlash, 9 May. https://www. bloomberg.com/news/articles/2020-05-09/oil-crash-spurs-nigeria-to-end-fuel-subsidies-risk-backlash.

Bannon, E. (2020a). Austrian Airlines' bailout 'climate conditions' explained, 30 June. https://www. transportenvironment.org/publications/austrian-airlines-bailout-climate-conditions-explained. Accessed 8 September 2020

(2020b). Air France's bailout 'climate conditions' explained, 3 June. https://www.transportenvironment. org/publications/air-frances-bailout-climate-conditions-explained. Accessed 8 September 2020.

Bennett, V. (2020). EBRD unveils proposal to be majority green bank by 2025, 8 July. https://www.ebrd.com/ news/2020/ebrd-unveils-proposal-to-be-majority-green-bank-by-2025.html. Accessed 14 October 2020.

Brazil, National Energy Policy Council (2020). Resolution No. 4 of 4 June 2020. Brasilia, Brazil: Diário Oficial da União.

Business Development Bank of Canada (2020). BDC to increase support to Canadian oil and gas sector companies, 17 April. https://www.bdc.ca/en/about/mediaroom/news-releases/bdc-increase-support-canadian-oilgas-sector-companies.

Carbon Copy Editorial Team (2019). No new coal plants for Gujarat, Chhattisgarh, 17 September 2019. https:// carboncopy.info/no-new-coal-plants-for-gujarat-chhattisgarh/.

CarbonBrief (2020). Coronavirus: Tracking how the world's 'green recovery' plans aim to cut emissions, 16 June. https://www.carbonbrief.org/coronavirus-tracking-how-the-worlds-green-recovery-plans-aim-to-cutemissions. Accessed 20 June 2020.

Carnell, R., Prakash Sakpal, Pang, I., Mapa, N. and Patterson, W. (2020). Asia's Lamentable Green Response to Covid-19. ING. https://think.ing.com/uploads/reports/Asias_green_response_100820_AOT.pdf.

Canada, Office of the Prime Minister of Canada (2020). Prime Minister announces additional support for businesses to help save Canadian jobs, 11 May. https://pm.gc.ca/en/news/news-releases/2020/05/11/ prime-minister-announces-additional-support-businesses-help-save. Accessed 31 August 2020

Central Electricity Authority (2020a). Broad Status Report June 2020: Under Construction Thermal Power Projects. New Delhi: Central Electricity Authority, Ministry of Power, Government of India. https://www.cea.nic.in/ reports/monthly/broadstatus/2020/broad_status-06.pdf.

China Energy Portal (2020). National Energy Administration Circular on 2023 Risk and Early Warning for Coal Power Planning and Construction. https://chinaenergyportal.org/en/circular-on-2023-risk-and-early-warning-forcoal-power-planning-and-construction/. Accessed 31 August 2020.

City Government of Mexico City (2020). Boletin: presenta semovi lineamientos para implementacion de ciclovias emergentes [SEMOVI Presents Guidelines for the Implementation of Cycle-Lines], 4 June. Mexico City, Mexico. https://www.semovi.cdmx.gob.mx/comunicacion/nota/boletin-guia-ciclovias-emergentes.

Climate Action Tracker (2020). Global update: Pandemic recovery with just a hint of green, 23 September. https:// climateactiontracker.org/publications/global-update-pandemic-recovery-with-just-a-hint-of-green/.

Columbia Law School (2020). Climate Deregulation Tracker. https://climate.law.columbia.edu/climatederegulation-tracker. Accessed October 2020

D Dang, H., Nuwal, V. and Acharya, M. (2020). Powering reforms: transforming India's power sector through GARUDA, 8 August. https://www.financialexpress.com/opinion/powering-reforms-transforming-indias-power-sectorthrough-garuda/2048378/.

De Freitas Paes, C. (2020). Researchers are worried that the recent spike in deforestation and land grabbing will worsen the damage done by the Amazon fires this year, 21 May. https://therising.co/2020/05/21/amazonfires-may-be-worse-2020/. Accessed 29 September 2020. 
Energy Policy Tracker (2020). Energy Policy Tracker: About. https://www.energypolicytracker.org/about/. Accessed 12 November 2020.

Environmental Protection Agency (2020). Continuous Emission Monitoring; Quality-Assurance Requirements During the COVID-19 National Emergency. https://www.govinfo.gov/content/pkg/FR-2020-04-22/ pdf/2020-08581.pdf.

Fernandes, A. and Sharma, H. (2020). The 3Rs of DISCOM Recovery: Retirement, Renewables and Rationalisation. Bengaluru: Climate Risk Horizons.

Flyvbjerg, B. (2020). The law of regression to the tail: How to survive Covid-19, the climate crisis, and other disasters. Environmental Science \& Policy 114, 614-618. https://doi.org/10.1016/j.envsci.2020.08.013.

France, Ministry for the Economy and Finance (2020a). Plan de relance - Technologies vertes: Développer une filière d'hydrogène vert en France. https://www.economie.gouv.fr/plan-de-relance/technologies-vertes. Accessed 10 November 2020.

Friedman, L. (2020). E.P.A., citing coronavirus, drastically relaxes rules for polluters, 26 March (updated 14 April). https://www.nytimes.com/2020/03/26/climate/epa-coronavirus-pollution-rules.html.

Gao, B. (2020). China relaxes restrictions on coal power expansion for third year running. https://chinadialogue. net/en/energy/11966-china-relaxes-restrictions-on-coal-power-expansion-for-third-year-running/. Accessed 17 July 2020.

Germany, Federal Ministry of Finance 2020 (2020). "Zukunftspaket 2020": Corona-Folgen bekämpfen, Wohlstand sichern, Zukunftsfähigkeit stärken. Berlin, Germany.

Ghosh, A. and Ruha, S. (2020). Jobs, Growth and Sustainability: A New Social Contract for India's Recovery. New Delhi: Council on Energy, Environment and Water and National Institute of Public Finance and Policy.

Global Energy Monitor (2020). A New Coal Boom in China. https://globalenergymonitor.org/wp-content/ uploads/2020/06/China-coal-plant-brief-June-2020v2.pdf.

Gonzales, J. (2020). Brazil dismantles environemntal laws via huge surge in executive acts: study, 5 August. https://news.mongabay.com/2020/08/brazil-end-runs-environmental-laws-via-huge-surge-in-executiveacts-study/.

Government of Chile (2020). Programa "Crédito verde". Santiago, Chile.

Government of Denmark (2020). Markante drivhusgasreduktioner og investeringer i den grønne omstilling. Kopenhagen, Denmark.

Government of France (2020). Support plan for a competitive green automotive industry. Paris, France.

Government of India (2020). Finance Minister announces short term and long-term measures for supporting the poor, including migrants, farmers, tiny businesses and street vendors, 14 May.

Government of Italy (2020a). Decreto Rilancio. Rome, Italy. (2020b). Comunicato stampa del Consiglio dei Ministri n. 61. Rome, Italy.

Government of Malaysia (2020). Request for Proposal (RFP) Bagi Pemilihan Pemaju Berkelayakan \& Tapak Projek. Kuala Lumpur, Malaysia.

Government of Nigeria (2020). Bouncing Back: Nigeria Economic Plan Sustainability Plan. Abuja, Nigeria.

Government of Spain (2020). Plan to Promote the Value Chain of the Automotive Industry. Madrid, Spain.

Government of the Russian Federation (2020). Government allocated 25 billion rubles to support the Russian car industry. Moscow, Russia.

Government of the United Kingdom (2020a). £2 billion package to create new era for cycling and walking, 9 May. https://www.gov.uk/government/news/2-billion-package-to-create-new-era-for-cycling-and-walking.

(2020b). Government grants Transport for London funding package, 15 May. https://www.gov.uk/ government/news/government-grants-transport-for-london-funding-package.

(2020c). PM commits $£ 350$ million to fuel green recovery, 22 July. https://www.gov.uk/government/ news/pm-commits-350-million-to-fuel-green-recovery. Accessed 8 September 2020.

Greenpeace (2020). European Airline Bailout Tracker (October 2020). https://www.greenpeace.org/eu-unit/ issues/climate-energy/2725/airline-bailout-tracker/. Accessed 20 November 2020.

Hepburn, C., O'Callaghan, B., Stern, N., Stiglitz, J. and Zenghelis, D. (2020). Will COVID-19 fiscal recovery packages accelerate or retard progress on climate change? Oxford Review of Economic Policy 36(S1), 46.

Höhne, N., Fransen, T., Hans, F., Bhardwaj, A., Blanco, G., den Elzen, M. et al. (2019). Bridging the Gap: Enhancing Mitigation Ambition and Action at G20 Level and Globally. Pre-release version of a chapter in the UNEP Emissions Gap Report 2019. United Nations Environment Programme, Nairobi.

Ho-Jeong, L. (2020). Car consumption tax cut remains, but discount less, 29 June. https://koreajoongangdaily.joins. com/2020/06/29/business/economy/individual-consumption-2ndhalf-changes/20200629173700373. html. Accessed 17 November 2020 
Hove, A. (2020). Trends and contradictions in China's renewable energy policy, 28 August. https://www.energypolicy. columbia.edu/research/commentary/trends-and-contradictions-china-s-renewable-energy-policy.

India, Ministry of Power (2018). Stressed/Non-Performing Assets in Electricity Sector: Thirty-seventh Report, Standing Committee on Energy (2017-2018). New Delhi: Lok Sabha Secretariat.

(2020a). Rajya Sabha Unstarred Question No.2701: Closure of Old Polluted Coal-Based Power Plants. https://powermin.nic.in/sites/default/files/uploads/RS17032020_Eng.pdf.

_ (2020b). Executive Summary on Power Sector: March 2020. New Delhi. https://www.cea.nic.in/ reports/monthly/executivesummary/2020/exe_summary-03.pdf.

India, Prime Minister's Office (2020). Prime Minister Modi to address launching of auction of 41 coal mines for commercial mining on 18th June, 2020. https://pib.gov.in/PressReleseDetailm.aspx?PRID=1632147. Accessed 8 September 2020.

International Energy Agency (2020). Sustainable Recovery. World Energy Outlook Special Report in collaboration with the International Monetary Fund. Paris, France. https://emis.vito.be/sites/emis/files/articles/91/2020/ Sustainable_Recovery.pdf.

International Monetary Fund (2020a). Fiscal Monitor Database of Country Fiscal Measures in Response to the COVID-19 Pandemic (October 2020). https://www.imf.org/en/Topics/imf-and-covid19/Fiscal-PoliciesDatabase-in-Response-to-COVID-19. Accessed 14 October 2020

(2020b). Fiscal Monitor: Policies for the Recovery. Washington, D.C

(2020c). IMF makes available $\$ 50$ billion to help address Coronavirus, 4 March. https://www.imf. org/en/News/Articles/2020/03/04/sp030420-imf-makes-available-50-billion-to-help-address-coronavirus. Accessed 11 November 2020.

(2020d). IMF Executive Board approves proposals to enhance the fund's emergency financing toolkit to US\$100 billion. Press Release No. 20/143, 9 April. https://www.imf.org/en/News/Articles/2020/04/09/ pr20143-imf-executive-board-approves-proposals-enhance-emergency-financing-toolkit-us-billion. Accessed 12 November 2020.

(2020e). The IMF's response to COVID-19, 28 October 2020. https://www.imf.org/en/About/FAQ/ imf-response-to-covid-19\#q1.1. Accessed 12 November 2020

Japan, Cabinet Office (2020). Emergency Economic Measures to Cope with the Novel Coronavirus (COVID-19). Tentative translation by Cabinet Office. 7 April 2020, amended on 20 April 2020. Tokyo, Japan: Cabinet Office, Government of Japan.

Japan, Ministry of the Environment (2020). Support for conversion to a carbon free society by installing selfconsumption type solar power generation facilities that contribute to companies in light of bringing back the production bases to Japan. [In Japanese.] Tokyo, Japan.

Jotzo, F., Longden, T. and Anjum, Z. (2020). Fiscal stimulus for low-carbon compatible COVID-19 recovery: criteria for infrastructure investment. CCEP Working Paper 2005. Australia: Crawford School of Public Policy, Australian National University.

Juhasz, A. (2020). Bailout: Billions of dollars of federal COVID-19 relief money flow to the oil industry, 26 August. https://www.sierraclub.org/sierra/bailout-billions-dollars-federal-covid-19-relief-money-flow-oil-industry. Accessed 18 November 2020

Khan, M.A.A. (2020). Opinion: Pakistan's 'Green Stimulus' to combat Covid-19, protect nature, 4 May. https://www. thethirdpole.net/2020/05/04/pakistans-green-stimulus-to-combat-covid-19-protect-nature/. Accessed 18 November 2020.

Kim, D. (2020). S. Korea to center on post-pandemic recovery, job creation in H2, 1 June. https://en.yna.co.kr/ view/AEN20200529008100320. Accessed 8 September 2020.

Kishore, R. (2020). The political economy of petrol-diesel price hike, updated 6 July. https://www. hindustantimes. com/india-news/the-political-economy-of-petrol-diesel-price-hike/story-n1wUkMkOa86mPvgNng0LsJ. html. Accessed 18 November 2020

L Larsen, K., Chaudhuri, P.P., Kirkegaard, J.F., Larsen, J., Wright, L., Rivera, A. and Pitt, H. (2020). It's Not Easy Being Green: Stimulus Spending in the World's Major Economies. New York, USA: Rhodium Group.

M Mackenna, J.F., Bustamante, J.M., Hurley, J.T. and Mendoza, V. (2020). CORFO creates Green Credit to boost investment in renewable energy, energy efficiency and circular economy projects, 15 June. https://www. carey.cl/en/corfo-creates-green-credit-to-boost-investment-in-renewable-energy-energy-efficiency-andcircular-economy-projects/. Accessed 18 November 2020. 
Malik, A., Bertram, C., Despres, J., Emmerling, J., Fujimori, S., Garg, A. et al. (2020). Reducing stranded assets through early action in the Indian power sector. Environmental Research Letters 15 (9), 094091. https://doi. org/10.1088/1748-9326/ab8033.

Martín, J.R. (2020). Malaysia eyes pandemic recovery with 1GW new solar tender, 1 June. https://www.pv-tech. org/news/malaysia-eyes-pandemic-recovery-with-1gw-new-solar-tender. Accessed 10 November 2020.

Moisio, M., Nascimento, L., Vivero, G. De, Gonzales, S., Hans, F., Lui, S. et al. (2020). Overview of Recently Adopted Mitigation Policies and Climate-Relevant Policy Responses to COVID-19: 2020 Update. https://newclimate. org/wp-content/uploads/2020/10/NewClimate_PBL-CLIMA_20200ctUpdate.pdf

Morton, A. (2020). Decision to renew Victorian logging agreements criticised after summer bushfires, 2 April. https://www.theguardian.com/australia-news/2020/apr/03/decision-to-renew-victorian-loggingagreements-criticised-after-summer-bushfires. Accessed 10 November 2020.

National Energy Administration (2020). National Energy Administration Circular on 2023 risk and early warning for coal power planning and construction. [In Chinese.] http://www.nea.gov.cn/2020-02/26/c_138820419. htm. Accessed 31 August 2020.

O'Callaghan, B., Yau, N., Janz, A., Flodell, H., Blackwood, A., Purroy Sanchez et al. (2020). Oxford Economic Stimulus Observatory. https://www.smithschool.ox.ac.uk/publications/wpapers/Oxford-Economic-StimulusObservatory.xIsx. Accessed 9 November 2020.

Observatório do Clima (2020). How threatened is the environment under the Bolsano Administration, so far? http://www.observatoriodoclima.eco.br/wp-content/uploads/2020/06/Doc-Response-0c2.pdf.

Overseas Development Institute (2020). Country policy responses to Covid-19 (as of 12 August 2020). https://set. odi.org/wp-content/uploads/2020/09/Country-fiscal-and-monetary-policy-responses-to-coronavirus_12Aug-2020_updated.pdf.

Parashar, U. (2020). Petrol, diesel price hike temporary, says Assam minister; cites fall in monthly revenue, 23 April. https://www.hindustantimes.com/india-news/petrol-diesel-price-hike-temporary-says-assam-ministercites-fall-in-monthly-revenue/story-y6DmRwFisr6WfkEelLSbON.html. Accessed 18 November 2020.

Ranjan, R. (2020). 5.1 GW of coal-based capacity to be shut down as part of India's phase-out plan, 18 September. https://mercomindia.com/5-1-gw-coal-based-capacity-to-be-shut-down/. Accessed 10 November 2020.

Republic of Korea, Ministry of Economy and Finance (2020). National Strategy for a Great Transformation: Korean New Deal. Seoul, Republic of Korea.

Sarkar, S. (2020). India seeks to open new coal mines in setback to climate action, 22 June. https:// indiaclimatedialogue.net/2020/06/22/india-to-open-new-coal-mines-in-setback-to-climate-action/. Accessed 18 November 2020.

Shen, J. (2020). China is investing RMB 10 billion in EV charging infrastructure, 10 April. https://technode. com/2020/04/10/china-is-investing-rmb-10-billion-in-ev-charging-infrastructure/. Accessed 18 November 2020.

Shrimali, G. (2020). Making India's power system clean: retirement of expensive coal plants. Energy Policy 139 (April), 111305. https://doi.org/10.1016/j.enpol.2020.111305.

Spencer, T. (2020). Bending the Curve: 2025 Forecasts for Electricity Demand by Sector and State in the Light of the Covid-19 Epidemic. TERI Discussion Paper. New Delhi: The Energy and Resources Institute (TERI). https:// www.teriin.org/sites/default/files/2020-07/Bending-the-Curve_Report.pdf.

Srikanth, R. and Krishnan, A.V. (2020). Transition Plan for Thermal Power Plants in India. Policy Brief NIAS/NSE/ EEP/U/PB/17/2020. Bengaluru: National Institute of Advanced Studies-Energy and Environment Programme.

State Government of Queensland (2020). COVID relief extends for explorers, 6 October. https://www.dnrme. qld.gov.au/home/news-publications/news/2020/october/covid-relief-extends-for-explorers. Accessed 18 November 2020.

State Government of South Australia (2020). Fee relief for COVID19-hit resources sector, 3 April. https://www. premier.sa.gov.au/news/media-releases/news/fee-relief-for-covid19-hit-resources-sector2. Accessed 18 November 2020.

Sweden, Ministry of Finance (2020). Budget Statement. https://www.government.se/4a73a0/contentassets/ ddfaf5ce78494ce991ec231acf9c5b83/summary-budget-statement.pdf.

Tiftik, E., Della Guardia, P., McDaniels, J., Standbridge, K. and Gibbs, S. (2020). Green Weekly Insight: Will COVID-19 reinvigorate the ESG agenda? 25 June 2020. https://www.iif.com/Publications/ID/3972/Green-WeeklyInsight-Will-COVID-19-reinvigorate-the-ESG-agenda. Accessed 18 November 2020. 
Transport \& Environment (2020). Bailout Tracker. https://www.transportenvironment.org/what-we-do/flying-andclimate-change/bailout-tracker. Accessed 10 November 2020.

U UN Regional Commissions (2020). Covid-19: Towards an Inclusive, Resilient and Green Recovery - Building Back Better through Regional Cooperation. https://repositorio.cepal.org/bitstream/handle/11362/45551/4/ COVID19TowardsAnInclusive_en.pdf.

United Nations Economic Commission of Africa (2020). ECA, Government of Ethiopia launch Decade of Action with tree planting, green jobs, livelihoods and health at the center, 13 August 2020. https://www.uneca.org/ stories/eca-government-ethiopia-launch-decade-action-tree-planting-green-jobs-livelihoods-and-health. Accessed 18 November 2020

Vivid Economics (2020a). Green Stimulus Index - August 2020 Update. https://www.vivideconomics.com/wpcontent/uploads/2020/08/200820-GreenStimulusIndex_web.pdf.

Vivid Economics (2020b). Green Employment and Growth: Integrating Climate Change and Biodiversity into the Response to COVID-19. https://www.vivideconomics.com/wp-content/uploads/2020/07/200720-greenlabour-note.pdf.

Webber, J. (2020). Mexico City gets pedalling, 21 July. https://www.ft.com/content/989be646-90ef-43a0-b17a7ab191e6bec9. Accessed 18 November 2020.

World Bank (2020a). World Bank Group increases COVID-19 response to \$14 billion to help sustain economies, protect jobs, 17 March. https://www.worldbank.org/en/news/press-release/2020/03/17/world-bankgroup-increases-covid-19-response-to-14-billion-to-help-sustain-economies-protect-jobs. Accessed 14 October 2020

(2020b). The World Bank Group moves quickly to help countries respond to COVID-19, 2 April. https://www.worldbank.org/en/news/feature/2020/04/02/the-world-bank-group-moves-quickly-to-helpcountries-respond-to-covid-19. Accessed 18 November 2020

_ (2020c). World Bank COVID-19 response, 14 October 2020. https://www.worldbank.org/en/news/ factsheet/2020/10/14/world-bank-covid-19-response. Accessed 12 November 2020.

(2020d). Proposed Sustainability Checklist for Assessing Economic Recovery Interventions - April 2020. Washington D.C, US.

Yim, H. (2020). How major South Korean airlines made profits during pandemic, 14 August. https://www. thejakartapost.com/news/2020/08/14/how-major-south-korean-airlines-made-profits-duringpandemic.html.

\section{Chapter 5}

A

Ash, N. and Scarbrough, T. (2019). Sailing on Solar: Could Green Ammonia Decarbonise International Shipping? London: Environmental Defense Fund (EDF).

B

Balcombe, P., Brierley, J., Lewis, C., Skatvedt, L., Speirs, J., Hawkes, A. et al. (2019). How to decarbonise international shipping: options for fuels, technologies and policies. Energy Conversion and Management 182, 72-88.

Becken S. and Mackey B. (2017). What role for offsetting aviation greenhouse gas emissions in a deep-cut carbon world? Journal of Air Transport Management 63, 71-83.

Becken, S. and Pant, P. (2019). Airline Initiatives to Reduce Climate Impact. Ways to Accelerate Action. Madrid: Amadeus. https://amadeus.com/en/insights/white-paper/airline-initiatives-to-reduce-climate-impact.

Becken, S. and Carmignani, F. (2020). Are the current expectations for growing air travel demand realistic? Annals of Tourism Research 80, 102840. https://doi.org/10.1016/j.annals.2019.102840.

Bier A. and Burkhardt U. (2019). Variability in contrail ice nucleation and its dependence on soot number emissions. Journal of Geophysical Research: Atmospheres 124, 3384-3400. https://doi.org/10.1029/2018JD029155.

Bier A., Burkhardt U. and Bock L. (2017). Synoptic control of contrail cirrus life cycles and their modification due to reduced soot number emissions. Journal of Geophysical Research: Atmospheres 122(21), 11584-11603. https://doi.org/10.1002/2017JD027011.

Brain D. and Voorbach, N. (2019). ICAO's global horizontal flight efficiency analysis. In ICAO Environmental Report 2019: Aviation and Environment - Destination Green the Next Chapter. Montreal: International Civil Aviation Organization (ICAO). Chapter 4. 138-144. https://icao.int/environmental-protection/Documents/ EnvironmentalReports/2019/ENVReport2019_pg17-23.pdf. 
Carlo, R., Marc, B.J., de la Fuente Santiago, S., Smith, T. and Søgaard, K. (2020). Aggregate investment for the decarbonisation of the shipping industry. University Maritime Advisory Services. https://www. globalmaritimeforum.org/content/2020/01/Aggregate-investment-for-the-decarbonisation-of-theshipping-industry.pdf.

CE Delft and Ecorys (forthcoming). Assessment of Impacts from Accelerating the Uptake of Sustainable Alternative Fuels in Maritime Transport.

Chen, Z., Zhang, M., Chen, Y., Sang, W., Tan, Z., Li, D. et al. (2019). Assessment on critical technologies for conceptual design of blended-wing-body civil aircraft. Chinese Journal of Aeronautics 32(8), 1797-1827 https://doi.org/10.1016/j.cja.2019.06.006.

Chiriboga, G., De La Rosa, A., Molina, C., Velarde, S. and Carvajal, C.G. (2020). Energy return on investment (EROI) and life cycle analysis (LCA) of biofuels in Ecuador. Heliyon 6(6), e04213. https://doi.org/10.1016/j. heliyon.2020.e04213.

Comer, B., Olmer, N., Mao, X., Roy, B. and Rutherford, D. (2017). Black Carbon Emissions and Fuel Use in Global Shipping 2015. Washington, D.C.: International Council on Clean Transportation (ICCT). https://theicct.org/ publications/black-carbon-emissions-global-shipping-2015.

DNV GL (2017). Navigating a Low-carbon Future. Report No. 2017-0205. https://brandcentral.dnvgl.com/

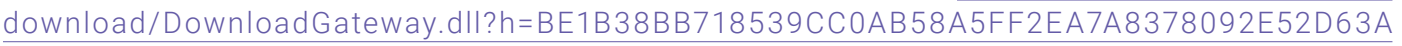
591F82C3E4881009D09A607E236EBE9C1CFBCF51DA76AF6BA7C8.

DNV GL (2019). Maritime Forecast to 2019. https://eto.dnvgl.com/2019/Maritime/forecast.

DNV GL (2020). Maritime Forecast to 2050. https://eto.dnvgl.com/2020/Maritime/forecast.

Eide, M.S., Dalsøren, S.B, Endresen, Ø., Samset, B., Myhre G., Fuglestvedt, J. et al. (2013). Reducing $\mathrm{CO}_{2}$ from shipping - do non- $\mathrm{CO}_{2}$ effects matter? Atmospheric Chemistry and Physics 13, 4183-4201. https://doi. org/10.5194/acp-13-4183-2013.

Epstein, A.H. and O'Flarity, S.M. (2019). Considerations for reducing aviation's $\mathrm{CO}_{2}$ with aircraft electric propulsion. Journal of Propulsions and Power 35(3). https://doi.org/10.2514/1.B37015.

Erling, U.M. (2018). How to reconcile the European Union Emissions Trading System (EU-ETS) for aviation with the Carbon Offsetting and Reduction Scheme for International Aviation (CORSIA)? Air and Space Law 43(4/5), 371-386.

Eyring, V., Isaksen, I.S.A., Berntsen, T., Collins, W.J., Corbett, J.J., Endresen, Ø. et al. (2010). Transport impacts on atmosphere and climate: shipping. Atmospheric Environment 44(37), 4735-4771. https://doi.org/10.1016/j. atmosenv.2009.04.059.

Faber, J, Behrends, B., Lee, D.S., Nelissen, D. and Smit, M. (2012). The Fuel Efficiency of Maritime Transport: Potential for Improvement and Analysis of Barriers. Delft: CE Delft. https://cedelft.eu/en/publications/1320/ the-fuel-efficiency-of-maritime-transport.

Faber, J., 't Hoen, M., Vergeer, R. and Calleya, J. (2016). Historical Trends in Ship Design Efficiency: The Impact of Hull Form on Efficiency. Delft: CE Delft. https://www.cedelft.eu/publicatie/historical_trends_in_ship_design_ efficiency/1761.

Faber, J and 't Hoen, M. (2017). Estimated Index Value of Ships 2009-2016: Analysis of the Design Efficiency of Ships that have Entered the Fleet since 2009. Delft: CE Delft. https://cedelft.eu/en/publications/1977/ estimated-index-values-of-ships-2009-2016.

Fleming, G. and de Lépinay, I. (2019). Environmental trends in aviation to 2050. In ICAO Environmental Report 2019: Aviation and Environment - Destination Green the Next Chapter. Montreal: International Civil Aviation Organization (ICAO). Chapter 1. 17-23. https://icao.int/environmental-protection/Documents/ EnvironmentalReports/2019/ENVReport2019_pg17-23.pdf.

Fuglestvedt, J.S., Berntsen, T., Eyring, V., Isaksen, I., Lee, D.S. and Sausen R. (2009). Shipping emissions: from cooling to warming of climate - and reducing impacts on health. Environmental Science and Technology 43, 9057-9062. https://doi.org/10.1021/es901944r.

Fuglestvedt, J., Rogelj, J., Millar, R. J., Allen, M., Boucher, O., Cain, M. et al. (2018). Implications of possible interpretations of 'greenhouse gas balance' in the Paris Agreement. Philosophical Transactions of the Royal Society A 376(2199), 20160445. https://doi.org/10.1098/rsta.2016.0445.

Fuhrman, J., McJeon, H., Patel, P., Doney, S.C., Shobe, W.M. and Clarens, A.F. (2020). Food-energy-water implications of negative emissions technologies in a $+1.5^{\circ} \mathrm{C}$ future. Nature Climate Change 10, 920-927. https://doi.org/10.1038/s41558-020-0876-z. 
Global Business Travel Association (2020). GBTA COVID-19 member poll results: semi-weekly polls track the impact of COVID-19 on the business travel industry. https://www.gbta.org/research-tools/covid-19member-polls. Accessed 1 November 2020.

Global Maritime Forum (2020). Getting to Zero Coalition. https://www.globalmaritimeforum.org/getting-to-zerocoalition/.

Gössling, S. and Humpe, A. (2020). The global scale, distribution and growth of aviation: Implications for climate change. Global Environmental Change 65, 102194. https://doi.org/10.1016/j.gloenvcha.2020.102194.

Halim, R.A., Smith, T and Englert, D. (2019). Understanding the Economic Impacts of Greenhouse Gas Emissions Mitigation Policies on Shipping. Policy Research Working Paper 8695. https://openknowledge.worldbank. org/bitstream/handle/10986/31167/WPS8695.pdf? sequence=1\&isAllowed=y.

Hall, C.A.S., Lambert, J.G. and Balogh, S.B. (2014). EROI of different fuels and the implications for society. Energy Policy 64, 141-152. https://doi.org/10.1016/j.enpol.2013.05.049.

Intergovernmental Panel on Climate Change (2018). Global Warming of $1.5^{\circ} \mathrm{C}$ : An IPCC Special Report on the Impacts of Global Warming of $1.5^{\circ} \mathrm{C}$ above Pre-industrial Levels and Related Global Greenhouse Gas Emission Pathways, in the Context of Strengthening the Global Response to the Threat of Climate Change, Sustainable Development, and Efforts to Eradicate Poverty. Masson-Delmotte, V., Zhai, P., Pörtner, H.-O., Roberts, D., Skea, J., Shukla, P. R. et al. (eds.). Geneva.

International Air Transport Association (2020a). Industry statistics. Fact sheet. June 2020. https://iata.org/ en/iata-repository/publications/economic-reports/airline-industry-economic-performance-june-2020data-tables/.

(2020b). Recovery delayed as international travel remains locked down, 28 July. https://www.iata. org/en/pressroom/pr/2020-07-28-02/.

(2020c). Air cargo market analysis: air cargo traffic recovers slowly amid insufficient capacity. https://www.iata.org/en/iata-repository/publications/economic-reports/air-freight-monthly-analysis--august-2020/.

International Civil Aviation Organization (undated a). Climate change technology standards https://icao.int/ environmental-protection/Pages/ClimateChange_TechnologyStandards.aspx.

_ (undated b). Operational measures. https://www.icao.int/environmental-protection/pages/ operational-measures.aspx.

(2010). Report of the Independent Experts on the Medium and Long Term Goals for Aviation Fuel Burn Reduction from Technology. ICAO Document 9963. Montreal.

(2016). Resolution A39-3: Consolidated statement of continuing ICAO policies and practices related to environmental protection - Global Market-based Measure (MBM) scheme. https://www.icao.int/ environmental-protection/documents/resolution_a39_3.pdf.

(2019a). Independent Expert Integrated Technology Goals and Review for Engines and Aircraft. ICAO Document 10127. Montreal.

(2019b). Resolution A40-19: Consolidated statement of continuing ICAO policies and practices related to environmental protection - Carbon Offsetting and Reduction Scheme for International Aviation (CORSIA). https://www.icao.int/environmental-protection/Documents/Assembly/Resolution_A40-19_CORSIA.pdf.

(2020). ICAO Council agrees to the safeguard adjustment for CORSIA in light of COVID-19 pandemic, 30 June. https://icao.int/Newsroom/Pages/ICAO-Council-agrees-to-the-safeguard-adjustment-forCORSIA-in-light-of-COVID19-pandemic.aspx. Accessed 27 November 2020

International Energy Agency (2018). Renewables 2018. Analysis and Forecasts to 2023. Paris.

(2019). Renewables 2019. Analysis and forecast to 2024. Paris.

(2020). Energy Technology Perspectives 2020. Paris. https://iea.org/reports/energy-technologyperspectives-2020.

International Maritime Organization (2020). Fourth IMO GHG Study 2020: Final Report. https://safety4sea.com/ wp-content/uploads/2020/08/MEPC-75-7-15-Fourth-IMO-GHG-Study-2020-Final-report-Secretariat.pdf.

Kober, T and Bauer, C. (eds.) (2019). Perspectives of Power-to-X Technologies in Switzerland. http://www.sccerhae.ch/resources/WP_P2X/Kober-et-al_2019_WhitePaper-P2X.pdf.

L Langford, J.S. and Hall, D.K. (2020). Electrified aircraft propulsion. The Bridge 50(20).

Lee, D.S., Fahey, D.W., Skowron, A., Allen, M.R., Burkhardt, U., Chen, Q. et al. (in press). The contribution of global aviation to anthropogenic climate forcing for 2000 to 2018. Atmospheric Environment 244, 117834. https:// doi.org/10.1016/j.atmosenv.2020.117834 
Lindstad, H. and Eskeland, G.S. (2015). Low carbon maritime transport: how speed, size and slenderness amounts to substantial capital energy substitution. Transportation Research Part D: Transport and Environment 41, 2015, 244-256. https://doi.org/10.1016/j.trd.2015.10.006.

Lloyd's Register and University Marine Advisory Services (2019). Zero-Emission Vessels: Transition Pathways. https://www.Ir.org/en/insights/global-marine-trends-2030/zero-emission-vessels-transition-pathways/.

M Maertens, S., Grimme, W., Scheelhaase, J. and Jung M. (2019). Options to continue the EU ETS for Aviation in a CORSIA-World. Sustainability 11(20), 5703. https://doi.org/10.3390/su11205703.

Martinez Romera, B. (2016). The Paris Agreement and the Regulation of International Bunker Fuels. Review of European Community and International Environmental Law 25(2), 215-227. https://doi.org/10.1111/ reel.12170.

McKinsey and Company (2020). Hydrogen-powered Aviation: A Fact-based Study of Hydrogen Technology, Economics, and Climate Impact by 2050. Luxembourg: Publications Office of the European Union. https:// www.fch.europa.eu/sites/default/files/FCH\%20Docs/20200720_Hydrogen\%20Powered\%20Aviation\%20 report_FINAL\%20web.pdf.

N Nuffield Council on Bioethics (2011). Biofuels: Ethical Issues. London. https://www.nuffieldbioethics.org/wpcontent/uploads/2014/07/Biofuels_ethical_issues_FULL-REPORT_0.pdf.

Peters, K., Stier, P., Quaas, J. and GraßI, H. (2012). Aerosol indirect effects from shipping emissions: sensitivity studies with the global aerosol-climate model ECHAM-HAM. Atmospheric Chemistry and Physics 12, 59856007. https://doi.org/10.5194/acp-12-5985-2012.

Poseidon Principles (undated). A global framework for responsible ship finance. https://poseidonprinciples.org.

Rehmatulla, N., and T. Smith (2015). Barriers to energy efficiency in shipping: a triangulated approach to investigate the principal agent problem. Energy Policy 84, 44-57. https://doi.org/10.1016/j.enpol.2015.04.019.

Scheelhaase, J., Maertens, S., Grimme, W. and Jung, M. (2018). EU ETS versus CORSIA - a critical assessment of two approaches to limit air transport's $\mathrm{CO}_{2}$ emissions by market-based measures. Journal of Air Transport Management 67, 55-62. https://doi.org/10.1016/j.jairtraman.2017.11.007.

Schmidt, P., Batteiger, V., Roth, A., Weindorf, W. and Raksha, T. (2018). Power-to-liquids as renewable fuel option for aviation: a review. Chemie Ingenieur Technik 90(1-2), 127-140. https://doi.org/10.1002/cite.201700129.

Sea Cargo Charter (undated). Aligning global shipping with society's goals. https://seacargocharter.org.

Searchinger, T., Hamburg, S.P., Melillo, J., Chameides, W., Havlik, P., Kammen, D.M. et al. (2009). Fixing a critical climate accounting error. Science 326(5952), 527-528. https://doi.org/10.1126/science.1178797.

Ship \& Bunker (undated). World bunker prices. https://shipandbunker.com/prices/. Accessed 29 September 2020. Smyth, M. and Pearce, B. (2008). Air Travel Demand. IATA Economics Briefing No 9. Geneva.

Sofiev, M., Winebrake, J.J., Johansson, L., Carr, E.W., Prank, M., Soares, J. et al. (2018). Cleaner fuels for ships provide public health benefits with climate tradeoffs. Nature Communications 9, 406. https://doi.org/10.1038/ s41467-017-02774-9.

The Royal Society (2019). Sustainable Synthetic Carbon Based Fuels for Transport. https://royalsociety.org/-/ media/policy/projects/synthetic-fuels/synthetic-fuels-briefing.pdf.

United Nations Conference on Trade and Development (2019). Review of Maritime Transport 2019. E.19.II.D.20.

United Nations World Tourism Organization (2019). International tourism highlights: 2019 edition. https://www.eunwto.org/doi/pdf/10.18111/9789284421152.

University College London (2020). Greenhouse gas emissions from international shipping increasing, 4 August. https://www.ucl.ac.uk/news/2020/aug/greenhouse-gas-emissions-international-shipping-increasing.

Valera-Medina, A., Xiao, H., Owen-Jones, M., David, W.I.F. and Bowen, P.J. (2018). Ammonia for power. Progress in Energy and Combustion Science 69, 2018, 63-102. https://doi.org/10.1016/j.pecs.2018.07.001.

Warnecke, C., Schneider, L., Day, T., La Hoz Theuer, S. and Fearnehough, H. (2019). Robust eligibility criteria essential for new global scheme to offset aviation emissions. Nature Climate Change 9, 218-221. https:// doi.org/10.1038/s41558-019-0415-y. 


\section{Chapter 6}

Aasness, M. A. and Odeck, J. (2015). The increase of electric vehicle usage in Norway-incentives and adverse effects. European Transport Research Review 7(34). https://doi.org/10.1007/s12544-015-0182-4.

Abrahamse, W. and Steg, L. (2013). Social influence approaches to encourage resource conservation: A metaanalysis. Global Environmental Change 23(6), 1773-1785.

Akenji, L. and Bengtsson, M. (2014). Making sustainable consumption and production the core of Sustainable Development Goals. Sustainability 6(2), 513-529.

Akenji, L., Bengtsson, M., and Olsen, S. (2012). Global outlook on SCP policies: Asia-Pacific. In Global Outlook on Sustainable Consumption and Production Policies: Taking Action Together. UNEP.

Akenji, L., Lettenmeier, M., Koide, R., Toivio, V. and Amellina, A. (2019). 1.5-Degree Lifestyles: Targets and Options for Reducing Lifestyle Carbon Footprints. Technical Report. Hayama, Japan: Institute for Global Environmental Strategies, Aalto University, and D-mat Itd.

Aleksandrowicz, L., Green, R., Joy, E. J., Smith, P. and Haines, A. (2016). The impacts of dietary change on greenhouse gas emissions, land use, water use, and health: A systematic review. PloS one 11(11), e0165797.

Amel, E., Manning, C., Scott, B. and Koger, S. (2017). Beyond the roots of human inaction: Fostering collective effort toward ecosystem conservation. Science 356(6335), 275-279.

Asia Energy Efficiency and Conservation Collaboration Center (2020). Final Reports on the Top Runner Target Product Standards. https://www.asiaeec-col.eccj.or.jp/top-runner-target-standards. Accessed 14 October 2020.

Attari, S. Z., KrantZ, D. H. and Weber, E. U. (2016). Statements about climate researchers' carbon footprints affect their credibility and the impact of their advice. Climatic Change 138(1-2), 325-338.

Attari, S. Z., Krantz, D. H. and Weber, E. U. (2019). Climate change communicators' carbon footprints affect their audience's policy support. Climatic Change 154(3-4), 529-545.

Bai, X., Dawson, R. J., Ürge-Vorsatz, D., Delgado, G. C., Barau, A. S., Dhakal, S. et al. (2018). Six research priorities for cities and climate change. Nature 555, 23-25. https://doi.org/10.1038/d41586-018-02409-z.

Bailey, R., Froggatt, A. and Wellesley, L. (2014). Livestock - Climate Change's Forgotten Sector: Global Public Opinion on Meat and Dairy Consumption. Chatham House.

Beckman, L. and Uggla, F. (2016). An ombudsman for future generations. In Institutions for Future Generations. González-Ricoy, I. and Gosseries, A. (eds.). Oxford Scholarship Online.

Beevor, J., Murray, L., Simms, A., Tricarico, E. and Gillett, R. (2020). Upselling Smoke: the Case to End Advertising of the Largest, Most Polluting New Cars. London: New Weather Institute. https://static1.squarespace. com/static/5ebd0080238e863d04911b51/t/5f21659998148a15d80ba9be/1596024223673/ Upselling+Smoke+FINAL+23+07+20.pdf

Bianchi, F., Dorsel, C., Garnett, E., Aveyard, P. and Jebb, S. A. (2018). Interventions targeting conscious determinants of human behaviour to reduce the demand for meat: a systematic review with qualitative comparative analysis. International Journal of Behavioral Nutrition and Physical Activity 15(1), 1-25.

Biesecker, A., Darooka, P., Gottschlich, D., Lanuza, M., Röhr, U., Schildberg, C. et al. (2014). A Caring and Sustainable Economy: A Concept Note from a Feminist Perspective. Berlin, Germany: Friedrich-Ebert-Stiftung. https:// library.fes.de/pdf-files/iez/10809.pdf.

Birkmann, J., Buckle, P., Jaeger, J., Pelling, M., Setiadi, N., Garschagen, M. et al. (2010). Extreme events and disasters: a window of opportunity for change? Analysis of organizational, institutional and political changes, formal and informal responses after mega-disasters. Natural Hazards 55, 637-655.

Bollinger, B. and Gillingham, K. (2012). Peer effects in the diffusion of solar photovoltaic panels. Marketing Science 31(6), 900-912.

Breadsell, J. K., Eon, C. and Morrison, G. M. (2019). Understanding resource consumption in the home, community and society through behaviour and social practice theories. Sustainability 11(22), 6513.

Briguglio, M., and Formosa, G. (2017). When households go solar: Determinants of uptake of a Photovoltaic Scheme and policy insights. Energy Policy 108(C), 154-162.

Büchs, M., Baltruszewicz, M., Bohnenberger, K., Busch, J., Dyke, J., Elf, P. et al. (2020). Wellbeing Economics for the COVID19 recovery: Ten Principles to Build Back Better. Wellbeing Economy Alliance, WEAll Briefing Papers: Short summaries of big issues. https://wellbeingeconomy.org/wp-content/uploads/2020/05/Wellbeing Economics_for_the_COVID-19_recovery_10Principles.pdf 
C40 Cities Network (2020). C40 Mayors' Agenda for a Green and Just Recovery. https://c40-production-images. s3.amazonaws.com/other_uploads/images/2093_C40_Cities_\%282020\%29_Mayors_Agenda_for_a_ Green_and_Just_Recovery.original.pdf?1594824518.

Capstick, S. B. (2013). Public understanding of climate change as a social dilemma. Sustainability 5(8), 3484-3501.

Capstick, S., Lorenzoni, I., Corner, A. and Whitmarsh, L. (2014). Prospects for radical emissions reduction through behavior and lifestyle change. Carbon Management 5(4), 429-445. https://doi.org/10.1080/17583004.2 015.1020011.

Carbon Trust (2020). Product Carbon Footprint Labelling: Consumer Research 2020. London: Carbon Trust. https:// www.carbontrust.com/resources/product-carbon-footprint-labelling-consumer-research-2020.

Carroll, N., and Conboy, K. (2020). Normalising the "new normal": Changing tech-driven work practices under pandemic time pressure. International Journal of Information Management 55, 102186.

Carstensen, T.A., Olafsson, A.S., Bech, N.M., Schmidt Poulsen, T. and Zhao, C. (2015). The spatio-temporal development of Copenhagen's bicycle infrastructure 1912-2013. Danish Journal of Geography 115(2), 142156. https://doi.org/10.1080/00167223.2015.1034151.

Casamayor, J. L. and Su, D. (2020). Review of directives, regulations and standards related to sustainable product design and manufacture. In Sustainable Product Development. Su D. (eds.). Switzerland: Springer, Cham. 15-37. https://doi.org/10.1007/978-3-030-39149-2.

Centola, D., Becker, J., Brackbill, D. and Baronchelli, A. (2018). Experimental evidence for tipping points in social convention. Science 360(6393), 1116-1119. https://doi.org/10.1126/science.aas8827.

Cervero, R., Sarmiento, O. L., Jacoby, E., Gomez, L. F. and Neiman, A. (2009). Influences of built environments on walking and cycling: lessons from Bogotá. International Journal of Sustainable Transportation 3(4), 203-226.

Chakravarty, S., Chikkatur, A., de Coninck, H., Pacala, S., Socolow, R. and Tavoni, M. (2009). Sharing global $\mathrm{CO}_{2}$ emission reductions among one billion high emitters. Proceedings of the National Academy of Sciences 106(29), 11884-11888. https://doi.org/10.1073/pnas.0905232106.

Chancel, L. and Piketty, T. (2015). Carbon and inequality: from Kyoto to Paris. Paris School of Economics. https:// doi.org/10.13140/RG.2.1.3536.0082.

Charter, M. and Keiller, S. (2016). The Second Global Survey of Repair Cafés: A Summary of Findings. https://www. semanticscholar.org/paper/The-second-global-survey-of-repair-caf\%C3\%A9s\%3A-a-summary-CharterKeiller/eefae4fa18581395083c968c87646d3d366f8c9d.

Chen, H., Wang, L., and Chen, W. (2018). Modeling on building sector's carbon mitigation in China to achieve the $1.5^{\circ} \mathrm{C}$ climate target. Energy Efficiency, 1-14. https://doi.org/10.1007/s12053-018-9687-8.

Cherry, E. (2006). Veganism as a cultural movement: A relational approach. Social Movement Studies 5(2), 155-170.

Cherry, C., Scott, K., Barrett, J. and Pidgeon, N. (2018). Public acceptance of resource-efficiency strategies to mitigate climate change. Nature Climate Change 8(11), 1007-1012.

Ciccone, A. (2018). Environmental effects of a vehicle tax reform: empirical evidence from Norway. Transport Policy 69(C), 141-157.

Cleveland, D. A., Phares, N., Nightingale, K. D., Weatherby, R. L., Radis, W., Ballard, J. et al. (2017). The potential for urban household vegetable gardens to reduce greenhouse gas emissions. Landscape and Urban Planning 157, 365-374.

Clewlow, R.R., Sussman, J.M. and Balakrishnan, H. (2014). The impact of high-speed rail and low-cost carriers on European air passenger traffic. Transport Policy, 33, 136-143. https://doi.org/10.1016/j.tranpol.2014.01.015.

Climate Action Tracker (2020). A Government Roadmap for Addressing the Climate and Post COVID-19 Economic Crises. https://climateactiontracker.org/documents/706/CAT_2020-04-27_Briefing_COVID19_Apr2020.pdf.

Colchero, M. A., Popkin, B. M., Rivera, J. A. and Ng, S. W. (2016). Beverage purchases from stores in Mexico under the excise tax on sugar sweetened beverages: observational study. British Medical Journal 352:h6704.

Convention Citoyenne pour le Climat (2020). Les Propositions de la Convention Citoyenne pour le Climat, Thématique: se déplacer. Paris. https://propositions.conventioncitoyennepourleclimat.fr/pdf/ccc-rapportfinal-sedeplacer.pdf.

Coote, A., Franklin, J. and Simms, A. (2010). 21 Hours. Why a Shorter Working Week Can Help Us All to Flourish in the 21st Century. New Economics Foundation https://b.3cdn.net/nefoundation/f49406d81b9ed9c977_ p1m6ibgje.pdf.

Creutzig, F., Fernandez, B., Haber, H., Khosla, R., Mulugetta, Y. and Seto, K. (2016). Beyond technology: Demandside solutions to climate change mitigation. Annual Review of Environment and Resources 41, 173-198. https://doi.org/10.1146/annurev-environ-110615-085428.

Creutzig, F., Roy, J., Lamb, W., Azevedo, I., Bruin de Bruin, W., Dalkmann, H. et al. (2018). Towards demand-side solutions for mitigating climate change. Nature Climate Change 8, 268-271. https://doi.org/10.1038/s41558018-0121-1. 
D Dauvergne, P. and Lister, J. (2013). Eco-Business: A Big-Brand Takeover of Sustainability. Cambridge, Massachusetts: MIT Press.

Davidson, J. (2020). \#futuregen: Lessons From a Small Country. United Kingdom: Chelsea Green Publishing Co.

Davis, S. J. and Caldeira, K. (2010). Consumption-based accounting of $\mathrm{CO}_{2}$ emissions. Proceedings of the National Academy of Sciences 107(12), 5687-5692.

De Young, R. (2011). Slow wins: patience, perseverance and behavior change. Carbon Management 2(6), 607-611.

Devaney, L., Torney, D., Brereton, P. and Coleman, M. (2020). Ireland's Citizens' Assembly on climate change: Lessons for deliberative public engagement and communication. Environmental Communication 14(2), 141-146.

Dietz, T., Gardner, G., Gilligan, J., Stern, P.C. and Vandenbergh, M.P. (2009). Household actions can provide a behavioral wedge to rapidly reduce US carbon emissions. Proceedings of the National Academy of Sciences 106(44), 18452-18456. https://doi.org/10.1073/pnas.0908738106.

Donthu, N., and Gustafsson, A. (2020). Effects of COVID-19 on business and research. Journal of Business Research 117, 284-289. https://doi.org/10.1016/j.jbusres.2020.06.008.

Dorband, I.I., Jakob, M., Kalkuhl, M. and Steckel, J.C. (2019). Poverty and distributional effects of carbon pricing in low- and middle-income countries - A global comparative analysis. World Development 115(C), 246-257. https://doi.org/10.1016/j.worlddev.2018.11.015.

Dryzek, J.S. and Niemeyer, S. (2019). Deliberative democracy and climate governance. Nature Human Behaviour 3, 411-413. https://www.nature.com/articles/s41562-019-0591-9.

Ebeling, F. and Lotz, S. (2015). Domestic uptake of green energy promoted by opt-out tariffs. Nature Climate Change 5(9), 868-871.

Econcept (2013). Konsum, Suffizienzpotenziale und Auswirkungen suffizienzfördernder Massnahmen. Unterschiede nach Einkommensklassen und Haushaltstypen. Available at https://www.stadt-zuerich.ch/suffizienz.

European Commission (2020a). Sustainable product policy \& ecodesign. https://ec.europa.eu/ growth/industry/sustainability/product-policy-and-ecodesign_en. Accessed 14 October 2020. (2020b). A Farm to Fork Strategy for a Fair, Healthy and Environmentally-Friendly Food System. https://ec.europa.eu/info/sites/info/files/communication-annex-farm-fork-greendeal_en.pdf.

Figenbaum, E. (2017). Perspectives on Norway's supercharged electric vehicle policy. Environmental Innovation and Societal Transitions 25, 14-34.

Feygin, S. and Pozdnoukhov, A. (2018). Peer pressure enables actuation of mobility lifestyles. Transportation Research Part C: Emerging Technologies 87, 26-45.

Fleming, S. (2019). The Netherlands is paying people to cycle to work, 21 February. https://www. weforum.org/agenda/2019/02/the-netherlands-is-giving-tax-breaks-to-cycling-commutersand-they-re-not-the-only-ones. Accessed 14 October 2020.

Fouquet R. and O'Garra, T. (2020). The behavioural, welfare and environmental impacts of air travel reductions during and beyond COVID-19. Centre for Climate Change Economics and Policy Working Paper 372/Grantham Research Institute on Climate Change and the Environment Working Paper 342. London: London School of Economics and Political Science.

France, Ministère de la Transition écologique (2017). Adoption du projet de loi mettant fin à la recherche et à l'exploitation des hydrocarbures, 19 December. https://www.ecologie.gouv. fr/adoption-du-projet-loi-mettant-fin-recherche-et-lexploitation-des-hydrocarbures-francetourne-dos. Accessed 14 October 2020.

Fremstad, A., Paul, M. and Underwood, A. (2019). Work hours and $\mathrm{CO}_{2}$ emissions: evidence from us households. Review of Political Economy 31(1), 42-59.

Friedlingstein, P., Jones, M. W., O'Sullivan, M., Andrew, R. M., Hauck, J., Peters, G. P. et al. (2019). Global carbon budget 2019. Earth System Science Data 11(4), 1783-1838.

G Gächter, S. and Renner, E. (2018). Leaders as role models and 'belief managers' in social dilemmas. Journal of Economic Behavior \& Organization 154, 321-334. https://doi.org/10.1016/j. jebo.2018.08.001.

Garnett, E. E., Balmford, A., Sandbrook, C., Pilling, M. A. and Marteau, T. M. (2019). Impact of increasing vegetarian availability on meal selection and sales in cafeterias. Proceedings of the National Academy of Sciences 116(42), 20923-20929. 
Gazetta Uficiale della Republica Italiana (2016). Legge sugli sprechi alimentari (Legge 19 agosto 2016 n.166): Disposizioni concernenti la donazione e la distribuzione di prodotti alimentari e farmaceutici a fni di solidarieta' sociale e per la limitazione degli sprechi (16G00179) GU Serie Generale n.202 del 30-08-2016. https://www.gazzettaufficiale.it/eli/id/2016/08/30/16G00179/sg.

Gill, M., Ebi, K. L., Smith, K. R., Whitmarsh, L. and Haines, A. (2020). We need health warning labels on points of sale of fossil fuels, 31 March. https://blogs.bmj.com/bmj/2020/03/31/we-need-health-warning-labels-onpoints-of-sale-of-fossil-fuels/.

Gladwell, M. (2006). The Tipping Point: How Little Things Can Make a Big Difference. United States: Little, Brown. Gössling, S., Humpe, A. and Bausch, T. (2020). Does 'flight shame' affect social norms? Changing perspectives on the desirability of air travel in Germany. Journal of Cleaner Production 266, 122015.

Gottschlich, D. and Bellina, L. (2017). Environmental justice and care: critical emancipatory contributions to sustainability discourse. Agriculture and Human Values 34(4), 941-953.

Gravely, E. and Fraser, E. (2018). Transitions on the shopping floor: Investigating the role of Canadian supermarkets in alternative protein consumption. Appetite 130, 146-156.

Graziano, M. and Gillingham, K. (2015). Spatial patterns of solar photovoltaic system adoption: the influence of neighbors and the built environment. Journal of Economic Geography 15(4), 815-839.

Guilbeault, D., Becker, J. and Centola, D. (2018). Complex contagions: A decade in review. In Complex Spreading Dynamics in Social Systems. S. Lehmann and Y. Ahn (eds.). New York: Springer. 3-25.

Hagedorn, G., Kalmus, P., Mann, M., Vicca, S., Van den Berge, J., van Ypersele, J. P. et al. (2019). Concerns of young protesters are justified. Science 364, 139-140.

Hasegawa, T., Havlik, P., Frank, S., Palazzo, A. and Valin, H. (2019). Tackling food consumption inequality to fight hunger without pressuring the environment. Nature Sustainability 2, 826-833. https://doi.org/10.1038/ s41893-019-0371-6.

Heindl, P. and P. Kanschik (2016). Ecological sufficiency, individual liberties, and distributive justice: Implications for policy making. Ecological Economics 126, 42-50. https://doi.org/10.1016/J.ECOLECON.2016.03.019.

Henrich, J., Chudek, M. and Boyd, R. (2015). The Big Man Mechanism: how prestige fosters cooperation and creates prosocial leaders. Philosophical Transactions of the Royal Society B: Biological Sciences 370(1683), 20150013.

Hertwich, E. G. and Peters, G. P. (2009). Carbon footprint of nations: A global, trade-linked analysis. Environmental science \& technology 43(16), 6414-6420.

Hoolohan, C. and Browne, A.L. (2020). Design thinking for practice-based intervention: Co-producing the change points toolkit to unlock (un)sustainable practices. Design Studies 67, 102-132.

Hoolohan, C., McLachlan, C. and Mander, S. (2016). Trends and drivers of end-use energy demand and the implications for managing energy in food supply chains: Synthesising insights from the social sciences. Sustainable Production and Consumption 8, 1-17. https://doi.org/10.1016/j.spc.2016.06.002.

House of Lords (2011). Behaviour Change. London: House of Lords Select Committee on Science \& Technology. Howarth, C., Bryant, P., Corner, A., Fankhauser, S., Gouldson, A., Whitmarsh, L. and Willis, R. (2020). Building a social mandate for climate action: Lessons from COVID-19. Environmental and Resource Economics 76, 1107-1115. https://doi.org/10.1007/s10640-020-00446-9.

Hubacek, K., Baiocchi, G., Feng, K., Muñoz Castillo, R., Sun, L. and Xue, J. (2017). Global carbon inequality, Energy, Ecology \& Environment 2, 361-369. https://doi.org/10.1007/s40974-017-0072-9.

Hyseni, L., Atkinson, M., Bromley, H., Orton, L., Lloyd-Williams, F., McGill, R. and Capewell, S. (2017). The effects of policy actions to improve population dietary patterns and prevent diet-related non-communicable diseases: scoping review. European Journal of Clinical Nutrition 71(6), 694-711.

IPES-Food (2017). Too Big to Feed: Exploring the Impacts of Mega-Mergers, Concentration and Concentration of Power in the Agri-Food Sector. http://www.ipes-food.org/_img/upload/files/Concentration_FullReport.pdf. Institute for Global Environmental Strategies (IGES), Aalto University and D-mat Itd. (2019). 1.5-Degree Lifestyles: Targets and Options for Reducing Lifestyle Carbon Footprints. Technical Report. Hayama, Japan: Institute for Global Environmental Strategies.

India, Bureau of Energy Efficiency (2020). Mandatory appliances. https://beeindia.gov.in/content/mandatoryappliances. Accessed 14 October 2020.

International Energy Agency (2019). World Energy Outlook 2019. Paris. https://www.iea.org/reports/world-energyoutlook-2019.

(2020). Global Energy Review 2020: The Impacts of the Covid-19 Crisis on Global Energy Demand and $\mathrm{CO}_{2}$ Emissions. Paris. https://www.iea.org/reports/global-energy-review-2020. 
Ipsos (2020). How Much Is the World Yearning for Change After the COVID-19 Crisis? Ipsos Survey for the World Economic Forum. https://www.ipsos.com/sites/default/files/ct/news/documents/2020-09/globalyearning-for-change-after-the-covid-19-crisis-2020-09-ipsos.pdf.

Ivanova, D., Barrett, J., Wiedenhofer, D., Macura, B., Callahan, M. and Creutzig, F. (2020). Quantifying the potential for climate change mitigation of consumption options. Environmental Research Letters 15(9). https://doi. org/10.1088/1748-9326/ab8589.

Ivanova, D. and Wood, R. (2020). The unequal distribution of household carbon footprints in Europe and its link to sustainability. Global Sustainability 3(e18), 1-12. https://doi.org/10.1017/sus.2020.12.

Ivanova, D., Stadler, K., Steen-Olsen, K., Wood, R., Vita, G., Tukker, A. and Hertwich, E. G. (2016). Environmental impact assessment of household consumption. Journal of Industrial Ecology 20(3), 526-536.

Jain, R.K., Gulbinas, R., Taylor, J.E. and Culligan, P.J. (2013). Can social influence drive energy savings? Detecting the impact of social influence on the energy consumption behavior of networked users exposed to normative eco-feedback. Energy and Buildings 66, 119-127. https://doi.org/10.1016/j.enbuild.2013.06.029.

Jebb, A., Tay, L., Diener, E. and Oishi, S. (2018). Happiness, income satiation and turning points around the world. Nature Human Behaviour 2(1), 33-38.

Kaiser, M., Bernauer, M., Sunstein, C.R. and Reisch, L.A. (2020). The power of green defaults: the impact of regional variation of opt-out tariffs on green energy demand in Germany. Ecological Economics 174, 106685. https:// doi.org/10.1016/j.ecolecon.2020.106685.

Kamat, A., Khosla, R., and Narayanamurti, V. (2020). Illuminating homes with LEDs in India: Rapid market creation towards low-carbon technology transition in a developing country. Energy Research and Social Sciences 66, 101488. https://doi.org/10.1016/j.erss.2020.101488.

Kashwan, P. (2016). What explains the demand for collective forest rights amidst land use conflicts? Journal of Environmental Management 183, 657-666.

Kennedy, S.F. and Rosen, B. (2020). The rise of community choice aggregation and its implications for California's energy transition: A preliminary assessment. Energy \& Environment. https://doi. org/10.1177\%2F0958305X20927381.

Kenworthy, J.R. (2006). The eco-city: ten key transport and planning dimensions for sustainable city development. Environment and Urbanization 18(1), 67-85. https://doi.org/10.1177/0956247806063947.

Khosla, R., Sircar, N. and Bhardwaj, A. (2019). Energy demand transitions and climate mitigation in low-income urban households in India. Environmental Research Letters 14(9), 095008. https://doi.org/10.1088/17489326/ab3760.

Kraft-Todd, G. T., Bollinger, B., Gillingham, K., Lamp, S. and Rand, D. G. (2018). Credibility-enhancing displays promote the provision of non-normative public goods. Nature 563(7730), 245-248.

Kraus, S. and Koch, N. (2020). Effect of Pop-Up Bike Lanes on Cycling in European Cities. https://arxiv.org/ pdf/2008.05883.pdf.

Kubitt, J. (2020). Linking Individual Behavior and Systems Change: Framing the Conversation. KR Foundation. https://www.rapidtransition.org/resources/individual-behaviour-and-system-change-how-they-areconnected/.

Kumar, R. (2016). Significance of domestic tourism in India as a major revenue generator. Asia Pacific Journal of Research I(XXXVIII).

Kunreuther, H. and Weber, E. U. (2014). Aiding decision making to reduce the impacts of climate change. Journal of Consumer Policy 37(3), 397-411.

Kurz, T., Gardner, B. Verplanken, B. and Abraham, C. (2015). Habitual behaviors or patterns of practice? Explaining and changing repetitive climate-relevant actions. WIRES Climate Change 6, 113-128.

Kyle, W. C., Jr. (2020). Youth are demanding action regarding climate change: Will educators have the wisdom and courage to respond? APEduC Revista/APEduC Journal 1(1), 150-160.

Kythreotis, A. P., Mantyka-Pringle, C., Mercer, T. G., Whitmarsh, L. E., Corner, A., Paavola, J. et al. (2019). Citizen social science for more integrative and effective climate action: A science-policy perspective. Frontiers in Environmental Science 7, 10.

L Lally, P., van Jaarsveld, C., Potts, H. and Wardle, J. (2010). How habits are formed: Modelling habit formation in the real world. European Journal of Social Psychology 40 (6), 998-1009.

Layard, R., Mayraz, G. and Nickell, S. (2008). The marginal utility of income. Journal of Public Economics 92(8-9), 1846-1857.

Langley, E., Dickman, A., Jenner, M., Duke, C., Suter, J., Sinn, M., Boulos, S., Dolley, P. (2012). Research on EU Product Label Options: Final Report. London: Ipsos MORI. https://ec.europa.eu/energy/sites/ener/files/ documents/2012-12-research-eu-product-label-options.pdf. 
Le Quéré, C., Jackson, R. B., Jones, M. W., Smith, A. J., Abernethy, S., Andrew, R. M., De-Gol, A. J., Willis, D. R., Shan, Y., Canadell, J. G., Friedlingstein, P., Creutzig, F. and Peters, G. P. (2020). Temporary reduction in daily global CO 2 emissions during the COVID-19 forced confinement. Nature Climate Change 10, 647-653.

Leeds City Council (2020). Report of Director of Resources and Housing: Climate Emergency Update. Leeds, UK. https://democracy.leeds.gov.uk/documents/s198403/Climate\%20Emergency\%20Cover\%20Report\%20 191219.pdf.

Lewis, J.J. and Pattanayak, S.K. (2012). Who adopts improved fuels and cookstoves? A systematic review. Environmental Health Perspectives 120(5), 637-645. https://dx.doi.org/10.1289\%2Fehp.1104194.

Li, W., Long, R., Chen, H., Chen, F., Zeng, X. and Yang, M. (2019). Effect of policy incentives on the uptake of electric vehicles in China. Sustainability 11(12), 3323. https://doi.org/10.3390/su11123323.

Liobikienè, G. and Dagiliūtè, R. (2016). The relationship between economic and carbon footprint changes in EU: the achievements of the EU sustainable consumption and production policy implementation. Environmental Science \& Policy 61, 204-211.

McCauley, D. and Heffron, R. (2018). Just transition: Integrating climate, energy and environmental justice. Energy Policy 119, 1-7.

Maniates, M. F. (2001). Individualization: Plant a tree, buy a bike, save the world? Global environmental politics, $1(3), 31-52$

Maréchal, K. (2010). Not irrational but habitual: The importance of "behavioural lock-in" in energy consumption. Ecological Economics 69(5), 1104-1114. https://econpapers.repec.org/ RePEc:eee:ecolec:v:69:y:2010:i:5:p:1104-1114.

Maréchal, K. and Lazaric, N. (2011). Overcoming inertia: insights from evolutionary economics into improved energy and climate policies. Climate Policy 10, 103-119.

Marquardt, J. (2020). Fridays for Future's disruptive potential: An inconvenient youth between moderate and radical ideas. Front. Commun. 5, 48. https://doi.org/10.3389/fcomm.2020.00048.

Marsden, G., Anable, J., Chatterton, T., Docherty, I., Faulconbridge, J., Murray, L., Roby, H. and Shires, J. (2020). Studying disruptive events: innovations in behaviour, opportunities for lower carbon transport policy? Transport Policy 94, 89-101.

Martin, E. and Shaheen, S.A. (2011). The impact of carsharing on public transit and non-motorized travel: an exploration of North American carsharing survey data. Energies 4(12), 2094-2114, https://doi.org/10.3390/ en4112094.

Mattioli, G., Roberts, C., Steinberger, J. K. and Brown, A. (2020). The political economy of car dependence: A systems of provision approach. Energy Research and Social Science 66, 101486.

Meddin, R., DeMaio. P, O’Brien, O., Rabello, R., Yu, C. and Seamon, J. (2020). The Meddin Bike-sharing World Map. http://bikesharingworldmap.com. Accessed 14 October 2020.

Méndez, M. (2020). Climate Change From the Streets: How Conflict and Collaboration Strengthen the Environmental Justice Movement. Yale University Press.

Milford, B. and Kildal, C. (2019). Meat Reduction by Force: The Case of "Meatless Monday" in the Norwegian Armed Forces. Sustainability 11(10), 1-13.

Millward-Hopkins, J., Steinberger, J.K., Rao, N.D. and Oswald, Y. (2020). Providing a decent living with minimum energy: A global scenario. Global Environmental Change 65, 102168. https://doi.org/10.1016/j. gloenvcha.2020.102168.

Mitchell, E. (2020). Climate change and nationally significant infrastructure projects: R (on the application of Plan B Earth) v Secretary of State for Transport. Environmental Law Review 22(2), 125-132. https://doi. org/10.1177/1461452920931325.

Moberg, K. R., Aall, C., Dorner, F., Reimerson, E., Ceron, J.-P., Sköld, B. et al. (2018). Mobility, food and housing: responsibility, individual consumption and demand-side policies in European deep decarbonisation pathways. Energy Efficiency, 1-23. https://doi.org/10.1007/s12053-018-9708-7.

Mogles, N., Walker, I., Ramallo-Gonzalez, A. P., Lee, J., Natarajan, S., Padget, J. et al. (2017). How smart do smart meters need to be? Building and Environment 125, 439-450. https://doi.org/10.1016/j.buildenv.2017.09.008.

Mourad, M. (2016). Recycling, recovering and preventing "food waste": Competing solutions for food systems sustainability in the United States and France. Journal of Cleaner Production 126, 461-477.

Mozaffarian, D., Angell, S. Y., Lang, T. and Rivera, J. A. (2018). Role of government policy in nutrition-barriers to and opportunities for healthier eating. British Medical Journal 361:k2426.

Müller, D. B., Liu, G., Løvik, A. N., Modaresi, R., Pauliuk, S., Steinhoff, F. S. and Brattebø, H. (2013). Carbon emissions of infrastructure development. Environmental Science \& Technology 47, 11739-11746. http:// dx.doi.org/10.1021/es402618m.

Mulugetta, Y., Carvajal, P. E., Haselip, J. A. and Spencer, T. (2019). Bridging the gap: Global transformation of the energy system. In Emissions Gap Report 2019. Chapter 6. UNEP, 46-55. 
Mundaca, L. and Samahita, M. (2020). What drives home solar PV uptake? Subsidies, peer effects and visibility in Sweden. Energy Research and Social Science 60, 101319.

Mundaca, L., Ürge-Voratz, D. and Wilson, C. (2018). Demand-side approaches for limiting global warming to 1.5 ${ }^{\circ} \mathrm{C}$. Energy Efficiency 12, 343-362. https://doi.org/10.1007/s12053-018-9722-9.

Muradova, L., Walker, H. and Colli, F. (2020). Climate change communication and public engagement in interpersonal deliberative settings: evidence from the Irish citizens' assembly. Climate Policy 20(10), 1-14.

New Zealand, Parliamentary Commissioner for the Environment (2020). Restricting the Production of Fossil Fuels in Aotearoa New Zealand. https://www.pce.parliament.nz/media/197019/report-restricting-the-productionof-fossil-fuels-in-aotearoa-new-zealand.pdf. Accessed 14 October 2020.

Nicolson, M., Huebner, G. M., Shipworth, D. and Elam, S. (2017). Tailored emails prompt electric vehicle owners to engage with tariff switching information. Nature Energy 2, 17073. https://doi.org/10.1038/nenergy.2017.73.

Nielsen, K. S., Clayton, S., Stern, P. C., Dietz, T., Capstick, S. and Whitmarsh, L. (2020). How psychology can help limit climate change. Advance online publication. American Psychologist. https://doi.org/10.1037/ amp0000624.

Nyborg, K., Anderies, J. M., Dannenberg, A., Lindahl, T., Schill, C., Schlüter, M. et al. (2016). Social norms as solutions. Science 354(6308), 42-43. https://spia.princeton.edu/system/files/research/documents/ Social\%20Norms\%20as\%20Solutions.pdf.

Okin, G.S. (2017). Environmental impacts of food consumption by dogs and cats. PLoS ONE 12(8), e0181301. https://doi.org/10.1371/journal.pone.0181301.

Olsho, L. E., Klerman, J. A., Wilde, P. E. and Bartlett, S. (2016). Financial incentives increase fruit and vegetable intake among Supplemental Nutrition Assistance Program participants: a randomized controlled trial of the USDA Healthy Incentives Pilot. The American Journal of Clinical Nutrition 104(2), 423-435.

Ordner, J. (2017). Community action and climate change. Nature Climate Change 7, 161-163. https://doi. org/10.1038/nclimate3236.

Organisation for Economic Co-operation and Development (2003). Voluntary Approaches for Environmental Policy. https://www.oecd-ilibrary.org/environment/voluntary-approaches-for-environmentalpolicy_9789264101784-en. Accessed 14 October 2020.

Ornetzeder, M., Hertwich, E.G., Klaus, H., Korytarova, K. and Haas, W. (2008). The environmental effect of car-free housing: A case in Vienna. Ecological Economics 65(3), 516-530.

O'Shaughnessy, E., Heeter, J., Gattaciecca, J., Sauer, J., Trumbull, K., and Chen, E. (2019). Empowered communities: The rise of community choice aggregation in the United States. Energy Policy 132, 1110-1119. https://doi. org/10.1016/j.enpol.2019.07.001.

Oswald, Y., Owen, A. and Steinberger, J. K. (2020). Large inequality in international and intranational energy footprints between income groups and across consumption categories. Nature Energy 5(349), 231-239.

Otto, I. M., Donges, J. F., Cremades, R., Bhowmik, A., Hewitt, R. J., Lucht, W. et al. (2020a). Social tipping dynamics for stabilizing Earth's climate by 2050. Proceedings of the National Academy of Sciences 117(5), 2354-2365. https://doi.org/10.1073/pnas.1900577117.

Otto, I. M., Wiedermann, M., Cremades, R., Auer, C., Donges, J. and Lucht, W. (2020b). Human agency in the Anthropocene. Ecological Economics 167, 106463.

Otto, I. M., Kim, K. M, Dubrovsky, N. and Lucht, W. (2019). Shift the focus from the super-poor to the super-rich. Nature Climate Change 9(2), 82-84. https://doi.org/10.1038/s41558-019-0402-3.

Oxfam (2015). Extreme Carbon Inequality. Why the Paris climate deal must put the poorest, lowest emitting and most vulnerable people first. https://oxfamilibrary.openrepository.com/bitstream/handle/10546/582545/ mb-extreme-carbon-inequality-021215-en.pdf? sequence=9.

Oxfam and Stockholm Environment Institute (2020). The Carbon Inequality Era: An Assessment of the Global Distribution of Consumption Emissions Among Individuals from 1990 to 2015 and Beyond. https://policypractice.oxfam.org.uk/publications/the-carbon-inequality-era-an-assessment-of-the-global-distributionof-consumpti-621049.

Page, N. C. and Nilsson, V. O. (2017). Active commuting: Workplace health promotion for improved employee well-being and organizational behavior. Frontiers in Psychology 7, 1994. https://doi.org/10.3389/ fpsyg.2016.01994.

Pattanayak, S.K., Jeuland, M., Lewis, J.J., Usmani, F., Brooks, N., Bhojvaid, V. et al. (2019). Experimental evidence on promotion of electric and improved biomass cookstoves. Proceedings of the National Academy of Sciences 116(27), 13282-287. https://www.pnas.org/cgi/doi/10.1073/pnas.1808827116.

Place-based Climate Action Network (2019). The Leeds Climate Change Citizens' Jury. September - November 2019. https://leedsclimate.org.uk/sites/default/files/REPORT\%20V1.2\%20FINAL.pdf. 
Pearson, A. L. and Wilson, N. (2013). Optimising locational access of deprived populations to farmers' markets at a national scale: one route to improved fruit and vegetable consumption? PeerJ 1, e94.

Pettifor, H., Wilson, C., Axsen, J., Abrahamse, W. and Anable, J. (2017). Social influence in the global diffusion of alternative fuel vehicles - a meta-analysis. Journal of Transport Geography 62, 247-261.

Pettifor, H., Wilson, C., McCollum, D. and Edelenbosch, O. (2017). Modelling social influence and cultural variation in global low-carbon vehicle transitions. Global Environmental Change 47, 76-87. https://doi.org/10.1016/j. gloenvcha.2017.09.008.

Pietinen, P., Nissinen, A., Vartiainen, E., Tuomilehto, A., Uusitalo, U., Ketola, A. et al. (1988). Dietary changes in the North Karelia project (1972-1982). Preventive Medicine 17(2), 183-193.

Ploll, U., Petritz, H. and Stern, T. (2020). A social innovation perspective on dietary transitions: Diffusion of vegetarianism and veganism in Austria. Environmental Innovation and Societal Transitions 36, 164-176.

Power, K. (2020). The COVID-19 pandemic has increased the care burden of women and families. Sustainability: Science, Practice and Policy 16 (1) 67-73. https://doi.org/10.1080/15487733.2020.1776561.

Priye, S. and Manoj, M. (2020). Exploring usage patterns and safety perceptions of the users of electric threewheeled paratransit in Patna, India. Case Studies on Transport Policy 8(1).

Pucher, J. and Buehler, R. (2008). Making cycling irresistible: lessons from the Netherlands, Denmark and Germany. Transport Reviews 28(4), 495-528.

Pulker, C. E., Trapp, G. S., Scott, J. A. and Pollard, C. M. (2018). Global supermarkets' corporate social responsibility commitments to public health: a content analysis. Globalization and Health 14(1), 121.

Pykett, J., Jones, R., Whitehead, M., Huxley, M., Strauss, K., Gill, N., McGeevor, K. et al. (2011). Interventions in the political geography of 'libertarian paternalism'. Political Geography 30(6), 301-310.

Railway Gazette (2020). Trains replace planes on Wien - Salzburg route, 2 July. https://www.railwaygazette. com/passenger/trains-replace-planes-on-wien-salzburg-route/56871.article. Accessed 14 October 2020.

Ralph, K. M. and Brown, A. E. (2017). The role of habit and residential location in travel behavior change programs, a field experiment. Transportation 46, 719-734. https://doi.org/10.1007/s11116-017-9842-7.

Rao., N. D., Min, J. and Mastrucci, A. (2019). Energy requirements for decent living in India, Brazil and South Africa. Nature Energy 6, 1025-1032. https://doi.org/10.1038/s41560-019-0497-9.

Rao, N. D., van Ruijven, B. J., Riahi, K. and Bosetti, V. (2017). Improving poverty and inequality modelling in climate research. Nature Climate Change 7, 857-862. https://doi.org/10.1038/s41558-017-0004-x.

Richter, L. (2013). Social Effects in the Diffusion of Solar Photovoltaic Technology in the UK. Cambridge Working Papers in Economics 1357, EPRG Working Paper 1332. https://www.repository.cam.ac.uk/bitstream/ handle/1810/255233/cwpe1357.pdf? sequence=1\&isAllowed=y.

Roberts, J. T., Steinberger, J., Dietz, T. and Lamb, W.F. (2020). Four agendas for research and policy on emissions mitigation and well-being. Global Sustainability 3, e3. https://doi.org/10.1017/sus.2019.25.

Rosas-Satizábal, D. and Rodriguez-Valencia, A. (2019). Factors and policies explaining the emergence of the bicycle commuter in Bogotá. Case Studies on Transport Policy 7(1), 138-149. https://doi.org/10.1016/j. cstp.2018.12.007.

Roy, D. (2015). A subaltern view of climate change. Economic \& Political Weekly 50(31), 31-39.

Roy, J., Dowd, A. M., Muller, A., Pal, S. and Prata, N. (2012). Lifestyles, well-being and energy. In Global Energy Assessment - Toward a Sustainable Future. Cambridge, UK: Cambridge University Press. Chapter 21. 1527-1548.

Sachs, W. (1993). Die vier E's: Merkposten für einen massvollen Wirtschaftsstil. Politische Ökologie 33, 69-72. https://nbn-resolving.org/urn:nbn:de:bsz:wup4-opus-668.

Schanes, K., Giljum, S. and Hertwich, E. (2016). Low carbon lifestyles: A framework to structure consumption strategies and options to reduce carbon footprints. Journal of Cleaner Production 139, 1033-1043.

Schultz, W., Nolan, J. M. and Cialdini, R. (2007). The constructive, destructive, and reconstructive power of social norms. Psychological Science 18(5), 429-434. https://doi.org/10.1111\%2Fj.1467-9280.2007.01917.x.

Seto, K. C., Davis, S. J., Mitchell, R. B., Stokes, E. C., Unruh, G. and Ürge-Vorsatz, D. (2016). Carbon lock-in: types, causes, and policy implications. Annual Review of Environment and Resources 41(1), 425-452. https://doi. org/10.1146/annurev-environ-110615-085934.

Shindell, D., Faluvegi, G., Walsh, M., Anenberg, S.C., Van Dingenen, R., Muller, N. Z. et al. (2011). Climate, health, agricultural and economic impacts of tighter vehicle-emission standards. Nature Climate Change 1, 59-66.

Shwom, R. and Lorenzen, J. A. (2012). Changing household consumption to address climate change: social scientific insights and challenges. Wiley Interdisciplinary Reviews: Climate Change 3(5), 379-395.

Sovacool, B. K., Burke, M., Baker, L., Kotikalapudi, C. K. and Wlokas, H. (2017). New frontiers and conceptual frameworks for energy justice. Energy Policy 105, 677-691. http://dx.doi.org/10.1016/j.enpol.2017.03.005. 
Sørensen, N. N., Tetens, I., Løje, H. and Lassen, A. D. (2016). The effectiveness of the Danish Organic Action Plan 2020 to increase the level of organic public procurement in Danish public kitchens. Public Health Nutrition. Cambridge University Press 19(18), 3428-3435. https://doi.org/10.1017/S1368980016001737.

Sparkman, G. and Attari, S. Z. (2020). Credibility, communication, and climate change: How lifestyle inconsistency and do-gooder derogation impact decarbonization advocacy. Energy Research and Social Science 59, 101290. https://doi.org/10.1016/j.erss.2019.101290.

Springmann, M., Mason-D'Croz, D., Robinson, S., Wiebe, K., Godfray, H. C. J., Rayner, M. and Scarborough, P. (2017). Mitigation potential and global health impacts from emissions pricing of food commodities. Nature Climate Change 7(1), 69-74.

Stern, P. C. (2000). New environmental theories: toward a coherent theory of environmentally significant behavior. Journal of Social Issues 56(3), 407-424.

Sustainable Consumption Roundtable (2006). Looking Back, Looking Forward: Lessons in Choice-Editing for Sustainability. National Consumer Council and the Sustainable Development Commission. http://www.sdcommission.org.uk/publications.php@id=1046.html.

Swift, S., Green, M., Hillage, J. and Nafilyan, V. (2016). Impact of the Cycle to Work Scheme. Report 509. Brighton, UK: Institute for Employment Studies. http://www.socialvalueuk.org/app/uploads/2016/09/impact-ofcycling-to-work-scheme.pdf.

Sztompka, P. (1991). Society in Action: The Theory of Social Becoming. University of Chicago Press.

Thompson, S., Michaelson, J., Abdallah, S., Johnson, V., Morris, D., Riley, K. et al. (2011). 'Moments of Change' as Opportunities for Influencing Behaviour. A Report to the Department for Environment, Food and Rural Affairs. New Economics Foundation. London: Defra.

Torney, D., and O'Gorman, R. (2019). A laggard in good times and bad? The limited impact of EU membership on Ireland's climate change and environmental policy. Irish Political Studies 34(4), 575-594.

Traill, W. B., Mazzocchi, M., Shankar, B. and Hallam, D. (2014). Importance of government policies and other influences in transforming global diets. Nutrition Reviews 72(9), 591-604.

Tudela, F. (2019). Obstacles and opportunities for moratoria on oil and gas exploration or extraction in Latin America and the Caribbean. Climate Policy 20(8), 922-930. https://doi.org/10.1080/14693062.2020.1760772.

Unander, F. (2004). Oil crises and climate challenges: 30 years of energy use in IEA countries. Energy \& Security in the Changing World, International Conference, 2004: International Association for Energy Economics.

United Nations Environment Programme (UNEP) (2016). The Emissions Gap Report 2016. Nairobi.

United Nations (2017). One United Nations for Habitat III. https://habitat3.org/wp-content/uploads/One-UN-forHabitatlll.pdf.

Urge-Vorsatz, D., Eyre, N., Graham, D., Harvey, D., Hertwich, E., Jiang, Y., Kornevall, C. et al. (2012). Energy enduse: buildings. In Global Energy Assessment - Toward a Sustainable Future. Johansson, T.B., Patwardhan, A., Nakicenovic, N. and Gomez-Echeverri, L. (eds.). Laxenburg, Austria: Cambridge University Press and IIASA. Chapter 10. 649-760.

Van den Berg, N., Hof, A. F., Akenji, L., Edelenbosch, O. Y., van Sluisveld, M. A. E., Timmer, V. J. and van Vuuren, D. P. (2019). Improved modelling of lifestyle changes in Integrated Assessment Models: Cross-disciplinary insights from methodologies and theories. Energy Strategy Reviews 26, 100420. https://doi.org/10.1016/j. esr.2019.100420.

Vávra, J., Daněk, P. and Jehlička, P. (2018). What is the contribution of food self-provisioning towards environmental sustainability? A case study of active gardeners. Journal of Cleaner Production 185, 1015-1023. https://doi. org/10.1016/j.jclepro.2018.02.261.

Vermeulen S, Park T, Khoury CK, Mockshell J, Béné C, Thi HT, Heard B, Wilson B. (2019). Changing Diets and Transforming Food Systems. CCAFS Working Paper no. 282. Wageningen, the Netherlands: CGIAR Research Program on Climate Change, Agriculture and Food Security (CCAFS).

Verplanken, B., Roy, D. and Whitmarsh, L. (2018). Cracks in the wall: Habit discontinuities as vehicles for behavior change. In The Psychology of Habit. Verplanken, B. (ed.). Springer, Cham.

Verplanken, B., Walker, I., Davis, A. and Jurasek, M. (2008). Context change and travel mode choice: Combining the habit discontinuity and self-activation hypotheses. Journal of Environmental Psychology 28, 121-127.

Vincent, A. (2012). Ombudspersons for future generations: Bringing intergenerational justice into the heart of policymaking. https://www.un.org/en/chronicle/article/ombudspersons-future-generations-bringingintergenerational-justice-heart-policymaking. Accessed 14 October 2020. Food Safety 9, 31-34. https://doi.org/10.1007/s00003-014-0896-6. 
Welsch, H. and Kühling, J. (2009). Determinants of pro-environmental consumption: The role of reference groups and routine behavior. Ecological Economics 69(1), 166-176.

Whittle, C., Brocklehurst, F., McAlister, C., Whitmarsh, L. (2019). The Effectiveness of Providing Pre-Purchase Factual Information in encouraging more Environmentally Sustainable Product Purchase Decisions: Expert Interviews and a Rapid Evidence Assessment. Waste and Resources Action Programme (WRAP).

Wiedenhofer, D., Smetschka, B., Akenji, A., Jalas, M. and Haberl, H. (2018). Household time use, carbon footprints, and urban form: a review of the potential contributions of everyday living to the $1.5^{\circ} \mathrm{C}$ climate target. Current Opinion in Environmental Sustainability 30, 7-17. https://doi.org/10.1016/j.cosust.2018.02.007.

Wiedman, T., Lenzen, M., Keyeßer, L. T. and Steinberger, J. (2020). Scientists' warning on affluence. Nature Communications 11, 3107. https://doi.org/10.1038/s41467-020-16941-y.

Willett, W., Rockstrom, J., Loken, B., Springmann, M., Lang, T., Vermeulen, S. et al. (2019). Food in the Anthropocene: the EAT-Lancet Commission on healthy diets from sustainable food systems. The Lancet 393(10170), 447492. https://doi.org/10.1016/S0140-6736(18)31788-4.

Williamson, O.E. (1998). Transaction costs economics: how it works; where it is headed. De Economist 146 (1), 23-58.

Wilson, C., Kerr, L., Sprei, F., Vrain, E. and Wilson, M. (2020). Potential climate benefits of digital consumer innovations. Annual Review of Environment and Resources 45, 113-144.

Wolske, K. S., Gillingham, K. T. and Schultz, W. (2020). Peer influence on household energy behaviours. Nature Energy 5, 202-212. https://doi.org/10.1038/s41560-019-0541-9.

Wood, W., Tam, L. and Guerrero Witt, M. (2005). Changing circumstances, disrupting habits. Journal of Personality and Social Psychology 88(6), 918-933.

Xiong, X., Zhang, L., Hao, Y., Zhang, P., Chang, Y. and Liu, G. (2020). Urban dietary changes and linked carbon footprint in China: A case study of Beijing. Journal of Environmental Management 255, 109877.

Yadama, G. N. (2013). Fires, Fuel, and The Fate of 3 Billion: The State of The Energy Impoverished. Oxford University Press. 


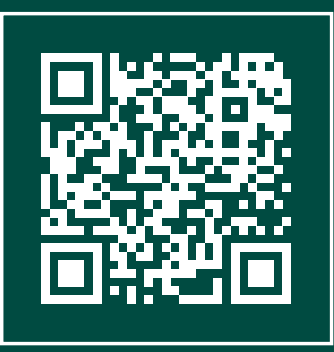

\section{UN environment programme}

United Nations Avenue, Gigiri

P.O. Box 30552, 00100 Nairobi, Kenya

Tel. +254 207621234

unep-publications@un.org

www.unep.org 